\title{
THE AQE
}

OF THE EARTH

\section{W.J.SOLLAS}

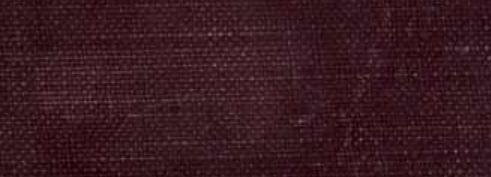




\section{LIBRARY}

UNIVERSITY OP CALIFORNIA

\section{EARTH SCIENCE LBRARY}

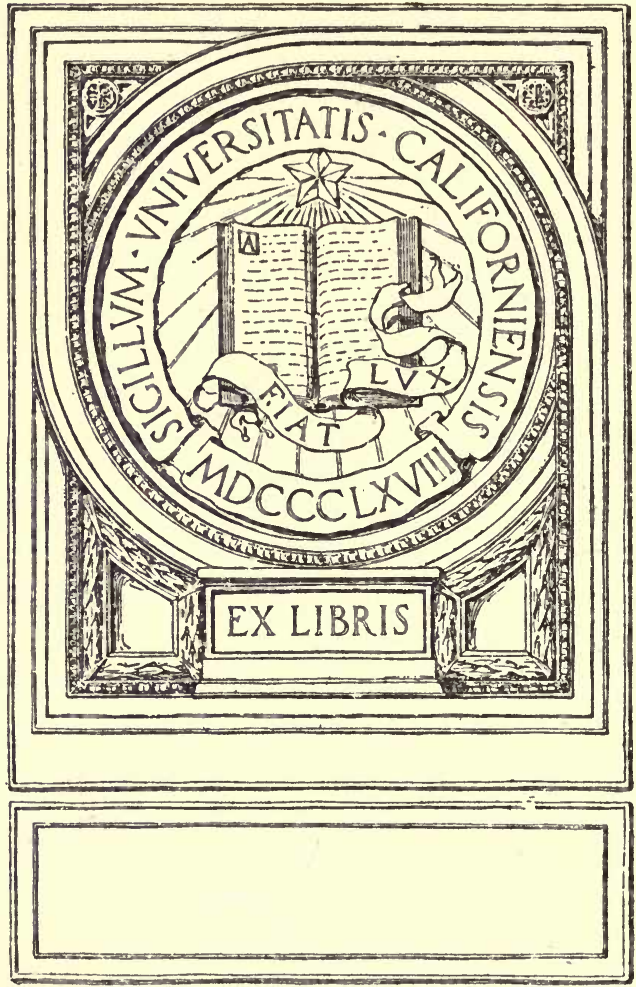






\section{THE AGE OF 'THE EAR'TH}




\section{Books on Science and Natural History.}

The Nature and Origin of Living Matter.

By H. Charlton Bastian, M.A., M.D (London), F.R S.. F.L S, Emeritus Professor of the Principles and Practice of Medicine, and of Clinical Medicine at University College, London. With 76 Illustrations. Medium 8vo, cloth. 12s. 6d. net.

\section{The Horse: A Pictorial Guide to its} Anatomy.

110 Drawings (reproduced by Photo-Lithography) by HERrManN DitTrich, with Explanatory Notes by Prof. Ellenberger and Prof. Baum. In portfolio, quarto. 30s. net.

The Psychology and Training of the Horse.

By Count Eugenio Martinengo Cesaresco. With Photogravure Frontispiece. Demy 8vo, cloth. 10s. 6d. net.

\section{Woodlanders and Field Folk.}

Sketches of Wild Life in Britain. By JоHN WAtson, Author of "Poachers and Poaching," "The Annals of a Quiet Valley," etc., and BLANCHE WINDER, Author of "Twixt Town and Country," etc. Illustrated. Large Crown 8vo, cloth. 5s. net.

\section{British Bird Life.}

By W. Percival Westeli, M.B.O.U., F.R.H.S., etc. With a Colomred Frontispiece and over 60 Illustrations. With an Introduction by Sir Herbert Maxwell, Bart. Large Crown Svo, cloth, 3s. 6d. net.

LONDON: T. FISHER UNWIN. 


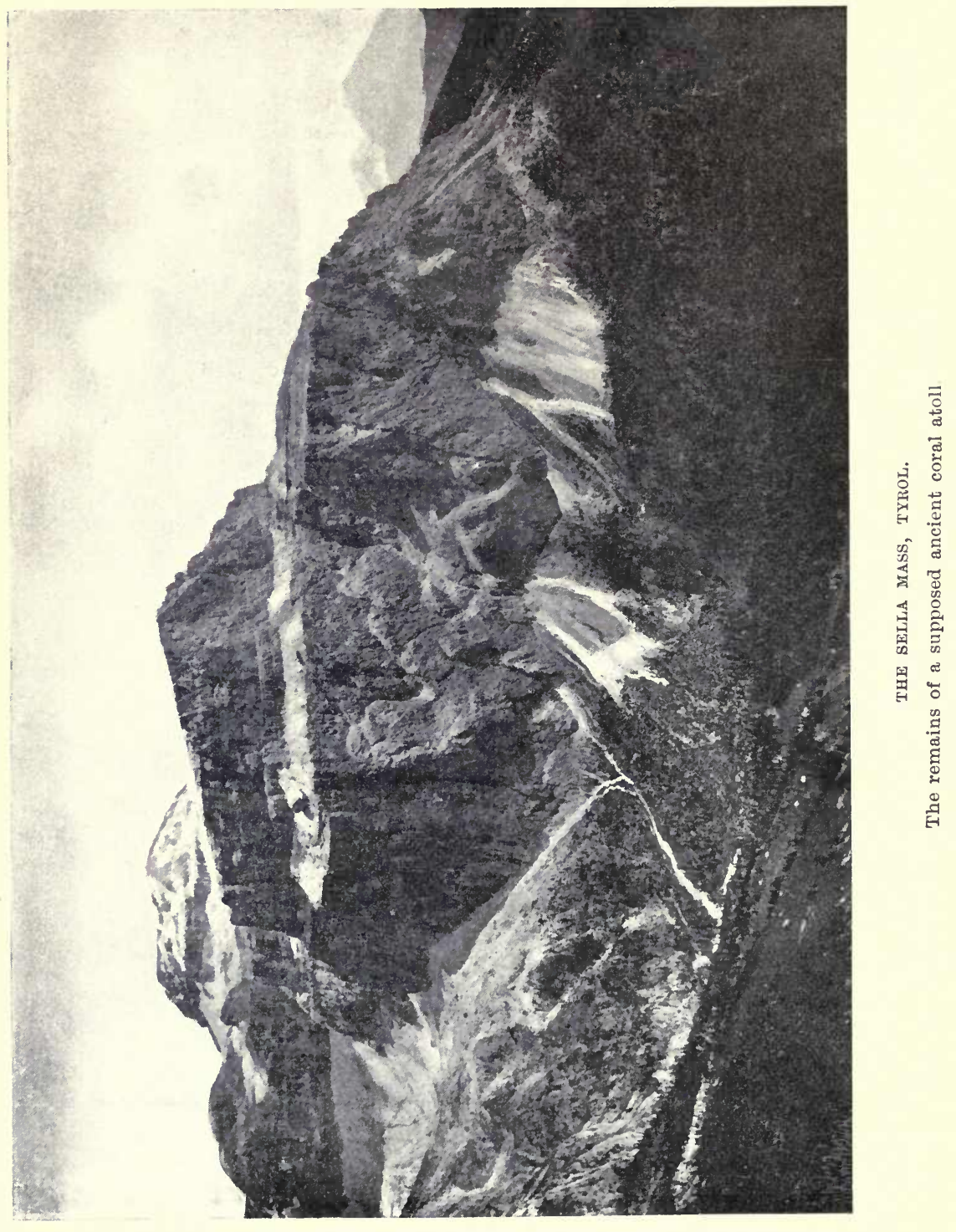




\title{
THE
}

\section{AGE OF THE EARTH}

AND

\section{OTHER GEOLOGICAL STUDIES}

\author{
BY \\ W. J. SOLLAS \\ D.Sc. CAmbridge; Ll.D. Dublin ; M A. Oxford ; F.R.S. \\ Fellow of University College, and Professor of \\ GeOLOGY IN THE UNIVERSITY OF OXFORD
}

SECOND MPRESTION

LONDON: T. FISHER UNWIN

ADELPHI TERRACE. MCMVIII 


\section{EARTH SCIENCE ; \\ LIBRARY}

First Impression $\quad 190.5$

Second Impression, 1908

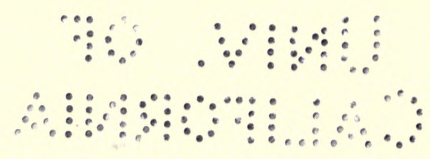

(All rights reseried.) 


\section{Preface}

TF asked unexpectedly for an explanation of this 1 volume, I can conceive myself replying that it is " a fortuitous concourse," but on reflexion it appears to have come together through a natural process of evolution. The majority of the articles were originally delivered as lectures or addresses, and some have already been published in scientific journals. On receiving an invitation to render these more generally accessible I very willingly accepted it, and took advantage of the opportunity thus presented for revision and expansion. The introduction of new matter once begun continued till three or four entirely new essays were the result.

The first article, on the "Age of the Earth," was originally delivered as a Presidential Address to the Geological Section of the British Association at its meeting in Bradford, and the subject-matter is a good deal more extensive than the title indicates; the next, on the "Figure of the Earth," may be regarded as a continuation of the preceding one, amplifying it in some - directions, amending it in others, and at the same time presenting a fresh conception of the form of the earth, which was arrived at independently by two investigators, one following the legitimate but strenuous path of the higher mathematics, and the other snatching at a result 
by pure empiricism. Many geologists have long suspected that two sets of deforming processes might be sufficient to account for the diversity that distinguishes the features of our planet, and now some promise of discovery in this direction does indeed seem to be dawning. The great meridional zone of folding and dislocation, resulting from its original pear-shaped form, and the equally great equatorial zone, due to its diminishing oblateness, may furnish on further investigation a solution of this problem.

The third article, on the "Lipari Isles," almost needs an apology for its somewhat too lively manner, so oddly in contrast with the gravity of its companions. Something perhaps may be allowed for the influence of the subject; it was written immediately after returning from a first personal acquaintance with volcanos in activity, and published as a Christmas article in the Daily Express of Dublin, in company with a number of others contributed by my colleagues in Trinity College. It has been extended by an attempt to account for the explosive character of a volcanic eruption on simple mechanical principles.

The story of "Funafuti," delivered as the Friday evening lecture to the British Association at its meeting in Bristol, and afterwards published in Natural Science, relates to an attempt to bore through a coral reef in the middle of the Pacific Ocean, in the hope of discovering its structure and history, and so to set at rest a longstanding controversy. The attempt failed, but was renewed under other auspices, and brought to a triumphant issue; the results, which confirm the truth of Darwin's theory, form the subject of the "Sequel," which appears here for the first time.

The "Formation of Flints" is also new; it gives a connected account of the results of observations and dis- 
coveries extending over a long series of years, and is perhaps the first attempt yet made to trace in detail the origin, growth, and final decay of that puzzling object, the common flint.

The "Origin of Freshwater Animals," * which in its present form is also new, is based on a communication made to the Royal Dublin Society some years ago. Its object is to explain how marine animals contrived to obtain a home in rivers and lakes, or how they became the captives of the freshwater domain: the shifts they are put to in maintaining their foothold, and the complications which result. A passing reference is made to the fauna of lake Tanganyika.

The "Influence of Oxford on Geology" was delivered as an Inaugural lecture on assuming the duties of the chair of Geology in the University ; it has already appeared in Science Progress. The subject chiefly treated is the early history of geology, when it was engaged in a lifeand-death struggle over the nature of fossils. Opportunity is taken to do justice to the genius of that truly great observer, Steno of Bologna.

The "Key to Terrestrial History," which appears here for the first time, was delivered as a lecture before the Royal Institution. It gives some account of the great progress made during the last few decades towards establishing the universality of geological epochs and episodes, and endeavours to countervail the damaging effects produced by the famous criticisms of Huxley and Herbert Spencer while at the same time vindicating the validity of the fundamental discovery of William Smith.

"Geologies and Deluges" was a British Association lecture to working men, delivered at the meeting in Oxford, and subsequently published in Nature. After * "On the Origin of Freshwater Faunas: a Study in Evolution," Sic. Trans. Roy. Dub. Soc., ser. II., vol. iii. p. 87, 1884. 
passing in rapid survey the influence of geology on the question of the Deluge, and of the Deluge on the theories of geology, it treats, in some detail, the latest views as to the nature of this great catastrophe which have been advanced by the great Viennese geologist, Edward Suess, in his work, "The Face of the Earth."

I cannot conclude this preface without confessing to a fear that in some cases interest in the subject may seem to have betrayed me into a momentary forgetfulness of the respect due to great names. I should be sorry if this were really so; for my earliest teacher, the late Professor Huxley, and for my latest master, Professor Suess, I have but one feeling, that of deep and affectionate reverence; any appearance to the contrary must be set down to the clumsiness of a geologist, who is more at home with the hammer than the pen. 


\section{Contents}

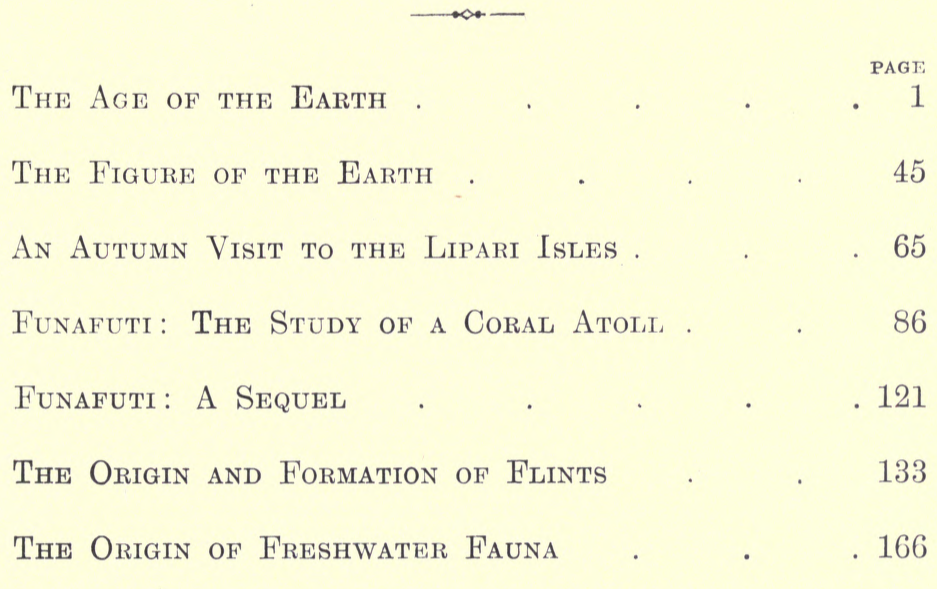

The Influence of Oxford on the History of Geology 219

The Key to Terrestrial History . . . 257

Geologies and Deluges . . . . 290

$\operatorname{Index} . \quad . \quad . \quad . \quad . \quad 323$ 



\section{List of Illustrations}

The Sella Mass, Tyrol . . . . . . . Frontispiece FIG.

1. Geothermal Map of the British Isles _ . . . . 19

2. Stages in the Formation of a Mountain Chain . . 35

3. Europe in the Cambrian Period . $\quad$. $\quad$. $\quad . \quad 42$

4. Form of the Earth subsequent to the Ejection of the Moon . $\quad 47$

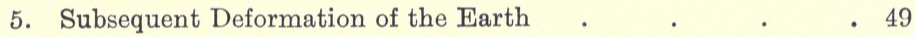

6. Map showing the Symmetrical Distribution of Land and Sea 53

7. Élie de Beaumont's Pentagonal Dodecahedron Unfolded • 57

8. Fractures in the Tyrrhenian Sea . . . . . . 67

9. Stromboli, from the West Side of the Crater . . . 73

10. Volcano in Eruption . . . . . . . 75

11. A Volcanic Bomb . . . . . $\quad 76$

12. Crater of Volcano, immediately before an Eruption _ . 77

13. First Puff of an Eruption, Vulcano . $\quad$. $\quad$ • 78

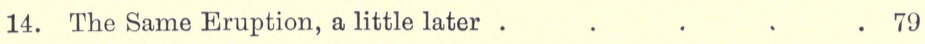

15. The Same Eruption, still later . . . . 80

16. Final Stage of the Eruption ․ . $\quad$. $\quad . \quad$. 81

17. Diagram to illustrate the Mechanism of a Strombolian Eruption 82

18. Diagram to illustrate the Mechanism of a Vesuvian Eruption $\$ 4$

19. A Coral Atoll, according to Chamisso . $\quad$ • $\quad$. 90

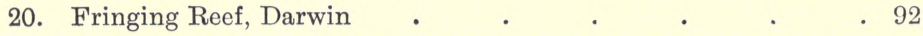

21. Encircling Reef, Darwin · . • • • . 93

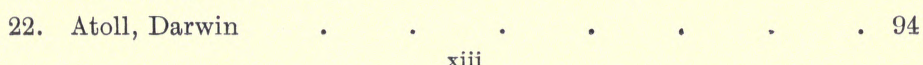


FIG.

23. Formation of an Atoll, according to Ainsworth

24. Formation of an Atoll, according to Murray . . . 96

25. Diagram illustrating the Difference between the Theories of

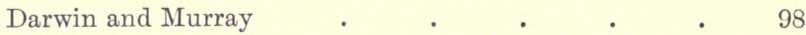

26. The Site of the First Boring, Funafuti . . . . 103

27. Lagoon Beach, Funafuti . $\quad$ • . $\quad$ • 104

28. Forest Scene, Funafuti . $\quad$. $\quad$ • $\quad$. $\quad$. 105

29. The Mangrove Swamp, Funafuti $\quad$. $\quad$. $\quad$. $\quad$. 107

30. A Raised Pinnacle of Coral, Funafuti . 109

31. Funafuti, on the Ocean Side $\quad$. $\quad$. $\quad$. $\quad$. $\quad$. 110

32. Funafuti, Tidal Platform and Margin of Reef . . . 111

33. A Group of Natives, Funafuti . $\quad$ • $\quad$. $\quad . \quad$. 115

34. Submarine Profile of Funafuti . $\quad$ • $\quad . \quad$. 117

35. Section in a Chalk Quarry . $\quad$. $\quad . \quad$. 135

36. View of a Chalk Pit at Horstead . $\quad$. $\quad . \quad$. 137

37. Coccoliths, after H. Lohmann . $\quad$ • $\quad$. $\quad$. $\quad$. 139

38. Examples of Flints Broken Open to Show the Structure . . 141

39. Venus's Flower Basket (Euplectella) • . . . . 144

40. A Fragment of the Skeletal Network of an Hexactinellid Sponge

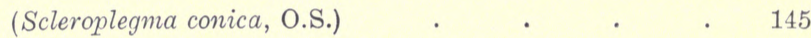

41. Sponge Spicules associated with Flints . . . . 147

42. Skeletal Remains of Sponges, converted into Fibrous Crystalline

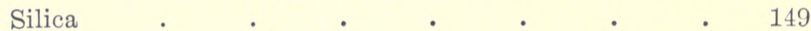

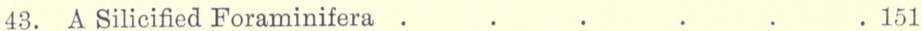

44. Banding Produced by the Spread of Oil in Writing Paper . 153

45. Diagram to Illustrate Volume of a Sponge and its Cortents in

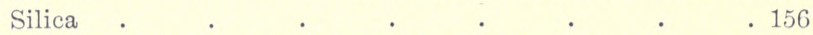

46. A Fossil Sea-Urchin (Ananchytes) from the Chalk . . 158

47. Siliceous Shell of a Common Diatom (Pinnularia) • . 161

48. A Polyzoon (Plumatella) . $\quad$ • • • • . 168

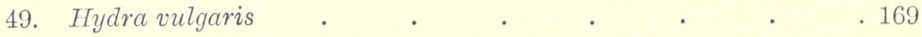

50. Diagram to Illustrate the Seasonal Changes in the Freshwater

Planctone . $\quad . \quad$. $\quad . \quad$. $\quad . \quad 174$

51. A Freshwater Crab, represented on a Sicilian Coin . $\quad 175$

52. Larval Form (glochidium) of the Freshwater Pond Mussel . 179 


\section{LIST OF ILLUS'TRA'TIONS}

FIG.

53. A Water Beetle (Dytiscus) Carrying a Bivalve Shell

54. The Free-Swimming Larva of Dreissena polymorpha

55. Paludina vivipara . . . . . .

56. Limnea stagnalis

57. The Development of the Gemmule of a Freshwater Sponge (Ephidatia fluviatilis) .

58. Eggs of Hydra riridis and H. grisea . . . . 186

59. Statoblasts of a Polyzoon (Plumatella fruticosa) . . . 187

60. Statoblast of a Polyzoon (Cristatella mucedo) • • • 188

61. A Tube-making Rotifer (Floscularia longicaudata) . 190

62. The Winter Egg, or Epihippium, of Water-Fleas . • 191

63. Apus cancriformis, a Freshwater Crustaeean • . 192

64. The Freshwater Prawn (Palcmon serratus) . . • 193

65. A Marine Prawn (Peneus) . . . . . . . 193

66. The Development of the Marine Prawn (Peneus), Nauplius and Zoëa Stages . . . . . . . . 194

67. Further Development of Peneus, the Mysis Stage . . 195

68. Air-breathing Shells from the Carboniferous System of North America . . . . . . . . . . . 197

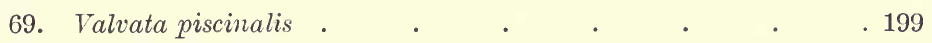

70. Goniobasis sp., Fascinella, and Symolopsis . . . 203

71. Stomatopsis, a Freshwater Shell from the Cosina Beds of Istria 204

72. Congeria, from the Pontic Beds . • . . . 205

73. Melanopsideæ, from the Miocene and Pliocene Beds . . 206

74. Transformation of Paludina by the Influence of Brackish Water 207

75. The Freshwater Limpet (Ancylus) . • . . . . 208

76. The Freshwater Jelly-fish (Limnocodium victoria) 209

77. Tiphobia Horei, from lake Tanganyika . • • • . 210

78. Pyrgulifera and Paramelania . • . • . 212

79. Paludinas from the Laramie Beds and lake Tanganyika . . 214

80. Steno's Figure of the Head of a Shark. 222

81. Successive Stages in the History of Tuscany as Represented by

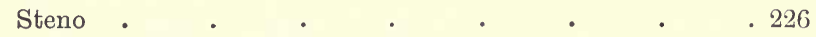

82. Section across England and Wales . . . . $\quad$. 261

83. Temperature Curve for the British Isles during the Tertiary Ara 269 


\section{xvi LIS'T OF ILLUS'TRA'TIONS}

FIG. PAGE

84. Diagram to illustrate Heilprin's Argument . . . 271

85. The Northern and Southern Floras at the Close of the Carboniferous Period . $\quad . \quad$. $\quad . \quad$. 273

86. A Graptolite in Various Stages of Growth . . . . . 282

87. A Graptolite, as Restored by Frech . . . . . 283

88. Chaos, according to Thomas Burnett _ . . . . . 291

89. Effects of Gravity on Chaos, after Burnett . . . 292

90. "Such was the Earth when First Formed" " . . . . 293

91. The Deluge, according to Burnett . . . . 294

92. Formation of the Mendip Hills . . . . . . . . 297

93. Mound of Mugheir (Ancient Ur) . . . . . 304

94. The Mound of Babil (Ruins of Babylon) . . . . . 307

95. Captives Building a Platform-mound . . . . 308

96. Gizdubar and the Lion $\quad$. $\quad$. $\quad$. $\quad$. $\quad$. $\quad 317$

97. Gizdubar and Eabani Fight the Bull of Ishtar . . 318

98. Scorpion Men $\quad . \quad$. $\quad . \quad$. 319 


\section{I \\ THE AGE OF THE EARTH}

THE close of one century, the dawn of another, may L naturally suggest some brief retrospective glance over the path along which our science has advanced, and some general survey of its present position from which we may gather hope of its future progress; but other connexion with geology the beginnings and endings of centuries have none. The great periods of movement have hitherto begun, as it were, in the early twilight hours, long before the dawn. Thus the first step forward, since which there had been no retreat, was taken by Steno in the year 1669; more than a century elapsed before James Hutton (1785) gave fresh energy and better direction to the faltering steps of the young science; while it was less than a century later (1863) when Lord Kelvin brought to its aid the powers of the higher mathematics and instructed it in the teachings of modern physics. From Steno onward the spirit of geology was catastrophic; from Hutton onward it grew increasingly uniformitarian; from the time of Darwin and Kelvin it has become evolutional. The ambiguity of the word "uniformitarian" has led to a good deal of fruitless logomachy, against which it may be as well at once to guard by indicating the sense in which it is used here. 


\section{xvi LIS'T OF ILLUS'TRA'TIONS}

PAGE

84. Diagram to illustrate Heilprin's Argument ․ . . 271

85. The Northern and Southern Floras at the Close of the Car-

boniferous Period . $\quad . \quad$. $\quad . \quad$. 273

86. A Graptolite in Various Stages of Growth . . . . . 282

87. A Graptolite, as Restored by Frech . . . . . 283

88. Chaos, according to Thomas Burnett . . . . . 291

89. Effects of Gravity on Chaos, after Burnett . . . 292

90. "Such was the Earth when First Formed" . . . . . 293

91. The Deluge, according to Burnett . . . . 294

92. Formation of the Mendip Hills . . . . . . . 297

93. Mound of Mugheir (Ancient Ur) . . . . . 304

94. The Mound of Babil (Ruins of Babylon) . . . . . 307

95. Captives Building a Platform-mound . . . . 308

96. Gizdubar and the Lion . . . . . $\quad$. 317

97. Gizdubar and Eabani Fight the Bull of Ishtar . . 318

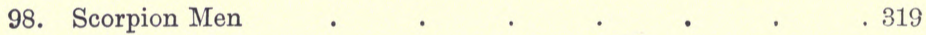




\section{I \\ THE AGE OF THE EARTH}

THE close of one century, the dawn of another, may 1 naturally suggest some brief retrospective glance over the path along which our science has advanced, and some general survey of its present position from which we may gather hope of its future progress; but other connexion with geology the beginnings and endings of centuries have none. The great periods of movement have hitherto begun, as it were, in the early twilight hours, long before the dawn. Thus the first step forward, since which there had been no retreat, was taken by Steno in the year 1669; more than a century elapsed before James Hutton (1785) gave fresh energy and better direction to the faltering steps of the young science; while it was less than a century later (1863) when Lord Kelvin brought to its aid the powers of the higher mathematics and instructed it in the teachings of modern physics. From Steno onward the spirit of geology was catastrophic ; from Hutton onward it grew increasingly uniformitarian; from the time of Darwin and Kelvin it has become evolutional. The ambiguity of the word "uniformitarian" has led to a good deal of fruitless logomachy, against which it may be as well at once to guard by indicating the sense in which it is used here. 


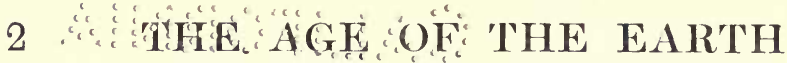

In one way we are all uniformitarians, i.e., we accept the doctrine of the " uniform action of natural causes," but, as applied to geology, uniformity means more than this. Defined in the briefest fashion it is the geology of Lyell. Hutton had given us a "Theory of the Earth," in its main outlines still faithful and true; and this Lyell spent his life in illustrating and advocating; but, as so commonly happens, the zeal of the disciple outran the wisdom of the master, and mere opinions were insisted on as necessary dogma. What did it matter if Hutton as a result of his inquiries into terrestrial history had declared that he found no vestige of a beginning, no prospect of an end? It would have been marvellous if he had! Consider that when Hutton's "Theory" was published William Smith's famous discovery had not been made, and that nothing was then known of the orderly succession of forms of life, which it is one of the triumphs of geology to have revealed; consider, too, the existing state of physics at the time, and that the modern theories of energy had still to be formulated; consider also that spectroscopy had not yet lent its aid to astronomy and the consequent ignorance of the nature of nebulæ; and then, if you will, cast a stone at Hutton. With Lyell, however, the case was different; in pressing his uniformitarian creed upon geology he omitted to take into account the great advances made by its sister sciences, although he had knowledge of them, and thus sinned against the light. In the last edition of the famous "Principles" we read: "It is a favourite dogma of some physicists that not only the earth, but the sun itself, is continually losing a portion of its heat, and that as there is no known source by which it can be restored we can foresee the time when all life will cease to exist on this planet, and on the other hand we can look back to a period when the heat was so intense as to be incompatible with the existence of any 


\section{DOCTRINE OF UNIFORMITY}

organic beings such as are known to us in the living or fossil world. . . . A geologist in search of some renovating power by which the amount of heat may be made to continue unimpaired for millions of years, past and future, in the solid parts of the earth. . . has been compared by an eminent physicist to one who dreams he can discover a source of perpetual motion and invent a clock with a self-winding apparatus. But why should we despair of detecting proofs of such regenerating and self-sustaining power in the works of a Divine Artificer?" Here we catch the true spirit of uniformity; it admittedly regards the universe as a self-winding clock, and barely conceals a conviction that the clock was warranted to keep true Greenwich time. The law of the dissipation of energy is not a dogma, but a doctrine drawn from observation, while the uniformity of Lyell is in no sense an induction: it is a dogma in the narrowest sense of the word, unproved, incapable of proof; hence, perhaps, its power upon the human mind; hence also the transitoriness of that power. Again, it is only by restricting its inquiries to the stratified rocks of our planet that the dogma of uniformity can be maintained with any pretence of argument. Directly we begin to search the heavens the possibility, nay, even the likelihood, of the nebular origin of our system, with all that it involves, is borne in upon us. Lyell, therefore, consistently refused to extend his gaze beyond the rocks beneath his feet, and was thus led to do a serious injury to our science: he severed it from cosmogony, for which he entertained and expressed the most profound contempt, and from the multilation thus inflicted geology is only at length making a slow and painful recovery. Why do I dwell on these facts? To depreciate Lyell? By no means. No one is more conscious than I of the noble service which Lyell rendered to our cause : his reputation is of too robust a kind to suffer 


\section{THE AGE OF 'THE EAR'TH}

from my unskilful handling, and the fame of his solid contributions to science will endure long after these controversies are forgotten. The echoes of the combat are alreały dying away, and uniformitarians, in the sense already defined, are now no more; indeed, were I to attempt to exhibit any distinguished living geologist as a still surviving supporter of the narrow Lyellian creed, he would probably feel, if such a one there be, that I was unfairly singling him out for unmerited obloquy.

Our science has become evolutional, and in the transformation has grown more comprehensive: her petty parochial days are done, she is drawing her provinces closer around her, and is fusing them together into a united and single commonwealth-the science of the earth.

Not merely the earth's crust, but the whole of earthknowledge is the subject of our research. To know all that can be known about our planet, this, and nothing less than this, is its aim and scope. From the morphological side geology inquires not only into the existing form and structure of the earth, but also into the series of successive morphological states through which it has passed in a long and changeful development. Our science inquires also into the distribution of the earth in time and space; on the physiological side it studies the movements and activities of our planet; and not content with all this, it extends its researches into ætiology and endeavours to arrive at a science of causation. In these pursuits geology calls all the other sciences to her aid. In our commonwealth there are no outlanders; if an eminent physicist enter our territory we do not begin at once to prepare for war, because the very fact of his undertaking a geological inquiry of itself confers upon him all the duties and privileges of citizenship. A physicist studying geology is by definition a geologist. Our only regret is, 


\section{FIRS'T CRI'TICAL PERIOD}

not that physicists occasionally invade our borders, but that they do not visit us oftener and make closer acquaintance with us.

If I am bold enough to assert that cosmogony is no longer alien to geology, I may proceed further, and, taking advantage of my temerity, pass on to speak of things once not permitted to us. I propose, therefore, to offer some short account of the early stages in the history of the earth. Into its nebular origin we need not inquire - that is a subject for astronomers. We are content to accept the infant earth from their hands as a molten globe ready made, its birth from a gaseous nebula duly certified. If we ask, as a matter of curiosity, what was the origin of the nebula, I fear even astronomers cannot tell us. There is an hypothesis which refers it to the clashing of meteorites, but in the form in which this is usually presented it does not help us much. Such meteorites as have been observed to penetrate our atmosphere and to fall on to the surface of the earth prove on examination to have had an eventful history of their own of which not the least important chapter was a passage through a molten state; they would thus appear to be the products rather than the progenitors of a nebula.

We commence our history, then, with a rapidly rotating molten planet, not impossibly already solidified about the centre and surrounded by an atmosphere of great depth, the larger part of which was contributed by the water of our present oceans, then existing in a state of gas. This atmosphere, which exerted a pressure of something like $5,000 \mathrm{lb}$. to the square inch, must have played a very important part in the evolution of our planet. The molten exterior absorbed it to an extent which depended on the pressure, and may some day be learnt from experiment. Under the influence of the rapid rotation of the earth the atmosphere would be much deeper in the 
equatorial than the polar regions, so that in the latter the loss of heat by radiation would be in excess. This might of itself lead to convectional currents in the molten ocean. The effect on the atmosphere is very difficult to trace, but it is obvious that if a high-pressure area originated over some cooler region of the ocean, the winds blowing out of it would drive before them the cooler superficial layers of molten material, and as these were replaced by hotter lava streaming from below, the tendency would be to convert the high into a low-pressure area, and to reverse the direction of the winds. Conversely under a low-pressure area the in-blowing winds would drive in the cooler superficial layers of molten matter that had been swept away from the anticyclones. If the difference in pressure under the cyclonic and anti-cyclonic areas were considerable, some of the gas absorbed under the anti-cyclones might escape beneath the cyclones, and in a later stage of cooling might give rise to vast floating islands of scoria. Such islands might be the first foreshadowings of the future continents. Whatever the ultimate effect of the reaction of the winds on the currents of the molten ocean, it is probable that some kind of circulation was set up in the latter. The universal molten ocean was by no means homogeneous: it was constantly undergoing changes in composition as it reacted chemically with the internal metallic nucleus: its currents would streak the different portions out in directions which in the northern hemisphere would run from N.E. to S.W., and thus the differences which distinguish particular petrological regions of our planet may have commenced their existence at a very early stage. Is it possible that as our knowledge extends we shall be able by a study of the distribution of igneous rocks and minerals to draw some conclusions as to the direction of these hypothetical lava currents? Our planet was pro- 


\section{BIR'TH OF THE MOON}

foundly disturbed by tides, produced by the sun; for as yet there was no moon; and it has been suggested that one of its tidal waves rose to a height so great as to sever its connection with the earth and to fly off as the infant moon. This event may be regarded as marking the first critical period, or catastrophe if we please, in the history of our planet. The career of our satellite, after its escape from the earth, is not known till it attained a distance of nine terrestrial radii ; after this its progress can be clearly followed. At the eventful time of parturition the earth was rotating, with a period of from two to four hours, about an axis inclined at some $11^{\circ}$ or $12^{\circ}$ to the ecliptic. The time which has elapsed since the moon occupied a position nine terrestrial radii distant from the earth is at least fifty-six to fifty-seven millions of years, but may have been much more. Professor Darwin's story of the moon is certainly one of the most beautiful contributions ever made by astronomy to geology, and we shall all concur with him when he says, "A theory reposing on verce cause, which brings into quantitative correlation the length of the present day and month, the obliquity of the ecliptic, and the inclination and eccentricity of the lunar orbit, must, I think, have strong claims to acceptance."

The majority of geologists have long hankered after a metallic nucleus for the earth, composed chiefly, by analogy with meteorites, of iron. Lord Kelvin has admitted the probable existence of some such nucleus, and lately Professor Wiechert has furnished us with arguments - " powerful" arguments, Professor Darwin terms them-in support of its existence. The interior of the earth for four-fifths of the radius is composed, according to Professor Wiechert, chiefly of metallic iron, with a density of 8.2 ; the outer envelope, one-fifth of the radius, or about 800 miles in thickness, consists of silicates, such as we are familiar with in igneous rocks and meteorites, 


\section{THE AGE OF THE EAR'TH}

and possesses a density of $3 \cdot 2$. It was from this outer envelope when molten that the moon was trundled off, twenty-seven miles in depth going to its formation. The density of this material, as we have just seen, is supposed to be $3 \cdot 2$; the density of the moon is $3 \cdot 39$, a close approximation, such difference as exists being completely explicable by the comparatively low temperature of the moon.

The outer envelope of the earth which was drawn off to form the moon was, as we have seen, charged with steam and other gases under a pressure of 5,000 lb. to the square inch; but as the satellite wandered away from the parent planet this pressure continuously diminished. Under these circumstances the moon would become as explosive as a charged bomb, steam would burst forth from numberless volcanos, and while the face of the moon might thus have acquired its existing features the ejected material might possibly have been shot so far away from its origin as to have acquired an independent orbit. If so we may ask whether it may not be possible that the meteorites, which sometimes descend upon our planet, are but portions of its own envelope returning to it. The facts that the average specific gravity of those meteorites which have been seen to fall is not much above $3 \cdot 2$, * and that they have passed through a state of fusion, are consistent with this suggestion.

The solidification of the earth probably became com-

* In a collection of meteorites the metallic kinds (irons) will be found to predominate over the rocky (stones), and the average density as deduced from a collection will consequently be higher than that given here. In the case of meteorites accidentally encountered on the ground the irons by their unusual characters may easily attract the attention of an observer while the stones may escape notice: but the phenomena produced by a falling meteorite are the same for both irons and stones, hence we must restrict our attention to meteorites of which the fall is recorded in order to obtain a fair result. 


\section{CONSOLIDA'TION OF THE EARTH 9}

pleted soon after the birth of the moon. The temperature of its surface at the time of consolidation was about $1,200^{\circ}$ C., and it was, therefore, still surrounded by its primitive deep atmosphere of stean and other gases. This was the second critical period in the history of the earth, the stage of the " consistentior status," the date of which Lord Kelvin would rather know than that of the Norman Conquest, though he thinks it lies between twenty and forty millions of years ago, probably nearer twenty than forty.

Now that the crust was solid there was less reason why movements of the atmosphere should be unsteady, and definite regions of high and low pressure might have been established. Under the high-pressure areas the surface of the crust would be depressed; correspondingly under the low-pressure areas it would be raised; and thus from the first the surface of the solid earth might be dimpled and embossed.*

The cooling of the earth would continuously progress, till the temperature of the surface fell to $370^{\circ} \mathrm{C}$., when that part of the atmosphere which consisted of steam would begin to liquefy; then the dimples on the surface would soon become filled with superheated water, and the pools so formed would expand and deepen, till they formed the oceans. This is the third critical stage in the history of the earth, dating, according to Professor Joly, from between eighty and ninety millions of years ago. With the growth of the oceans the distinction between land and sea arose-in what precise manner we may proceed to inquire. If we revert to the period of the "consistentior status," when the earth had just solidified, we shall find,

* It would be difficult to discuss with sufficient brevity the probable distribution of these inequalities, but it may be pointed out that the moon is possibly responsible, and that in more ways than one, for much of the existing geographical asymmetry. 
according to Lord Kelvin, that the temperature continuously increased from the surface, where it was $1,200^{\circ} \mathrm{C}$., down to a depth of twenty-five miles, where it was about $1,460^{\circ} \mathrm{C}$., or $260^{\circ} \mathrm{C}$. above the fusion-point of the matter forming the crust. That the crust at this depth was not molten but solid is to be explained by the very great pressure to which it was subjected-just so much pressure, indeed, as was required to counteract the influence of the additional $260^{\circ} \mathrm{C}$. Thus if we could have reduced the pressure on the crust we should have caused it to liquefy ; by restoring the pressure it would resolidify. By the time the earth's surface had cooled down to $370^{\circ} \mathrm{C}$. the depth beneath the surface at which the pressure just kept the crust solid would have sunk some slight distance inwards, but not sufficiently to affect our argument.

The average pressure of the primitive atmosphere upon the crust can readily be calculated by supposing the water of the existing oceans to be uniformly distributed over the earth's surface, and then by a simple piece of arithmetic determining its depth: this is found to be 1.718 miles, the average depth of the oceans being taken at 2.393 miles Thus the average pressure over the earth's surface, immediately before the formation of the oceans, was equivalent to that of a column of water 1.718 miles high on each square inch. Supposing that at its origin the ocean were all " gathered together into one place," and " the dry land appeared," then the pressure over the ocean floor would be increased from 1.718 miles to $2 \cdot 393$ miles, while that over those portions of the crust which now formed the land would be diminished by 1.718 miles. This difference in pressure would tend to exaggerate those faint depressions which had arisen under the primitive anti-cyclonic areas, and if the just solidified material of the earth's crust were set into a state of flow it might 


\section{BIRTH OF THE OCEAN}

move from under the ocean into the bulgings which were rising to form the land, until static equilibrium were established. Under these circumstances the pressure of the ocean would be just able to maintain a column of rock 0.886 mile in height, or ten twenty-sevenths of its own depth. It could do no more; but in order that the dry land may appear some cause must be found competent either to lower the ocean bed the remaining seventeen twenty-sevenths of its full depth or to raise the continental bulgings to the same extent. Such a cause may, I think, be discovered in a further effect of the reduction in pressure over the continental areas. Previous to the condensation of the ocean, these, as we have seen, were subjected to an atmospheric pressure equal to that of a column of water 1.718 miles in height. This pressure was contributory to that which caused the outer twentyfive miles of the earth's crust to become solid; it furnished, indeed, just about one-fortieth of that pressure, or enough to raise the fusion-point $6^{\circ} \mathrm{C}$. What, then, might be expected to happen when the continental area was relieved of this load? Plainly a liquefaction and corresponding expansion of the underlying rock.

But we will not go so far as to assert that actual liquefaction would result; all we require for our explanation is a great expansion; and this would probably follow whether the crust were liquefied or not. For there is good reason to suppose that when matter at a temperature above its ordinary fusion-point is compelled into the solid state by pressure, its volume is very responsive to changes either of pressure or temperature. The remarkable expansion of liquid carbon dioxide is a case in point: 120 volumes of this fluid at $-20^{\circ} \mathrm{C}$. become 150 volumes at $33^{\circ} \mathrm{C}$. ; a temperature just below the critical point. A great change of volume also occurs when the material of igneous rocks passes from the crystalline 


\section{2}

\section{THE AGE OF THE EAR'TH}

state to that of glass; in the case of diabase * the difference in volume of the rock in the two states at ordinary temperatures is 13 per cent. If the relief of pressure over the site of continents were accompanied by volume changes at all approaching this, the additional elevation of seventeen twenty-sevenths required to raise the land to the sea-level would be accounted for. $t$ How far down beneath the surface the unloading of the

* C. Barus so names the material on which he experimented; apparently the rock is a fresh dolerite without olivine.

+ Professor Fitzgerald has been kind enough to express part of the preceding explanation in a more precise manner for me. He writes: "It would require a very nice adjustment of temperatures and pressures to work out in the simple way you state it; but what is really involved is that in a certain state diabase (and everything that changes state with a considerable change of volume) has an enormous isothermal compressibility. Although this is very enormous in the case of bodies which melt suddenly, like ice, it would also involve very great compressibilities in the case of bodies even which melted gradually, if they did so at all quickly, i.e., within a small range of temperature. What you postulate, then, is that at a certain depth diabase is soft enough to be squeezed from under the oceans, and that, being near its melting-point, the small relief of pressure is accompanied by an enormous increase in volume which helped to raise the continents. Now that I have written the thing out in my own way it seems very likely. It is, anyway, a suggestion quite worthy of serious consideration, and a process that in some places must almost certainly have been in operation, and maybe is still operative. Looking at it again, I hardly think it is quite likely that there is or could be much squeezing sideways of liquid or other viscous material from under one place to another, because the elastic yielding of the inside of the earth would be much quicker than any flow of this kind. This would only modify your theory, because the diabase that expands so much on the relief of pressure might be that already under the land, and raising up this latter, partly by being pushed up itself by the elastic relief of the inside of the earth, and partly by its own enormous expansibility near its melting-point. The action would be quite slow, because it would cool itself so much by its expansion that it would have tô be warmed up from below, or by tidal earth-squeezing, or by chemical action, before it could expand isothermally." 


\section{'THE PRIMI'TIVE OCEAN}

continents would be felt is difficult to say, though the problem is probably not beyond the reach of mathematical analysis ; if it affected an outer envelope twenty-five miles in thickness, a lineal expansion of 4 per cent. would suffice to explain the origin of ocean basins. If now we refer to the dilatation determined by Carl Barus for rise in temperature in the case of diabase, we find that between $1,093^{\circ}$ and $1,112^{\circ} \mathrm{C}$. the increase in volume is 3.3 per cent. As a further factor in deepening the ocean basins may be included the compressive effect of the increase in load over the ocean floor; this increase is equal to the pressure of a column of water 0.675 mile in height, and its effect in raising the fusion-point would be $2^{\circ} \mathrm{C}$., from which we may gain some kind of idea of the amount of compression it might produce on the yielding interior of the crust. To admit that these views are speculative will be to confess nothing; but they certainly account for a good deal. They not only give us ocean basins, but basins of the kind we want, that is, to use a crude comparison once made by the late Dr. Carpenter, basins of a tea-tray form, having a somewhat flat floor and steeply sloping sides; they also help to explain how it is that the value of gravity is greater over the ocean than over the land.

The ocean when first formed would consist of highly heated water, and this, as is well known, is an energetic chemical reagent when brought into contact with silicates like those which formed the primitive crust. As a result of its action saline solutions and chemical deposits would be formed; the latter, however, would probably be of no great thickness, for the time occupied by the ocean in cooling to a temperature not far removed from the present would probably be included within a few hundreds of years.

The course of events now becomes somewhat obscure, 


\section{4 'THE AGE OF THE EAR'TH}

but sooner or later the familiar processes of denudation and deposition started into activity, and have continued acting uninterruptedly ever since. The total maximum thickness of the sedimentary deposits, so far as I can discover, appears to amount to no less than fifty miles, made up as follows:-

\begin{tabular}{lrrrll} 
& \multicolumn{5}{c}{ Feet. } \\
Recent and Pleistocene & 4,000 & $\ldots$ & Man. \\
Pliocene... & $\ldots$ & $\ldots$ & 5,000 & $\ldots$ & Pithecanthropus. \\
Miocene... & $\ldots$ & $\ldots$ & 9,000 & $\ldots$ & \\
Oligocene & $\ldots$ & $\ldots$ & 12,000 & $\ldots$ & \\
Eocene ... & $\ldots$ & $\ldots$ & 12,000 & $\ldots$ & Eutheria. \\
Cretaceous & $\ldots$ & $\ldots$ & 14,000 & $\ldots$ & \\
Jurassic... & $\ldots$ & $\ldots$ & 8,000 & $\ldots$ & \\
Trias $\ldots$ & $\ldots$ & $\ldots$ & 13,000 & $\ldots$ & Mammals. \\
Permian... & $\ldots$ & $\ldots$ & 12,000 & $\ldots$ & Reptiles. \\
Carboniferous & $\ldots$ & $\ldots$ & 24,000 & $\ldots$ & Amphibia. \\
Devonian & $\ldots$ & $\ldots$ & 22,000 & $\ldots$ & Fish. \\
Silurian ... & $\ldots$ & $\ldots$ & 15,000 & $\ldots$ & \\
Ordovician & $\ldots$ & $\ldots$ & 17,000 & $\ldots$ & \\
Cambrian & $\ldots$ & $\ldots$ & 16,000 & $\ldots$ & Invertebrata. \\
Keweenawan & $\ldots$ & $\ldots$ & 50,000 & $\ldots$ & \\
Penokee & $\ldots$ & $\ldots$ & 14,000 & $\ldots$ & \\
Huronian & $\ldots$ & $\ldots$ & 18,000 & $\ldots$ &
\end{tabular}

Geologists, impressed with the tardy pace at which sediments appear to be accumulating at the present day, could not contemplate this colossal pile of strata without feeling that it spoke of an almost inconceivably long lapse of time. They were led to compare its duration with the distances which intervene between the heavenly bodies; but while some chose the distance of the nearest fixed star as their unit, others were content to measure the years in terms of miles from the sun.

The stratified rocks were eloquent of time, and not to

* It is very doubtful whether the Keweenawan possesses so great a thickness as this. 
the geologist alone, they appealed with equal force to the biologist. Accepting Darwin's explanation of the origin of species, the present rate at which form flows to form seemed so slow as almost to amount to immutability. How vast, then, must have been the period during which by slow degrees and innumerable stages the protozoon was transformed into the man! And if we turn to the stratified column, what do we find? Man, it is true, at the summit, the oldest fossiliferous rocks thirty-four miles lower down, and the fossils they contain already representing most of the great classes of the Invertebrata, including Crustacea and Worms. Thus the evolution of the Vertebrata alone is known to have occupied a period represented by a thickness of thirty-four miles of sediment. How much greater, then, must have been the interval required for the elaboration of the whole organic world! The human mind, dwelling on such considerations as these, seems at times to have been affected by a surexcitation of the imagination, and a consequent paralysis of the understanding, which led to a refusal to measure geological time by years at all, or to reckon by anything less than "eternities."

After the admirable Address of your President last year it might be thought needless for me to again enter into a consideration of this subject; it has been said, however, that the question of geological time is like the Djin in Arabian tales, and will irrepressibly come up again for discussion, however often it is disposed of. For my part I do not regard the question so despondingly, but rather hope that by persevering effort we may succeed in discovering the talisman by which we may compel the unwilling Djin into our service. How immeasurable would be the advance of our science could we but bring the chief events which it records into some relation with a standard of time! 
Before proceeding to the discussion of estimates of time drawn from a study of stratified rocks let us first consider those which have been already suggested by other data. These are as follows:-(1) Time which has elapsed since the separation of the earth and moon, fiftysix millions of years, minimum estimate by Professor G. H. Darwin. (2) Since the "consistentior status," twenty to forty millions (Lord Kelvin). (3) Since the condensation of the oceans, eighty to ninety millions, maximum estimate by Professor J. Joly.

It may be at once observed that these estimates, although independent, are all of the same order of magnitude, and so far confirmatory of each other. Nor are they opposed to conclusions drawn from a study of stratified rocks; thus Sir Archibald Geikie, in his Address to this Section last year, affirmed that, so far as these were concerned, 100 millions of years might suffice for their formation. There is, then, very little to quarrel about, and our task is reduced to an attempt, by a little stretching and a little paring, to bring these various estimates into closer harmony.

Professor Darwin's estimate is admittedly a minimum ; the actual time, as he himself expressly states, "may have been much longer." Lord Kelvin's estimate, which he would make nearer twenty than forty millions, is founded on the assumption that since the period of the "consistentior status" the earth has cooled simply as a solid body, the transference of heat from within outwards having been accomplished solely by conduction.

It may be at once admitted that there is a large amount of truth in this assumption; there can be no possible doubt that the earth reacts towards forces applied for a short time as a solid body. Under the influence of the tides it behaves as though it possessed a rigidity approaching that of steel, and under sudden blows, such as those 
which give rise to earthquakes, with twice this rigidity, as Professor Milne informs me. Astronomical considerations lead to the conclusion that its effective rigidity has not varied greatly for a long period of past time.

Still, while fully recognising these facts, the geologist knows-we all know-that the crust of the earth is not altogether solid. The existence of voleanos by itself suggests the contrary, and although the total amount of fluid material which is brought from the interior to the exterior of the earth by volcanic action may be, and certainly is, small-from data given by Professor Penck, I estimate it is as equivalent to a layer of rock uniformly distributed $2 \mathrm{~mm}$. thick per century; * yet we have every reason to believe that volcanos are but the superficial manifestation of far greater bodies of molten material which lie concealed beneath the ground. Even the wide areas of plutonic rock, which are sometimes exposed to view over a country that has suffered longcontinued denudation, are merely the upper portion of more extensive masses which lie remote from view. The existence of molten material within the earth's crust naturally awakens a suspicion that the process of cooling has not been wholly by conduction, but also to some slight extent by convection, and to a still greater extent by the bodily migration of liquid lava from the deeper layers of the crust towards the surface.

The existence of local reservoirs of molten rock within the crust is even still more important in another connection, that is, in relation with the supposed " average rate of increase of temperature with descent below the ground." It is doubtful whether we have yet discovered a rate that in any useful sense can be spoken of as "average." The widely divergent views of different

* The heat thus brought to the surface would amount to one seventeenth of that conveyed by conduction. 
authorities as to the presumed value of this rate may well lead to reflection. The late Professor Prestwich thought a rise of $10 \mathrm{~F}$. for every 45 feet of descent below the zone of constant temperature best represented the average; Lord Kelvin in his earlier estimates has adopted a value of $1^{\circ} \mathrm{F}$. for every 51 feet; the Committee of this Association appointed to investigate this question arrived at a rate of $1^{\circ} \mathrm{F}$. for every 60 feet of descent; Mr. Clarence King has made calculations in which a rate of $10 \mathrm{~F}$. for 72 feet is adopted ; a re-investigation of recorded measurements would, I believe, lead to a rate of $1^{\circ} \mathrm{F}$. in 80 or 90 feet as more closely approaching the mean. This would raise Lord Kelvin's estimate to nearly fifty millions of years.

When from these various averages we turn to the observations on which they are based, we encounier a surprising divergence of extremes from the mean; thus in the British Isles alone the rate varies from $1^{\circ} \mathrm{F}$. in 34 feet to $1^{\circ} \mathrm{F}$. in 92 feet, or in one case to $1^{\circ} \mathrm{F}$. in 130 feet.* It has been suggested, and to some extent shown, that these irregularities may be connected with differences in conductivity of the rocks in which the observations were made, or to the circulation of underground water; but many cases exist which cannot be explained away in such a manner, but are suggestive of some deep-seated cause, such as the distribution of molten matter below the ground. Inspection of the accompanying map of the British Isles, on which the rates of increase in different localities have been plotted, will afford some evidence of the truth of this view. Comparatively low rates of increase are found over Wales and in the province of Leinster, districts of relatively great stability, the remnants of an island that have in all probability stood for the most part above the sea ever since the close of the * See note on the Geothermic Gradient, p. 61. 
Silurian period. To the north of this, as we enter a region which was subject to volcanic disturbances during the Tertiary period, the rate increases.

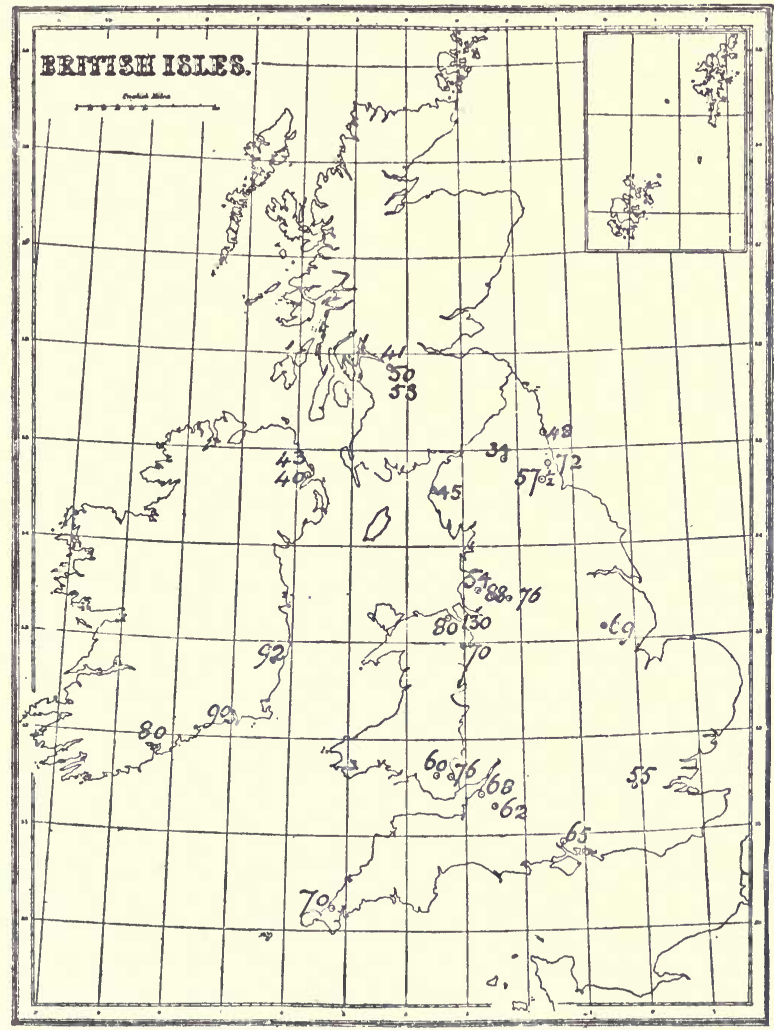

Frg. 1.-Map of the British Isles, showing the distribution of rates of increase of temperature with descent. The rates are taken from the "British Association Report," except in the case of those in the south of Ireland.

It is obvious that in any attempt to estimate the rate at which the earth is cooling as a solid body the disturbing influence of subterranean lakes of molten rock must as far 
as possible be eliminated; but this will not be effected by taking the accepted mean of observed rates of increase of temperature: such an average is merely a compromise, and a nearer approach to a correct result will possibly be attained by selecting some low rate of increase, provided it be based on accurate observations.

It is extremely doubtful whether an area such as the British Isles, which has so frequently been the theatre of volcanic activity and other subterranean disturbance, is the best fitted to afford trastworthy results; the Archæan nucleus of a continent might be expected to afford surer indications. Unfortunately the hidden treasures of the earth are seldom buried in these regions, and bore-holes in consequence have rarely been made in them. One exception is afforded by the copper-bearing district of Lake Superior, and in one case, that of the Calumet and Hecla mine, which is 4,580 feet in depth, the rate of increase, as determined by Professor A. Agassiz, was 10 F. for every 223.7 feet.* The Bohemian "horst" is a somewhat ancient part of Europe, and in the Przibram mines, which are sunk in it, the rate was $1^{\circ} \mathrm{F}$. for every 126 feet of descent. In the light of these facts it would seem that geologists are by no means compelled to accept the supposed mean rate of increase of temperature with descent into the crust as affording a safe guide to the rate of cooling of a solid globe: and if the much slower rate of increase observed in the more ancient and more stable regions of the earth has the importance which is suggested for it, then Lord Kelvin's estimate of the date of the " consistentior status" may be pushed back into a remoter past.

If, as we have reason to hope, Lord Kelvin's somewhat

* Subsequent investigation has shown that this result is erroneous. $\mathrm{Mr}$. Lane considers that the rate of increase in the Calumet district is $1^{\prime} \mathrm{F}$. for 107 feet. 


\section{JOLY'S ES'TIMA'TE}

contracted period will yield to a little stretching, Professor Joly's, on the other hand, may take some paring. His argument, broadly stated, is as follows. The ocean consisted at first of fresh water; it is now salt, and its saltness is due to the dissolved matter that is constantly being carried into it by rivers. If, then, we know the quantity of salt which the rivers bring down each year into the sea, it is easy to calculate how many years they have taken to supply the sea with all the salt it at present contains. For several reasons it is found necessary to restrict attention to one only of the elements contained in sea salt: this is sodium. The quantity of sodium delivered to the sea every year by rivers is about $160,000,000$ tons ; but the quantity of sodium which the sea contains is at least ninety millions of times greater than this. The period during which rivers have been carrying sodium into the sea must therefore be about ninety millions of years. Nothing could be simpler; there is no serious flaw in the method, and Professor Joly's treatment of the subject is admirable in every way; but of course in calculations such as this everything depends on the accuracy of the data, which we may therefore proceed to discuss. Professor Joly's estimate of the amount of sodium in the ocean may be accepted as sufficiently near the truth for all practical purposes. We may therefore pass on to the other factor, the annual contribution of sodium by river water. Here there is more room for error. Two quantities must be ascertained: one the quantity of water which the rivers of the world carry into the sea, the other the quantity or proportion of sodium present in this water. The total volume of water discharged by rivers into the ocean is estimated by Sir John Murray as 6,524 cubic miles. The estimate being based on observations of thirty-three great rivers, although only approximate, is perhaps sufficiently 
exact; at all events such alterations as it is likely to undergo may not greatly affect the final result. When, however, we pass to the last quantity to be determined, the chemical composition of average river water, we find that only a very rough estimate is possible, and this is the more unfortunate because changes in this may very materially affect our conclusions. The total quantity of river water discharged into the sea is, as we have stated, 6,524 cubic miles. The average composition of this water is deduced from analyses of nineteen great rivers, which altogether discharge only 488 cubic miles, or $7 \cdot 25$ per cent. of the whole. The danger in using this estimate is twofold: in the first place $7 \cdot 2.5$ is too small a fraction from which to argue to the remaining $92 \cdot 75$ per cent., and, next, the rivers which furnish it are selected rivers, i.e., they are all of large size. The effect of this is that the drainage of the volcanic regions of the earth is not sufficiently represented, and it is precisely this drainage which is richest in sodium salts. The lavas and ashes of active volcanos rapidly disintergate under the energetic action of various acid gases, and among volcanic exhala-, tions sodium chloride has been especially noticed as abundant. Consequently we find that while the proportion of sodium in Professor Joly's average river water is only 5.73 per million, in the rivers of the volcanic island of Hawaii it rises to 24.5 per million.* No doubt the area occupied by volcanos is trifling compared with the remaining land surface. On the other hand, the majority of volcanos are situated in regions of copious rainfall, of which they receive a full share owing to their mountainous form. Much of the fallen rain percolates through the porous material of the cone, and, richly charged with alkalies, finds its way by underground passages towards the sea,

* Walter Maxwell, "Lavas and Soils of the Hawaiian Islands," p. 170. 


\section{JOLY'S ES'TIMA'TE}

into which it sometimes discharges by submarine springs.

Again, several considerations lead to the belief that the supply of sodium to the ocean has proceeded, not at a uniform, but at a gradually diminishing rate. The rate of increase of temperature with descent into the crust has continuously diminished with the flow of time, and this must have had its influence on the temperature of springs, which furnish an important contribution to river water. The significance of this consideration may be judged from the composition of the water of geysers. Thus Geyser, in Iceland, contains 884 parts of sodium per million, or nearly 160 times as much as Sir John Murray estimates is present in average river water. A mean of the analyses of six geysers in different parts of the world gives 400 parts of sodium per million, existing partly as chloride, but also as sulphate and carbonate.

It should not be overlooked that the present is a calm and quiet epoch in the earth's history, following after a time of fiery activity. More than once, indeed, has the past been distinguished by unusual manifestations of volcanic energy, and these must have had some effect upon the supply of sodium to the ocean. Finally, although the existing ocean water has apparently but slight effect in corroding the rocks which form its bed, yet it certainly was not inert when its temperature was not far removed from the critical point. Water begins to exert a powerful destructive action on silicates at a temperature of $180^{\circ} \mathrm{C}$., and during the interval occupied in cooling, from $370^{\circ}$ to $180^{\circ} \mathrm{C}$., a considerable quantity of sodium may have entered into solution.

A review of the facts before us seems to render some reduction in Dr. Joly's estimate imperative. A precise assessment is impossible, but I should be inclined myself to take off some thirty or forty millions of years. 
We may next take the evidence of the stratified rocks. Their total maximum thickness is, as we have seen, 265,000 feet, and consequently if they accumulated at the rate of one foot in a century, as evidence seems to suggest, more than twenty-six millions of years must have elapsed during their formation.*

Before discussing the validity of the argument on which this last result depends, let us consider how far it harmonises with previous ones. It is consistent with Lord Kelvin's and Professor Darwin's, but how does it accord with Professor Joly's? Supposing we reduce his estimate to fifty-five millions: what was the earth doing during the interval between the period of fifty-five millions of years ago and that of about twenty-six millions, when, it is presumed, sedimentary rocks commenced to be formed? Hitherto we have been able to reason on probabilities; now we enter the dreary regions of possibilities, and open that obscure chapter in the history of the earth previously hinted at. For there are many possible answers to this question. In the first place the evidence of the stratified rocks may have been wrongly interpreted, and two or three times the amount of time we have demanded may have been consumed in their formation. This is a very obvious possibility, yet again our estimate concerning these rocks may be correct, but we may have erroneously omitted to take into account certain portions of the Archæan complex, which may represent primitive sedimentary rocks, formed under exceptional conditions, and subsequently transformed under the influence of the internal heat of the earth.

This, I think, would be Professor Bonney's view. Finally, Lord Kelvin has argued that the life of the sun as a luminous star is even more briefly limited than that of our oceans. In such a case, if our oceans were formed * See Note on Radium, p. 63. 


\section{AGE OF THE ORGANIC WORLD 25}

fifty-five millions of years ago, it is possible that after a short existence as almost boiling water they grew colder and colder, till they became covered with thick ice, and moved only in obedience to the tides. The earth, frozen and dark, except for the red glow of her volcanos, waited the coming of the sun, and it was not till his growing splendour had banished the long night that the cheerful sound of running waters was heard again in our midst. Then the work of denudation and deposition seriously recommenced, not to cease till the life of the sun is spent. Thus the thickness of the stratified series may be a measure rather of the duration of sunlight than of the period which has elapsed since the first formation of the ocean. It may have been so-we cannot tell--but it may be fairly urged that we know less of the origin, history, and constitution of the sun than of the earth itself, and that, for aught we can say to the contrary, the sun may have been shining on the just-formed ocean as cheerfully as he shines to-day.

But, it will be asked, how far does a period of twentysix millions satisfy the demands of biology? Speaking only for myself, although I am aware that eminent biologists are not wanting who share this opinion, I answer, Amply. But it will be exclaimed, Surely there are "comparisons in things." Look at Egypt, where more than 4,000 years ago the same species of man and animals lived and flourished as to-day. Examine the frescos and study the living procession of familiar forms they so faithfully portray, and then tell us, how comes it about that from changes so slow as to be inappreciable in the lapse of forty centuries you propose to build up the whole organic world in the course of a mere twenty-six millions of years? To all which we might reply that even changeless Egypt presents us with at least one change-the features of the ruling race to-day are not 
quite the same as those of the Pharaohs. But putting this on one side, the admitted constancy in some few common forms proves very little, for so long as the environment remains the same natural selection will conserve the type, and, so far as we are able to judge, conditions in Egypt have remained remarkably constant for a long period.

Change the conditions, and the resulting modification of the species becomes manifest enough ; and in this connection it is only necessary to recall the remarkable mutations observed and recorded by Professor Weldon in the case of the crabs in Plymouth Harbour. In response to increasing turbidity of the sea water these crabs have undergone or are undergoing a change in the relative dimensions of the carapace, which is persistent, in one direction, and rapid enough to be determined by measurements made at intervals of a few years.

Again, animals do not all change their characters at the same rate: some are stable in spite of changing conditions, and these have been cited to prove that none of the periods we look upon as probable, not twenty-five, not a hundred millions of years, scarce any period short of eternity, is sufficient to account for the evolution of the living world. If the little tongue-shell, Lingula, ${ }^{*}$ has endured with next to no perceptible change from the Cambrian down to the present day, how long, it is sometimes inquired, would it require for the evolution of the rest of the animal kingdom? The reply is simple: the cases are dissimilar, and the same record which assures us of the persistency of the Lingula tells us in language equally emphatic of the course of evolution

* In connection with the longevity of this genus, may be mentioned the extraordinary tenacity of life exbibited by the individual; its resistance to unfavourable conditions has becn remarked on by Morse and other observers. 
which has led from the lower organisms upwards to man. In recent and Pleistocene deposits the relics of man are plentiful: in the latest Pliocene they have disappeared, and we encounter the remarkable form Pithecanthropus; as we descend into the Tertiary systems the higher mammals are met with, always sinking lower and lower in the scale of organisation as they occur deeper in the series, till in the Mesozoic deposits they have entirely disappeared, and their place is taken by the lower mammals, a feeble folk, offering little promise of the future they were to inherit. Still lower, and even these are gone; and in the Permian we encounter reptiles and the ancestors of reptiles, probably ancestors of mammals too; then into the Carboniferous, where we find amphibians, but no true reptiles; and next into the Devonian, where fish predominate, after making their earliest appearance at the close of the Silurian times; thence downwards, and the vertebrata are no more found-we trace the evolution of the invertebrata alone. Thus the orderly procession of organic forms follows in precisely the true phylogenetic sequence: invertebrata first, then vertebrates, at first fish, then amphibia, next reptiles, soon after mammals, of the lowlier kinds first, of the higher later, and these in increasing complexity of structure till we finally arrive at man himself. While the living world was thus unfolding into new and nobler forms, the immutable Lingula simply perpetuated its kind. To select it, or other species equally sluggish, as the sole measure of the rate of biologic change would seem as strange a proceeding as to confound the swiftness of a river with the stagnation of the pools that lie beside its banks. It is occasionally objected that the story we have drawn from the palæontological record is mere myth or is founded only on negative evidence. Cavils of this kind prove 
a double misapprehension, partly as to the facts, partly as to the value of negative evidence, which may be as good in its way as any other kind of evidence.

Geologists are not unaware of the pitfalls which beset negative evidence, and they do not conclude from the absence of fossils in the rocks which underlie the Cambrian that pre-Cambrian periods were devoid of life; on the contrary, they are fully persuaded that the seas of those times were teeming with a rich variety of invertebrate forms. How is it that, with the exception of some few species found in beds immediately underlying the Cambrian, these have left behind no vestige of their existence? The explanation does not lie in the nature of the sediments, which are not unfitted for the preservation of fossils, nor in the composition of the then existing sea water, which may have contained quite as much calcium carbonate as occurs in our present oceans; and the only plausible supposition would appear to be that the organisms of that time had not passed beyond the stage now represented by the larvæ of existing invertebrata, and consequently were either unprovided with skeletons, or at all events with skeletons durable enough for preservation. If so, the history of the earlier stages of the evolution of the invertebrata will receive no light from palæontology; and no direct answer can be expected to the question whether, eighteen or nineteen millions of years being taken as sufficient for the evolution of the vertebrata, the remaining available eight millions would provide for that of the invertebrate classes which are represented in the lowest Cambrian deposits. On à priori grounds there would appear to be no reason why it should not. If two millions of years afforded time enough for the conversion of fish into amphibians, a similar period should suffice for the evolution of trilobites from annelids, or of annelids 
from trochospheres. The step from gastrulas to trochospheres might be accomplished in another two millions, and two millions more would take us from gastrulas through morulas to protozoa.

As things stand, biologists can have nothing to say either for or against such a conclusion: they are not at present in a position to offer independent evidence; nor can they hope to be so until they have vastly extended those promising investigations which they are only now beginning to make into the rate of the variation of species.

Two difficulties now remain for discussion: one based on theories of mountain chains, the other on the unaltered state of some ancient sediments. The latter may be taken first. Professor van Hise writes as follows regarding the pre-Cambrian rocks of the Lake Superior district: "The Penokee series furnishes an instructive lesson as to the depth to which rocks may be buried and yet remain but slightly affected by metamorphosis. The series itself is 14,000 feet thick. It was covered before being upturned with a great thickness of Keweenaw rock. This series at the Montreal River is estimated to be 50,000 feet thick. Adding to this the known thickness of the Penokee series, we have a thickness of 64,000 feet. ... The Penokee rocks were then buried to a great depth, the exact amount depending upon their horizon and upon the stage in Keweenaw time, when the tilting and erosion, which brought them to the surface, commenced.

"That the synclinal trough of Lake Superior bagan to form before the end of the Keweenaw period, and consequently that the Penokee rocks were not buried under the full succession, is more than probable. However, they must have been buried to a great depth-at least several miles-and thus subjected to high pressure and tempera- 
ture, notwithstanding which they are comparatively unaltered." *

I select this example because it is one of the best instances of a difficulty that occurs more than once in considering the history of sedimentary rocks. On the supposition that the rate of increment of temperature with descent is $1^{\circ} \mathrm{F}$. for every 84 feet, or $1^{\circ} \mathrm{C}$. for every 150 feet, and that it was no greater during these early Penokee times, then at a depth of 50,000 feet $\dagger$ the Penokee rocks would attain a temperature of nearly $333^{\circ}$ C.; and since water begins to exert powerful chemical action at $180^{\circ} \mathrm{C}$., they should, on the theory of a solid cooling globe, have suffered a metamorphosis sufficient to obscure their resemblance to sedimentary rocks. Either, then, the accepted rate of downward increase of temperature is erroneous, or the Penokee rocks were never depressed, in the place where they are exposed to observation, to a depth of 50,000 feet. Let us consider each alternative, and in the first place let us apply the rate of temperature increment determined by Professor Agassiz in this very Lake Superior district: it is $1^{\circ} \mathrm{C}$. for every 402 feet, $\ddagger$ and twenty-five millions of years ago, or about the time when we may suppose the Penokee rocks were being formed, it would be $1 \circ \mathrm{C}$, for every 305.5 feet, with a resulting temperature at a depth of 50,000 feet of $163^{\circ} \mathrm{C}$. only. Thus the admission of a very low rate of temperature increment would meet the difficulty; but on the other hand it would involve a period of several hundreds of millions of years for the age of the "consistentior status," and thus greatly exceed Professor Joly's maximum

* “Tenth Annual Report U.S. Geol. Survey," 1888-89, p. 457.

† From information received from Mr. A. C. Lane, State Geologist of Michigan, 30,000 feet would be nearer the mark. On the other hand the rise of temperature is now estimated at $1^{\circ} \mathrm{C}$. for 193 feet.

+ We have already seen that this rate is far too low. 
estimate of the age of the oceans. We may therefore turn to a second alternative. As regards this it is by no means certain that the exposed portion of the Penokee series ever was depressed 50,000 feet: the beds lie in a synclinal the base of which, indeed, may have sunk to this extent, and entered a region of metamorphosis; but the only part of the system that lies exposed to view is the upturned margin of the synclinal, and as to this it would seem impossible to make any positive assertion as to the depth to which it may or may not have been depressed. To keep an open mind on the question seems our only course for the present, but difficulties like these offer a promising field for investigation.

It is frequently alleged that mountain chains cannot be explained on the hypothesis of a solid earth cooling under the conditions and for the period we have supposed. This is a question well worthy of consideration, and we may first endeavour to picture to ourselves the conditions under which mountain chains arise. The floor of the ocean lies at an average depth of 2,000 fathoms below the land, and is maintained at a constant temperature, closely approaching $0^{\circ} \mathrm{C}$., by the passage over it of cold water creeping from the polar regions. The average temperature of the surface of the land is above zero, but we can afford to disregard the difference in temperature between it and the ocean floor, and may take them both at zero. Consider next the increase of temperature with descent, which occurs beneath the continents: at a depth of 13,000 feet, or at the same depth as the ocean floor, a temperature of $87^{\circ} \mathrm{C}$. will be reached on the supposition that the rate of increase is $1 \circ \mathrm{C}$. for 150 feet, while with the usually accepted rate of $10 \mathrm{C}$. for 108 feet it would be $120^{\circ} \mathrm{C}$. But at this depth the ocean floor, which is on the same spherical surface, is at $0^{\circ} \mathrm{C}$. Thus surfaces of equal temperature within the earth's crust will not be 
spherical, but will rise or fall beneath an imaginary spherical or spheroidal surface according as they occur beneath the continents or the oceans. No doubt at some depth within the earth the departure of isothermal surfaces from a spheroidal form will disappear; but considering the great breadth both of continents and oceans this depth must be considerable, possibly even forty or fifty miles. Thus the sub-continental excess of temperature may make itself felt in regions where the rocks still retain a high temperature, and probably not far removed from the critical fusion-point. The effect will be to render the continents mobile as regards the ocean floor; or, vice versâ, the ocean floor will be stable compared with the continental masses. Next it may be observed that the continents pass into the bed of the ocean by a somewhat rapid flexure, and that it is over this area of flexure that the sediments denuded from the land are deposited. Under its load of sediment the sea-floor sinks down, subsiding slowly, at about the same rate as the thickness of sediment increases; and, whether as a consequence or a cause, or both, the flexure marking the boundary of land and sea becomes more pronounced. A compensating movement occurs within the earth's crust, and solid material may flow from under the subsiding area in the direction of least resistance, possibly towards the land. At length, when some thirty or forty thousand feet of sediment have accumulated in a basin-like form, or, according to our reckoning, after the lapse of three or four millions of years, the downward movement ceases, and the mass of sediment is subjected to powerful lateral compression, which, bringing its borders into closer proximity by some ten or thirty miles, causes it to rise in great folds high into the air as a mountain chain.

It is this last phase in the history of mountain-making which has given geologists more cause for painful thought 
than probably any other branch of their subject, not excluding even the age of the earth. It was at first imagined that during the flow of time the interior of the earth lost so much heat, and suffered so much contraction in consequence, that the exterior, in adapting itself to the shrunken body, was compelled to fit it like a wrinkled garment. This theory, indeed, enjoyed a happy existence till it fell into the hands of mathematicians, when it fared very badly, and now lies in a pitiable condition neglected of its friends.*

For it seemed proved to demonstration that the contraction consequent on cooling was wholly, even ridiculously, inadequate to explain the wrinkling. But when we summon up courage to inquire into the data on which the mathematical arguments are based, we find that they include several assumptions the truth of which is by no means self-evident. Thus it has been assumed that the rate at which the fusion-point rises with increased pressure is constant, and follows the same law as is deduced from experiments made under such pressures as we can command in our laboratories down to the very centre of the earth, where the pressures are of an altogether different order of magnitude; so with a still more important coefficient, that of expansion, our knowledge of this quantity is founded on the behaviour of rocks heated under ordinary atmospheric pressure, and it is assumed that the same coefficient as is thus obtained may be safely applied to material which is kept solid, possibly near the critical point, under the tremendous pressure of the depths of the crust. To this last assumption we owe the terrible bogies that have been conjured out of " the level of no strain." The depth of this as calculated by the

* With some exceptions, notably Professor George Darwin and Mr. C. Davison, who have consistently supported the theory of contraction. 
Rev. O. Fisher is so trifling that it would be passed through by all very deep mines.* Mr. C. Davison, however, has shown that it will lie considerably deeper, if the known increase of the coefficient of expansion with rise of temperature be taken into account. It is possible, it is even likely, that the coefficient of expansion becomes vastly greater when regions are entered, where the rocks are compelled into the solid state by pressure. So little do we actually know of the behaviour of rock under these conditions that the geologist would seem to be left very much to his own devices; but the evidence of earthquakes shows there is one temptation he must resist-he may not take refuge in the hypothesis of a liquid interior.

We shall boldly assume that the contraction at some unknown depth in the interior of the earth is sufficient to afford the explanation we seek. The course of events may then proceed as follows. The contraction of the interior of the earth, consequent on its loss of heat, causes the crust to fall upon it in folds, which rise over the continents and sink under the oceans, and the flexure of the area of sedimentation is partly a consequence of this folding. partly of overloading. By the time a depression of some 30,000 or 40,000 feet has occurred along the ocean border the relation between continents and oceans has become unstable, and readjustment takes place, probably by a giving way of the continents, and chiefly along the zone of grcatest weakness, i.e., the area of sedimentation, which thus becomes the zone of mountain building. (Fig. 2.) It may be observed that at great depths readjustment will be produced by a slow flowing of solid rock, and it is only comparatively near the surface, five or ten miles at the most below, that failure of support can lead to sudden fracture and collapse; hence the comparatively superficial origin of earthquakes.

* See Note on Mountain Chains in "Figure of the Earth," p. 59. 
Given a sufficiently large increase in the value of the coefficient of expansion with rise in temperature-and

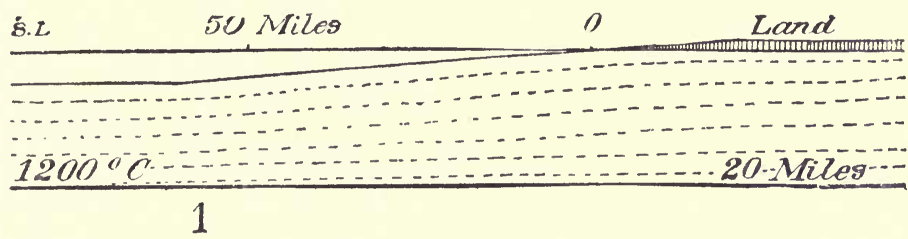

S.L Area of Depostion
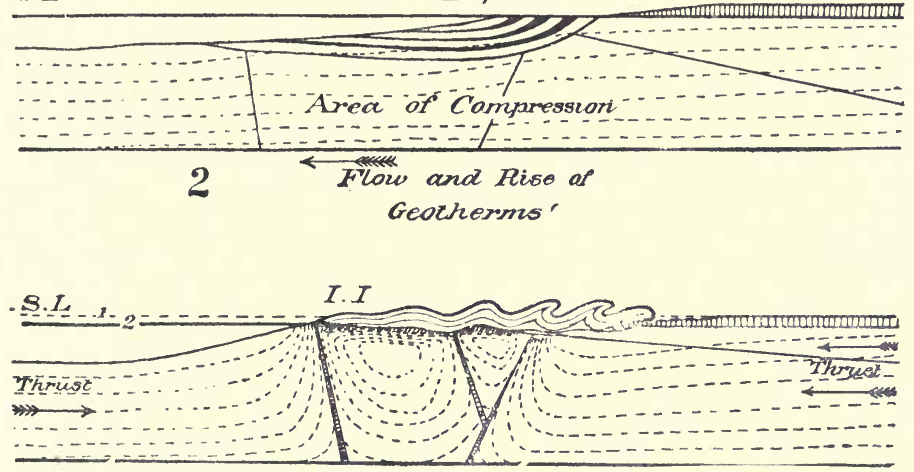

3

FIG. 2.-Diagram drawn to scale to illustrate the successive stages in the formation of a mountain chain. 0 to 50 represents a horizontal distance of fifty miles: S.L. sea-level.

1. The first stage previous to the deposition of sediment. Tho dotted lines are subterranean geotherms.

2. The second stage after the deposition of five miles of sediment in the course of about three millions of years. The sinking of the sea-floor over a.a.a. pari passu with deposition is accompanied by compression of the underlying crust, and by a flow of superheated rock in the direction of the arrow. The removal of this rock leads to a rise of the subterranean geotherms, below the area of deposition. The lowest line in this figure should be bent downwards below the area of deposition.

3. The third stage. The contraction of the interior of the earth due to cooling for three millions of years or so has set up stresses throughout the crust. Some of these are relieved by thrusting. The continental land with the superficial crust moves along these towards the ocean, and so produces folding of the sediments. Liquefaction results wherever the superheated rocks are relieved of some part of the overlying pressure, and molten magma is injected into the mountain chain. 
there is much to suggest its existence *-and all the phenomena of mountain ranges become explicable: they begin to present an appearance that invites mathematical treatment; they inspire us with the hope that from a knowledge of the height and dimensions of a continent and its relations to the bordering ocean we may be able to predict when and where a mountain chain should arise, and the theory which explains them promises to guide us to an interpretation of those world-wide unconformities which Suess can only account for by a transgression of the sea. Finally it relieves us of the difficulty presented by mountain formation in regard to the estimated duration of geological time.

This may perhaps be the place to notice a highly interesting speculation which we owe to Professor Blytt, who has attempted to establish a connection between periods of readjustment of the earth's crust and variations in the eccentricity of the earth's orbit. Without entering into any discussion of Professor Blytt's methods, we may offer a comparison of his results with those that follow from our rough estimate of one foot of sediment accumulated in a century.

Table showing the Time that has elapsed since the Beginning of the Systems in the first column, as reckoned from Thickness of Sediment in the second column, and by Professor Blytt in the third:-

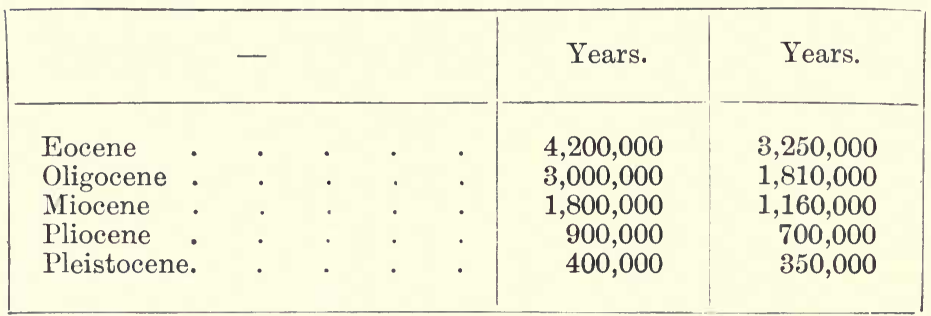

*Vide pp. 11 and 60. 
It is now time to return to the task, too long postponed, of discussing the data from which we have been led to conclude that a probable rate at which sediments have accumulated in places where they attain their maximum thickness is one foot per century.

We owe to Sir Archibald Geikie a most instructive method of estimating the existing rate at which our continents and islands are being washed into the sea by the action of rain and rivers : by this we find that the present land surface is being reduced in height to the extent on an average of $\frac{1}{2400}$ foot yearly.* If the material removed from the land were uniformly distributed over an area equal to that from which it had been derived, it would form a layer of rock $\frac{1}{2400}$ foot thick yearly, i.e., the rates of denudation and deposition would be identical. But the two areas, that of denudation and that of deposition, are seldom or never equal, the latter as a rule being much the smaller. Thus the area of that part of North America which drains into the Gulf of Mexico measures 1,800,000 square miles; the area over which its sediments are deposited is, so far as I can gather from Professor Agassiz' statements, less than 180,000 square miles; while Mr. McGee estimates it at only 100,000 square miles. Using the larger number, the area of deposition is found to measure one-tenth the area of denudation; the average rate of deposition will therefore be ten times as great as the rate of denudation, or $\frac{1}{240}$ foot may be supposed to be uniformly distributed over the area of sedimentation in the course of a year. But the thickness by which we have measured the strata of our geological systems is not an average but a maximum thickress; we have, therefore, to obtain an estimate of the maximum rate of deposition. If we assume the deposited sediments to be arranged somewhat after the fashion of a wedge with the thin end

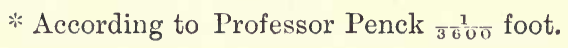


seawards, then twice the average would give us the maximum rate of deposition: this would be one foot in 120 years. But the sheets of deposited sediment are not merely thicker towards the land, thinner towards the sea, they also increase in thickness towards the rivers in which they have their source, so that a very obtuse-angled cone, or, better, the down-turned bowl of a spoon, would more nearly represent their form. This form tends to disappear under the action of waves and currents, but a limit is set to this disturbing influence by the subsidence which marks the region opposite the mouth of a large river. By this the strata are gradually let downwards, so that they come to assume the form of the bowl of a spoon turned upwards. Thus a further correction is necessary if we are to arrive at a fair estimate of the maximum rate of deposition. Considering the very rapid rate at which our ancient systems diminish in thickness when traced in all directions from the localities where they attain their maximum, it would appear that this correction must be a large one. If we reduce our already corrected estimate by one-fifth, we arrive at a rate of one foot of sediment deposited in a century.

No doubt this value is often exceeded; thus in the case of the Mississippi River the bar of the south-west pass advanced between the years 1838 and 1874 a distance of over two miles, covering an area $2 \cdot 2$ miles in width with a deposit of sediment 80 feet in thickness; outside the bar, where the sea is 250 feet in depth, sediment accumulates, according to Messrs. Humphreys and Abbot, at a rate of 2 feet yearly. It is quite possible, indeed it is very likely, that some of our ancient strata have been formed with corresponding rapidity. No gravel nor coarse sand is deposited over the Mississippi delta; such material is not carried further seawards than New Orleans. Thus the vast sheets of conglomerate and 


\section{RA'TE OF CRUS'T MOVEMEN'TS 39}

sandstone which contribute so largely to some of our ancient systems, such as the Cambrian, Old Red Sandstone, Millstone Grit, and Coal Measures, must have accumulated under very different conditions-conditions for which it is not easy to find a parallel; but in any case these deposits afford evidence of very rapid accumulation.

These considerations will not tempt us, however, to modify our estimate of one foot in a century ; for though in some cases this rate may have been exceeded, in others it may not have been nearly attained.

Closely connected with the rate of deposition is that of that changing level of land and sea; in some cases, as in the Wealden delta, subsidence and deposition appear to have proceeded with equal steps, so that we might regard them as transposable terms. It would, therefore, prove of great assistance if we could determine the average rate at which movements of the ground are proceeding; it might naturally be expected that the accurate records kept by tidal gauges in various parts of the world would afford us some information on this subject; and no doubt they would, were it not for the singular misbehaviour of the sea, which does not maintain a constant level, its fluctations being due, according to Professor Darwin, to the irregular melting of ice in the polar regions, Of more immediate application are the results of various observations in Scandinavia, which appear to prove an average rise of the peninsula at the rate of 3 feet in a century to be still in progress; ${ }^{*}$ and Mr. G. K. Gilbert's measurements in the great Lake district of North America, which indicate a tilting of the continent at the rate of 3 inches per hundred miles per century.

* See on this question, Suess, "Das Antliz der Erde," vol. ii., and "Grundzüge der Physischen Erdkunde," by A. Supan, Leipzig, 1903 pp. 341-365. The latter contains a long list of references. 
But while measurements like these may furnish us with some notion of the sort of speed of these changes, they are not sufficient even to suggest an average; for this we must be content to wait till sufficient tidal observations have accumulated, and the disturbing effect of the inconstancy of the ser-level eliminated.

It may be objected that in framing our estimate we have taken into account mechanical sediments only, and ignored others of equal importance, such as limestone and coal. With regard to limestone, its thickness in regions where systems attain their maximum may be taken as negligible; nor is the formation of limestone necessarily a slow process. The successful experiments of Dr. Allan cited by Darwin, prove that some reef-building corals may grow at the astonishing rate of 6 feet in height per annum.

In respect of coal there is much to suggest that its growth was rapid. The carboniferous period well deserves its name, for never before, never since, have carbonaceous deposits accumulated to such a remarkable thickness or over such wide areas of the earth's surface. The explanation is doubtless partly to be found in favourable climatal conditions, but also, I think, in the youthful energy of a new and overmastering type of vegetation, which then for the first time acquired the dominion of the land. If we turn to our modern peat-bogs, the only carbonaceous growths available for comparison, we find from data given by Sir A. Geikie that a fairly average rate of increase is 6 feet in a century, which might perhaps correspond to one foot of coal in the same period.

The rate of deposition has been taken as uniform through the whole period of time recorded by stratified rocks; but lest it should be supposed that this involves a tacit admission of uniformity, I hasten to explain that in this matter we have no choice; we may feel convinced 
that the rate has varied from time to time, but in what direction, or to what extent, it is impossible to conjecture. That the sun was once much hotter is probable, but equally so that at an earlier period it was much colder; and even if in its youth all the activities of our planet were enhanced, this fact might not affect the maximum thickness of deposits. An increase in the radiation of the sun, while it would stimulate all the powers of subaërial denudation, would also produce stronger winds and marine currents; stronger currents would also result from the greater magnitude and frequency of the tides, and thus, while larger quantities of sediment might be delivered into the sea, they would be distributed over wider areas, and the difference between the maximum and average thickness of deposits would consequently be diminished. Indications of such a wider distribution may, I think, be recognised in the Palæozoic systems. Thus we are compelled to treat our rate of deposition as uniform, notwithstanding the serious error this may involve.

The reasonableness of our estimate will perhaps best appear from a few applications. Fig. 3 is a chart, based on a map by De Lapparent, representing the distribution of land and sea over the European area during the Cambrian period. The strata of this system attain their maximum thickness of 12,000 feet in Merionethshire, Wales; they rapidly thin out northwards, and are absent in Anglesey; scarcely less rapidly towards Shropshire, where they are 3,000 feet thick; still a little less rapidly towards the Malverns, where they are only 800 feet thick; and most slowly towards St. David's Head, where they are 7,400 feet thick. The Cambrian rocks of Wales were in all probability the deposits of a river system which drained some vanished land once situated to the west. How great was the extent of this land none can 
say; some geologists imagine it to have obliterated the whole or greater part of the North Atlantic Ocean. For my part I am content with a somewhat large island. What area of this island, we may ask, would suffice to supply the Cambrian sediments of Wales and Shropshire?

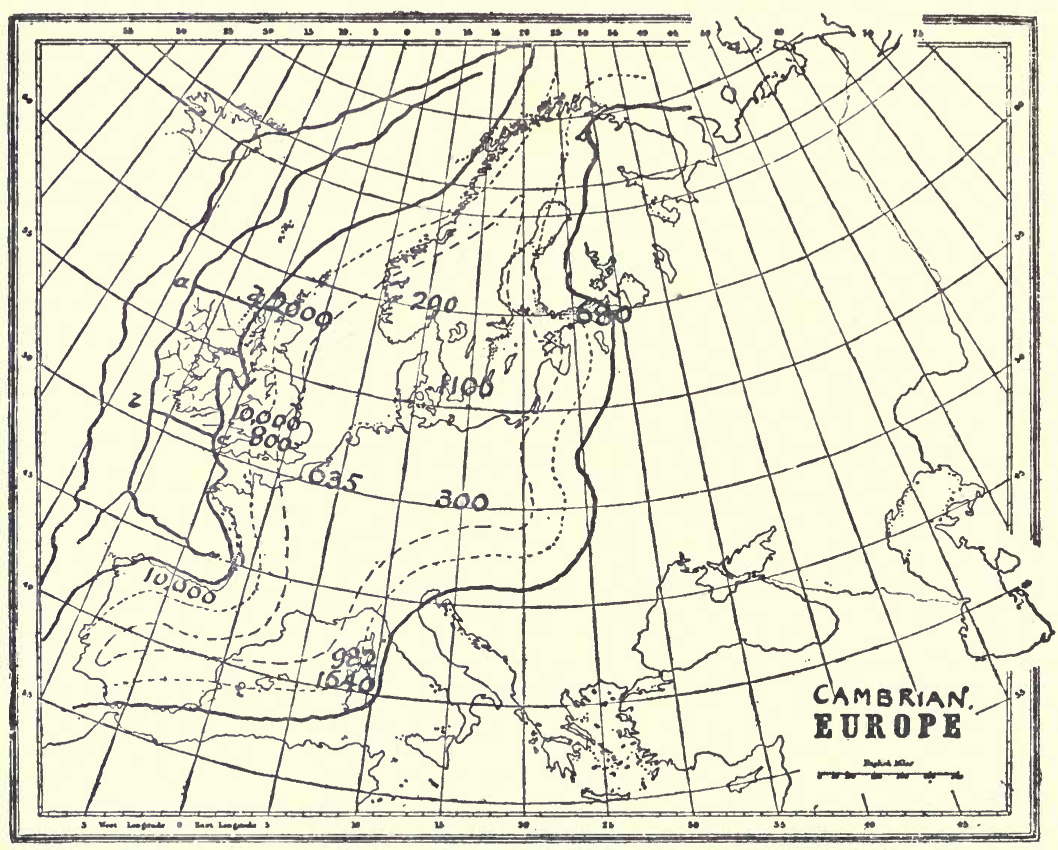

FIG 3.-Chart of the distribution of land and sea, and of the thickness of deposits of the Cambrian system. The dotted lines indicate distances of 100 and 20 miles from the shore.

Admitting that the area of denudation was ten times as large as the area of deposition, its dimensions are indicated by the figure $a b c d$ on the chart. This evidently leaves room enough on the island to furnish all the other deposits which are distributed along the western shores of the Cambrian Sea, while those on the east are amply 
provided for by that portion of the European continent which then stood above water.

If one foot in a century be a quantity so small as to disappoint the imagination of its accustomed exercise, let us turn to the Cambrian succession of Scandinavia, where all the zones recognised in the British series are represented by a column of sediment 290 feet in thickness. If $1,600,000$ years be a correct estimate of the duration of Cambrian time, then each foot of the Scandinavian strata must have occupied 5,513 years in its formation. Are these figures sufficiently inconceivable?

In the succeeding system, that of the Ordovician, the maximum thickness is 17,000 feet. Its deposits are distributed over a wider area than the Cambrian, but they also occupied longer time in their formation; hence the area from which they were derived need not necessarily have been larger than that of the preceding period.

Great changes in the geography of our area ushered in the Silurian system: its maximum thickness is found over the Lake district, and amounts to 15,000 feet; but in the little island of Gothland, where all the subdivisions of the system, from the Landovery to the Upper Ludlow, occur in complete sequence, the thickness is only 208 feet. In Gothland, therefore, according to our computation, the rate of accumulation was one foot in 7,211 years.

With this example we must conclude, merely adding that the same story is told by other systems and other countries, and that, so far as my investigations have extended, I can find no evidence which would suggest an extension of the estimate I have proposed. It is but an estimate, and those who have made acquaintance with "estimates" in the practical affairs of life will know how far this kind of computation may guide us to or from the truth. 


\section{THE AGE OF THE EAR'TH}

This Address is already unduly long, and yet not long enough for the magnitude of the subject of which it treats. As we glance backwards over the past we see catastrophism yield to uniformitarianism, and this to evolution, but each as it disappears leaves behind some precious residue of truth. For the future of our science our ambition is that which inspired the closing words of your last President's Address, that it may become more experimental and exact. Our present watchword is Evolution. May our next be Measurement and Experiment. 


\section{II}

\section{THE FIGURE OF THE EARTH}

THE history of discovery into the form of the earth, 1 beginning with the three famous voyages of Columbus, Vasco de Gama, and Magellan, and even yet not brought to an end, constitutes one of the most interesting chapters in the story of our science. Soon after the demonstration of its generally spherical form, Newton showed, as a deduction from mechanical principles, that its true figure should depart from that of a sphere in the direction of an oblate spheroid, and he was able to calculate from first principles what the difference in length of its polar and equatorial diameters should be. As we now know, the result he obtained was surprisingly near the truth. In popular language, the earth, according to Newton, was shaped like an orange. Later the French astronomers, led by Cassini, concluded, and quite justly, that, judged from the measurements then existing of arcs of meridians in different localities, the form of the earth could not be that of an orange, that the polar diameter, instead of being shorter than the equatorial, as Newton supposed, was in fact longer, and that thus the true form was more like that of a lemon. Hence arose the controversy, celebrated by Swift in "Laputa" as the battle between the "little-endians" and the "big- 


\section{THE FIGURE OF 'THE EAR'TH}

endians." A prediction from general principles was now in conflict with an inference drawn from actual observation: induction and deduction were opposed. It was impossible that both could be right, and the French Government, with a view to deciding the controversy, sent out two expeditions to make a renewed appeal to fact by fresh measurements of meridional arcs. One expedition was despatched to Lapland, the other to Peru. The result was to prove that Newton was right; deduction had triumphed over induction, and that not for the first time nor the last in the history of science.

With continued improvements in the methods of measurement, which are always in progress, and with the multiplication of these measurements, our knowledge of the earth's form may be expected to become increasingly exact. Already in 1878 Colonel Clarke, as a result of a laborious discussion of the then existing data, was led to the conclusion that the earth is not quite a true spheroid, but an ellipsoid with three unequal axes, one of the equatorial diameters being slightly longer than another at right angles to it. The longer axis intersects the surface in Africa. While Colonel Clarke placed the extremity of the axis in longitude $8^{\circ} 15^{\prime} \mathrm{W}$., General Schubert placed it in longitude $41^{\circ} 4^{\prime} \mathrm{E}$., or $49^{\circ} 19^{\prime}$ more to the east, but otherwise their results were in general agreement. In the discovery of this apparently trivial divergence from a true spheroidal form observation had outrun explanation, and the fact, if it be a fact, remained for a long time isolated and barren.

Quite recently, however, it has acquired a new and unexpected importance, for the inequality is just what might have been anticipated, if the novel hypothesis of Mr. Jeans should prove to be sound. There is a particu- 
lar interest for us in the speculations of Mr. Jeans, since they throw fresh light on that very difficult question, the origin of the ocean.*

The conclusion which Mr. Jeans reaches, as the result of a train of mathematical reasoning, is that immediately before consolidation our planet may have possessed a form somewhat similar to that of a pear (Fig. 4). It looks as though, after giving birth to the moon, the earth was on the way to eject a second satellite, but stopped

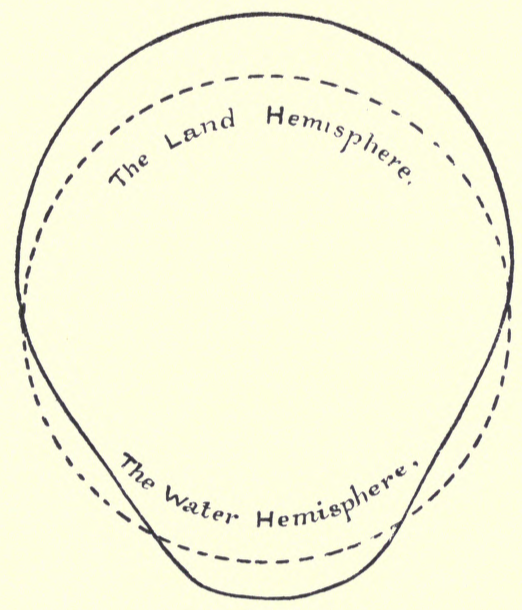

FIG 4.

short of this, perhaps, on account of completed solidification. If the earth had at this juncture a pear-like form, then Mr. Jeans says: "It is easy to see that enormous stresses would be set up in the interior of the earth after consolidation. An equilibrium figure depends in general upon the compressibility of the material; and a con-

* "On the Vibrations and Stability of a Gravitating Planet," by J. H. Jeans, B.A., Fellow of Trinity College, Cambridge, Phil. Trans. A., vol. 201, pp. 157-184, 1903. 


\section{8 'THE FIGURE OF 'THE EAR'TH}

figuration, which was one of equilibrium for the compressibility obtaining at the moment of solidification, would not remain so after the compressibility and rigidity of the material had increased by cooling. If we suppose the earth to cool in an asymmetrical configuration the stresses set up will soon become very great. In fact, Professor Darwin has shown that the stresses which would be produced by the weights of our continents in an earth initially homogeneous (i.e., by an irregularity of less than a thousandth part of the radius) would be so great that the material would be near the breaking-point.

"We must therefore suppose that, as the earth cools and the elastic constants change, there will be a series of ruptures resulting from the stresses set up in the interior. The configuration will become approximately spherical (spheroidal if rotation be taken into account) as soon as the point of bifurcation is passed.

"The fact that the ultimate configuration is reached only as the result of a long succession of ruptures puts the whole question outside the range of exact mathematical treatment. We can, however, see that the final configuration (disregarding rotation) will probably be not quite spherical, but will retain traces of the initial asymmetrical configuration . . . when the final stage is reached (the) surface would not be quite an equipotential, and the centre of gravity would not quite coincide with the centre of figure. If water is placed on the surface of a planet of this kind it will form a circular sea, of which the centre will be on the axis of harmonics, while the dry land will form a spherical cap."

Thus, then, the astronomer prepares for us an ocean bed by forces incomparably more powerful than those differences of atmospheric pressure, to which, in default of this explanation, I have had recourse. But those con- 


\section{COLIAPSE OF 'THE PEAR}

sequences of the condensation of the atmosphere of steam, which we have depicted on page 10, would now follow, the hot rain would accumulate in the ocean basin, increasing by its pressure the previously existing depth, and so assisting to disturb the already unstable configuration.

In a letter Mr. Jeans was good enough to write me he makes the following suggestion: "If we imagine the two [hemispheres, one of land and the other of sea] represented by two halves, upper and lower, of the figure

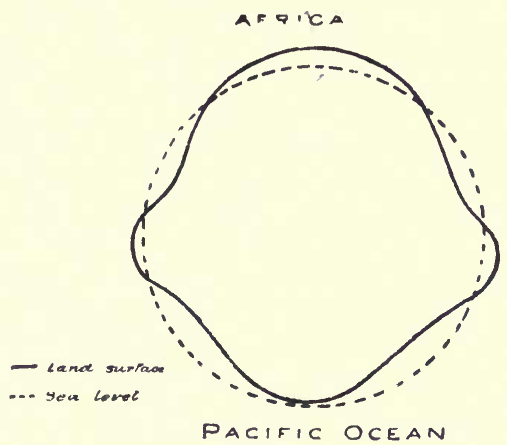

FIG. 5 .

(Fig. 4) crushing together under their mutual attraction, as, of course, they would tend to do in the cooling process, and expelling matter near their equator, which is at least a plausible conjecture of what would happen, then the form resulting is roughly that shown in Fig. 5. Of course this is enormously exaggerated, but does it not fit in well with the earth's figure, * taking the features as I

* So well does it agree that I had drawn a figure, essentially the same, to illustrate a paper on the form of the earth, as obtained solely by observation. This, however, was not introduced into the paper, as it was thought the facts were obvious enough without it. 


\section{THE FIGURE OF THE EAR'TH}

have placed them? This is what I have tried to suggest at the end of my note. Has geology anything to say about it?"

To my mind geology has a good deal to say in the way of welcome to this hypothesis. If we place a charted globe in such a position that Africa lies in the middle of the hemisphere facing us we discover an unexpected symmetry. The greater part of the land occupies the African hemisphere; the largest ocean covers a great part of the opposite hemisphere. This stands in connection with the most primitive stage in the earth's figure as imagined by Mr. Jeans, the most apparent difference being the absence of a circular island in the middle of the Pacific, to represent the stalked end of the pear. There is, however, an increasing body of evidence to show that such an island was once in existence; the coral atolls of the Pacific have some bearing on this point (see p. 97), and the distribution of terrestrial mollusca has more than once led observers to infer that a great tract of land must at some past time have occupied some part of the tropical region of this ocean.

In Fig. $5 \mathrm{Mr}$. Jeans represents the probable state of affairs after the earth had passed from the primitive form to a later one. The Atlantic and Indian Oceans are there indicated as subsidences in the original land hemisphere. Some difference might then be expected to distinguish them from the Pacific, and it is a remarkable fact that, long before these suggestions were made, Suess, as a direct result of observation, had been led to particularly emphasise the contrast between a Pacific type as opposed to an Atlantic type of coast.*

The Pacific border is fronted by mountain chains; it is a zone of active movement in the earth's crust, move-

* See E. Suess, "Face of the Earth," Oxford, 1904, vol. i., Introduction. 


\section{CON'TINEN'TAL RING}

ment signalised by earthquakes, subsidences, and volcanic action.

The Atlantic coast is not fronted by mountain chains; its coasts correspond with great lines of fracture, along which the once-existent land has sunk down to form the ocean floor. It is by such subsidences that both the Atlantic and Indian Oceans are supposed by Suess to have been enlarged.

There is independent evidence to show that large parts of the existing Atlantic and Indian Oceans were at one time dry land; the character of many geological deposits, the distribution of the fossil organisms they contain, as well as certain facts in the distribution of existing animals and plants, all combine in favour of this view.

Between the Pacific on the one hand and the Indian and Atlantic Oceans on the other, a terrestrial globe shows us a nearly continuous ring of continental land, North and South America, the Antarctic Continent, Australia, the East Indian islands (probably the fragmentary remains of a once much more continuous area), and finally Asia.

This is the bulging ring produced, as Mr. Jeans imagines, by the crushing together of the two hemispheres.

The symmetry of the earth, at least as to the distribution of land and sea, would thus appear to be less marked in relation to its axis of rotation than to one of its equatorial diameters. This diameter, indeed, is that we have already indicated as passing through the middle of Africa. From a general consideration of terrestrial symmetry I was led* to place its intersection with the surface in lat. $6^{\circ} \mathrm{N}$., long. $28^{\circ} \mathrm{E}$., or between the positions obtained

* "The Figure of the Earth," Quart. Journ. Geol. Soc., vol. lix. np. 180-188, 1903, 


\section{THE FIGURE OF 'THE EAR'TH}

from geodesic measurements by Colonel Clarke and General Schubert.

There is still a great deal to be learned with regard to the symmetrical arrangement of the terrestrial features. A glance at the map (Fig. 6) seems to suggest that the land hemisphere in its collapse has fallen in with some approach to symmetry.

The Pacific Ocean has broken across the Pacific girdle of land into the second annular ocean at three places, situated roughly at about $120^{\circ}$ from each other, one between South America and the Antarctic continent, the second between the latter and Australia, the third, corresponding to the Arctic Ocean, between America and Europe. These three inbreaks face the three longest sides of Africa.

Africa itself is a trilobed mass of land. Its north-west lobe points towards the Carribean Sea, the site of a vanished continent; its south lobe extends in the direction of the Antarctic continent, from which it is separated by the second annular ocean of Mr. Jeans, as the northwest lobe is from America; the north-east lobe, on the other hand, is continuous with Asia, from which, however, it differs in structure, and there have been periods in geological history when a wide oceanic channel connecting the Mediterranean and the Indian Ocean separated these two masses. Still it must be admitted that it is the extension of Asia to the west and south-west that constitutes the greatest disturbance of terrestrial symmetry, as here described.

In the figure (Fig. 6) six great circles are drawn intersecting in the middle of Africa, and making equal angles of $60^{\circ}$ with each other; three of them, shown by continuous lines, run in the direction of the three lobes; the other three, shown by broken lines, are intermediate with these, and correspond to regions of greatest sub- 


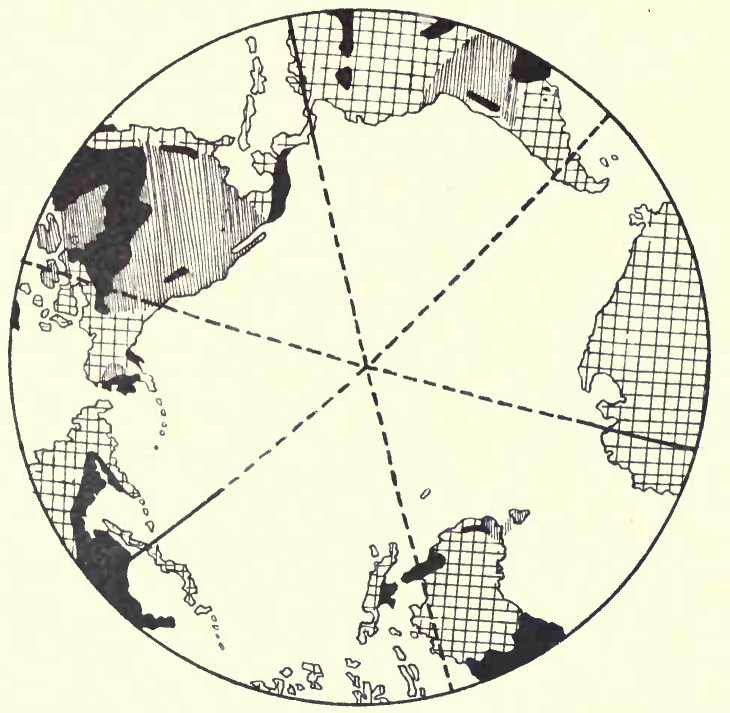

:

范

笌

施

용

舶

잉ㅇㅁ

†

․ㅠ ᄚ

वृ

들

ग्ठ

की

언

ลํㅛㅁ

웡

. 월

ڤ్

근

믕

$\therefore$

허욤

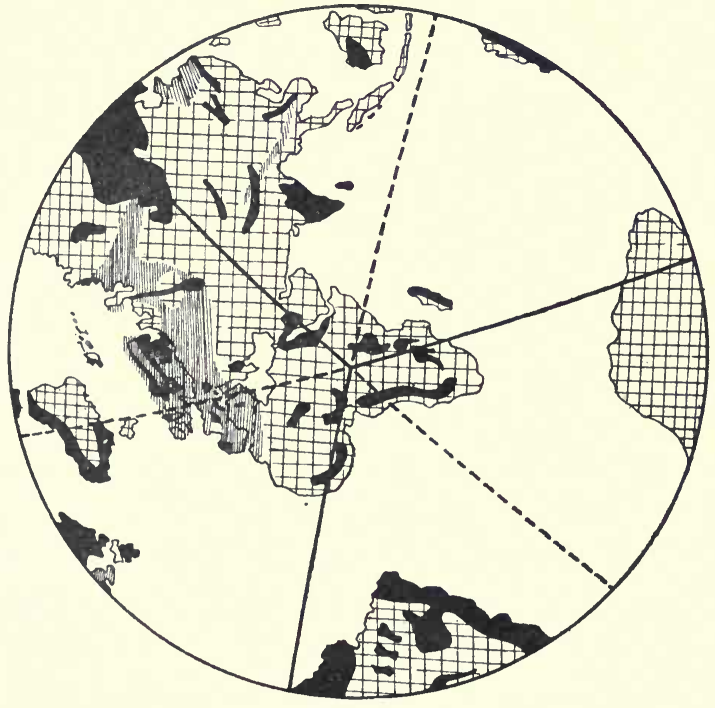

a...

要

E

๖े

के ?

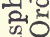

.

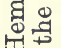

떵

๘

$\beta .0$

'령

त) 0

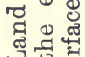

岳焉

링

E

0 융

近 


\section{THE FIGURE OF THE EAR'TH}

sidence. It will be seen that the line which forms the axis of the African-Asiatic land is very symmetrically placed with regard to the Archæan masses it passes through in its course; two of these are situated upon it; one of them borders the Red Sea, the other forms the nucleus of Asia; symmetrically placed on each side of it, diverging at about equal angles, are the Archæan ridges of the Ural and Thibet, while outside these the Scandinavian mass on the one hand, and the Indian peninsula on the other, approximately correspond.

In its continuation over the opposite hemisphere, this great circle crosses the Pacific Ocean in its greatest length, as previously it had traversed the land mass of the opposite hemisphere; in so doing it passes near the great abyss, which lies off the Japanese coast, and through South America, close to the place where this continent rapidly curves near its southern extremity from a north and south course to one due east and west. This locality is also not far from the gap by which the Pacific enters the South Atlantic. The other great circles also present interesting peculiarities, which will be obvious to the geologist by mere inspection.

The general course of events in the transformation of the physiognomy of our planet would thus appear to be as follows: Soon after the birth of the moon it acquired a form like that of a pear, and so consolidated; the aqueous atmosphere then condensed and gave rise to an ocean, which was deepest about the neck of the pear. This was the ancestor of the existing Pacific; it formed a broad girdle round the globe, with a smaller continental mass in the middle on one side, and a much larger continent on the other, or the land hemisphere. We may speak of this as the primitive form of the earth. The land hemisphere then collapsed, partly along an annulus, concentric with the Pacific, and now represented by a 
part of the Atlantic, Mediterranean, and Indian Oceans, and partly along three radial lines making angles of $120^{\circ}$ with each other. This stage may be referred to as that of primary deformation. While the Atlantic and Indian Oceans have been subsequently enlarged by subsidences, the ancient Mediterranean has been to a great extent obliterated, and even replaced, by mountain chains. There have been produced in addition many other fractures, subsidences, and elevations, of a less symmetrical character, due to secondary causes, which it is one of the problems of the future to discover.

A comparison of the earth with a tetrahedron has been made by Mr. Lowthian Green,* and it is impossible not to admit a certain degree of resemblance. Professor Michel Lievy has endeavoured to bring the two forms into closer harmony by a readjustment in the position of the supposed tetrahedron, with regard to the earth, and by erecting on each of its faces a hexagonal pyramid; and M. Bertrand has given us a new tetrahedral theory, which, however, rests on a comparison with a pair of coaxial tetrahedra placed base to base. The original view of Mr. Lowthian Green seems to make the nearest approach to the facts, and is not in absolute discordance with our own explanation; indeed, if we suppose the tetrahedral deformation to be superposed upon the figure characteristic of our primary stage of deformation, we obtain a very harmonious result: the Pacific Ocean is then already given as one of the faces of the tetrahedron; if we next take the Arctic Ocean as the second, we obtain the Antarctic continent as the opposite corner or quoin, and the Indian and South Atlantic Oceans as the two other faces, approximately symmetrical with it. The simplest way by which the student may familiarise

* Lowthian Green, "Vestiges of the Molten Globe," London, 1873. 


\section{THE FIGURE OF 'THE EAR'TH}

himself with the consequences which follow from the tetrahedral deformation of a sphere is to experiment with a hollow indiarubber ball. Among some of the more interesting results which will then appear is the connexion between the three longitudinal ridges (corresponding with America, Africa, and Australia) and the quoin representing the Antarctic continent. Although in the actual case of our planet this connexion can no longer be perceived, it is believed by many geologists on zoological evidence to have existed in past times.

A still earlier attempt to refer the irregularities of the earth's form to a polyhedral figure was made by Élie de Beaumont, * who was led to suppose that a pentagonal dodecahedron best represented the facts. His views are now generally regarded as of merely historical interest, and it would be impossible to maintain them in matters of detail; on the other hand, a very remarkable and unexpected correspondence can be traced between the general symmetry of de Beaumont's figure, as orientated by him, and that which we have been led to adopt. Three contiguous faces lie symmetrically placed over our land hemisphere; they meet along edges which are not far from coincidence with the triradial lines we have drawn extending through Africa, and these three edges intersect at a point not very far from our morphological centre of the land hemisphere. On the other side of the globe three contiguous faces lie symmetrically over the oceanic hemisphere, while the remaining six faces form a girdle, which corresponds to our Pacific zone of land. Thus we seem to encounter another instance of the existence of a common germ of truth in theories widely different and at first sight opposed, a not infrequent phenomenon in the history of science.

* "Notice sur les Systèmes de Montagnes," by L. Élie de Beaumont, Paris, 1852. 3 vols., duodecimo. 


\section{PEN'TAGONAL DODECAHEDRON 57}

An objection to all speculations of the kind in which we have just engaged will naturally arise in the mind of every geologist: it is to be found in the fact that nearly all the land which now rises above the sea has at

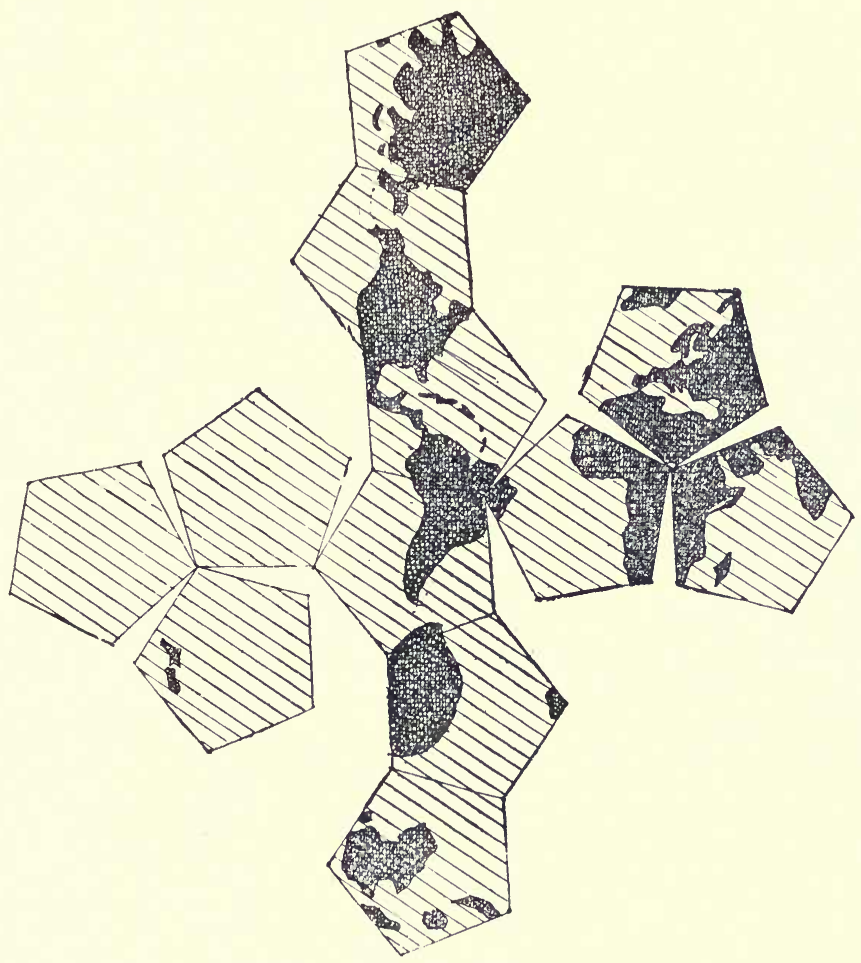

Jig. 7.-Elie de Beaumont's pentagonal dodecahedron unfolded to show its correspondence with the symmetry of a pear-shaped earth.

some time or other been submerged beneath it, and, indeed, that the larger part of the existing land is composed of marine sediments. This objection might very easily prove fatal were it not equally the fact that these 


\section{THE FIGURE OF THE EAR'TH}

marine sediments appear to be in almost all cases those characteristic of shallow water. A large part of the existing continental surface is not so far above the sea but that a slight rise of the ocean-level would suffice to submerge it. At the same time, even the shallow water accumulations, out of which our mountain chains are to a large extent built up, were deposited in sinking areas or synclinals, which deepened pari passu with the progress of deposition, till they attained a depth of 30,000 or 40,000 feet, or, singularly enough, that of the deepest abysses of the ocean. These sinking areas, however, were always situated near the margin of the sea, and their distribution does not conflict with the course of deformation as we have imagined it. Africa is distinguished from the other continents by a comparative immunity from subsidence. The great mass of sediments which form the larger part of the interior appear to be continental deposits, i.e., laid down by fresh water over an area of dry land. They contain no marine fossils, and, so far, such fossils as they have afforded are remains of reptiles and land plants.

In providing an explanation of the origin of ocean basins Mr. Jeans' hypothesis affords a welcome support to the theory of mountain formation, as a consequence of the contraction of a cooling globe; for the opponents of this theory have often sought to burden it with a task probably beyond its powers, that is, of accounting for all the inequalities of terrestrial relief, including the oceanic depressions. These, however, as we see, are, in the main, the result of the passage of our planet from one form of equilibrium to another; so that the effects of cooling and contraction are only to be looked for in comparatively subordinate features, such as comparatively late subsidences and mountain chains. The great difficulty which in recent years has been urged against 
the theory, even when thus restricted, has been the supposed position of the level of no strain, imagined to occur not far from the existing surface of the ground.

It seems impossible to concede the validity of all the reasoning on which this conclusion is based. The Rev. O. Fisher* writes :-

"Hence the condition that the shell at $x$ is situated at the level of no strain will be, since $\mathrm{E}=3 e$,

$$
\frac{3 e}{(r-x)^{2}} \int_{\mathrm{x}}^{\mathrm{r}}(r-x)^{2} \frac{d v}{d t} d x=e(r-x) \frac{d v}{d t} .
$$

It will be observed that the position of this level of no strain does not depend on the coefficient of contraction, which will divide out."

The fallacy, as it appears to me, lies in the words I have underlined. The statement is obviously true if the coefficient $e$ is the same on both sides of the equation, i.e., if it is constant, but this it most certainly is not; the value of a coefficient of expansion depends on the temperature, and is usually expressed by physicists according to a formula $e=\left(1+a t+\beta t^{2}\right)$, where $a$ and $\beta$ are constants and $t$ the temperature. Mr. Davison, taking the effects of the first constant into consideration, has shown how this will modify the result ; and if the second term involving the square of the temperature be introduced into the calculation still further modification must follow. It may be objected that in the case of high temperatures, approaching the fusing-point of basalt, the application of such a formula as we have suggested would be a very dangerous use of extrapolation. All the more welcome, therefore, are the experiments of

* "Physies of the Earth's Crust," by the Rev. Osmond Fisher, London, 1889, p. 95. 


\section{THE FIGURE OF 'THE EAR'TH}

Professor Joly* and Dr. Carl Barus, $\dagger$ which provide us, by direct observation, with the coefficients of expansion of diabase and basalt up to and beyond the meltingpoint.

Mr. Fisher has taken the coefficient, supposed to be constant as 0.0000071 .

The observations of Carl Barus show that between $0^{\circ} \mathrm{C}$. and $855^{\circ} \mathrm{C}$. the value of $e$ is 0.000024 , or a little more than three times as great as has been supposed; between $855^{\circ}$ and $914^{\circ} \mathrm{C}$. it rises to 0.00003576 , and between $914^{\circ}$ and $1,093^{\circ}$ it is 0.0000345 , a falling off, due probably to errors of experiment; between $1,093^{\circ}$ and $1,190^{\circ}$ C. a very rapid expansion takes place, the increment of volume being 0.0343 , the original volume being taken as unity; this gives a coefficient of expansion of 0.000354. No doubt this sudden change indicates a change of condition possibly from the crystalline to the glassy state; the rock now becomes viscous, and with further rise of temperature expands like a liquid, the average coefficient between $1,190^{\circ}$ and $1,421^{\circ} \mathrm{C}$. being 0.000047 .

Professor Joly's results are sufficiently concordant with those of Dr. Barus, but since they were not made on crystalline rock, but on glass obtained from it by fusion, they do not show so sudden change in volume just below the fusion-point. It is just possible they would for this reason be more applicable to the material forming the interior of the earth, but we have very little evidence as to the mode of behaviour of matter restrained from fusion by excess of pressure.

It is to be hoped that some one skilled in the higher

* "On the Volume Change of Rocks and Minerals attending Fusion," Sci. Proc. Trans. Roy. Dublin Soc., vol ii., series ii., p. 283, 1897.

† Am. Journ. Sci., vol. xlii., 1891, p. 498; vol. xliii., 1892, p. 56. 


\section{GEO'THERMIC GRADIEN'T}

branches of mathematics will discuss these results in relation to the level of no strain.

In this connexion a word may be added in reference to the geothermic gradient. A statement made on page 17 called forth a protest from the late Professor Everett, to whose unwearied zeal as Secretary of the Committee appointed by the British Association to investigate the rate of increase of underground temperature geologists owe a great debt of gratitude. In the twenty-second report of this Committee we read: * “. . . In view of the fact that the President of Section C last year characterised the variation in the British Isles 'from $1^{\circ}$ in 34 feet to $1^{\circ}$ in 92 feet' as 'a surprising divergence from the mean,' it is well to emphasise the connexion between gradient and conductivity. If there is anything like uniformity in the annual escape of heat from the earth at different places there must necessarily be large differences in geothermic gradients, since the rate of escape is jointly proportional to the gradient and the conductivity."

The notion that " there is anything like uniformity in the annual escape of heat from the earth at different places " is hardly likely to commend itself to the geologist. Such indications as there are point altogether to the contrary. The mere existence of volcanos obviously invalidates the statement as an absolute affirmative, and ancient laccolites show that in past time concealed sources of heat lay not very far from the surface.

If, then, there is not uniformity in the annual escape of heat at different places, it might be thought unnecessary to labour the question further; yet in view of the importance of the subject to geological inquiry it may be worth while to point out that the connexion between gradient and conductivity does not account for the surprising difference of extremes from the mean; an instance will make this clear. Of the various rocks * "Report Brit. Assoc.," 1901, p. 66. 


\section{2 'THE FIGURE OF 'THE EAR'TH}

which have been passed through in borings, rock-salt is distinguished as possessing the highest conductivity, and consequently the borings which have been made through it should afford a lower temperature gradient than the average. If now we turn to the results actually obtained in the deep Sperenberg boring, ${ }^{*}$ which passed chiefly through rock-salt, we find a temperature increase of 10 for

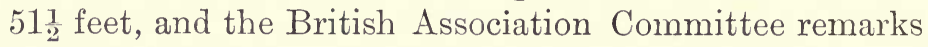
upon it, "This result is entitled to special weight, not only on account of the great depth (of the boring), but also on account of the powerful means employed to exclude convection." The mean result for observations made from a large number of bore holes in the most various kinds of other rock is given as $1^{\circ}$ for 60 feet.

It will be seen, then, that the gradient for the Sperenberg bore, so far from being below the mean, as it should have been, owing to the high conductivity of the material passed through, actually rises not inconsiderably above it; and thus the connexion between gradient and conductivity does not afford a sufficient explanation of the divergence of extremes from the mean.

Again, the Sperenberg boring shows that the escape of heat from the earth does not proceed at a uniform rate; for while the mean rate of escape is 51.4 gram degrees, the rate at Sperenberg is $176 \cdot 2$ gram degrees per year per square centimetre.

Besides the cause already suggested in explanation of local irregularities in the temperature gradient, there is another which evidently plays a very important part; this is the chemical action, which talies place in underground mines where metallic sulphides are present. This has been specially emphasised by Messrs. Haldane and Meachem. $\dagger$

* “Report Brit. Assoc.," 1882, p. 88.

+ Proc. Soc. Mining Engineers, 1889, Haldane and Meachem. 
It was clearly shown by these investigators that the heat resulting from the oxidation of marcasite (iron sulphide) in coal seams is three times as much as is required to account for the total rise in temperature, which the air of the ventilating current undergoes in passing through the mines.

But recently a new cause of disturbance has been discovered, and this looms up before us, vague and gigantic, threatening to destroy all faith in hitherto ascertained results, and to shatter the fabric of reasoning raised upon them. This apparition is radium, with its companion radio-active bodies.

The special property of radium which concerns us here is the apparently spontaneous evolution of heat, which accompanies its existence, or perhaps its destruction, as it disintegrates into simpler constituents. A gram of radium emits something like 90 or 100 gram degrees of heat per hour, or as much as escapes on the average from two square yards of the earth's surface in the same time. Hence, since radium is a constituent of the earth's crust, it furnishes us with a new and unexpected source of terrestrial heat; ${ }^{*}$ and it has been asserted that if radium is distributed uniformly throughout the earth's volume, to the extent of $1-5,000,000$ th of a gram per cubic metre, this would be sufficient to compensate for the whole of the heat lost by radiation into outer space, and thus to maintain the temperature gradient unchanged for a very long period.t Whether radium is present to this extent throughout the globe, and whether under the conditions which exist in the interior it would behave as it does at the surface, are

* C. H. Darwin, "Radio-activity and the Age of the Sun," Nature, vol. Ixviii., p. 496, 1903; J. Joly, "Radium and the Geological Age of the Earth," ibid., p. 526.

$\dagger$ G. Liebenow, Nature, vol. lxxi., p. 113, 1904. 


\section{THE FIGURE OF THE EAR'TH}

questions which may be difficult to answer; but in any case it would now appear that Lord Kelvin's view of the earth-as simply a hot solid body in process of coolingcan no longer be maintained without qualification, and the argument founded upon it as to the age of the earth either ceases to be valid, or must remain in abeyance till an increased knowledge of radium and its distribution enables us to arrive at a definite judgment.

The possible effect of radium in the sun has also been pointed out; $3 \cdot 6$ grams distributed through each cubic metre of the sun's volume would suffice to supply for some thousands of years its entire output of heat.*

The products of decomposition of this extraordinary element have been supposed by Professor Boys to give rise to those things of mystery-the tails of comets. $\dagger$ But these steps are only a beginning. Our whole conception of the cosmos seems destined to undergo something like a transformation in the growing light of the new discoveries; while as regards this vexed question of the age of the earth, the least untrustworthy of our estimates would appear for the present to be that founded on the thickness of the sedimentary series.

* W. E. Wilson, Nature, vol. lxviii., p. 222, 1903.

† C. V. Boys, Presidential Address, Section A. Brit. Assoc., 1903, p. 530 . 


\section{AN AUTUMN VISIT TO THE LIPARI ISLES}

T $\mathrm{HE}$ ruined volcanos of Carlingford had for a long 1 time engrossed my attention, and I had undertaken to prepare an account of them for the Royal Irish Academy. The task proved one of continually increasing difficulty; fresh problems started up day by day, till, driven by desperation, I determined to visit some still active volcanos, in hopes, which proved not too sanguine, that their living fires might shed some stray gleams of light on the history of their ancient Irish prototypes. So on September the 3rd I left Dublin for Messina, en route for Lipari, accompanied by my friend Mr. T. H. Thomas, special artist of the Graphic. It took us over a fortnight to get there, so many were the temptations that assailed us by the way-Paris, with its Exhibition and Eiffel Tower, snowing post-cards from its summit all over the civilised world; Lucerne, which we left pale and beautiful in the early morning for the imposing grandeur of the St. Gothard Pass; and the dreamlike beauty of Como, lying voluptuously tranquil beneath the passionate warmth of the Italian sun. Very amusing was it to watch the court about the prima donna of the previous evening as we took an al-fresco lunch in the gardens of a café chantant lying on the borders of the lake. Then on to 


\section{AU'TUMN VISI'T TO LIPARI ISLES}

Milan, with its cathedral-wonderful example of the art of carving in stone; surely a woman had a hand in it; Florence, with its tall towers strong in their own strength, rising straight and true, unbuttressed, city dear to the heart of Englishmen; and so on, and on, through Rome, Naples, and at last Messina, queenly Messina, where, on a brilliant September morning-one such would be the making of an English summer-we joined a small but scientific party of Englishmen and Italians, met to start on a cruise among the Aolian or Lipari Islands, and thus to celebrate the centenary of the famous visit made to them in 1789 by the renowned naturalist Lazzaro Spallanzani.

We were soon aboard our boat, the Villa San Giovanni, an excellent screw steamer, with first-class accommodation for sixteen passengers, just the number of our party. She was all our own for a week, and eagerly we overhauled our prize, finally pronouncing all to be very good. The beds we had ordered in were new and of luxurious dimensions: of provisions there was a goodly store-piles of tinned meat, fancy biscuits, buckets full of lemons with a view to lemon squash, and our bread, in the form of hollow rings a foot or two in diameter, was a greedy sight, as it hung threaded on cord festooned about the pantry walls. Oh! goodly bread of Messina; too soon you ran short, and we, murmuring at the dispensations of our improvidence, vainly attacked the bread of Lipari. This must be seen to be believed. It is baked in a furnace till it is too hard to be cut with a knife, and then, lest it should prove too appetising, is kept in the sun till it can only be broken by geological hammers; the fragments soaked in wine refuse to swell up, but crumble into a fine volcanic sand. Bread we could not call it, except by euphemism, and " trachyte" was the name it always went by with us. 


\section{MAP OF 'THE ISLANDS}

Once on board we were soon under way, and by evening found ourselves in the port of Lipari, the principal island of the group. Forgive us, dear abstaining friends, if we made straight for the wine-shop, and drank out of tumblers the famous wine of Lipari, called Malvasia now,

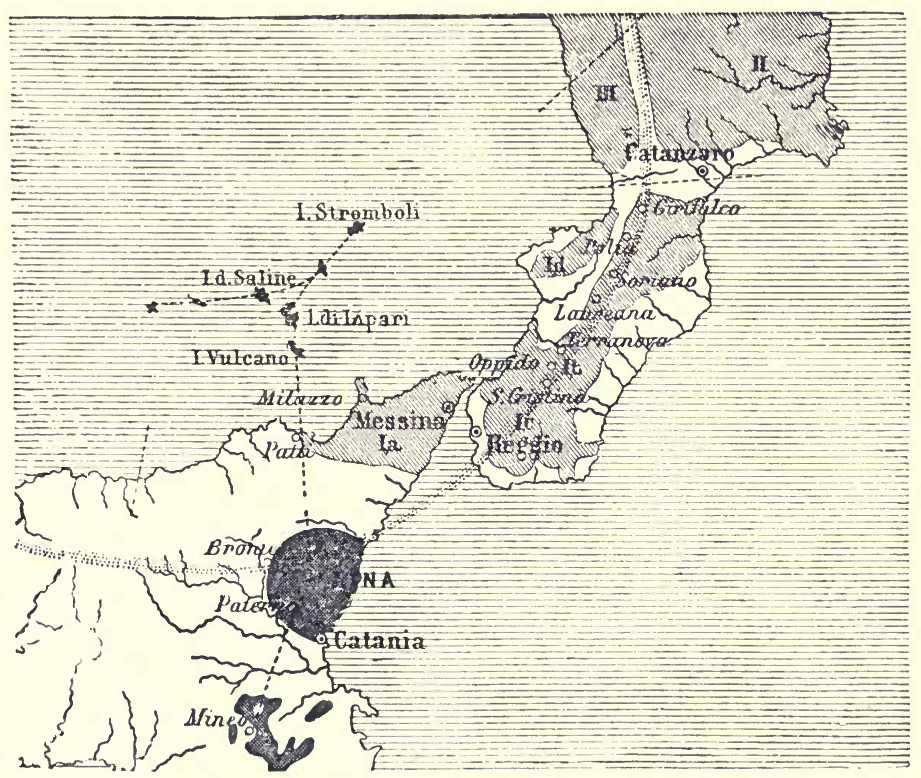

FIG. 8.-The Peripheral and Radial Lines of the Lipari Islands. Ia. The Peloritan Mountains; Ib and Ic. Aspromonte; Id. Fragment of the Vaticano. II. Mass of the Sila. III. Mass of the Cocuzzo, faulted down towards the sea. (From Suess, "The Face of the Earth," p. 83.)

but more familiar to our ears under its ancient name of Malmsey, first brought by the Normans to our own shores. Here some of the principal inhabitants met us, and, best of all, the well-known guide Bartholomeo, whose services we secured at once and put into immediate requisition, starting between eight and nine 


\section{AU'TUMN VISI'T TO LIPARI ISIES}

o'clock in the evening to ascend the southern part of the island called Monte San Salvatore, which commands a fine view of Vulcano, in the hope of witnessing an eruption of this mountain. Vulcano boasts of all volcanos the best recorded history. It is mentioned as active by Thucydides, writing in the fifth century B.c., and by nearly all the greater writers subsequentlyAristotle, Diodorus, Strabo, and Pliny, and a host of others down to our own time. In the older mythologies it figures as the forge of Vulcan, where, according to Virgil, was wrought the armour of Aneas. No doubt much of the attention it attracted from the earlier writers was due to the fact that it was in full activity at a time when Vesuvius lay dormant. After a grand eruption in 1786, however, it fell into a state of almost complete repose, so profound that some authors considered it extinct. About twenty years ago it was purchased by Messrs. Narlian \& Co., for $£ 8,000$, and converted into a chemical manufactory. Such an insult to an ancient historic volcano was not to be passed over, and last year (1888) it was amply avenged. A terrible eruption occurred, and Mr. Narlian was driven from his house and possessions, fleeing for his life. The following is an extract from a letter which he wrote describing the event: "As night approached the leading fumerole had begun to show a clear high flame, somewhat greenish or bluish. This phenomenon, together with the sudden stopping of the smoke from the crater, was evidently not a good omen. Consequently, without undressing, I spent the night on a sofa in the drawing-room. Towards morning I was overpowered by sleep, and went into the little bedroom which looks towards the mountain, rested on the bed, and was soon sound asleep. Shortly afterwards I was awakened by a tremendous din which can hardly be described. As I jumped from my bed I felt stones falling on the roof 


\section{ERUP'TION OF VULCANO}

like hail-such a cannonading going on! I understood what was the matter, and ran to the opposite room, where I had made my children sleep that night. They were also up in consequence of the indescribable noise of thunder, rush of gases, flames, falling of huge boulders and rocks. I took them to the drawing-room, but as soon as the door was opened, a big stone, red-hot-for all these stones were quite red with heat-fell through the ceiling and floor a few yards from us, smashing all, setting fire to everything. Now I took my children back to my bedroom, which looks on the verandah, and tried to gain the terrace by that side. The house doors were shivering and shaking, so that it was a difficult matter to open them. At last I succeeded, but before we were out in the verandaih another stone fell at our feet, was smashed to fragments, and burned the feet and legs of my boys. Now we passed through the verandah, and regained the house at the top of the stairs; here another stone fell near us. None of these stones was less than two feet in diameter. This last stone, the fourth that struck the house, had nearly blocked our way out with the rubbish it brought from the roof. We passed through over the heap of rubbish, and were now out in the open to the north of the house. By this time (not many minutes after all) the whole place was lighted up. Woods, grass, buildings, hedges-all was on fire; the huge boulders and stones were literally raining everywhere about us. What confusion! Nathali, the faithful boy, had by this time come to the help of my little boys. We all began to run to Vulcanello and away from the dreadful thundering mountain. All the communication we possessed at Vulcano consisted in an old half-broken 20-foot boat, and a lighter, both of which the men in their panic had taken away with them, leaving us on the sands of Vulcanello. Towards noon, however, boats of rescue reached us from 


\section{AUTUMN VISIT 'TO LIPARI ISLES}

Lipari, and thus ended one of the most eventful days of our life. How we escaped death I do not know." One of the bombs that fell during this eruption measures ten yards in diameter. Ever since the volcano has remained in an incessant state of activity, sometimes ejecting volumes of steam and ashes, at others bursting forth in paroxysms like that described by Mr. Narlian.

This was the volcano that we were climbing the mountains of Lipari by night to see. It was a picturesque ascent ; a dozen happy little ragamuffins scampered along with us; merry Bartholomeo, gaily singing, hurriedly led the way; the blazing torches * -and every one carried a torch-cast a brilliant glare far into the night. We scrambled up as fast as possible, sometimes running and leaping, sometimes going more cautiously where a precipice cut too far into the path, only occasionally stopping when a vineyard proved too inviting. It was not long (about an hour) before we reached our coign of vantage, and there before us, seemingly not far away, loomed the regular conical outline of Vulcano, rising to about 1,000 feet above the sea; far away to our left lay Stromboli, flashing forth in vivid gleams at frequent intervals. Torches were now ordered to be put out-lest they should extinguish the volcano-pipes were lighted, and we sat down to wait, in a state of excited expectancy. For more than an hour nothing happened, and a good many of us in despair began to talk of returning, but on appeal to their better feelings these agreed to make one more pipe the measure of our stay. Long before this was finished we were startled by a sudden explosion, and with a roar like thunder there burst upwards from the crater a dense fiery red column of steam and ashes. Roar succeeded roar in quick succession, with accompanying

* These were bundles of canes tied together, such, Mr. Thomas remarked, as may be seen sculptured on old Roman monuments. 


\section{ERUPTION OF VULCANO}

rushes of steam and ash, till the mighty column surged upwards to a height of at least 1,000 feet above the edge of the crater, and then spread out in a vast canopy of cloud, shining lurid in the blinding light of the molten lava which boiled in the crater below; while on its margin sheet-lightning in vivid flashes played incessantly. Stones and bombs, red-hot, white-hot, looking like shooting stars in the darkness, were continually shot up, and so high that they pierced the cloud canopy, and then, falling back in graceful curves, fell at first slowly, then faster, and finally with fury, till they reached the sides of the cone or the plain at its foot. The detonations grew fainter, the rushes of steam ceased, and the eruption was over as suddenly as it began.

We were fortunate in this our first experience of an active volcano. We had witnessed a paroxysmal eruption, similar in type, differing only in magnitude and duration from that of Vesuvius described by the younger Pliny when Herculaneum and Pompeii were overwhelmed. The next day we steamed away at 4 a.m. for Stromboli- "the lighthouse of the Mediterranean." Always in a state of moderate activity, it illumines the night with a sudden glow at irregular intervals of some two to twenty minutes. It is also known as the "fishermen's weather-glass," and it was perhaps by studying the changes in the character of its eruptions, or in the cloud canopy which it produces, in connexion with the weather, that King Aiolus acquired his reputation as God of the Winds. Scientific men were not so prodigal of their discoveries in those days, and, like the Egyptian priests, kept their secrets to themselves.

Directly we landed on Stromboli we made for a farmhouse, and under its friendly pergola, a square, flat roof of canes, vine-covered, we ate the rocky bread of Lipari, which, for the sake of the wine, I now forgive. Then 


\section{AU'TUMN VISI'T 'TO LIPARI ISLES}

we started on the ascent-3,000 feet to the summit, first through rich vineyards, which kept us well supplied with grapes, and then on to rugged lava and loose ash, weltering under the blazing sun. At length, as we turned an angle, we caught sight of the active cones, firing away viciously, like so many pieces of devilish artillery. In half an hour more we were on the edge of the middle crater ring, about 2,500 feet high. Outside it is another crater ring, concentric, encircling it ; inside are the active cones, which vary in number from time to time; when we saw them there were five, all active, exploding in turns, a magnificent spectacle. Amongst other points of interest we noticed that the smoke from one of the smaller cones was puffed out in rings like those a skilful smoker can blow from his mouth; but these were on a grander scale, some yards across.

A steep ash-slope extended from the edge of the crater to the foot of the active cones, and down this, crossing the still smoking cakes of lava which the cones were continually ejecting, my friend Signor Sambon, an experienced and intrepid volcanologist, started to run. Anxious to get a nearer view, I followed him, and as we stopped together he remarlied, "Now you are here, there is but one thing to say-Don't run away, or you will be killeri." “ Run away!" This to an Englishman born in Tipperary! Was it likely? "As to the four cones to the right," said Sambon, "don't mind them; the only one I fear is that littie spitfire on the left" (we were close to it!) "Good; but when it goes off tell me what I am to do." "You must look up into the air, and when you see the stones coming down, dodge them!"

We waited in the position the front rank takes to receive cavalry. It seemed a long time, but was only five minutes, and then the volcano went off like a cannon, but a cannon with a mouth many yards across. Red-hot 
stones, sand, and steam were shot out with an appearance remarkably like the flash from a gun, but of longer duration. One glance at this, and then upwards into the air. Down plunged the ragged fragments of half-cooled lava, from a height of 200 feet or more. We had only to stay still without much dodging, but one large mass fell between us, and that is now on its way home to Trinity College Museum. Then a loud cry of "Look

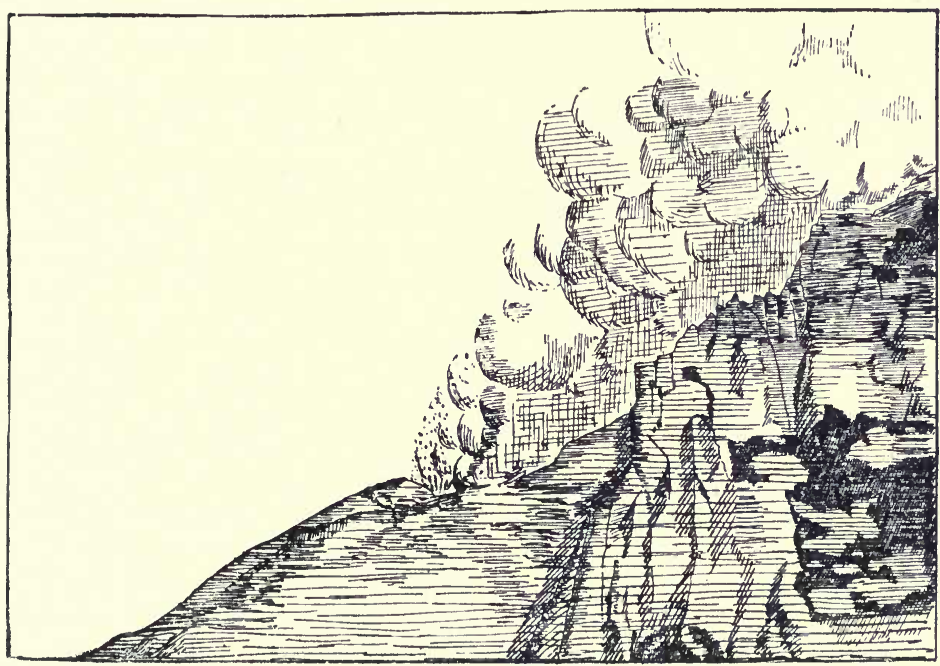

FIG. 9.-Stromboli, seen from the west side of the crater, Sept. 19, 1889. (Drawn from a photograph by Dr. J. Johnstone Lavis.)

out!" from our friends out of range above; for the scoriæ had fallen above and behind us, and were now rolling and bouncing down the loose, steep ash slopes. It must have been a ludicrous sight, the activity we displayed as we hopped, skipped, and jumped out of this avalanche, while all the time fine sand and little stones ("lapilli") drove down upon us like a shower of hail. It was over at last, and we rushed up the slope to join 


\section{AU'TUMN VISI'T 'TO LIPARI ISLES}

our friends, lest another explosion should catch us on the way. Hearty congratulations from them; it was something to have passed unscathed through the volcanic fires.

The descent of the cone was made very rapidly; the long slopes of fine ash tempted us to try a glissade, but they proved too loose; however, we could run down them with great speed. The cultivated region reached, we regaled ourselves with ripe figs, a luscious change from the volcanic ash, of which we had taken too much. The steamer had been brought round to meet us, and we swam off to her, leaving our clothes to be brought on by the boat. Wrapped in a sheet (the glorious climate renders further clothing unnecessary), we sat down to dinner [John Dory and cuttle-fish stewed in oil; then coffee and grapes, as Mr. Thomas reminds me], and as evening came on steamed off to lie opposite the Sciarra del Fuoco, a steep slope, which descends from the seaward edge of the crater straight to the sea. The lava in the crater of one of the cones "blobs" over the edge and runs down the sides of the Sciarra in a continual chain of fire; while at every explosion a host of red-hot fragments covers the sides of the cones and the Sciarra with a starry mantle, glowing brilliantly from out the pitchy blackness of the night.

Next morning we visited Panarea and some other islands, and the day after Vulcano. Here the first sight that met us was Mr. Narlian's deserted house, to which the swing still standing in the ash-covered garden gave a final pathetic touch. Thence we walked through the deserted vineyards, now half buried in ash, and so on to the foot of the cone. On the way we met with numerous volcanic bombs-rounded masses of porous lava a yard or so in diameter. They had been ejected from the crater, 1,000 feet above us, and to such a height beyond 
- perhaps another 1,000 feet or so-that, clearing the cone completely, they had fallen on the plain at its foot. A rivet, falling from the Forth Bridge, has been known to pierce a two-foot plank. The energy with which these bombs are endowed on falling from a height of 2,000 feet may be judged. On reaching the ground they had dug out conical pits a yard in depth. In these

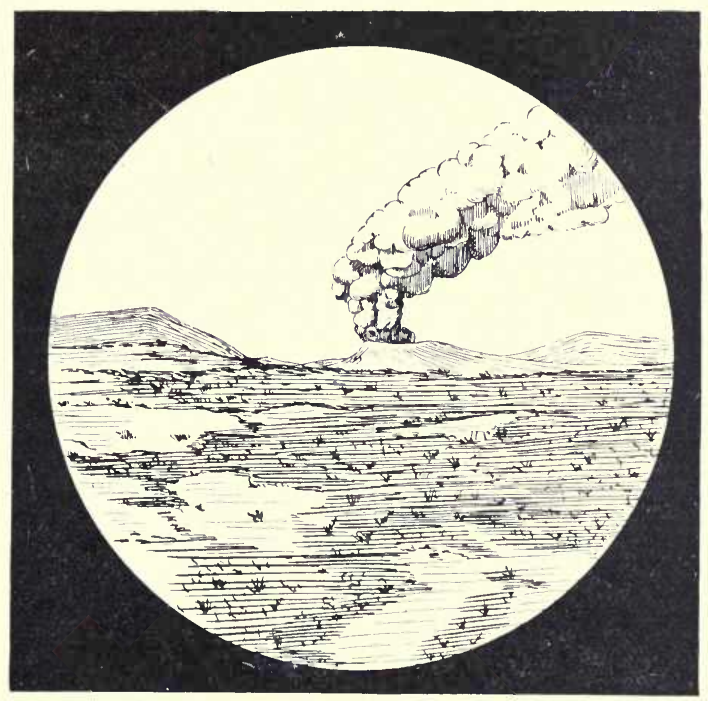

FIG. 10.-Vulcano in Eruption, Sept. 23, 1889. (From a photograph.)

some of them still rested entire, others broken in pieces, while in some cases the pits were empty, and the fragments scattered far and wide around. On the sides of the cone the bombs were more numerous than on the plain, and one (Fig. 11) we found still aglow with heat. It had probably been thrown out the night before; and some, no doubt, were those we had seen shooting through the air on the night of our first visit to Lipari. It was hard 


\section{AU'TUMN VISI'T 'TO LIPARI ISLES}

work ascending the gigantic dust-heap which formed the cone; the sun burned unmercifully above us, and scorched the ground under our feet; the ashes, of course, were always slipping, and it was often two steps down for one up. Sambon and I were in front, and when about 100 feet from the edge of the crater we rested to get breath for a final rush. This was necessary, for

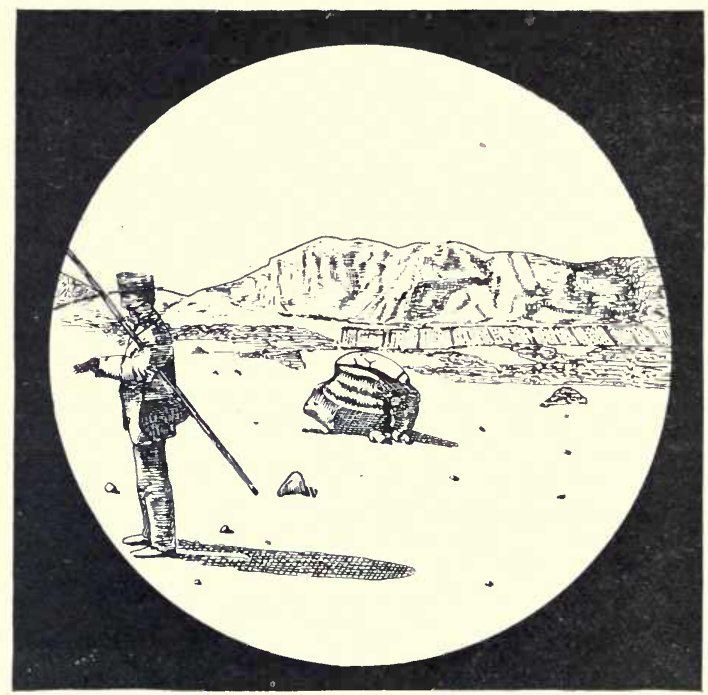

FIG. 11.-Volcanic Bomb, fallen at the foot of Vulcano. (From a photograph.)

no one knew what state the crater might be in, and we might have to retreat faster than we wished. The final rush was made, and behold! the crater was a comparatively shallow pit (Fig. 12), filled, not with lava, but with ash and fragments of stone, a little steam escaping, but, on the whole, looking so peaceful that one might count the chances of safely walking across it. Down into it Sambon and I ventured a little way, but did 
not linger long. A loud hurrah signalled to the others that all was well, and they soon joined us on the edge of the crater, where we stood waiting for an eruption, in open order, so that in the event of a catastrophe as few of us as possible might be killed. Then we produced the bottle of wine which we had carried wrapped in a coat up the mountain. We sprinkled the

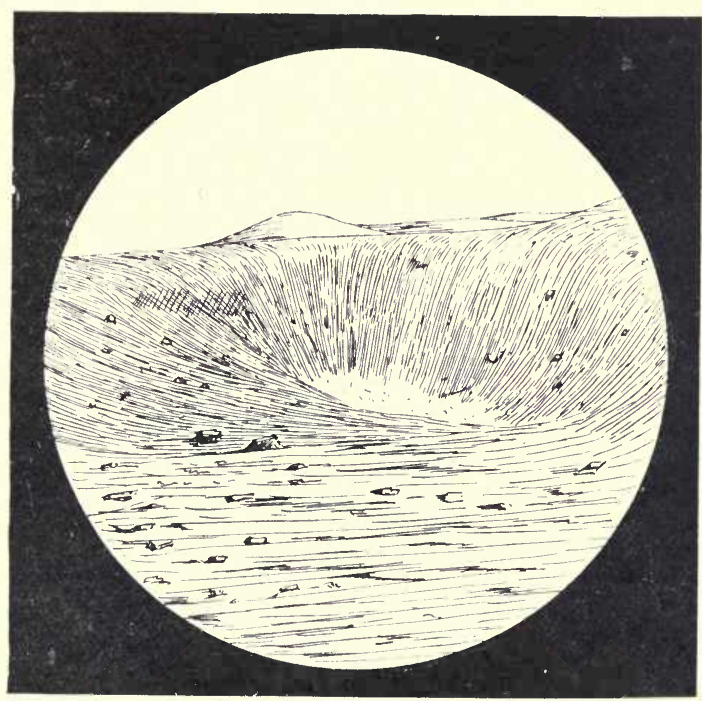

FIG. 12.- Crater of Vulcano, just before an Eruption, Sept. 21, 1889. (From a photograph.)

ground, three times involed the god, grim old Vulcan, and then took a refreshing drink ourselves. The heat, and especially the fine penetrating dust, had parched us till we felt our tongues rattling against our teeth like dice in a box. Seldom was wine more needed; never did it taste so delicious. It was a good quarter of an hour before an eruption took place, and it was a comparatively mild one when it did. With a rushing sound like the 


\section{AU'TUMN VISI'T TO LIPARI ISLES}

beating of waves on the strand, the escaping steam carried with it the loose ash that covered out of sight the lava lying below, steam and ash rising together in a huge cloud like a gigantic cauliflower (Figs. 13 and 14). Puff followed puff, cloud was added to cloud, and all compelled upwards in a great whirling column, raining down ash in torrents (Figs. 15 and 16). The puffs ceased, the wind drove the

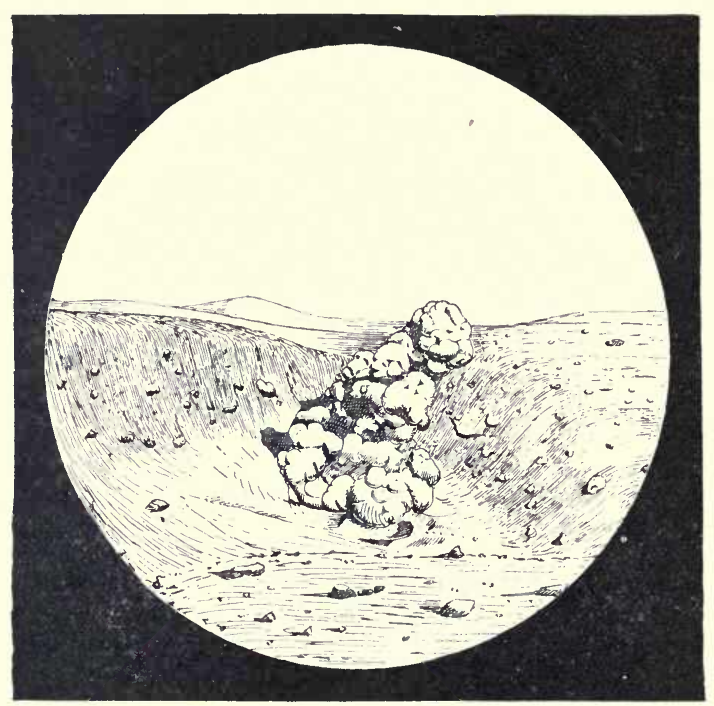

Fig. 13.-First puff of an Eruption from Vulcano, Sept. 21, 1889. (From a photograph.)

rising steam before it, and the crater again lay peacefully below us-a quiet sandy desert. The whole eruption more resembled that of a geyser than a volcano, and a volcano in this state might not inappropriately be termed a "sand geyser." A second eruption occurred before we left the crater, and this was more violent, some large bombs being ejected. We now descended to the fumeroles which open on the sides of the cone-an unholy region full of 
suffocating fumes of burning brimstone, worse, if possible, than the Metropolitan Railway at Gower Street. Here, from a rent in the ground, steam and gas were issuing under high pressure with a loud, hissing sound, and sulphur was being deposited in vivid yellow and orange incrustations, which looked doubly bright seen against the intense blueness of the sky. We managed to secure

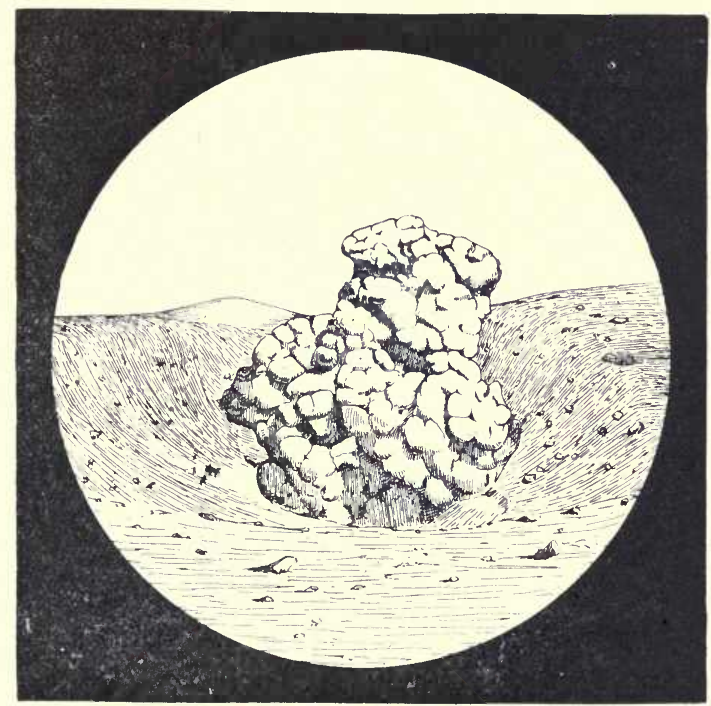

FIG. 14.-The same Eruption as in Fig. 13 a few seconds later. (From a photograph.)

some specimens. It was warm work-the steam is hot enough to melt zinc-but we did it.

Our last day was spent in walking round Vulcano. In the evening we reached the Marino built by Mr. Narlian. A felucca came to take us to the San Giovanni. The rhythmic movements of the rowers, the plash of the waves, attuned themselves to our thoughts. We looked down into the deep, solid majolica blue of the Medi- 
terranean waters, we looked back on the receding picturesque, jagged rocks of the Faraglione, looming phantom-like in the red glow of the setting sun. We were to sleep in the Casa Inglesi after ascending the cone of Etna, to mount to the top of Vesuvius, by "funiculare," to visit the earthquake-stricken district of Ischia, to enjoy the beauties of Capri and Sorrento; but

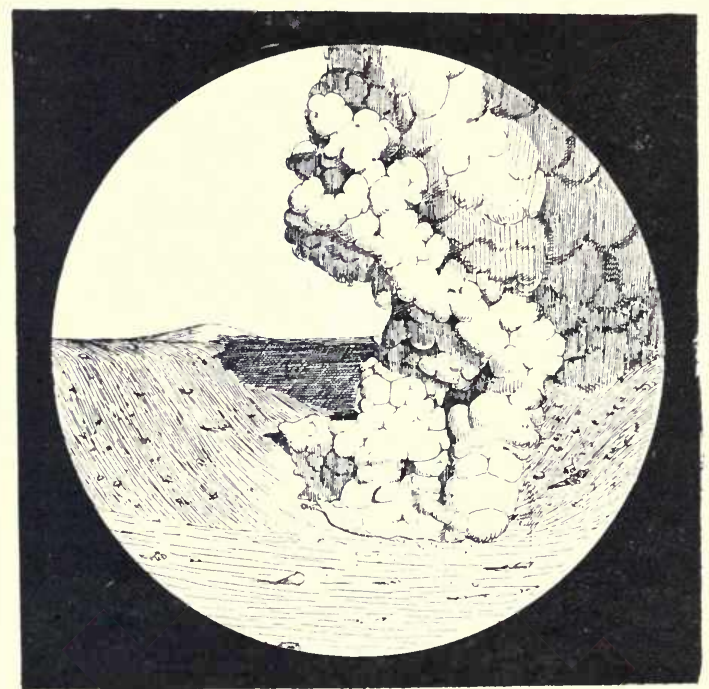

Fig. 15.-A later stage of the same Eruption. (From a photograph.)

we knew well none of this would atone for these Lipari days. The morning and evening plunge from the captain's bridge into the warm sea, the exciting swim with minds full of the sailors' ghastly tales of sharks, the exhilarating mountain climbing, the daring of volcanic fires, the glorious sunlit climate, and the life and fellowship on board boat-these are things to dream upon. 


\section{'THE FRAC'TURED SEA BASIN 81}

The slight sketch we have just given treats only of appearances, and we may now venture on a few words of explanation.

The origin of the Lipari isles is directly connected with their situation. They occur within an area of the earth's crust which has been fractured by a series of great cracks, and has then sunk down towards the interior.

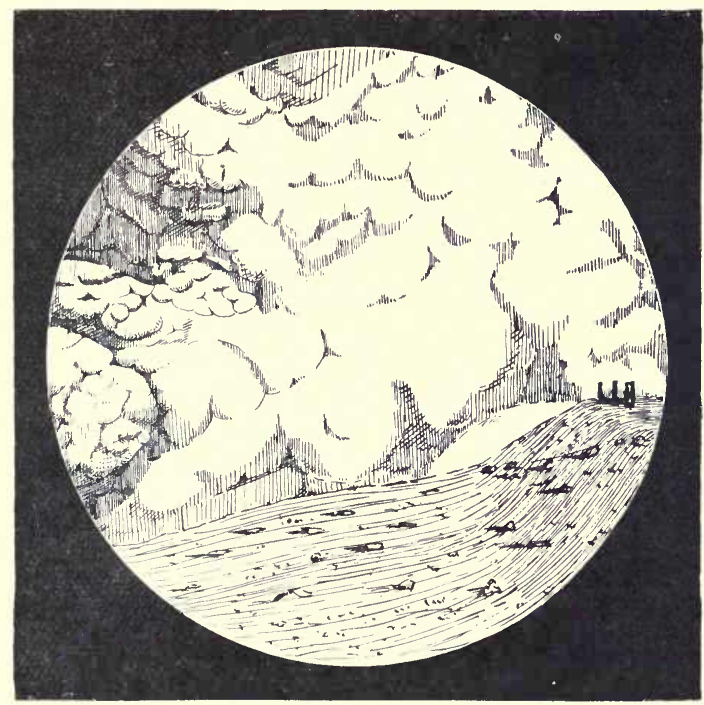

Fig. 16.-The last stage of the Eruption, from a slightly different point of view. (From a photograph.)

The cracks are arranged in a system which recalls that produced when we batter in the end of an egg with a spoon. There is a large peripheral rent forming part of a circular arc (Fig. 8). This passes through the southern extremity of Italy and the north of Sicily; from a point within this four other rents radiate outwards, crossing the peripheral one; on these the Lipari Isles, which are volcanic, stand; and Etna rises immediately over the 


\section{AU'TUMN VISIT 'TO LIPARI ISLES}

point of intersection, where one of the radial cracks crosses the peripheral crack. It is through these fissures that molten matter finds its way to the surface.

The eruption of Stromboli is obviously due to the escape of confined steam. We may picture to ourselves a long pipe descending through the axis of the volcano to a great but unknown distance below the ground, and filled with molten lava supplied by some subterranean reservoir. The lava is charged with steam, and this throughout its mass. But the liquid lava exerts a hydrostatic pressure upon the steam, equal to about one pound per square inch for every vertical foot, so that no deeper down than the bottom of the cone-i.e., at a depth of

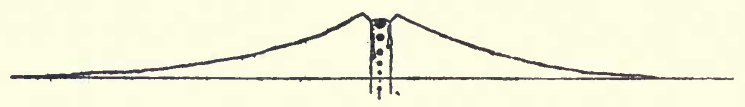

FIG. 17.-Diagrammatic Section through a Volcano of the Stromboli type. The black dots represent ascending bubbles of steam, enlarging as they go.

2,000 feet-the pressure is equal to 2,000 pounds, or 170 atmospheres, per square inch.

The lava is in a state of slow circulation in the pipe, the hotter lava rising up the axis, bringing its steam with it, the cooler descending by crawling down the sides (Fig. 17).

Under the pressure of the lava at the base of the cone the steam is highly compressed, and perhaps exists in a state of solution; but as it rises the pressure correspondingly diminishes, little bubbles begin to appear and grow larger as they ascend, and these gather together beneath the tough, thick film of cooler lava, which covers like a scum the upper surface of the molten column. The steam does not immediately escape owing to the tenacity of this tough film, but when a sufficient quantity 


\section{CAUSE OF VOLCANIC EXPLOSIONS 83}

has accumulated it distends the film, blowing it up in a dome, till it becomes too thin to resist the pressure, and is then blown to shreds, which are spluttered into the air as scoriæ and lapilli.

The eruption of Stromboli is more or less rhythmical, an explosion taking place at irregular intervals of from 30 seconds to 20 minutes.

This periodicity will readily be seen to follow as a consequence of the process just described.

The eruption of Vulcano, of so much greater intensity than that of Stromboli, may possibly be due to the steam having to overcome a greater resistance before effecting its escape.

But the terrible explosions, of which striking examples have been afforded by Krakatoa and Mount Pelée in comparatively recent times, require some more powerful machinery for their explanation. Let us start, as before, with a volcanic pipe filled with molten lava saturated with steam under pressure; but let us endeavour to devise some other means than the slow movement of convection currents to bring about a reduction of pressure on the steam. It would greatly help us in this attempt if we knew what was taking place beneath the base of an active volcano. And, though knowledge of this kind cannot be obtained directly, yet some useful hints may be gathered from a study of ancient volcanic regions. In these, even within the compass of our own islands, we find cases where a once-existing volcano has been completely destroyed by the denuding action of rain and rivers, and perhaps the sea.* Then the ground upon which it stood is exposed to view, and one of the most striking features it exhibits is a multitude of sheets of consolidated lava, some more or less vertical, some approximately horizontal, which proceed from the vol* A. Geikie, "The Ancient Volcanos of Great Britain." 


\section{AU'TUMN VISIT 'TO LIPARI ISLES}

canic pipe, having been injected from it into the surrounding country. From this we may fairly conclude that similar injections take place from time to time beneath the base of existing and active cones, as well as into the cones themselves. But a little consideration will show that one effect of this will be in all probability to reduce the pressure in the volcanic pipe, and that rapidly. Thus in the case of the volcanic pipe represented in the diagram (Fig. 18), we may suppose the lava to sink from $a$ to $b$ as it fills the fissure $d$; the pressure will then be diminished by the height of the vertical column $a b$. On the other hand, we may suppose the lava to well up from $c$ to $b$, and then to escape into

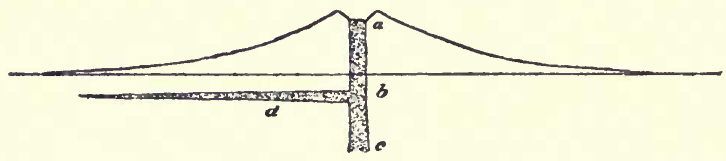

FIG. 18.-Diagrammatic Section of a Volcano of the Vesurian type. $a, b, c$, the chimney; $d$, a dyke or sill.

the fissure $d$. But this will also bring about a reduction in the pressure, measured by the vertical height of the column $c b$. Thus in either case a fall in pressure will result, which may also be very rapid, even sudden. The steam will consequently flash into a much greater volume, and so blow the contents of the pipe out into the air. Successive enlargements and injections of the fissure at $d$ will be accompanied by corresponding explosions of the volcano. The liquid lava may be reduced to fine spray by the violently escaping steam, and thus those finelydivided particles spoken of as volcanic ash will be produced. If this interpretation be correct, then every spasmodic eruption of a volcano may be interpreted as a fresh injection of some subterranean fissure, and, vice 


\section{REGISTRA'TION BY DYKES}

versâ, the dykes which are revealed to us in ancient volcanic regions may be supposed to present us with a register of the eruptions of past times. Further, the formation of the fissures would be attended by earthquake shocks, and they would result from a readjustment of the earth's crust to unequally distributed stress. In connexion with the last great eruptions in the West Indies, such a readjustment evidently affected a large part of the globe, and was signalised by earthquakes in numerous localities. 


\section{IV}

\section{FUNAFUII: THE STUDY OF' A CORAL ATOLL}

$Y$ far the largest portion of the untrodden surface of
our planet is formed by the floor of the Pacific Ocean. Submerged at an average depth of over 1,000 fathoms, it lies out of reach of the geologist's hammer for all time, and for the present at least is inaccessible to the diamond drill.* The geology of an almost entire hemisphere is thus the secret of the Pacific.

"It is the nature of a God," Bacon quaintly remarks, "to conceal a thing, it is the glory of a man to find it out," and certainly there would seem to be few secrets in Nature to which a clue has not somewhere been left for those who have virtue to discover it.

The mountainous margins of the ocean, still young and actively moving, may doubtless furnish us with many precious hints, but it is to the multitudinous islands, which in serried rows like the tops of submerged mountain-chains extend across it, that we must turn in search of the true guiding thread.

* Professors John Joly and Edgeworth David think it may be possible by suitable machinery to bore a hole in the floor of the deep sea. 
Some of these islands, like New Zealand and New Caledonia, are in many important respects similar to our own, and seem to be the surviving fragments of a lost continent, which has fallen into ruins and sunk beneath the waves. Others, such as the Sandwich Isles and Fiji, are also of a kind long since familiar to us, clusters of volcanic cones which, like Stromboli and Vulcano of the Mediterranean, rise from the depths of the sea.

In addition to these, however, there exists a third and strange kind of islands, restricted to the torrid zone, and known to the daring mariners of the Elizabethan period as "low" islands, a name well deserved, since few of them attain a greater elevation than many of the pebble beaches which fringe our own coasts: few, indeed, so great, the loftiest summits of most not exceeding the insignificant height of 10 feet. Owing to this fact they are scarcely visible till a ship is close upon them, and the first glimpse of a low island presents itself as a thin dark-green band, which separates the deep azure of the sky from the still deeper blue of the sea: with nearer approach a cream-coloured streak inserts itself below the green, and is instantly followed by a line of dazzling snowy white, which is soon recognised as the fringe of surf which marks the boundary of the sea. Sailing nearer, the streak of cream-colour becomes the island beach, and the zone of green resolves itself into a mass of luxuriant vegetation, over which the feathery crowns of the graceful cocoa-nut palms, towering to a height of 80 feet, wave indolently in the sea-breeze.

As the details of this gracious scene, rising like an apparition from the deep, unfold before the eyes, one seems to gaze on some island of enchantment, and with the music of the surf thundering in one's ears one thinks 
of the Tritons sounding the loud conch, and half expects to "see old Proteus rising from the lea!"

If it be with surprise that we first make the acquaintance of these islands, the feeling is in no degree abated with closer familiarity; from beginning to end their whole story is a chapter of surprises.

Mariners soon learned to dread the surf-beaten shores, for they could find no anchorage within a safe distance of the breakers, the sides of the island descending precipitously to great depths within a few hundred yards of the coast; and within this distance a reef of rough and rugged rocks forms the shelving floor of the sea. A barque once driven on to this heels over, with its deck facing the overwhelming waves, and is swept clean from stem to stern.

Bristling with dangers on the outside, the island conceals within itself a spacious inner sea, or lagoon, into which, through dangerous passages, a ship may make its way, and, once there, securely ride cut the most destructive storm. The island thus differs from most others in being hollow in its midst: a mere rocky rim to a sea-lake, which may be as much as 60 or even 100 miles across, and 60 fathoms deep, though 20 fathoms is more usual. From this feature the islands are known, not only as "low" islands, but as "lagoon" islands. The shores of the lagoon are bordered by a smooth, gently-sloping beach of flesh-coloured sand, over which the wavelets fall faintly: and paims and laurel-like shrubs growing down to the water's edge are reflected in its crystal margin.

When the voyager first set foot on this strange new land it was a fresh surprise to him to find it peopled. The inhabitants, usually graceful and prepossessing in appearance and amiable in manners, came timidly forth to welcome him, speaking a language full of soft vowel 
sounds, which has been aptly styled the Italian of the Pacific. In some cases, particularly when the natives were not red men but black, they showed less favour to strangers, and the islands sometimes became the theatre of bloody strife.

Besides man, whose presence is an additional problem of the islands, no other mammals are indigenous, their place being taken by various land crabs and spiders of many kinds.

An examination of the rocks of a low island reveals another singular feature: save for a few fragments of pumice, brought from distant volcanos by sea-currents and cast by the waves upon the strand, they present us with but one kind of material, carbonate of lime, which has been extracted from solution in the sea, and built up into a diversity of solid forms by the agency of organisms, - plants and animals, of which the most conspicuous are corals. Thus but one kind of rock enters into the constitution of the island, and this is limestone: of granite, slate, sandstone, clay, such as we are familiar with at home, there is none: all is limestone, whatever you see!

The interest of this fact is enhanced by another. Repeated investigation has proved that the island is not merely a residuum, a mortuary of calcareous organisms, but that it is still alive and in active growth. A profusion of gaily-tinted corals forms reefs within the lagoon, and the whole of the shelving platform, which descends from the surf to a distance of 20 or 30 fathoms below the sea, is alive with them: this platform is indeed the true growing surface of the island.

Corals, by reason of their considerable size and brilliant colours, first attract the attention of the observer, and hence, although numerous other kinds of creatures col- 
laborate with the corals in the construction of the reef, these islands are known not only as "low" islands and "lagoon" islands, but also as "coral " islands, or more particularly as "coral atolls."

The remarkable discovery that coral atolls consist of the remains of animals and plants of precisely the same kinds as those which are at present adding to its substance, excited general interest, and led to many fantastic speculations, which need not now be recalled. The state of opinion at the beginning of this century may best be learned from the works of the poet-naturalist, Chamisso, who may probably be more widely known as the author of "Peter Schlemihl's wunderbare Geschichte"

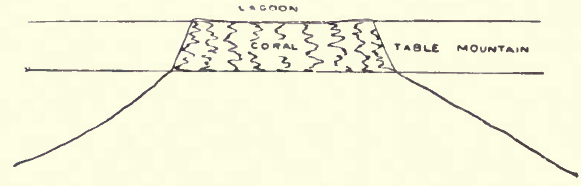

CMAMISSO

FIG. 19.

(The Story of the Man who sold his Shadow) than as an investigator of coral reefs. In a description, which even in the light of the most recent research must still be pronounced excellent, Chamisso speaks of atolls as table-mountains which rise steeply from great depths (Fig. 19). The summit of the table-mountain is always under water, and is covered by the living reef, which surrounds its margin as a broad platform, and rises to the level of low tides. Sandbanks resting on this form the dry land. Since, he observes, every particle of the atoll which lies within the reach of observaticn consists of coral, it is only just to conclude that the whole structure, including the table-mountain, is formed of the same material. Not, perhaps, a strictly logical con- 


\section{LIMI'T OF CORAL GROW'TH 91}

clusion, yet, as events have proved, in the main correct.

Chamisso's opinion was not destined to remain long unchallenged, for two famous French naturalists-Quoy and Gaimard-asserted, as the result of their observations, that the coral rock of an atoll is only skin-deep, i.e., it forms, according to them, a mere superficial crust, not more than about 25 feet in thickness; the restChamisso's " table-mountain "-being, on this view, of volcanic, or at all events of inorganic, origin.

Few of the arguments by which it was attempted to sustain this erroneous conclusion strike one as being very satisfactory, but they include one highly important observation, viz., that reef-building corals do not live at greater depths than 25 feet below the level of low tides. Subsequent inquiry, while fully confirming the existence of a limit, has at the same time extended it down to a depth of as many as 25, or perhaps even 40 , fathoms. Yet, even with this modification, the unexpected discovery of Quoy and Gaimard seems to stand in flagrant contradiction to the views of Chamisso. If corals cannot grow below a depth of 25 fathoms, how could they possibly have built up islands of over 100 fathoms in thickness?

The answer to this question, as is well known, was given by Charles Darwin. If we admit the truth of both the apparently conflicting statements, it is obvious that the corals at the base of a reef 100 fathoms in thickness must have been situated within the limit of 25 fathoms at the time they were alive. But in order to bring them within this limit it is only necessary to suppose that the foundation on which they grew originally stood 75 fathoms nearer the sea-level than it does now ; or, in other words, that since the lower layers of the reef were alive and flourishing, the ground which supported them has sunk 
75 fathoms deeper in the sea. No fact is better established than the rise and fall of islands situated in midocean, and thus there is nothing antecedently improbable in this supposition. But once grant it and Darwin's explanation of atolls naturally follows. Thus, let $a$ be an island with its summit rising 100 fathoms above the sea; let its shores become peopled with corals, which extend seawards down to the limit of 25 fathoms, beyond which, as we admit, they cannot proceed: a reef is thus started, which will continue to grow, rising upwards till it reaches the level of low tides: when this is attained

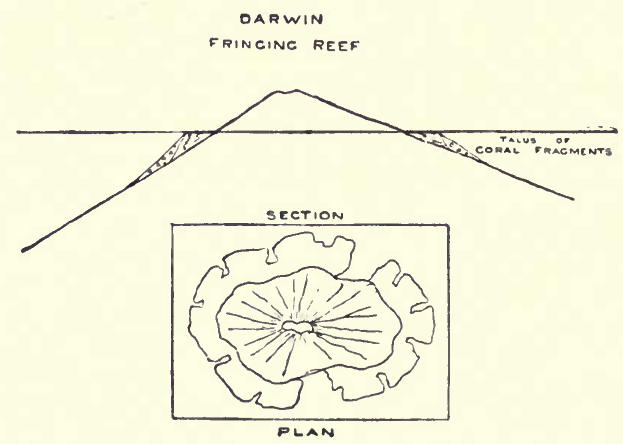

Fig. 20.-First Stage.

upward growth will cease, and the reef will begin to pass into decay, from the shore-edge outwards. So long as the island remains stationary, neither rising nor falling with respect to the sea-level, this is practically all that will happen, and the final result is a reef not much exceeding 25 fathoms in thickness (Fig. 20, first stage). But let us next suppose that the island begins slowly to sink into the sea, carrying the reef with it; the upward limit to the growth of the corals will be displaced; they will commence to flourish afresh, and the reef will continue to extend upwards till the level of the low 
tides is once more encountered, and growth again arrested. This process of submergence and upward growth may, of course, be repeated indefinitely, and by the time the island has descended 50 fathoms below its original position, the reef will have acquired a corresponding thickness. In such a case the unfavourable conditions to coral growth which prevail on the inner side of the reef, together with the retreating slope of the flanks of the island, will have led to the formation of a channel of sea-water between the reef and the shore (Fig. 21, second stage). Finally, let the submergence of

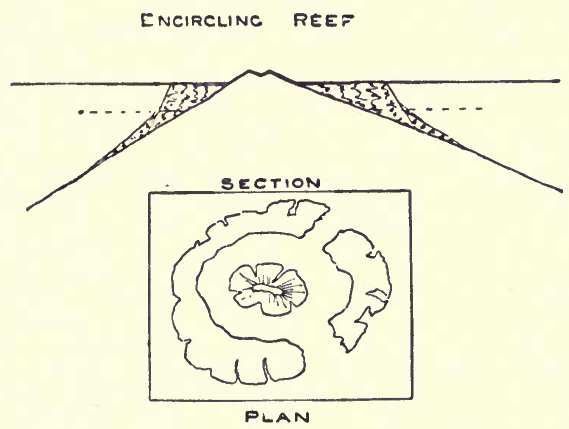

FIG. 21.-Second Stage.

the island continue till it is completely swallowed up by the sea, not a vestige of its summit remaining to mark its place; the upward growth of the corals, constantly proceeding, will bring them once more to the level of low tides, and the result will be the formation of a ringshaped reef surrounding a central lagoon, or, in other words, of an atoll (Fig. 22, third stage).

If this hypothetical scheme of the progress of events correspond to the facts, we may expect to find its various stages still represented among the numerous islands of the Pacific; and this, as Darwin endeavoured to show 
is clearly the case. The first stage, in which the reef is no more than 25 fathoms thick, and forms a selvage accurately following the margin of the land, is represented by that numerous class known as "fringing" reefs. The second, in which a comparatively thick reef surrounds an island with an intervening saltwater channel, is illustrated by another class, known as "encircling" or "barrier" reefs. In these, as we might expect, the form of the reef is only remotely related to the contour of the enclosed island, the valleys of which present

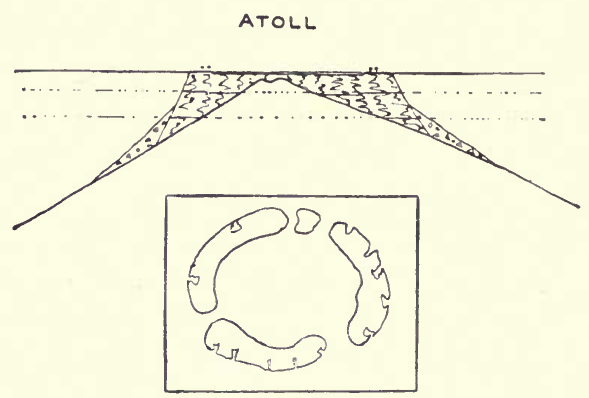

Fig. 22.-Third Stage.

that fiord-like character so suggestive of sunken land. The last stage is that of the atoll itself.

The excellence of Darwin's theory lies in this, that it explains all the essential features of an atoll on one simple assumption. It is inconsistent with no known fact, and as additional discoveries have been made it has not required to be supplemented by fresh hypotheses. It is not like a Gothic structure, supported by flying buttresses and other tours de force, but rather resembles some noble Italian tower, which rises from its base, straight, simple, and self-sufficing. It was no sooner given to the world than it commanded almost universal assent. 


\section{MURRAY'S THEORY}

Nevertheless it has never been without a rival: even before Darwin published his celebrated work, Ainsworth * had suggested a different explanation. $\mathrm{He}$ rightly pointed out that Quoy and Gaimard had not established a limit for all reef-building organisms, and that, although certain corals, such as they had observed, might be restricted to shallow waters, there might yet be others capable of flourishing at greater depths. If so, these deep-water organisms might be engaged in laying the foundations of an atoll on which the shallower water forms might erect the superstructure (Fig. 23). This suggestion seems to have fallen still-born, but the notion

$$
\text { AINSWORTH }
$$

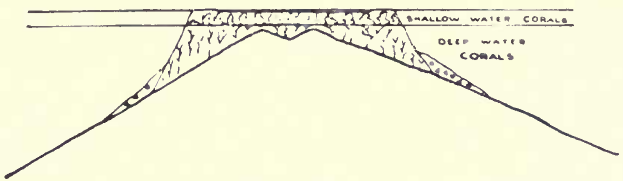

Fig. 23.

of "laying the foundation" of an atoll was not destined to perish : it has been revived of late years by Sir John Murray, who, guided by his observations made when on board the Challenger, was led to suppose that the submerged summits of deeply-sunken islands might be raised to within the limit of 25 fathoms, not by the upward growth of corals, but by the incessant downward rain of minute organisms from the surface of the sea. The same agencies which were supposed to be spreading out a layer of chalky mud or ooze over the abyssal floor of the ocean

* G. W. Ainsworth, "Analysis of a Voyage to the Pacific and Behring's Straits, to co-operate with the Polar Expedition, performed in H.M. Ship Blossom, under command of Capt. F. W. Beechey, R.N., in the years 1825-28," Geog. Jour., vol. i ., 1831. 
were also imagined as engaged in piling a Pelion of mud on every submarine Ossa (Fig. 24).

The publication of Sir John Murray's views was followed by a long controversy, in which Darwin's theory was subjected to a most searching criticism. An impartial summary of the arguments arrayed on both sides of the question is given by Professor Bonney, in the last edition of Darwin's "Coral Reefs," and the general subject is treated in the fullest manner by Langenbeck, in a work entitled “Die Theorieen ueber die Entstehung der Koralleninseln und Korallenriffe”' (Leipzig, 1890).

So far as the opposition to Darwin's views has come to count among its adherents a number of distinguished

SIR JOMN MURRAY

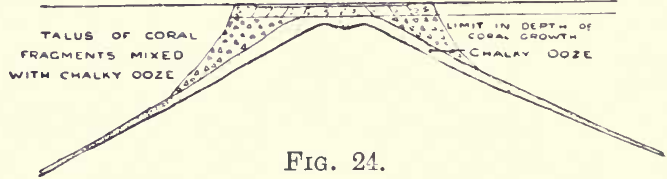

thinkers, it can only be regarded as having achieved a certain measure of success : a result not, to my thinking, to be wholly accounted for by the nature of the arguments employed; possibly in this, as in similar cases, the ostensible objections are mere weapons of combat, while the real power has lain in the strong and subtle influence exercised by some general current of thought. Such a current is indicated in the tendency to a belief in what is spoken of as the Permanence of Continental Areas and Oceanic Basins.

According to Darwin, every atoll marlis the site of a vanished island, but the atolls of the Pacific are so numerous that if one imagines all the islands they represent as summoned back from the "vasty deep" and 


\section{PERMANENCE OF THE OCEAN 97}

restored to their original position above the sea, they will constitute a very considerable tract of land, and this situated in the very middle of the Pacific Ocean. Such a prospect could not fail to be unpleasing to those who believed in the immutability of the ocean.

Of late years, however, this doctrine of "permanence" has begun to look a little threadbare. In a theoretical restoration of the distribution of land and sea during the Jurassic times, Neumayr has treated it with scant consideration, since he represents the North and South Atlantic, as well as the Indian Ocean, as then to a great extent occupied by land, and it is now very generally supposed that this land did not disappear to make way for existing seas till a comparatively late period in the history of the earth. Bold as Neumayr showed himself in the treatment of these oceans, he had not the temerity to take liberties with the Pacific. This he and geologists in general are disposed to regard as having maintained its existing features from a very early period: * of this ocean, and of it alone, would they exclaim, "Such as Creation's dawn beheld, thou rollest now."

Darwin's theory, as we have seen, does not hesitate to recall to existence land in the middle of even this ocean; this is its unforgivable offence-it lays sacrilegious hands on the Pacific, and thus attacks the doctrine of " permanence" in its stronghold.

While the recent controversy on Darwin's theory was at its fiercest, and both sides seemed equally persuaded that the truth was theirs and must prevail, it occurred to me that a simple solution might be obtained by sinking a bore-hole through some well-characterised atoll, and

* I find I have underestimated the courage of this brilliant thinker. Neumayr has indeed proposed to bridge the Pacific by a continent joining Eastern Asia and Western North America in order to explain the similarity in the faunas of these two regions. 
thus obtaining specimens of the material of which it is composed, down to a depth considerably greater than that at which corals are supposed to build. How would this illustrate the question? Allow me to employ a homely illustration: buyers of cheese are not, I presume, naturally more suspicious than other persons engaged in trade, but they are unwilling to trust too much to mere outward appearance; they are not inclined to adopt the argument which commended itself to Chamisso in a parallel case, that because there is good cheese on the

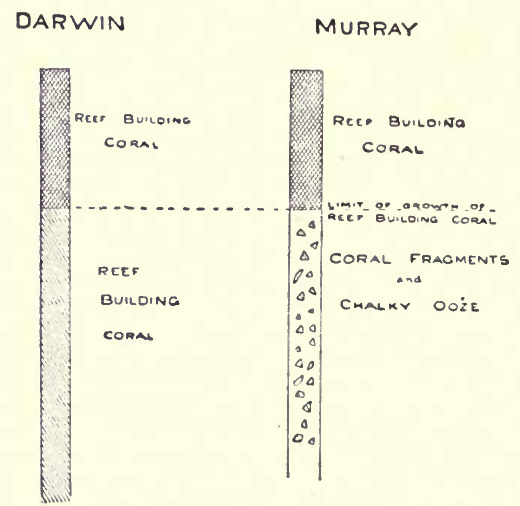

Fig. 25.

surface it must be good cheese all through: consequently, by means of a boring instrument, called a scoop, they make a hole through the cheese and bring out a core or cylindrical rod, in which the several strata of the material, if there be more than one, are displayed in their true thickness and natural position. The atoll is our cheese, which we propose to sample with a complicated kind of scoop called a diamond drill. This should provide us with a core in which the various layers of the coral reef should be faithfully represented. Should Darwin's theory prove correct, the core will contain the remains of reef- 


\section{A CRUCIAL TEST}

building corals as far down as the reef extends; if, on the other hand, Sir John Murray's explanation make a nearer approach to the truth, layers of chalky ooze will be present at depths greater than that of the limit of coral growth (Fig. 25).

No one who has any notion of the extraordinary thoroughness with which Darwin attacked this as every other problem that he investigated, will be at all surprised to learn that the same solution had already occurred to him, and in a letter to A. Agassiz (May 5, 1881) he sighs for "some doubly rich millionaire, who would take it into his head to have borings made in some of the Pacific and Indian atolls, and bring home cores for slicing from a depth of 500 or 600 feet." As the wished-for millionaire did not appear to be forthcoming, it appeared to me that the boring might be achieved in another way, by a method very familiar to this Association-I allude, of course, to a "Committee." On approaching Professor Bonney with a suggestion to this effect he warmly entertained the proposal, and in 1891 a strong Conmittee, including the most distinguished supporters and opponents of Darwin's theory, was formed, having for its object the investigation of an atoll by boring and other means.

Through the kind offices of Professor Stuart, of Sydney, we obtained from the Government of New South Wales the offer of the free loan of a diamond drill. Our next step was to select an island for investigation. This was rendered an easy task through the invaluable assistance afforded by Admiral Wharton, whose extensive knowledge of coral-reefs renders him one of the most formidable of Darwin's opponents. At his suggestion our choice fell on Funafuti, one of the Ellice or Lagoon Islands, situated in the middle of the Pacific (lat. $8 \frac{1}{2}$ S.), seven days' sail northwards of Fiji. No better selection could possibly 
have been made. Not only is Funafuti an atoll of unexceptional character itself, but it belongs to a family of atolls all of equally unexceptional character; and these again to a system which includes the Gilbert and Marshall Islands, all of them excellent atolls. So far as these are all distinguished by the same characters, whatever may be found true of Funafuti will apply to all the rest.

The labours of the Committee of the British Association were then taken over by a Committee of the Royal Society, at whose request the Admiralty generously assigned to our assistance the Penguin, one of H.M. gunboats, commanded by Captain Field, and stationed in the Pacific for exploring purposes. The Royal Society furnished funds to defray expenses, and the direction of the expedition was placed in my hands: two volunteers, Mr. Gardiner, of Cambridge, and Mr. Hedley, of Sydney, were, with my permission, to accompany me.

We joined the Penguin and left Sydney on May 1, 1896, taking with us a boring party which had been selected for the work by Mr. Slee, the Government Inspector of Mines and Drills. Its foreman, Ayles, had acquired great reputation in the colony by his success in conducting boring operations of exceptional difficulty. On May 21st, after three weeks' voyage, we heard the welcome cry, "Land ho!" and Funafuti was seen on the horizon. The ship was steered for the southern entrance; this was safely made, and we steamed into the noble lagoon. Flying-fish spurted from under our bows, and zigzagged in their darting flight around us; here and there in the midst of the blue waters green and purple shallows marked the site of growing coral patches. On the starboard side lay the beautiful island of Funafuti proper, its pale sands ablaze in the light of the tropical sun, its groves of palms cool with a refreshing green. A 


\section{AN OFFICIAL, RECEP'LON}

boat put off from the beach manned by a crew of coppercoloured natives, their black hair crowned with wreaths of Gardenia and Hibiscus flowers. They were soon swarming over our sides, bringing with them the solitary white trader of the island, who safely piloted us to anchor within a mile of the shore. Captain Field and a party immediately landed, and we went at once to pay our respects to the king, who, notwithstanding the narrow limits of his realm and the smallness of his nation, which numbers only some 240 souls, we found to be every inch a king. His Majesty received us with gracious dignity, led us into his palace, one of the few stone huts on the island, and seated us by his side on the daïs, which consisted of packing-cases. The chief men sat round the walls on the floor, and smiling damsels, with large black eyes, ivory white teeth, and long black tresses floating loose, shyly presented us with freshly-opened cocoanuts to drink, a civility which as inevitably attends a call in Funafuti as the afternoon cup of tea at home. We told our errand, and received permission to choose a site for boring operations. We then requested that a house should be built for us, and were promised that this should be done for the modest sum of $£ 6$. The reception ended, we proceeded to choose a site for the boring and for landing gear, and marked out the plan of our house; it was to measure 15 by 20 feet. We were anxious to have the building of this put in hand at once, and were assured that it should be ready for us by the afternoon of the next day. The East is supposed to be more fertile in promise than performance, and our expectation was that we should see this house when we did see it. Judge, therefore, of our surprise when, on passing the same spot the day after, we found a substantial structure already standing there. It had grown up like Aladdin's palace in a single night! The whole population had been em- 
ployed on the work: the men had cut down trees and shaped them into poles, sunk these in the ground, and bound them together into a solid framework: the children had been set to gather palm-leaves from the forest, and the women had woven these into mats, which were used to form both the walls and thatch of our dwelling. The result was an excellent house which served all our needs, protecting us from sun and storm during our residence of nearly three months. Not a nail was driven in its construction, all the joints being firmly made with cocoanut cord.

After contemplating the work with great satisfaction I left for a stroll, and returning an hour after was aghast to find our new house surrounded with smoke and flames! To my great relief it turned out that the conflagration proceeded from the surrounding bush, which the thoughtful natives had purposely set alight to prevent its taking fire by accident.

The work of landing gear and erecting machinery was set about vigorously; the crew of the Penguin toiled all day heroically in the burning sun, refreshing themselves at sunset in swimming matches with the natives; progress was so rapid that by June 3rd, not quite a fortnight after landing, the boring party were already at work (Fig. 26). So far all our plans had been carried out with expedition and success, and since "things done well and with a care" are said to "exempt themselves from fear," we may now safely leave our miners industriously boring while we take a walk across the island. Standing on the shore of the lagoon near the site of our boring, it is just possible to catch a glimpse of the palms on the opposite side, some ten miles away. The beach slopes so gently, that, although the tide falls only about 5 feet, it leaves a wide expanse of sand uncovered; this is a perfect warren of shore crabs (Calappa), 
which scurry along like blown thistledown and vanish into holes with mysterious suddenness. It is at night that these are most active, when they dig deep burrows in the sand, casting up conical hillocks at the entrance nearly a foot high, which give the beach the appearance of a miniature encampment (Fig. 27). The sand is the famous "coral" sand; but on picking up a handful for

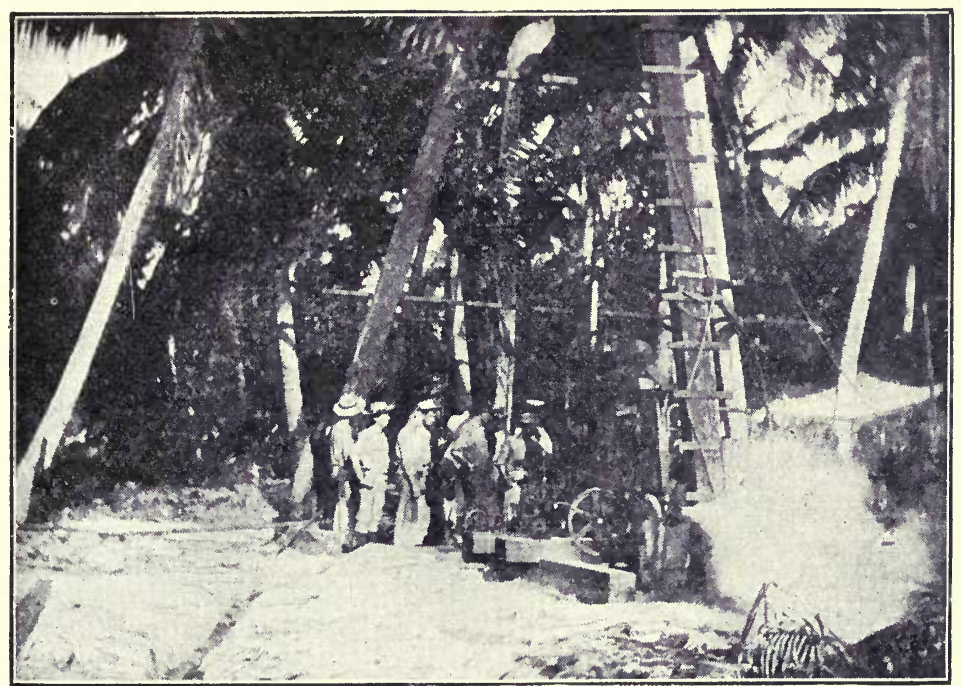

FIG. 26. - The Site of the First Boring, with Derrick and Machinery.

nearer inspection we are surprised to find that it contains scarcely any coral ; and, so far from consisting of detrital material, it is almost entirely composed of the shells of Foraminifera, two species predominating, Tinoporus baculatus and Orbitolites complanata. From specimens collected on other atolls by the late Professor Moseley, and preserved in the University Museum at Oxford, it would appear that the sand at Funafuti is by no means 
singular in this respect, and the term "coral" sand is only another instance of the "lucus a non."

The lagoon beach ends in a tiny cliff about a foot in height,* to the very edge of which sparse turf and vegetation of a larger growth extends; the land to which this cliff is boundary consists chiefly of small fragments of coral and shells of Foraminifera; it rises a little so as

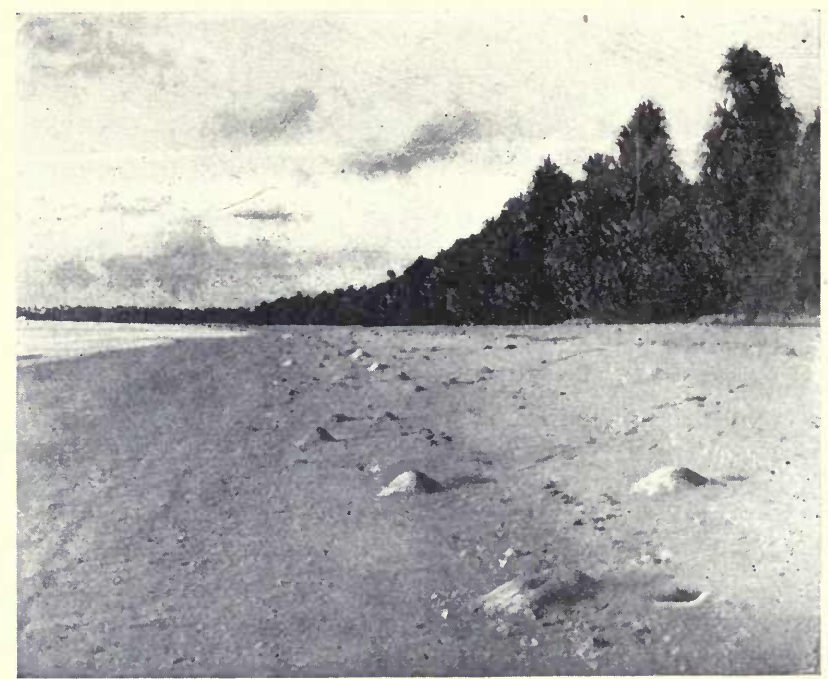

Frg. 27.-Lagoon Beach, just in front of our "fale" (hut), showing mounds thrown up by shore crabs. The mounds were frequently more numerous than in this instance.

to attain a maximum height of 3 or 4 feet above highwater mark. In breadth it varies considerably, and where broadest the native village stands, with the church, large

* This applies to that part of the islet on which our house was built; in some places more considerable cliffs are met with, e.g., on one of the northern islets of Funafuti, called Amatupu, where a conglomerate of coral pebbles forms steep faces some 6 feet or more in height. 


\section{FORES'I GROW'IH}

enough to contain the whole population, all church-goers, the school, mission-house, and palace. A row of graves, made tomb-like with slabs of coral, runs down the middle of the main street. The whole of this sandy flat is covered with rich forest growth (Fig. 28), cocoanut palms in all stages, from the young plant just sprouting from the shell to the ancient of the groves, 80 feet in height, bearing heavy clusters of ripe fruit beneath its

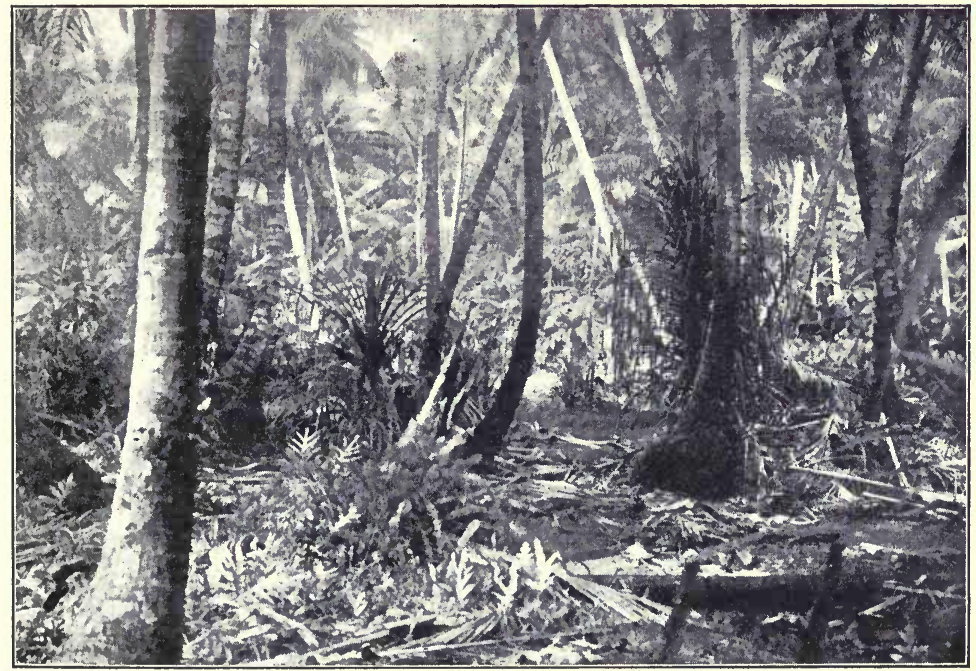

Fig. 28.-Forest Scene in Funafuti.

crown of feathery fronds; pandanus, with its strange adventitious roots and truculent sword-shaped leaves, broken in the middle; the laurel-like Nono (Morinda citrifolia); and the "Nya" tree (Pemphis), with its heavy stem of hard red wood, and delicate foliage. Ferns abound, and some brightly-coloured flowering plants; an Abutilon, which puts forth fresh blossoms day by day; and a handsome bean, which trails through 
the forest bearing large heart-shaped leaves and heavy racemes of lilac flowers.

The great robber-crab (Birgus), which feeds on cocoanuts and pandanus fruit, is at home here, and may be seen climbing the cocoa-palms by night. Other land crabs scramble through the fallen palm-leaves which thickly strew the ground. Many of these are of the hermit kind, and one of them has a curious habit of croaking like a frog when captured. But no part of the island is free from land crabs; like rats and mice, they are the universal scavengers; they undermined our house, attacked our tinned provisions, and we could not sit down to eat a cocoanut without some of these weird creatures gathering round to pick up the fallen crumbs.

As we continue our passage across the sand, the scene rapidly, even abruptly, changes its aspect; the place of the forest so rich and varied is taken by a grotesque growth of "Nya" trees, whose stubborn contorted trunks, strangely at variance with their dainty foliage, bar the way; struggling through these, one enters upon a savage plain, "horrid" with rugged fragments of blackened coral, and cumbered here and there with huge boulders of coral rock some tons in weight.* At low water this desolate region is dry and burns in the sun, but as the tide rises sea-water oozes up through holes in the ground and covers it with shallow pools. Few animals live in this desert; spiders, that infest the "Nya" trees, and mosquitos, that lie greedily in wait by day as well as night, are the chief that I bear in mind. Proceeding lengthwise along this plain, which lies in the middle of the island, it broadens out and passes into a muddy swamp, planted by the natives with taro, a delicious substitute for potatoes, and bananas, which one still reflects upon with pleasure; their fruit * One of these measured 6 feet by 5 feet by 4 feet. 


\section{THE MANGROVE SW AMP}

was our chief luxury, and we willingly paid for it at the somewhat exorbitant price of four fathoms of calico a bunch.

Farther on beyond the plantation the depression becomes still wider, forming an extensive flat, partly margined by mangrove-trees and Hibiscus; this was known to us as the mangrove swamp (Fig. 29). It is an interesting corner of the island. The floor represents

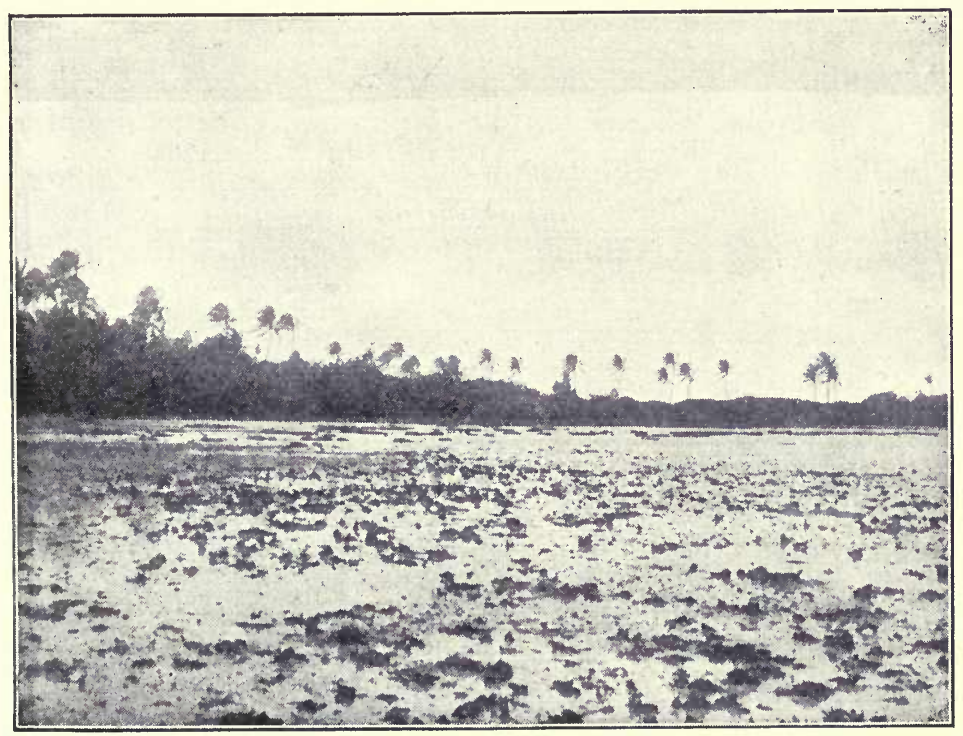

Fig. 29.-Heliopora in the foreground, Porites beyond; the Mangrove Swamp, Funafuti.

the upper surface of a dead coral reef, composed partly of great masses of Porites; their flattened summits, standing some 8 or 10 inches above the floor, give them the appearance of a row of stepping-stones, and mark what was the level of low tide at the time the reef was living. *

* The last episode in the history of the island appears to have been a slight elevation of some 4 or 5 feet: at least, I was led 
Radiating from these blocks as from a nucleus are vertical plates of the "blue coral" (Heliopora corulea), which extend outwards, branching as they go, for a distance of 3 yards or more. Overlapping the reef lies a layer of consolidated coral breccia; it has suffered much from erosion by the sea, and bounds the inner side of the depression in cliffs 3 or 4 feet in height. A sheet of clear green water covers the swamp at high tide, converting it into a shallow lake, which as the tide falls empties itself through deep holes in the floor into subterranean passages, which freely communicate with the outer sea. The northern end of this depression is closed by coral breccia, and overgrown with mangroves; but farther on it recommences and extends through the remainder of the island, almost as far as its northernmost extremity, forming a discontinuous narrow trough bordered by steep cliffs. This trough, and the depression to which it belongs, owes its origin in some degree to solution by sea-water.

We have deviated from our walk across the island to follow the course of its central depression, let us now return and resume our traverse. The blackened fragments of coral, resembling nothing so much as the clinkers of lava which cumber the slopes of Etna, continue seawards, and are loosely piled to form a gentlyrising ascent; so loosely piled that they often topple over at a touch, and afford very uncertain or even dangerous foothold.

Walking circumspectly, therefore, up the slope we soon reach the summit of a long ridge, and find ourselves looking towards the Andes, some thousands of miles

to this conclusion from evidence furnished by the "dead reef " of the mangrove swamp, by the "sea-stacks," or pinnacles of coral-rag of the tidal-platform, and by the steep cliffs which in some of the islets border the lagoon. 


\section{OCEAN SIDE OF THE ATOLL 109}

away over the broad waters of the Pacific Ocean. We stand on the top of the "storm-beach," the loftiest region of our island, at the imposing altitude of 10 or even 15 feet, according to the state of the tide. On the seaward face the storm-beach descends somewhat rapidly, and near its foot a sheet of hard consolidated coral-rag emerges from under it, to form a gently-sloping platform, over which the tide ebbs and flows. In places this tidal

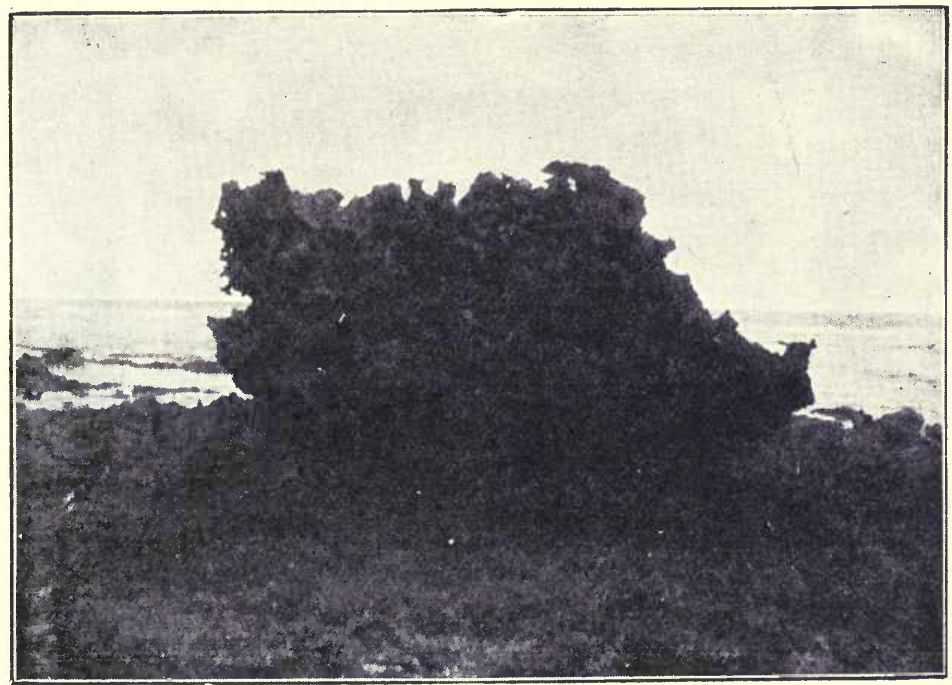

FIG. 30.-A Raised Pinnacle of Coral.

platform rises in low cliffs, ridges, and pinnacles * of fantastic shape (Fig. 30), but for the most part it presents itself as a sheet of limestone, smoothed and polished by the wearing action of the waves. For about fifty yards from its seaward edge it is hollowed into a broad shallow depression (Fig. 31), not deep enough to be called a channel, and finally swells into a narrow rounded rim

* See footnote, p. 107. 
formed by the growth of a pink-coloured calcareous seaweed known as Melobesia.* Beyond this rim, which projects above the sea at low tide, lies the growing surface of the reef, which is constantly submerged, so that under no circumstances are the corals which thickly cover it at any time exposed to the air.

Deep chasms gash the edge of the tidal platform, the continuation inland of the lanes of clear sea which wander

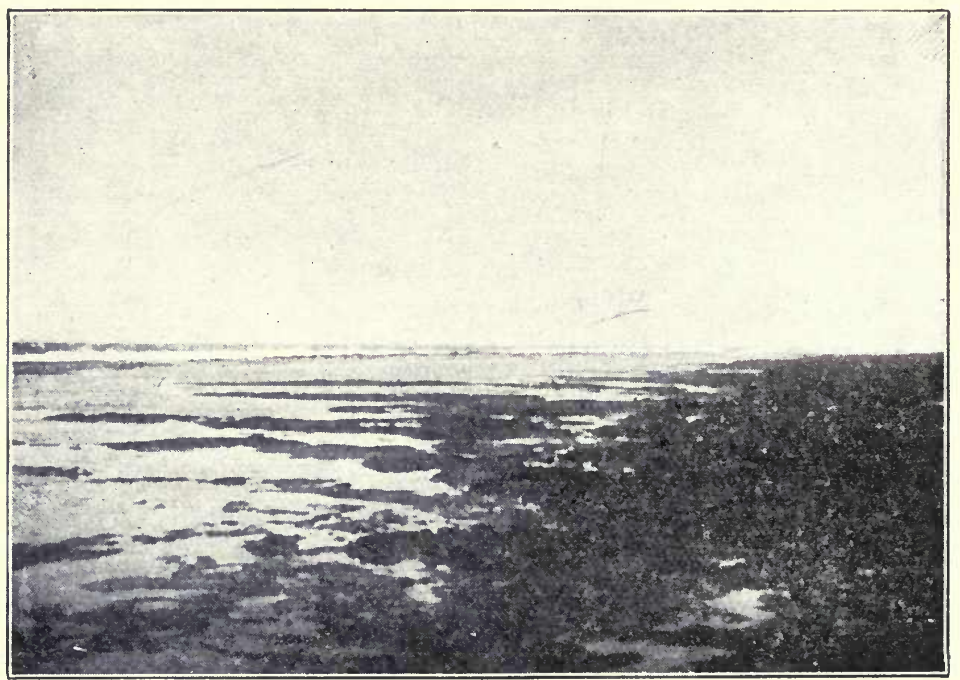

FIG. 31.-Funafuti on the Ocean Side.

through the growing reef; in these chasms a few corals may generally be found, their polypes sometimes brilliantly coloured and in full expansion.

The calcareous alga, previously alluded to as Melobesia, forms the lips of these chasms, and by its luxuriant growth may more or less completely roof them over, generally leaving one or more apertures, which act as blow-holes.

* Now known as Lithothamnium. 


\section{OCEAN SIDE OF THE ATOLL 111}

The ocean side of the reef is one of the pleasantest parts of the island; a cool breeze almost always blows there; and, under the welcome shelter of the palms and pandanus which crown the summit of the storm-beach, one may watch the beautiful and impressive spectacle below (Fig. 32) ; the ocean, of a deep majolica blue, rolls inwards in majestic waves, which suddenly grow gigantic

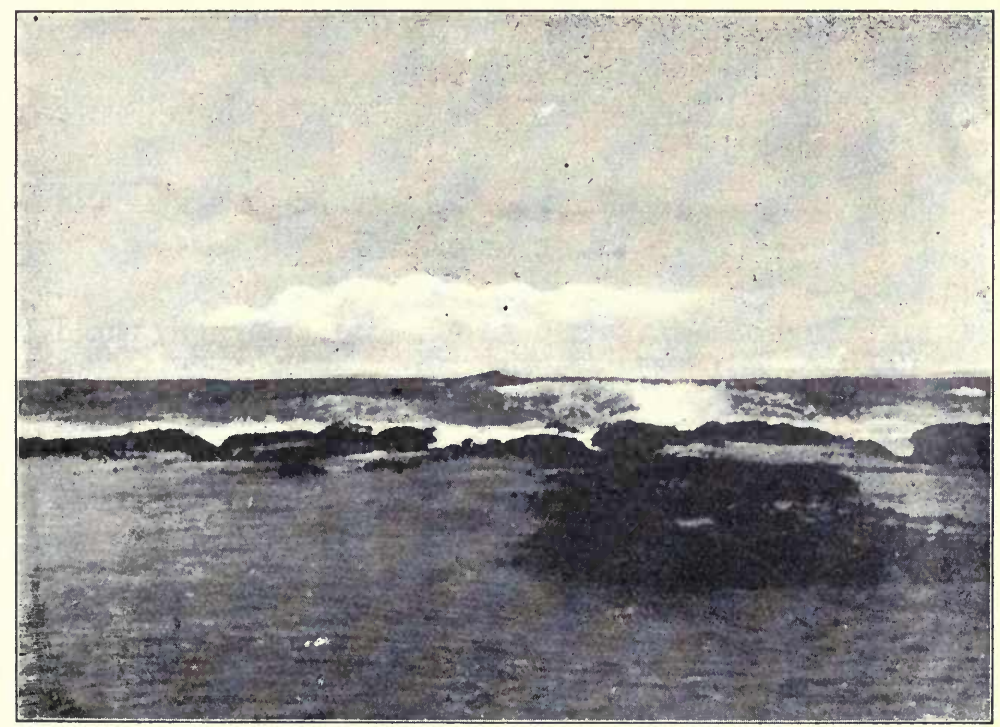

FIG. 32.-Tidal Platform and Margin of Reef.

as they approach the shore, towering in a wall of water above the reef; and then spring with a furious roar into a confusion of white foam, which seethes about the madder-tinted margin of Melobesia, rushes through the chasms of the tidal platform, and often spouts up through the blow-holes with sudden and explosive violence, like a kind of marine geysers. It is only on calm days that the extreme margin of the reef can be approached with safety. 
Such is the violence of the breakers that the tidal platform presents the appearance of an almost lifeless desert; a few green and brown seaweeds, little fish darting in the pools, occasional sea-snails with dense shells, and a few hermit-crabs heavily armoured, are all that is seen at first glance. All the inhabitants of the tidal platform seem to stand in dread of the sea; even the active shore crabs (Grupsus) are afraid of it, and only venture in when inspired by their greater terror of the human form; even then they cling tenaciously with their many legs close to the sides of the rocky shore, and sidle off to land directly they fancy the enemy's back is turned.

The observer who trusted to first impressions, and judged the platform by its outer aspect, would fall into grievous error; it is by no means so dead as it seems. On breaking off a fragment with a hammer a new world of life is revealed; the rock is tunnelled through and through, as closely as it can be mined, by a variety of animals, which have taken to an underground life as a protection against the sea; worms, shell-fish, crabs, seasquirts, and barnacles are to be found in these subterranean dwellings; they constitute a specialised fauna of marine troglodytes, which might, if we wished to add to the burden of nomenclature, be designated the "Cryptone."

After this brief description of the superficial features of the atoll, we may next endeavour to trace the history of that part of it which rises above the sea and properly constitutes the land. The sheet of hard coral-rock, which we mentioned as cropping out beneath the stormbeach, can be traced into the interior of the island, where it forms the floor of the central depression; and again to the lagoon side, where it emerges to form the floor of the lagoon, and in many places the beach, or as well even a low line of cliffs. In the little islet of Pava, north of Funafuti, it is seen to extend continuously from one 


\section{FORMA'TION OF THE LAND 113}

side of the land to the other-from the ocean to the lagoon.

We may therefore fairly conclude that this sheet of rock forms the solid base on which the land above it rests. It is composed mainly of slabs of coral, lying not quite horizontally, but overlapping like the tiles of a roof, with a slight inclination towards the ocean side of the reef.

These fragments have evidently been derived from the outer zone of growing coral. Before the land, as it now exists, was formed, the waves were incessantly engaged in tearing off fragments from the coral zone, and driving them across the reef into the lagoon, till a thick sheet of débris was the result. This became consolidated as it formed, partly by the growth of incrusting calcareous algæ, and now forms the solid floor of the island.

Masses of broken corals, torn up and driven inland by the breakers, continued to accumulate after the formation of the floor; and thus that great pile of coral clinkers, which forms the storm-beach, has been and is still being built up.

On the other side, the wavelets of the lagoon have washed up smaller fragments of coral and foraminiferal shells, and thus the strip of land which borders the lagoon, and on which the village of Funafuti stands, has been produced.

The middle of the island-the great central depression including the taro ground and the mangrove swamp-is the remains of the original solid platform left exposed between the storm-beach on the one hand and the lagoon land on the other. Thus all that portion of Funafuti which stands above high tide has been cast up from the ocean and the lagoon, and this beautiful island, like another Aphrodite, has been born with the foam from the waves of the sea. 
If this be the true history of the island, how then did it acquire its inhabitants? (Fig. 33.) Did they climb upwards, like the corals, as the island was submerged, or did they arrive as flotsam and jetsam of the sea? As regards the natives there can be but one answer-they came by boat. In former days the Polynesians possessed excellent sea-going craft, in which they were accustomed to make long voyages, steering by the stars and other signs in the sky. They well knew how to preserve food by drying, and thus had no difficulty in provisioning for a cruise. The routes they followed in passing from island to island are gradually becoming known to us, and have been indicated on a chart by Professor Haddon. Considering the remarkable similarity of language which characterises all Polynesia, from New Zealand on the south to the Sandwich Isles on the north, there can be little doubt that the migrations of these peoples must have taken place comparatively recently, and, judging from tradition, one might conjecture within the last seven or eight hundred years.

Thus long before the illustrious townsman of this city, John Cabot, had anticipated Columbus in his famous voyage to America, these navigators, whom we libel with the name of savages, were venturing on equally arduous explorations, with still more imperfect means at their command. It was not often, however, that long voyages of over a thousand miles were made of set purpose; too frequently they were the result of accident, as when frail canoes were overtaken by a sudden storm and driven at the mercy of the winds, sometimes to perish miserably, sometimes by good hap to land on undiscovered shores.

The Funafuti people seem some of them to have entered the island with intent, others are mere waifs and strays cast away by shipwreck on the reef. The pre- 
vailing stock is Samoan, with an admixture of Tongan. In bygone times the Tongans used to make periodical descents upon the island, after the fashion of the Vikings in early English history. The Tongans, however, came not only to kill but to eat their foes, a proceeding not wholly unintelligible among a people who knew absolutely of no other kind of meat. In

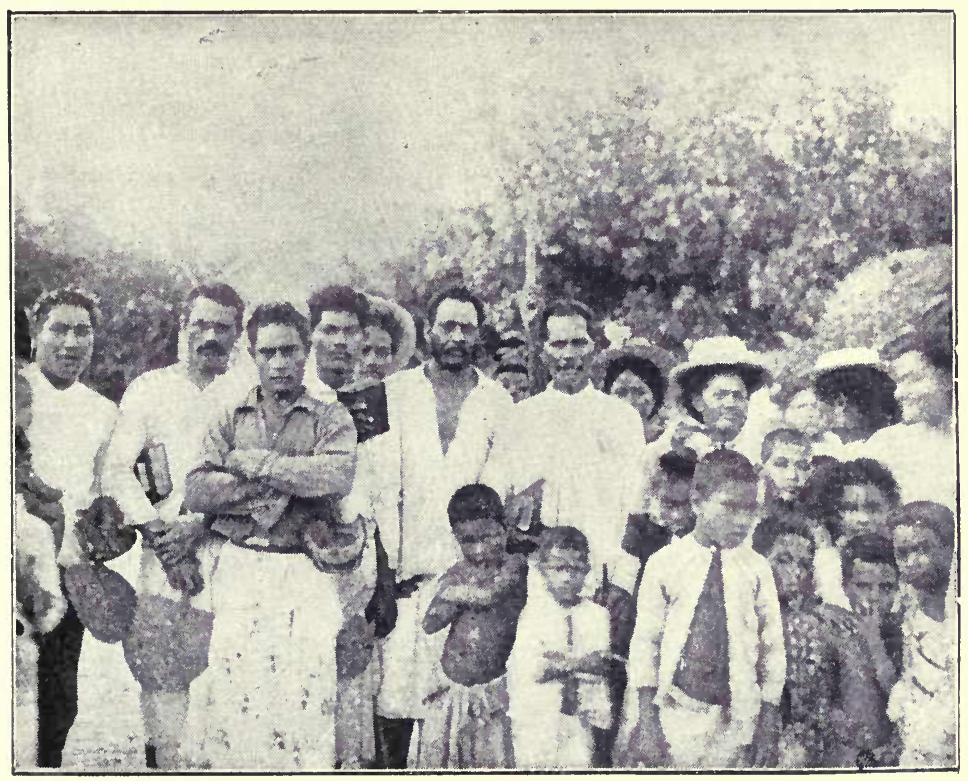

FIG. 33.-A Group of Natives, Funafuti.

justice to the copper-coloured races of Polynesia, I hasten to add that cannibalism was seldom the custom of this folk; wherever it is met with it may be taken to indicate the influence of black blood. So far as we know, cannibals are almost always black people.

Returning to the boring party, which we left busily engaged. For nearly three weeks they worked by shifts 
continuously night and day, but at the end of that time, when the bore-hole was only 105 feet deep, their most arduous efforts failed to advance it further. The difficulties opposed by the nature of the ground-a mixture of flowing sand and obdurate boulders-were such that neither the good-will of the workmen nor the ingenuity of Ayles, the foreman, could contend against them, and there was no alternative but to abandon the undertaking.

Thinking that there might be a better prospect of success on the ocean side of the reef, we determined to make a fresh attempt there, and in two days, without the help of wheels and in a country without roads, we succeeded in transporting the bulk of our twenty-five tons of machinery across the island to a fresh site. The new boring commenced in hard rock and at first deepened rapidly. Before long, however, it entered a mixture of sand and boulders similar to that we had previously encountered, and after attaining a depth of 72 feet further progress became impossible. We left the island on the 30th of July, and on reaching Fiji had the mortification to learn that we had passed on the way a ship coming to our assistance with a fresh supply of machinery, which our friends in Sydney had promptly despatched on hearing of our difficulties.

Our attempt to penetrate the reef had proved a failure, but it was not wholly without result. It had revealed the nature of the material with which any subsequent attempts at boring would have to contend, and it had added one more surprise to the history of atolls, for no one had suspected that for a depth of over 100 feet the island would be found to consist of more sand than coral, or, in other words, that the organisms which play the chief part in the construction of a coral reef are not corals, but foraminifera : 


\section{CONICAL, FORM OF 'THE A'TOLL 117}

The expedition had other objects in view besides boring. The next in importance was the investigation of the atoll by sounding. This was accomplished with complete success by Captain Field. Other atolls had been sounded before, but never before had an atoll been sounded with such accuracy and completeness as was Funafuti on this occasion. The form of the floor of the lagoon was made more exactly known than that of most lakes in the British Isles. The slopes of the flanks of the atoll were determined in four different directions,

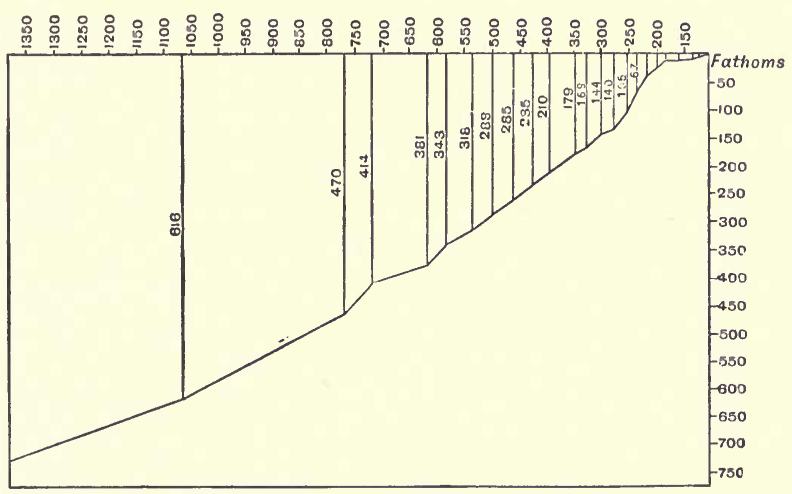

FIG. 34.-Submarine profile of western side of atoll, drawn to true scale.

approximately at right angles to each other and running about N., S., E., and W. A study of these enables us to frame a clear picture of the general form of the atoll. It is a conical mountain with an oval base situated at a depth of about 2,000 fathoms, measuring 30 miles in length by 28 in breadth. It rises at first with a very gentle slope, but gradually grows steeper as it ascends (Fig. 34), till at a depth of 400 or 500 fathoms it begins to present precipitous faces, and above 130 to 140 fathoms is crowned by the almost vertical cliffs of Chamisso's 
" table-mountain," which, as he rightly divined, is of a similar nature from base to summit. All this is coral reef; how much more may be so it is impossible in the present state of our knowledge to say.

The general feeling of disappointment with which our failure to bore through the reef was received was fully shared by our friends in Sydney. Determined not to be put off with a first rebuff they promptly commenced to make arrangements for a second attempt, and last year (1897) an expedition again left Sydney for Funafuti, this time under the direction of Professor Edgeworth David, of the University of Sydney. Under his leadership the boring proved a complete success. The reef was penetrated to a depth of 697 feet, or 116 fathoms. Thus Darwin's wish has now been more than satisfied. The core brought up was sent over to this country, and is now in the hands of Professor Judd for investigation. Till he has completed his report it would be premature to enter into details, but from a general examination, made without the aid of the microscope, I think I may fairly venture to say this much, that the material brought up from the boring, and of which the reef is composed, presents much the same general character throughout, and so far supports Darwin's theory; that layers of chalky ooze, such as on Sir John Murray's hypothesis we might have expected to find in the lower parts, are conspicuously absent; and finally, that it presents no trace of volcanic material.

On whatever side judgment may ultimately be given in this question, the thanks of the scientific world must undoubtedly be conceded to Sir John Murray for having disturbed a decided opinion from its slumber, for having awakened a fresh interest in Darwin's theory, and in thus leading to renewed investigation, which is both adding to our knowledge and suggesting fresh inquiry. 


\section{A SUCCESSFUL BORING}

The sand showing little trace of consolidation which was noticed in our boring down to 100 feet is maintained . in Professor David's boring down to about 100 fathoms, and it is not a little remarkable that material so loosely aggregated should be able to sustain itself in slopes of as much as $80^{\circ}$, such as characterise the flanks of Funafuti. It is important, however, to observe that none of the borings yet made have been sunk through the true growing substance of the atoll. They have commenced on the lagoon side of the true coral-reef, and the deeper they have descended, the more remote they have become from the ocean flanks. The possibility exists, and should not be overlooked, that a great part of the material passed through in the bore-holes represents deposits of the lagoon and of the fragmentary débris driven towards it by the breakers.

It will be observed that Professor David's bore-hole does not traverse the whole thickness of the table-mountain; judging from the soundings, it would have to descend 20 or 30 fathoms deeper to do this, and it would seem likely that the material obtained from this last 20 or 30 fathoms might surpass in interest all the rest. Our friends in Sydney fully appreciate this, and are so bent on probing this question to the utmost, that they have already despatched, at great pecuniary risk, an expedition to make a third attempt on Funafuti, and this time to carry the bore-hole right through the table-mountain.

The boring party is at this moment at work on the island, and before many weeks have elapsed we may expect to receive tidings of their success. A great stride will then have been taken towards a final determination of the long-standing controversy on the origin of atolls. *

* The critical point has been passed. According to the news from Funafuti (Sept. 6, 1898), the boring attained a depth of 987 feet, or 147 feet below the base of the steepest cliff. The 
We eagerly await the result, which will inform us whether these central oceanic islands are ancient remains of land which nave plunged beneath the sea and are renewing their youth, or whether they are among the latest products of our planet-aspiring mountains which have scarcely yet succeeded in their struggle upward to the light of day; whether they are, as has been said, "a garland laid by the hand of Nature on the tomb of a sunken island," or whether they may not be a wreath of victory crowning a youthful summit on its first conquest of the main.

material passed through was coral limestone. It is of interest to observe that, soon after passing the bottom of Professor David's borehole, loose unconsolidated deposits ceased to be encountered, and the drill passed with comparative facility through a hard limestone containing numerous well-preserved corals. A crux of all theories of atolls is the lagoon. On Darwin's theory its explanation follows naturally from the fundamental assumption. Sir John Murray has to supplement his hypothesis by a separate explanation, and proposes to account for the lagoon by solution. In this connection the success which has attended an attempt of the present expedition to bore into the bed of the lagoon is most welcome. The boring was made from the deck of H.M.S. Porpoise, commanded by Captain Sturdee, and after passing through 101 feet of water, sank 144 feet into the deposits of the floor. The first 80 feet were found to consist of the calcareous alga Halimeda mixed with shells; the remaining 64 feet of the same material, mingled with coral gravel. This alga is universally distributed over the floor of the lagoon, as proved by an examination of the material obtained by Captain Field in sounding. 


\section{V \\ FUNAFUTI: A SEQUEL}

SIX years have elapsed since the preceding lecture was S delivered; during this interval a number of distinguished investigators have devoted themselves to a study of the observations and material amassed in the course of three expeditions to the island, and at length we are in possession of a full report of their labours.*

Let us cast a brief glance over this report, and endeavour to discover the conclusion towards which the facts tend. $\dagger$ The story of the struggle with obstacles and acci-

* "The Atoll of Funafuti: Borings into a Coral Reef and the Results, being the Report of the Coral Reef Committee of the Royal Society," London, 1904, one vol. 4to, pages xiv and 428, and one vol. plates, edited by Rev. Prof. T. G. Bonney, D.Sc., F.R.S.

+ I take this opportunity of quoting Professor David's enumeration of the causes which led to the failure of the first attempt at boring. He says: "(1) The supply of lining pipes, with which the expedition was provided, was insufficient. (2) No steel shoes to screw on to the leading end of the lining pipes were sent. (3) No under reamers constructed to project a strong stream of water from their under surface were sent." Professor David adds : "Our experience of 1897 showed that it was impossible with a boring apparatus wanting in the above respects to have bored deeper than was done. In view of our 1897 experience we were surprised that it was found possible to bore, without an under reamer, to a depth of over 100 feet in the reef rock of Funafuti, as was done in the expedition of 1896 " (op. cit., p. 41) For this frank explanation so generously volunteered I offer my most grateful acknowledgments. 
dents encountered in making the first of the successful borings is a veritable epic.* This contest between the powers of Nature and human enterprise was waged strenuously on both sides, and for a long time with varying success, victory inclining sometimes in one direction, sometimes in the other; and at one time, owing to a failure on the part of the machinery, the evil genii seemed to have got the upper hand, but at this crisis a cog-wheel, which had been accidentally left behind by the previous expedition, and had since lain buried at the foot of some cocoanut trees as a charm to fertilise the ground, was dug up by my old friend Tili, and this, when put to the purpose for which it had been designed, gave splendid proof of its magic powers. The mastery of the difficulty accomplished by its means seems to have been the turningpoint in the campaign, and after this the boring steadily advanced. When Professor David left the island to return to Sydney its success was assured. It had then been sunk 537 feet. Under Mr. Sweet, who next took command, it was deepened to 698 feet, and finally, as a result of a third expedition, under the leadership of Mr. A. E. Finckh, it attained the depth of $1,114.5$ feet, or $18.5 \cdot 75$ fathoms, and was then abandoned.

For the first 637 feet the boring passed through similar material to that encountered in the first boring, and loosely cemented sand and gravel was in such excess that the total quantity of solid core obtained amounted only to 66 feet. The rock then changed in character, it became soft, and, though still porous, less incoherent, so that boring was comparatively easy. This continued down to 748 feet, when the rock again changed in character, became hard and compact, though still cavernous enough to produce a very destructive effect on the diamonds used in boring.

$$
\text { * Op. cit., pp. 40-60. }
$$




\section{UNIFORMI'TY OF COMPOSITION 123}

The essential nature of the rock, or the organic remains of which it is composed, was found to be the same throughout; the soft material met with between 637 and 748 feet, which superficially resembles chalk, and the hard rock from 748 feet to the bottom, not differing in this respect from the rest, the hardness in the one case being due to cementation by crystalline deposit, and the softness in the other to decomposition.

The chemical investigation of the core by Dr. C. G. Cullis and Dr. E. W. Skeats prove it to possess a remarkable purity. It consists almost entirely of the carbonates of lime and magnesia; of material insoluble in acids there was no more than from 0.001 to 0.083 per cent., and of calcium phosphate from $0 \cdot 136$ to $0 \cdot 288$ per cent. There is thus a remarkable absence of all such sediments as may be derived from ordinary soil (terrigenous sediment). The two carbonates were present in various proportions, from the surface down to 637 feet (except between 15 and 20 feet) the magnesium carbonate amounts to only 1 to 5 per cent., but from this depth to the bottom the quantity is much greater, for the most part as much as 40 per cent. In the exceptional case referred to, between 15 and 20 feet, the amount is 16 per cent.

A vast quantity of other important work was carried on by the members of the second and third expeditions, which included Professor David, and Messrs. Sweet, Halligan, and Finckh, but for an account of this the original report may be consulted. We must now content ourselves with such citations as are necessary to our argument.

The material obtained from the boring, together with other specimens which might be expected to throw light on the problem of the formation of the reef, were sent to Professor Judd in London, who had the solid core prepared for study by slicing it longitudinally through 
the middle. Whenever necessary thin, transparent slices were obtained from it for examination under the microscope. No less than four hundred of these slices were made and afterwards carefully investigated. All this material is now deposited in the British Museum, and is open to the examination of any competent observer who may desire to see it. Dr. Hinde, especially distinguished for his studies of such organisms as contribute to the formation of coral reefs and other oceanic formations, and well known for his accuracy in observation and cautious judgment, was good enough to undertake the investigation of the cores, and devoted a not inconsiderable portion of his life to the accomplishment of this work. It is on the statements of this observer that we shall mainly rely.

The editor of the report has carefully abstained from "pointing a moral "; he contents himself with the remark that "the composition, zoological and chemical, of an atoll down to a depth of 1,114 feet has now for the first time been made known." *

The question is thus left open to discussion. Some may think that the facts speak so plainly for themselves as to stand in no need of an interpreter. This may indeed be the case, but a conclusion admitted by one person may be contested by another; and so, without further apology, I shall venture to point out the consequences which, to my mind, seem to follow naturally from the observations.

I do this the more readily because science shares, in common with all subjects which admit of exact proof, an exemption from the bitterness of controversy. When the prospect of proof seems to lie remote there may be a danger of yielding to our tastes or prepossessions, but when it is both attainable and not far out of reach, it necessarily imposes a wholesome restraint, so that neither * op. cit., p. xiii. 
on one side nor the other is a friendly discussion likely to degenerate into strife.

Such discussions are of the highest value, for they render possible a differentiation and consequent saving of labour; since one of the severest tasks which presents itself to the scientific thinker is the invention of arguments against his own position, in which he puts his imagination to work as an adrocatus diaboli. Where thinkers are ranged on opposite sides this self-imposed labour may be often spared, since antagonists may usually be trusted to perform it for one another, and all the more efficiently for having their heart in the work.

We may turn then, first, to the suggestion, which we owe to Professor Alexander Agassiz, who has himself added immensely to our knowledge of coral reefs, particularly by the two works which have appeared during the present year.* This is to the effect that the limestone passed through by the boring in Funafuti may not all belong to a continuous series of deposits, but may consist of an upper part formed during the existing period resting upon a lower part of much greater antiquity, indeed of Tertiary age. Such Tertiary limestones are well known; they are said to occur in the Pacific at various localities, Fiji, Tonga, and elsewhere, and present characters which, fortunately for the point in discussion, may be readily recognised, so that if they should be present in the Funafuti core there would be little difficulty in identifying them. We turn, therefore, to Dr. Hinde's report, and we shall find no indication that might be supposed to point in this direction, but much to the contrary, and in the summary which

* "The Coral Reefs of the Tropical Pacific," by Alexander Agassiz, one vol. text, pp. xxxiii and 410 , and 3 vols. plates; also "The Coral Reefs of the Maldives," one vol., 4to, pp. xxv and 168, and one vol. plates, 1903. 
follows his observations of detail we find the following*: "The corals recognised belong to twenty-eight genera; with one exception they are present in the main boring. They all belong to well-known reef-building forms, and most of them still exist on the reef and in the lagoon of Funafuti. Of the foraminifera forty-one genera have been determined, thirty-five of which occur in the main boring. Only seven of these genera are of significance as rock formers, and, like the corals, they are still flourishing on the present reef or in the lagoon.

"Although there are considerable differences in the character of the rock in different parts of the main boring, the evidence appears to me to indicate a continuous formation of reef rock, without any abrupt break, from the depth of 1,114 feet to the surface."

This question is also dealt with by Professor Judd, who writes: "But although nearly 400 feet of core from the bottom of the Funafuti core were very carefully scrutinised by both Mr. F. Chapman and Dr. Hinde, for the purpose of determining the presence of Tertiary limestone, not a trace of these Tertiary organisms could be detected. On the contrary, as the reports show, the same recent species of foraminifera, corals, and other organisms occur from the top to the bottom of the series of cores. On this point the evidence appears to be conclusive, and we are justified in stating that no basis of old Tertiary limestone was reached in the deep boring at Funafuti." † This seems fairly conclusive, and we next turn to another suggestion, also due to Professor A. Agassiz.

This rests on the fact that a reef may extend itself into depths greater than those of coral-growth by building on its own débris; for in the case of a reef seated on a gentlysloping sea-floor, fragments broken from it by the waves will accumulate in a talus at its foot, and thus raise the * Report, p. 334. † Op. cit., p. 175. 
sea-floor till it passes above the limit of, say, 45 fathoms. It may then serve as a foundation for fresh reef-forming growth; this again furnishes débris to form another talus, on which once more new reef will be formed, and so on, the reef constantly extending seawards over fragments of its dead self.

The process is naturally a slow one, and the steep slopes now existing around the Funafuti atoll (Fig. 34) do not impress us as offering conditions the most favourable to it. But to argue from probabilities would be a long way round when a short cut is provided by the evidence of the core. This is threefold. In the first place, if the suggested explanation be correct, the material of the core must be of the nature of talus from a depth of between 10 and 45 fathoms down to the bottom of 188 fathoms. But between a depth of 45 and 188 fathoms organisms of a different kind to those which furnish the reef-material are found to flourish, and these would contribute their quota to the general mass; thus the talus would not possess the same assemblage of organisms as the true reef. A difference would exist which should be discoverable in the material obtained from the boring; but in spite of careful search not the least sign of such a difference could be detected. Professor Judd writes: "Now, had any portion of the rock of the core consisted of material fallen from above, and resting at lower points on the ocean slope, we should expect to find an admixture of these shallow-water forms that had fallen with others belonging to a greater depth, which had grown on and around the fallen fragments. But distinct as are many of the forms of life which occur living on the ocean face of the reef between 100 and 200 fathoms, not a trace of these was found in the lower portions of the Funafuti core. Dr. Hinde's carefully-drawn-up lists show that from top to bottom the same organisms occur, sometimes 
plants, sometimes foraminifera, and sometimes corals predominating; but in the whole depth bored the same genera and species of these various groups of organisms take their part in building up the mass." *

In the next place, the accumulation of débris in a talus would result in the formation of a rude kind of stratification, in which the successive layers of débris would be found to slope at a somewhat steep angle, corresponding to the angle of repose for such material, and this would be rendered all the more evident by the occasional intercalation of layers of oceanic ooze. But here again the core answers for itself in no uncertain terms. Professor Judd enters rather fully into this important point, as follows: "The question of the existence of anything like stratification . . was one to which special attention was directed. Professor David, whose notes on the specimens were of great service to us, called attention to several cores, on the outside of which obscure markings suggesting stratification, usually with a very steep dip, were noticed by him. These cores were carefully cut at right angles to the supposed dipping laminæ, and in all cases the appearance proved to be fallacious. . . . The conclusion at which we arrived was that nowhere could a stratification, such as might be expected in a talusformation, be found, but only such irregular accumulation of detrital materials as takes place between and around the corals ; and these appearances were presented at many points, from the top to the bottom of the bore-hole, whenever consolidated rock could be examined."

Lastly, in the case of reef-growth over a talus, we should expect to find a definite change in character on passing from one mode of accumulation to the other, i.e., at some depth between 10 and 45 fathoms. But of this, again, the boring shows not the least trace; from the * Report, p. 174. 


\section{LIMI'T OF CORAI GROW'TH 129}

surface down to about 100 fathoms the material obtained from the boring belongs to a continuous series, showing the same mode of arrangement throughout.

This completes the case for the core, but there still remains another class of objections, which demands our attention. How far is the generally accepted limit of growth of reef-forming organisms to be regarded as exactly known? The difficulties in the way of determining this limit greatly impressed me during my residence on Funafuti, so that I then wrote: "Not till I had obtained a close acquaintance with the difficulties of dredging on the steep sides of an atoll did I recognise on how frail a basis our accepted conclusions rest. It is a task difficult enough to get up corals from the lagoon in comparatively shallow water; from the sides of the reef it is well-nigh impossible. To obtain dead corals from great depths proves very little; living corals are generally found with dead associates, and the latter are the more readily detached and brought to the surface."* Neither difficulties nor dangers, however, seem to have had any meaning for Professor David and his colleagues, Messrs. G. H. Halligan and A. E. Finckh. Armed with various ingenious devices they ventured themselves in a frail boat on the outer waters of the reef and brought up from its face all that is essential for us to know. The results are completely in accord with those previously obtained, and have entirely dispelled any misgivings I may have once entertained.

Thus the following inferences appear to have been established by the investigation of the atoll :-

1. The limit of reef-building growth does not exceed, if indeed it reaches, a depth of 45 fathoms below the level of the sea.

* Proc. Roy. Soc., vol. 1x. p. 512, 1897. 
2. True reef-rock was passed through in the boring from the surface down to 185 fathoms.

3. No rock, other than reef-rock, was encountered, and in particular no Tertiary limestone.

4. The structures met with were such as to exclude the notion that the reef had grown upwards on talus of its own débris.

From these inferences, but one conclusion appears possible, and we must admit that this atoll at least has been formed during a subsidence of the foundation on which it rests, a subsidence which must amount at least to 877 feet.

An unexpected confirmation of this result has lately been afforded by the investigations of Dr. Skeats into the process of dolomitisation of coral limestones. It has already been pointed out that from a little more than 100 fathoms down to the bottom of the bore-hole the core contains as much as 40 per cent. of magnesium carbonate. When first formed the limestone was comparatively free from this constituent, which has been subsequently introduced, and Dr. Skeats has shown that the replacement is most readily accomplished at depths of from 1 to 25 fathoms; it would, therefore, seem to follow that the magnesian limestone at the bottom of the bore-hole or now at a depth of over 185 fathoms, originally stood within the 25 -fathom level, i.e., the limit of coral growth, at the time dolomitisation took place.

Now that we have completed our discussion of the most important results, we may pass to others, which, though subsidiary, are still of great interest.

We have already alluded to the boring made from the bows of H.M.S. Porpoise, by Commander F. C. D. Sturdee, R.N., and Mr. G. H. Halligan.* This was sunk through 110 feet of water and 245 feet of deposits, in all * P. 120 


\section{LAGOON DEPOSI'TS}

346 feet, or 57 fathoms from the surface. The calcareous alga, Halimeda opuntia, forms the greater part of the first 60 feet of material passed through, and is then replaced by a loosely compacted coral rock, which continues down to 245 feet, with occasional intercalations of solid coral reef. The greater part of the floor of the lagoon is at present covered by Halimeda, growing at an unexpectedly rapid rate; a fortunate observation showed that in one case a mass of this alga, 3 inches in thickness and the same in height, was formed in the course of six weeks. The layer, 60 feet in thickness, below the living superficial film, shows us what it has been able to accomplish in the past, and we are reminded by it of the mode of growth of moss in a peat bog. The hypo. thesis, that the lagoon of an atoll owes its existence to solution, had previously been shown to be inconsistent with observation by the discovery that soundings within a lagoon made at sufficiently long intervals prove a gradual filling up; and in the living film of Halimeda we now recognise a constructive agent more than competent to compete with the destructive effects of solvent water.

It is a far cry from the low islands of the Pacific Ocean to the mountains of the Tyrol, yet that these noble dolomite peaks once formed parts of ancient atolls, washed by the warm waves of a vanished sea, is an idea which gains in probability with the progress of research. It was first suggested by Baron von Richthofen, and subsequently maintained by von Mojsisoviks in his great work, "Die Dolomiten Riffe von Tirol." Subsequently it was shown by Miss Ogilvie (Mrs. Gordon) that the form of these mountain masses was by no means original, but due to subsequent movements of the earth's crust followed by extensive denudation. It was also pointed out that calcareous algæ (Gyroporella) contribute largely to their 
composition, and at one time this fact was supposed to militate against a belief in their having once been atolls; but we now perceive that, so far from being inconsistent, it is in complete harmony with such an origin.

Quite recently fresh evidence has been given in favour of Richthofen's view by Dr. Skeats; we have already mentioned that the limestone of Funafuti is remarkably free from impurity, consisting almost entirely of calcium and magnesium carbonates; it is thus distinguished from all other organic limestones known to us. Hence it occurred to Dr. Skeats to examine the limestones of the Tyrol to determine how far they resemble or differ from coral limestone in this respect. His results have now (December 7, 1904) been communicated to the Geological Society of London.* They show that an extremely close resemblance in chemical composition exists between the two limestones, and the argument in favour of the dolomite peaks of Tyrol having once formed coral reefs acquires fresh confirmation.

We have thus reason to suppose that the mountains of Tyrol, which now rise to a height of 10,000 feet above the sea, once lay submerged beneath it, bearing above their summits shallow water lagoons; while on the other hand the atolls of the Pacific seem to crown the summits of mountains, which at one time rose to an unknown height above its waters, and the fancy often entertained that a large tract of land once rose out of the bosom of this mightest of oceans gains, as research proceeds, more and more an appearance of reality.

* Since published in full, Quart. Journ. Geol. Soc., vol. lxi. p. 97. 


\section{CHAPTER VI}

\section{THE ORIGIN AND FORMATION OF FIINTS}

HLINT seems to have been one of the first stones that mankind turned to useful account; indeed, the weapons fashioned from it afford the earliest testimony we possess of the existence of man, who is thus presented to us at his first appearance upon the scene, already distinguished as a tool-making animal. From remote times it furnished the readiest means of obtaining fire. Struck against marcasite, a form of iron sulphide which occurs in association with flint, it produces a shower of sparks, which were at first possibly a source of mere general wonderment, till some Prometheus showed how to capture the transient fire and domesticate it.

In virtue of its spark-producing power, flint again entered into service as a weapon, contributing to the discharging mechanism of a gun: whence a brief revival of flint-chipping, which became an important industry, and continued to flourish at Brandon, in Suffolk, long after the introduction of percussion caps ; for, until quite recently, we found a use for our discarded flint-locks, shipping them, along with other blessings of civilisation, to supply the eager natives of Africa.

Flint makes a good building-stone, much used in 


\section{THE FORMA'TION OF FLIN'TS}

places where it abounds; even churches are built of it. It enters into the composition of some kinds of china and earthenware; but in flint-glass, needless to remark, there is no flint.

In London and many towns in the east of England we are most familiar with flint as the pebbles and gravel which form our gravel walks. Let us start on our investigation with this material. Its warm orange colour, ill-deserving of Thackeray's jest, has nothing to do with the flint, but is due to the presence of an iron ochre, which may be easily removed, for the most part, by washing. Examining a clean pebble, we observe its round, smooth form-an indication of transport by water. In some cases we shall find the surface marked all over by small concentric circles, the outlines of cracks which extend deeper into the stone. These are the result of blows, given and taken as it was hurried along by stormy water.

If we proceed to the pit whence the gravel was dug out we shall find it arranged in layers, generally of very irregular thickness, and of all degrees of fineness or coarseness. As a rule, the gravel-pits are excavated in shelving banks or terraces which run with the valley, and at various heights above the level of the existing river; some form its actual banks, others are found at increasing elevations of $20,40,100$, or 300 feet or more above it. These terraces evidently mark successive stages in the excavation of the valley. That which is now 100 feet above the river contributed at the time of its deposition to form the river bed. The most ancient flint implements which are found in our islands have been dug out from the gravels of this ledge, whence we may conclude that man was contemporaneous with its formation, which dates back to the glacial period. The terraces extending along the 


\section{SOURCE OF FLIN'T PEBBLES 135}

valley at greater heights than 100 feet have not afforded implements of human workmanship.

The flint pebbles in the gravel are evidently not in their original home; they have been rolled down by a river, and if we would trace them to their source we must follow them up stream. If we ascend the Thames or its tributaries to the high ground which bounds a part of its basin-as, for instance, the Chiltern Hills, or the

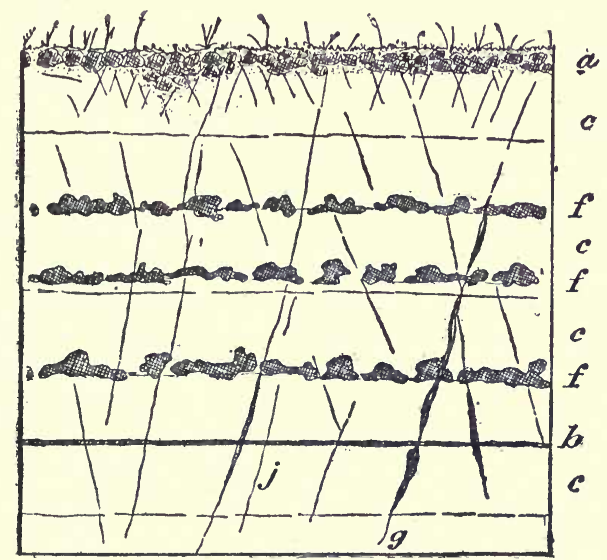

FIG. 35.-Section in a Chalk Quarry. a. Soil cumbered with flints. $b$. A thin bed of flint. $c$. Chalk. $f$. Beds of nodular flints. $j$. Joints. $g$. Joint filled with flint.

North Downs-we shall view with surprise the vast quantity of flint, no longer in the form of pebbles, which lies scattered over a wide expanse of soil. Let us now enter one of the numerous quarries which are dotted about every here and there in the chalk hills, and we shall encounter the object of our search. The chalk (Fig. 35) itself lies in beds of great thickness, which are defined by more or less horizontal lines, generally sloping or dipping towards the south-east in the Chilterns, but to 


\section{6 'THE FORMA'TION OF FLIN'TS}

the north in the North Downs and the south in the South Downs. Besides the planes of separation between the beds indicated by these lines, we shall discover others, crossing the beds, often alnıost at right angles. These are cracks or joints formed, probably, as a consequence of the movement which raised the chalk from the bottom of the sea, where it was originally formed, into dry land. Running parallel with the bedding planes are long rows of nodules, of various size, and irregular, often grotesque and fantastic, form. These are the flints, as a tap with the hammer will disclose. Besides these discontinuous or nodular layers we shall find some which form thin, fairly regular sheets, also running parallel with the bedding, as well as others which cross it, filling the joints, or coating their sides. There is even a fourth form in which flint may occur-that is, as large, hollow, cylindrical masses, sometimes of great size, and not infrequently arranged one over the other in a vertical series, like a rudely-jointed column, which stands at right-angles to the bedding. These are known as pot-stones, or paramoudras (Fig. 36). The etymology of the last word is not clear. It is said that when Dean Buckland came across these objects in Antrim he asked his guide what name they went by. The Irishman, who had heard the Dean calling stones by strange names, was equal to the occasion, and invented "paramoudra" without a moment's hesitation.

In tracing the flint into association with the chalk, its natural home, we have made a great advance in our inquiry, for with the circumstances under which chalk was formed we are now generally familiar, and a knowledge of these cannot fail to throw some light on the origin of flint.

Chalk consists of the calcareous remains of marine animals, most of them very minute, and it is dis- 
tinguished by a very remarkable purity, especially in its uppermost flint-bearing beds, which are almost entirely free from admixture with terrigenous sediment. This of itself would suffice to show that it must have accumulated in a clear sea, uncontaminated by muddy water, and seldom visited by showers of volcanic ash. Its nearest equivalent at the present day is the grey ooze of the deep sea, on which so much light has been thrown

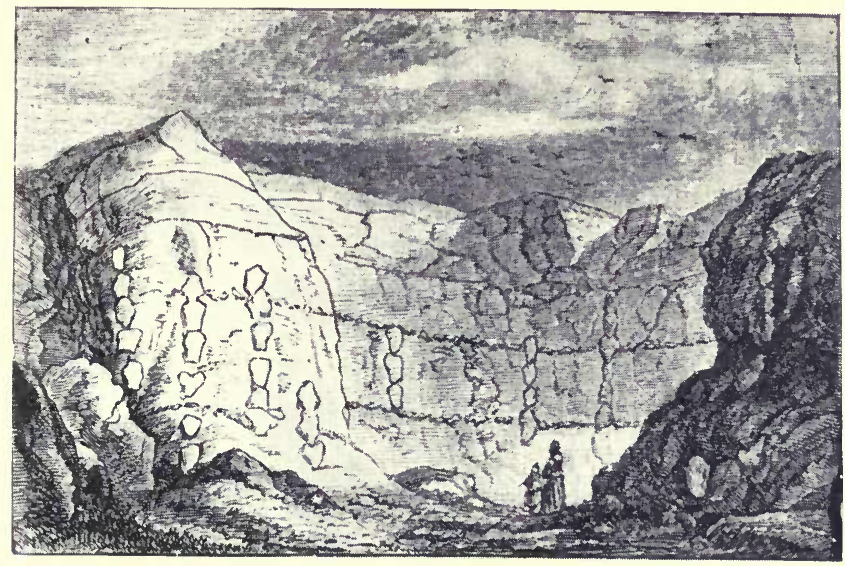

FIG. 36.-View of a Chalk Pit at Horstead, near Norwich, showing the position of the paramoudra. From a drawing by Mrs. Gunn. Taken from Lyell's " Student's Elements of Geology," with kind permission of Messrs. A. \& J. Murray.

by the dredgings of the Challenger. Both chalk and grey ooze consist to a large extent of coccoliths (Fig. 37), extremely minute discs or rings of carbonate of lime, which were for a long time a standing puzzle to the biologist. There was a general disposition at one time to regard them as the skeleton of some simple form of calcareous alga; but quite recently they have been definitely shown by Lohmann to belong to a lowly 


\section{8 'THE FORMATION OF FLIN'T}

animal group known as the flagellate Infusoria.* Foraminifera, fragments of shells, and other calcareous débris make up the remainder of the calcareous constituents in the case both of chalk and grey ooze. With so many characters in common, we might fairly expect to find flints also in both; but in this we should be disappointed. Flints have never yet been found in the grey ooze or in any other deposits of the existing sea. We will turn aside, therefore, for a short space to investigate the flints themselves a little more closely.

If we break open a flint we find that it is composed, for the most part, of a hard, black substance-so hard that it cannot be scratched by a knife-and if the sharp edges of a broken flint and a blade of steel are struck together, minute splinters of the steel fly off, and some of these are heated by the blow to such a pitch that they take fire and burn in the air. The high temperature is due to the fact that in striking sharp edges together the energy of the blow is concentrated over a very small area, and so likewise is the resulting heat. This is the philosophy of a "strike-a-light." The substance of the flint is very homogeneous, with no pronounced tendency to break in one direction rather than another, resembling glass in this respect, so that it gives under a blow with a conchoidal fracture-i.e., with an undulating surface. If struck full face by the corner of a hammer, a cone of fracture extends into the mass, or a number of cones surrounding the same axis. These are revealed as concentric circles on the surface of a pebble which has been battered in a stream. It is the homogeneous nature of the flint, combined with its great hardness, which bas rendered it so serviceable in the fabrication of implements. Flint, again, is highly insoluble. Rain-water

* H. Lohmann, "Die Coccolithophoridæ, Arch. f. Protistenkunde," Bd. I., 1902, p. 89. 


\section{COMPOSI'TION OF FLIN'T}

acts but very slowly upon it; hence its enduring quality as a building material. These properties are largely

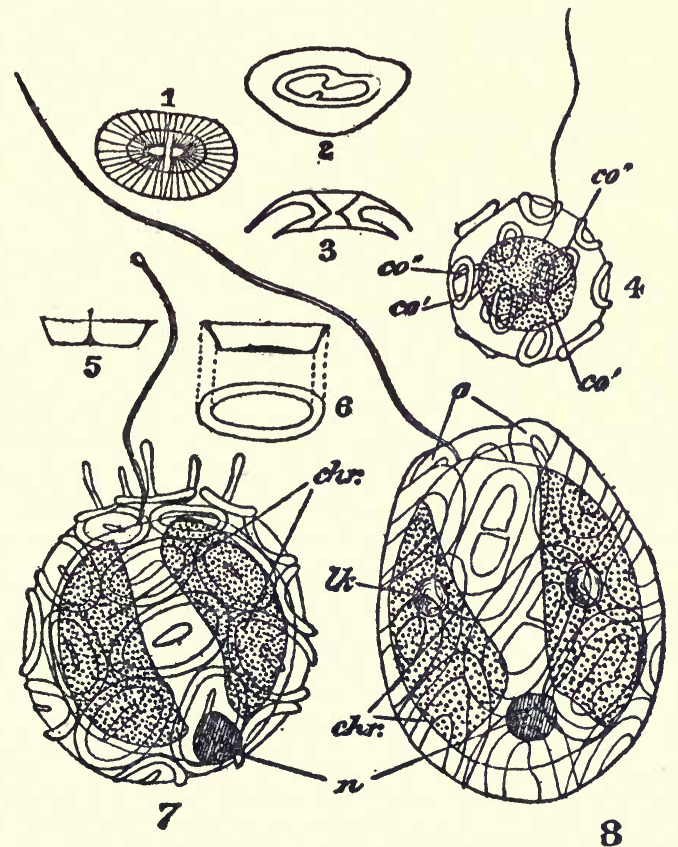

FIG. 37.-Coccoliths, after H. Lohmann. 1. Coccolithophora pelagica, Wallich: seen en face. 2 and 3. Coccolithophora wallichi, Lohmann: 2 seen en face, 3 in optical section, longitudinal. 4. Pontosphara huxleyi, Lohmann, a single complete individual. $\mathrm{co}^{\prime}$. Outer coccoliths. $c o^{\prime \prime}$. Inner coccoliths. 5 and 6. Pontosphcera hackeli, Lohmann, coccoliths. 7. Syracosphera pulchra, Lohmann, complete individual. chr. Chromatophore. 8. Coccolithophora wallichi, complete individual. $n$. The nucleus. o. Opening in the cyst. $l k$. Refractile body. All figures magnified 2,000 diameters, except Figs. 5 and 6 , which are more highly magnified.

dependent on its chemical composition. Flint, unlike chalk, does not consist of carbonate of lime, but of silica, which is known to us in another form as rock- 


\section{THE FORMATION OF FLIN'TS}

crystal, or Bristol diamonds. Like, these, flint is truly crystalline, but the crystals of which it consists are very minute, and crowded together in confusion, so that they do not present crystal outlines. When a flint nodule is hollow inside, as often happens, the silica sometimes takes advantage of elbow-room, and, being free to develop, assumes the characteristic form of rock-crystal.

If we extract a flint nodule from its place in the chalk, and clean its surface of all adherent material, as by washing, we shall find that its exterior is white and porous, like the chalk itself. We may remove the last traces of chalk by placing the flint in acid-hydrochloric acid for choice-but on washing again with water and drying, the surface is still white as before. On breaking the nodule open we shall find, as a rule, that the whiteness of the exterior is confined to a thin superficial film, coating the internal mass of black flint, though this itself is not uniformly black all through, but spotted here and there with greyish blotches, some whiter, some darker, with every degree of transition between the lightest-coloured and the black flint. So much is generally true, but the differences in detail which distinguish nodules from different localities, or even from one and the same bed, are many and great (Fig. 38). It is not at all uncommon to find nodules which are hollow within, the enclosed cavity being filled with some other material. Frequently this is a white, chalky powder, which we shall examine later in detail; sometimes it is the skeleton of a sponge, and in this case an interval may occur between the exterior of the skeleton and the surrounding envelope of flint. The interval may be filled with a chalky powder of the same nature as that just mentioned, or it may be empty and lined with projecting crystals of quartz. Again, in some cases there is no interval, but a mass of greyish-white, or even black, 


\section{VARIOUS FORMS OF FLIN'TS 141}

flint obliterates the cavity and pervades the canals and interstices of the skeleton. When the flint encloses a
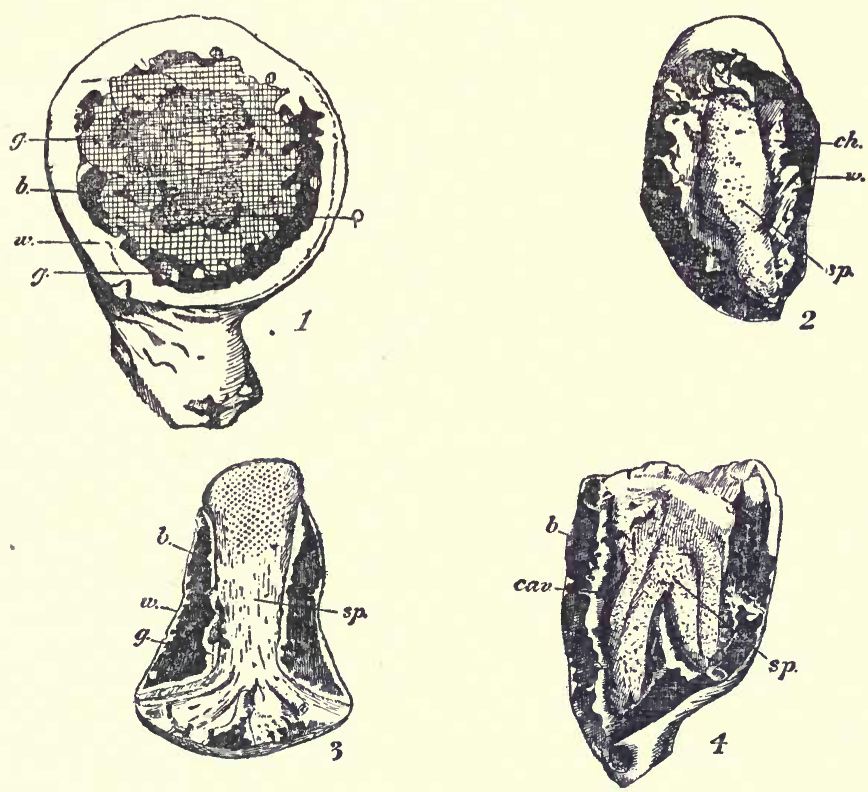

FiG. 38.-Examples of Flints, broken open to show the structure.

1. In this the black flint, $b$, has been converted into white flint, $w$, towards the exterior by weathering. Towards the interior it passes into incompletely silicified chalk or grey flint, $g$. This is succeeded by a cavity, further towards the middle, coated with crystals of quartz, $q$.

2. Here the black flint is coated with a very thin film of white flint. It includes the skeleton of a sponge, $s p$, from which it it is separated by a layer of chalk, $c h$.

3. This flint also includes a sponge, one of the Ventriculites, which branches below into spreading roots, a necessary provision for support in the soft sea-ooze.

4. Is similar, but the sponge is of a different kind, and separated from the surrounding flint by a cavity which, no doubt, was once filled with chalk.

sponge skeleton it sometimes faithtully follows the form of the latter, so that a glance at the exterior of the nodule is sufficient to show that there is a sponge inside; 


\section{2 'THE FORMA'TION OF FLIN'TS}

sometimes, on the contrary, the flint takes its own form, uninfluenced, apparently, by that of the sponge. Occasionally the flint fills partly or wholly the test of a sea-urchin, sometimes exuding, as it were, from the natural openings of this test, and sometimes more or less completely enveloping it. Shells and fragments of shells, derived from mussels, such as Inoceramus, or lampshells, such as Terebratula, retaining their calcareous composition, are not infrequently included in a nodule.

The whiteness of the outer layer is to be explained in the same way as the whiteness of snow. The minute grains of which it consists are individually transparent and colourless, but, owing to their extreme minuteness and the immense number of little spaces between them, they offer an infinite number of reflecting surfaces within a slight thickness, and thus scatter the light that falls upon them in all directions. The black flint is transparent in very thin slices, and almost colourless, or only slightly tinged with a faint brown colour, due to the presence of a carbonaceous pigment, the last residuum of the living protoplasm once present in the chalk. Light penetrates the flint for a considerable distance, but is absorbed by the brown pigment. The quantity of pigment present differs in different cases, and this partly explains why some black flints are blacker than others.

The association of the remains of sponges with flints was noticed as early as the middle of the eighteenth century, and was especially emphasised some fifty or sixty years ago by Bowerbank, who was led by it to the conclusion that flints are petrified sponges, and though this cannot now be seriously maintained, yet it will surprise no one who is familiar with the forms of these objects, which are sometimes so singularly organic in appearance as to seem purposely designed to deceive.

It is scarcely necessary to remark that the sponges 


\section{SILICEOUS SPONGES}

found along with flints are of a very different nature to the familiar bath-sponge. That, in the form we are acquainted with it, is the skeleton of a particular species which lives in the Mediterranean and the Caribbean Sea. It is formed of a network of delicate elastic horny fibres, and to their elasticity it owes its wonderful softness. But the sponges we are concerned with possess, like the great majority of their class, a skeleton formed of hard mineral matter, often of so harsh a texture that no one would think of applying it to the skin, unless as a counter-irritant. The beautiful Venus's flower-basket (Euplectella) is an example of one of these sponges (Fig. 39), and the nearest familiar representative of one of the forms (Ventriculites) sometimes found associated with flints. The living Euplectella is fished up by the Japanese from the deep sea; it is considered by them a very appropriate wedding present, partly because it rather commonly contains a pair of crab-like inhabitants, which, being caged in so that there is no chance of escape, are supposed to symbolise a state of conjugal felicity.

The mineral matter forming the skeleton of this group of sponges is siliceous; it consists of silica, the same material which forms the substance of flint, but in this case in chemical combination with water, so that it is known to the chemist as as silica hydrate or silicic acid, and may be represented by the symbols $\mathrm{Si}_{5} \mathrm{O}_{\mathrm{Io}} \mathrm{H}_{2} \mathrm{O}$; it is familiar to all of us in another form as opal. Opal plays a large part in the organic world, the skeletons of those lowly plants the diatoms are formed of it, it occurs in grasses, and forms the tabasheer which is sometimes found accumulated in the joints of bamboos; in the animal kingdom it not only forms the hard parts of the vast majority of sponges, but the beautiful and diversified tests of the radiolaria, and the rasping teeth of some kinds of sea-snails. 


\section{4 'THE FORMA'TION' OF FLINTS}

The properties of opal are not yet as completely known as we could wish; it differs greatly from quartz, particularly in the matter of solubility; the latter, as we have seen, is to all intents insoluble in rain-water-indeed,

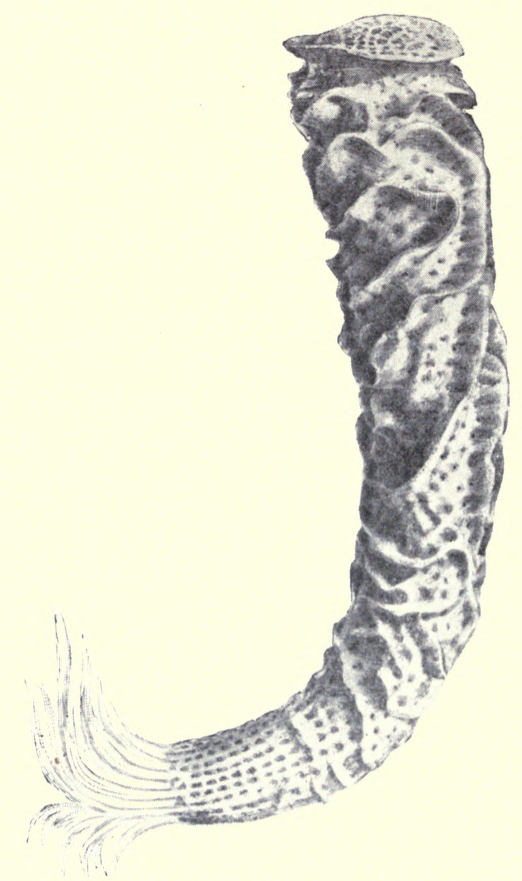

Fig. 39.-Venus's Flower Basket (Euplectella aspergillum, Owen), dredged by the Challenger, from a depth of 95 fathoms, off the Philippine Islands. About one-third the natural size. After F. E. Schulze.

it is attacked by few chemical reagents. Opal is certainly more soluble, it is readily dissolved by caustic alkalies, and yields slightly to hydrochloric acid; possibly some of the products of decaying organic matter, or solutions of carbonate of lime may have some solvent effect upon it, 


\section{REPLACEMEN'T OF OPAL 145}

but this is one of the points on which information is at present lacking.

That the opal of organic skeletons may enter into solution, so that these may completely dissolve away, has been proved in the most convincing manner. The first complete proof was given in the case of a sponge, which, on account of the regular cross-like knots formed by the siliceous threads of its skeleton, has received the name of Stauronema. It occurs as a fossil at the base of the chalk, and its skeleton, while agreeing in every essential detail with siliceous sponges belonging to the same group

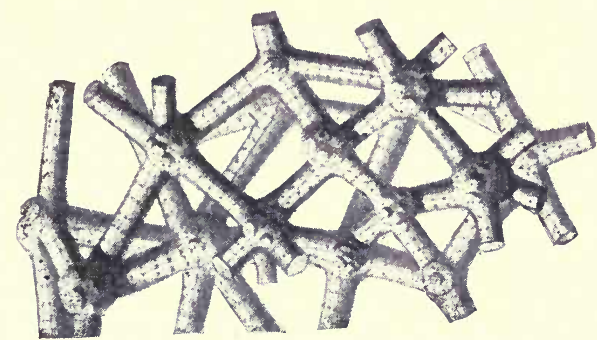

FIG 40.-A Fragment of the Skeletal Network of an Hexactinellid Sponge (Scleroplegma conica, O.S., after F. E. Schulze), magnified 50 diameters.

(Fig. 40) as the Venus's flower-basket (Hexactinellidæ), yet consists no longer of opal but of carbonate of lime. The natural conclusion to be drawn from this is that the opal of which the skeleton of this sponge was originally composed has been removed in solution and its place taken by the mineral carbonate of lime. This is an instance of a process familiar to mineralogists as pseudomorphosis. Confirmation is given to this view by the existence of intermediate stages of replacement; some parts of the skeleton have escaped solution to a greater or less extent, and the residual silica deprived of water may now be recognised under the microscope. 


\section{THE FORMA'TION OF FLIN'TS}

Notwithstanding this evidence both chemists and geologists were far from giving immediate acceptance to the conclusions just set forth; they found it difficult to believe that a substance so insoluble as silica could have been so completely displaced by a substance such as carbonate of lime, which is more soluble than itself. No doubt the difficulty was due largely to the fact that the distinction between the opal of sponge skeletons and the quartz of the mineral world was not sufficiently kept in view; but even with the full recognition of this difference, a real difficulty still remains, for there can be no question that under ordinary circumstances opal is far less soluble in rain-water than carbonate of lime.

Whatever may be the difficulties in the way of explanation, there is no longer any doubt as to the facts. The number and variety of skeletons originally siliceous but now found to consist of carbonate of lime is too great to admit of any other interpretation, and the solution of opal as well as its replacement by carbonate of lime has become one of the commonplaces of geological teaching.

But if we turn to the chalk in the immediate vicinity of a bed of flints this will yield us additional evidence of the fact that sponge skeletons have passed into solution. We have only to examine the freshly-fractured surface of a piece of the chalk under a simple pocket lens, and we shall perceive a number of hollow cavities having very definite forms : some are circular, the transverse sections of long cylindrical holes which extend into the rock; others are elongated triangles, evidently longitudinal sections of the same cavities. Sometimes at the broad end of these triangles three shorter ones are seen proceeding from it, forming as it were a three-pronged fork. Sometimes the longitudinal section tapers away at both ends. As a result of these observations we conclude that we have before us cavities of very definite shape; some 
are cylindro-conical, sharp at one end and triradiate at the other; others are needle-shaped, sharp at both ends; but these are the characteristic forms of some sponge spicules, and in particular of some of those spicules which we still find in the solid state accompanying the flints (Fig. 41); not only do the hollow cavities precisely agree with these bodies in form, but in size also. There is nothing in the organic or inorganic world which presents us with these forms except sponge spicules, and consequently we cannot resist the conclusion that the empty spaces having these forms which now exist in the chalk were once occupied by sponge spicules; the substance of these bodies has disappeared, their form alone remains. The silica which has been removed is far from being a negligible quantity; it is possible to estimate it by measuring under the microscope the area of a given surface of chalk and of the spicular cavities visible upon it. In the case of the chalk near Pangbourne railway station the hollow casts are present sometimes to the extent of 3 per cent. This is a sufficiently striking result, but there

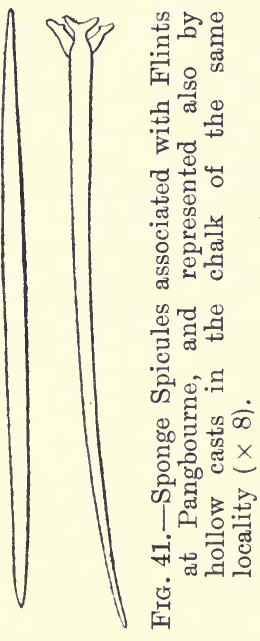
can be little doubt that in the space now occupied by the flint nodules themselves, spicules were once present in far greater abundance than this.

Besides these spicules, the form of which is preserved, countless others must have existed which have left no vestige of a trace behind. In existing sponges the elements of the skeleton are of two kinds, which differ markedly in size, and are thus distinguished under the names of megascleres and microscleres; but it is the larger form, or megascleres, alone which have left their 


\section{8 'THE FORMA'TION OF FLIN'TS}

traces in the chalk, the microscleres have never yet been observed in the fossil state. That they coexisted with the larger spicules, making up in number for what they lack in size, there can be little doubt, and their universal disappearance is probably due to their minute dimensions, which render them an easy prey to solution.

Thus, then, we have the clearest evidence of the presence at some past time of abundant opal in the form of sponge skeletons in the chalk, and we have equally convincing proof that it has since been removed in solution. But if so, where has it gone, and what has become of it? Recalling the association of sponge skeletons with flint nodules, does it not seem possible that the opal which has disappeared in solution has made its reappearance in the form of flint? The flints which, judging from analogy with the grey ooze of the existing ocean, were not originally present, have subsequently made their appearance; the sponge skeletons which were originally present have to a large extent vanished. These facts are correlative, and find a single explanation in an affirmative answer to the question just suggested.

Let us next attempt to discover the nature of the process by which this transformation may have been effected, and for this purpose we will return to the white powder which occurs in the middle of many flints. In outward appearance it closely resembles ordinary chalk, and if we examine it under a microscope we shall discover in it abundant foraminifera, coccoliths, and other structures characteristic of this rock, as well as a multitude of sponge spicules and other skeletal remains of siliceous sponges. It is of interest to note with regard to the latter that in many cases they betray obvious signs of solution; the interior has been eaten away, leaving only a hollow corroded shell behind; others are solid, but these have suffered a remarkable mineral change; they no longer 


\section{TRANSFORMATION OF SILICA 149}

consist of opal, but of crystalline silica, devoid of the water which is one of the constituents of opal. The crystalline silica very frequently occurs in the form of slender prisms crowded in radiate growth about a centre (Fig. 42). It is possible that the silica of these solid crystalline spicules is due to subsequent deposition within the cavity of spicules previously corroded. On the other hand, it may be formed by a direct transformation of the

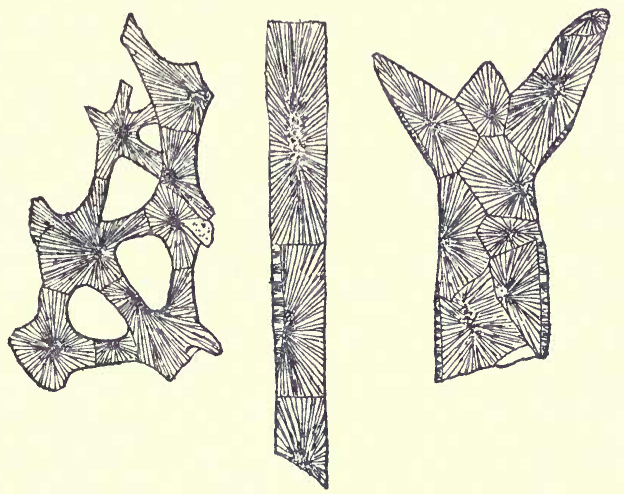

Frg. 42.-Skeletal Remains of Sponges, converted into Fibrous Crystalline Silica : on the right, the head of a three-pronged spicule; in the middle, part of the shaft of a needle-shaped spicule; on the left, a fragment of the siliceous network of a Hexactinellid sponge $(\times 45)$.

opal of spicules which have not suffered from solution, though this seems less likely. In the same flint we may find every transition between spicules consisting of opal and others wholly composed of crystalline silica.

These observations do not advance us very far, but now we will transfer some of the chalky powder to a glasss vessel, and pour upon it a quantity of dilute hydrochloric acid. A brisk effervescence at once assures us that carbonate of lime is in process of solution; the foramini- 


\section{THE FORMATION OF FLIN'TS}

fera, coccoliths, and other calcareous constituents of the chalky powder, are being dissolved away. When all action has ceased we may conclude that all the carbonate of lime has been removed, but to make certain we add a little more acid. Assured on this point, we now observe that a white sediment still remains at the bottom of the vessel ; this we might assume to consist of sponge spicules, but not to take anything for granted, we will now pour off the acid, wash with clean water, and place the insoluble residue under the microscope. The sponge spicules, as we had expected, are obvious enough, but, to our surprise, so likewise are numerous foraminifera,* still presenting their characteristic form, even down to details of ornament. The minute coccoliths are also represented, and if now we bring to our aid the effects of polarised light, we shall discover that these objects possess the optical properties of crystalline silica, and indeed differ in no essential respect from flint (Fig. 43). Thus we have before us evidence of a process which is the direct opposite of that we referred to in the case of Stauronema, where carbonate of lime had taken the place of opal. Here, on the contrary, silica in a crystalline form has replaced carbonate of lime and produced siliceous pseudomorphs of the constituents of chalk. This, then, is the first step in the formation of a flint, grain by grain, particle by particle, the substance of the foraminifera and coccoliths is removed and silica deposited in its place.

The next step is a simple deposition of silica from solution by which the siliceous chalk with the mingled remains of sponge spicules, both opaline and crystalline, are cemented together to form a white porous flint. With continued deposition of silica the pores of the white flint are obliterated, and it passes into black flint.

* This fact was first observed by Mr. Joseph Wright (Rep. Belfast Field Naturalists Club, Appendix III., vol. i., 1875, p. 74). 


\section{SILIFICATION OF CHALK}

Patches of chalk escape to a slight but variable extent complete replacement, and these remain as the grey flint which occurs in irregular layers or scattered blotches in the midst of the black.

The pores of ordinary chalk amount to somewhat over 30 per cent. of its bulk, and consequently 70 per cent. of the silica of a flint, disregarding included sponge spicules, has been deposited as a pseudomorph after carbonate of lime, the remaining 30 per cent. has filled up the pores. *

In the case of some hollow flints the solution of silica has traversed the whole thickness of the wall, and
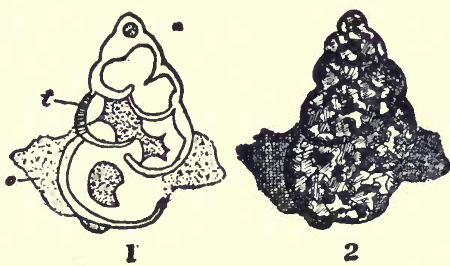

FIG. 43.-A Silicified Foraminifer.

1. Seen in optical section. $t$. The shell, still showing traces of fibrous structure. o. Opal.

2. The same, seen by polarised light, between crossed Nicols ( $\times 100)$.

reaching the central cavity, has crystallised out in wellformed crystals of quartz. In this we have evidence of a long-continued permeability which permitted the passage of the solution till the pores of the walls were destroyed.

As a rule the grey flint is irregularly distributed, but in some cases it occurs in layers more or less regularly alter-

* Out of the regular form of these blotches the fertile fancy of the older observers sometimes derived strange shapes. As we sometimes picture faces in the fire, so they saw in these outlines various animal forms, cocks and hens, human faces, and much else, which were solemnly described as fossils, and elaborately illustrated by numerous copper-plate engravings. 


\section{2 'THE FORMA'TION OF FLIN'TS}

nating with the black flint, thus giving rise to a banded appearance. Such "banded" flints have excited a good deal of curiosity, which seems somewhat disproportionate to their importance; but they are difficult to explain. The banding recalls that of certain agates, and points to some rhythmic or periodic action, probably connected with surface tension, or such a process as gives rise to the "tears" of strong wine. A somewhat analogous banding may be obtained by allowing oil to saturate sheets of paper, as shown in the illustration (Fig. 44). To discuss this experiment in detail would occupy us too long, ${ }^{*}$ and we must take the blame of a flagrant attempt to explain one difficulty by comparing it with another.

The store of silica which was eventually to form our flint was accumulated at the time when siliceous sponges were flourishing at the bottom of the deep chalk sea; so much we may regard as definitely ascertained; but at what period and under what conditions the transformation of this material into flint took place is another question, and not so easy to answer. The lie of the irregular nodules conformably with the bedding, and their rounded, flowing outlines, so singularly organic in appearance, might well give rise, as they have often done, to the notion that the flints were formed either contemporaneously with the growth of the sponges, or not long after their death. But all ideas of this nature will sooner or later be dispelled by an impartial study of almost any chalk quarry, in which the flint is well displayed: the rounded forms prove far from universal, and flint of precisely the same characters as that forming the nodules will be found lining and filling the joints of the chalk. The joints are cracks which almost certainly owe their

* Much light is thrown on this subject by a very instructive paper on the "Separation of Solids in the Surface-layers of Solutions," by Dr. W. Ramsden, Proc. Roy. Soc., vol. lxxii., p. 156. 


\section{AGE OF FORMATION}

origin to upheaval; they were formed as the chalk of the deep sea was raised to form the dry land of the Chiltern hills and other regions. If, then, the joints have determined the deposition of the flint, as they seem to have done, then the flint must be subsequent to the joints, and subsequent, consequently, to the upheaval. This is in harmony with the fact that flints have never yet been

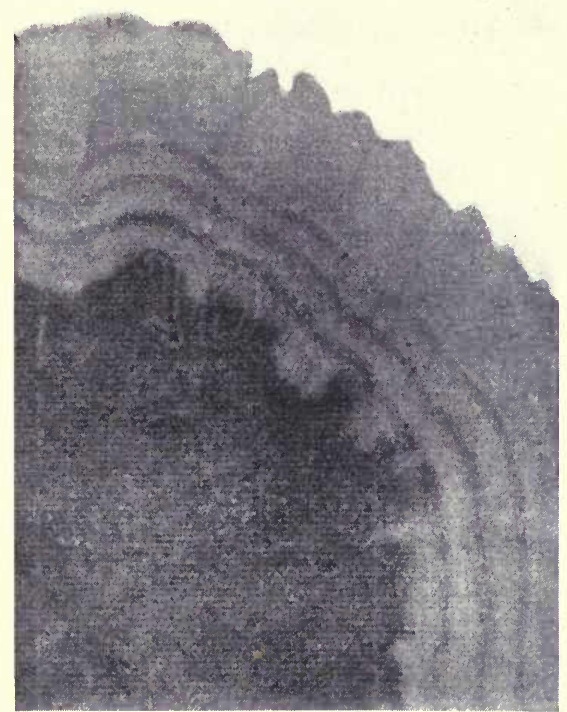

Fig. 44.-Banding produced by the spread of Oil in Writing-paper.

dredged from the ooze of the existing sea, and it is consistent with the discovery of hollow casts of sponge spicules in the chalk, which must have acquired a considerable degree of consistency before it could preserve in such a remarkable state of perfection these perishable cavities. Probably the deposition of the flint about the joints is due to the open cavity, which these 


\section{THE FORMATION OF FLIN'TS}

present, offering free egress to the siliceous solutions wandering through the pores of the chalk. But if the flint of the joints has been formed since the chalk became dry land, there would appear to be no good reason why this should not have been the case with the other forms of flint. The nodular layers may possibly mark horizons in the chalk where the growth of sponges was unusually profuse; sponge spicules and whole skeletons of sponges are much more richly distributed among them than elsewhere, and there is even an almost sudden increase in these remains as we pass from the immediately adjacent chalk into the nodular layer. The even sheets, sometimes of very wide extent, as in St. Margaret's Bay, near Dover, where a layer about an inch and a half in thickness has been traced for a distance of two miles, are possibly the result of gentle current action, spreading out the débris of a sponge bed in a more or less uniform manner.

It has sometimes been imagined that the sponge skeletons, since they consist of silica, may have exerted an attractive influence on the silica in solution, but this will not accord with the fact already mentioned, that a considerable interval sometimes separates a sponge skeleton from the surrounding flint. The presence of sponge skeletons probably indicates regions in the chaik where silica was unusually abundant, and where, consequently, solutions of this material attained their highest degree of concentration.

We have now traced the building up of a flint, and have seen how the scattered silica in the chalk passes into solution, and is then gathered together into another place, where it accumulates in a solid form ; but after the completion of this process another ensues, and, strange to say, in the opposite direction. No sooner has Nature made the flint with seeming care and deliberation than she proceeds to unmake it, taking it to pieces with the 
same persistent activity that she showed in its making. If we examine the flints built into a wall or a church, we shall find that their black surface is now veiled with a white film; similarly, flint implements, which we may be sure were quite black when freshly chipped into shape, are now found covered with a white patina, which may be of considerable thickness; and, again, flint pebbles may be met with in all stages of destruction, some when broken open proving to be white all through. This change of appearance is accompanied by a loss of substance; the black flint is impervious, the white extremely porous, as may be proved by applying it to the tongue, when it will be found to adhere, or more elegantly by immersing it in some staining fluid, when it will become coloured by absorption. Thus the silica which under certain conditions passes out of solution into the solid form, under others is again dissolved away. The change in conditions is possibly brought about by removal from the enclosing chalk; evidently it is a somewhat nicelybalanced play of forces which determines whether solution or crystallisation shall prevail.

Having traced the silica of a flint to its source in siliceous sponges, we may next inquire, Whence does the sponge obtain its silica? The only possible source would appear to be the sea. The sponge lives by maintaining an almost constant flow of sea-water through the walls of its body. It thus obtains food and oxygen, and probably the silica which forms its skeleton. Of course there is a chance that some of this may be derived from its food, but this consists of minute organisms, which in their turn must have obtained any silica they contain from sea-water. Still, in what follows we shall assume that the silica is extracted directly from the sea. If now we turn to chemical analyses of sea-water we shall find, as we might expect, that they agree in indicating the 


\section{6 'THE FORMA'TION OF' FLIN'TS}

presence of this substance as one of its constituents; but the quantity is amazingly small, 14 parts of silica in $1,000,000$ of sea-water would perhaps be rather above than below the average. Evidently the sponge would require to be brought into contact with a very considerable amount of water before it produced a skeleton of any appreciable size. The question seemed to me worthy of a little investigation, which led to the following result:

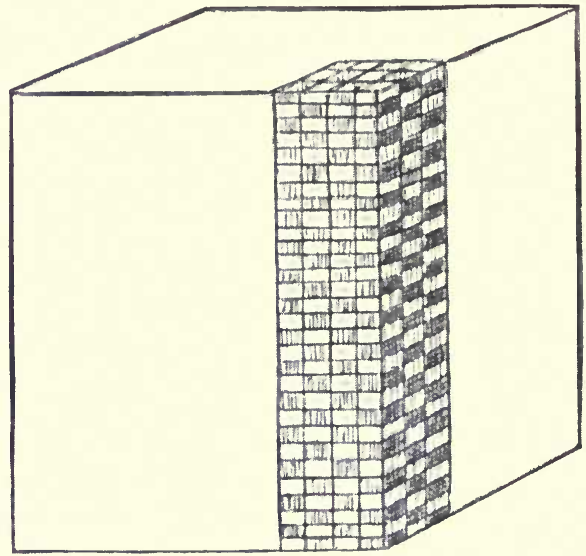

FIG. 45.-A Cube to represent a Sponge having a volume of 59 cubic centimetres, with a prism indicated by chequers to show the volume of silica it would contain.

Experiments made on eleven different kinds of sponges showed that the siliceous slieleton formed on an average 13 per cent. of the total bulk of the organism, so that a sponge 58 cubic centimetres in volume* (Fig. 45) - a fair average size-may possess a skeleton containing 14 grams of silica, or as much as is contained in 1,000 litres of seawater, the weight of which is considerably over a ton.

* A volume of 60 cubic centimetres would be represented by a rectangular prism $3 \mathrm{c} . \mathrm{m}$. by $4 \mathrm{c.m}$. in section and $5 \mathrm{c.m}$. high. 


\section{SPONGES AND SIIICA}

Prodigious, no doubt; but if we assume that the sponge takes five years to grow from the larval stage to maturity - a mere guess suggested by what is known of the rate of growth of the bath-sponge* - then the average quantity per year required to flow through the sponge is 200 litres, and this will be found to work out to something less than half a cubic centimetre per minute; thus the prodigy is reduced to quite commonplace dimensions. How gentle such a flow would be may be judged from the following considerations. Let us suppose the water to enter through little pores in the outer surface of the sponge, as in fact it does, and let us further suppose for the sake of calculation that these pores are restricted to the four upright sides of our prism, or an area of 7,000 square millimetres. Take half this to represent the area of the pores, then the rate at which the water would be flowing into the sponge would be 0.11 of a millimetre per minute, or a little slower than the movement of the hour-hand of an ordinary watch. We have said our prodigy becomes commonplace. Let us recall that word; there is nothing commonplace in Nature. And even if we reserve our wonder for the immediately unexplained, we may well marvel at the subtle chemistry by which, out of the various constituents of sea-water, that living laboratory, the sponge, is able to extract a single one, and that one of the least abundant, in a state of almost absolute purity. $\dagger$

In connexion with the subject of time, the question naturally arises as to the period which would be required to furnish the silica for a single flint. If we suppose the

* It is found by observation that a bath-sponge requires from five to seven years to grow from a fragment one eubic inch in bulk to the "size of a saleable sponge."

+ It is said that our chemists are about to rival this process by extracting in paying quantities the gold of sea-water, a rarer constituent even than silica. 


\section{THE FORMA'TION OF FLIN'TS}

flint to have the same size as the sponge, the calculation is easily made: it would require the silica of eight sponges to form the substance of one such flint, and if the life of each sponge is limited to five years, this gives us forty years for the period sought; this is the time that would be necessary for the accumulation of sufficient silica to form a layer of flints five centimetres in thickness.

In the middle of the last century geologists had escaped so recently from the restrictions of a six days' creation that they were not uncommonly occupied in proving to themselves and others that the age of the earth must be very great. Thus so late as 1868 Huxley says in his lecture, "On a Piece of Chalk," * “. . . Geologists find in the chalk a fossilised sea-urchin, to which is attached

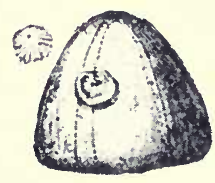

Frg. 46.-A Fossil Sea-Urchin (Ananchytes) from the chalk with lower valve of a brachiopod (Crania) attached. Reduced one-half. $b$. Upper valve of the Crania detached. Taken from Lyell's "Student's Elements," with kind permission of Messrs. A. \& J. Murray.

the lower valve of a Crania (Fig.46). This is a kind of shellfish, with a shell composed of two pieces, of which, as in the oyster, one is fixed and the other free." "The upper valve is almost invariably wanting, though occasionally found in a perfect state of preservation in the white chalk at some distance. In this case we see clearly that the sea-urchin first lived from youth to age, then died and lost its spines, which were carried away. Then the young Crania adhered to the bared shell, grew and perished in its turn, after which the upper valve was separated from the lower before the sea-urchin became enveloped in the chalky mud." †

* "Lay Sermons," p. 190.

† "Elements of Geology," by Sir C. Lyell, p. 23. 
"A specimen in the Museum of Practical Geology in London still further prolongs the period which must have elapsed between the death of the sea-urchin and its burial by the Globigerinæ. For the outward face of the valve of a Crania, which is attached to a sea-urchin (Micraster), is itself overrun by an incrusting coralline, which spreads thence over more or less of the surface of the sea-urchin. It follows that, after the upper valve of the Crania fell off, the surface of the attached valve must have remained exposed long enough to allow of the growth of the whole coralline, since corallines do not live imbedded in mud.

"The progress of knowledge may, one day, enable us to deduce from such facts as these the maximum rate at which the chalk can have accumulated, and thus to arrive at the minimum duration of the chalk period. Suppose that the valve of the Crania, upon which a coralline has fixed itself in the way just described, is so attached to the sea-urchin that no part of it is more than an inch above the face upon which the sea-urchin rests; then, as the coralline could not have fixed itself, if the Crania had been covered up with chalk mud and could not have lived had itself been so covered, it follows that an inch of chalk mud could not have accumulated within the time between the death and decay of the soft parts of the sea-urchin and the growth of the coralline to the full size which it has attained. If the decay of the soft parts of the sea-urchin, the attachment, growth to maturity, and decay of the Crania, and the subsequent attachment and growth of the coralline, took a year (which is a low estimate enough), the accumulation of the inch of chalk must have taken more than a year, and the deposit of a thousand feet of chalk must consequently have taken more than twelve thousand years."

No doubt this famous illustration, which, in its moderation, is beyond all criticism, was simply intended to 


\section{0 'THE FORMATION OF FLIN'TS}

bring home to a general audience the great antiquity of the earth, but the danger of such isolated instances lies in the vagueness of the impression they produce. In Huxley's time no doubt they had their use; at the present day we are convinced believers in the untold æons of geological time; but nevertheless we are anxious to take a step in advance, to count these xons, and to formulate a consistent scheme of geological dates. We have already seen that a by no means niggardly estimate gives a little over 26 million years as the whole period required for the deposition of the stratified rocks of the earth's crust (p. 24). In the table on page 14 the maximum thickness of the Cretaceous system is given as 14,000 feet. Of this, 7,500 feet may be assigned to the upper cretaceous, and at least 5,000 to the chalk. The beds which attain this thickness are chiefly sandstones, to which our estimate of one foot in a hundred years may apply, so that their equivalent of 1,000 feet of chalk would have consumed half a million years in its formation, and this gives an allowance of forty years for each inch, or a period forty times greater than that demanded by Huxley-ample, and more than ample, for the accomplishment of the processes which he describes, and yet perfectly consistent with the conclusions we have reached as to the age of the earth.

If we are in the mood to push our inquiry as far as possible, we may next demand whence does the sea obtain its store of silica?

The sea obtains it in tribute from the rivers, the rivers from springs and the superficial drainage of the soil. It is instructive to observe how this constituent increases in quantity as it is traced towards its source; thus in the sea, as we have mentioned previously, there is on an average about fourteen parts of silica in a million of water; in rivers the amount rises to sixty-six in a 
million, * while in springs it is no less than one hundred and fifty-two parts in a million. + This is susceptible of a simple explanation; as soon as the water begins to flow at the surface of the ground it becomes the home of those simple plants, the diatoms, which extract the silica and convert it to their own purposes, building up out of it a pair of fragile valves of glass-like opal (Fig. 47). Wherever water is found, in pools or lakes or rivers or canals, these living atomies are present, engaged in making inroads on its store of dissolved silica, and thus it suffers a continual impoverishment through the whole course of its journey to the sea.

The ultimate source of the silica is the primitive substance of the earth's crust, granite, or rocks such as granite, and in particular one mineral which these contain, i.e., the felspar. It is to the decomposition of this mineral that most of our sedimentary rocks and most of the silica carried in solution by water must be traced.

Having reached this stage, our labours as geologists are concluded. To investigate the origin of the
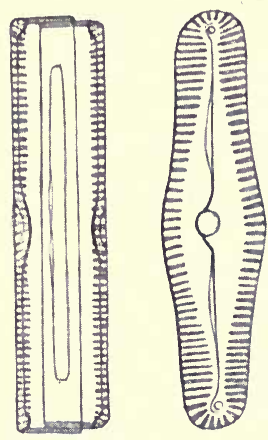

Fig. 47. - Siliceous Shell of a Common Diatom, Pinnularia, magnified and somewhat diagramatic. On the left, as seen en face; on the right, a lateral view. After Prantl. molten planet is no function of ours, and we may safely leave it in the hands of the astronomer, whose business it is.

Briefly to recapitulate our results, we perceive some four or five millions of years ago a clear blue sea extending above the site of the British Isles; over its floor a sheet of chalky ooze was spread, formed by the birth,

* This is the average of twenty-five analyses.

$t$ This is the average of eight analyses of as many deep wells. 


\section{THE FORMA'TION OF FLIN'TS}

growth, death, and decay of a host of calcareous organisms, and continuously in process of formation ; here and there beds of various kinds of sponges flourished in rich profusion, twenty or thirty species, or even more, might have been collected at a single sweep of the dredge, just as happened with some of the most successful hauls of the Challenger in the existing ocean. These sponges built up siliceous skeletons formed of opaline network or variously-shaped needles; the latter they had a habit of shedding during their lifetime, extruding them from their surface till they fell out and mingled with the ooze of the sea floor. Periodically they produced swarms of young, and at their death left behind a rich legacy of silica. Possibly other siliceous organisms, diatoms, and radiolaria contributed to the increasing accumulation of silica, but direct evidence of this is rare or wanting. Then, as the result of some change of circumstances, the sponge life grew rare, the growth of chalk predominated, till again some alteration occurred and fresh fields of sponges covered the sea floor, to be smothered up once more beneath the allpervading chalk, and thus by slow mutations a great thickness of chalk and sponge beds accumulated within the ocean basin. Then came a revolution of the times; the sea gave place and made way for the ascending land; the sheets of chalk were thrown into mighty rolling folds and rose into the air. Within the mass of the rock a fresh series of events was set in train; molecules of silica and lime carbonate were set marching and countermarching this way and that, till at length the silica had gathered itself together in concentrations of flint. Rain and rivers, wearing away the softer chalk, left the hard flints exposed upon the ground or rolled them into pebbles. Then a creature of but yesterday, in whom the life of the earth attains its intellectual culmination, came by and found in these pebbles and nodules a substance 


\section{QUAR'TZ AND FLINT}

to suit his needs, shaped them into weapons, on which he depended for his life, in defence against wild beasts or in pursuit of prey for food, or as a means to yield him fire. Great were their services; untrumpeted by fame; belonging to a forgotten past. Now we find in them material for investigation, and some of us take a curious pleasure, to the astonishment of others, in following their strange metamorphoses, searching out their history, and weaving it into the general scheme we fabricate of the world.

\section{Note on the Crystalline Silica of Flint.}

The silica of flint approaches quartz so closely in most of its properties that it is usually identified with this mineral. Certain differences, however, exist, which are worthy of consideration; thus, for instance, the specific gravity of quartz is 2.65 , that of black flint only 2.59 . This might be accounted for by the presence of a certain amount of opal. Thirteen per cent. of opal, with a specific gravity of $2 \cdot 2$, would account for the discrepancy. Water to the extent of 1 per cent. is not uncommon in flint, and this would be sufficient to supply 16 per cent. of opal. But again, quartz is far less readily soluble in caustic alkalies than flint. Rammelsberg found that by treatment with caustic potash 8 per cent. of quartz was dissolved, and of flint 80 per cent., or ten times as much, and his results have been confirmed by Renard and $\mathrm{C}$. Klement. *

On the assumption that opal is present, this might be accounted for in the following way: the opal would first pass

* These investigators experimented on flint of sp. gr. $2 \cdot 606$, which lost 1.3 per cent. on heating. Placed on the water bath in a 20 per cent. solution of caustic potash, it lost 51 per cent. in three hours, and 86 per cent. in twelve hours. 


\section{4 'THE FORMA'TION OF FLIN'TS}

into solution, for it very readily dissolves in alkalies, and its removal would leave behind numerous minute cavities, which would increase the area of the flint exposed to the attack of the potash, and solution would consequently be accelerated.

If, however, opal were present to the extent of even 10 per cent. only, we should expect to find some other signs of it. Its refractive index is so much lower than that of quartz that it should be visible under the microscope, but it has never yet been detected. Again, opal, by virtue of its porosity, readily absorbs coloured fluids, so that it may be readily made. visible in rocks containing it by staining; but prolonged immersion of flint in alcoholic solutions of aniline dyes reveals only the merest trace of opal, scarcely 1 per cent., if we may judge by mere inspection. On the other hand, as we have seen, opal stains owing to its porosity, and if its pores were already filled with crystalline silica, staining fluids would be excluded, so that the argument drawn from the absence of staining is not absolutely conclusive.

These difficulties give increased interest to the observations of Messrs. Michel Lévy and Munier-Chalmers, * who, after a searching investigation into the properties of chalcedony (which agrees as regards specific gravity and solubility with flint) and other forms of fibrous silica, have been led to the conclusion that in these substances we are presented with a third form of crystalline silica (tridymite and quartz being the other two). It differs from quartz in being optically bi-axial, and by a slightly higher degree of bi-refringence, as well as in its specific gravity, which is that of flint. These observers, however, and subsequently Mr. Wallerand, + suggest that quartz

* I have to thank my friend and colleague, Professor Miers, for calling my attention to these observations.

† Bull Min. Fr. Soc., vol. xv. p. 159, 1892, vol. xx. p. 52, 1897 


\section{QUARTZ AND FLIN'T 165}

itself may be built up of fibres of this mineral, a conception hardly in accord with its specific gravity.

The subject is evidently still very obscure, and there is need for renewed research, which, however, will make great demands on the time, ingenuity, and skill of the investigators.*

* I take this opportunity to add the following references on the general subject:-Buckland, Trans. Geol. Soc., vol. iv. p. 413. Woodward, S. P., Geol. Mag., 1864, p. 145. Rupert Jones, Proc. Geol. Assoc., 1878, vol. iv. p. 450. Sollas, W. J., Ann. and Mag. Nat. Hist., 1881 (5), vol. vi. p. 384 and 437. Brit. Assoc. Rep., 1882, p. 549 ; 1899, p. 744 . Renard and Klement, Bull. ac. roy. Belgique, 1887 (3), vol. xiv. p. 773. Zirkel, Lehrb. Pétrographie, 1894, vol. iii. p. 549 . 


\section{CHAPTER VII}

\section{THE ORIGIN OF FRESHWATER FAUNA}

$7 \mathrm{HE}$ great original home of all living things is the 1 sea: the history of all animals dwelling upon the land or in its waters, when traced far enough back in time, will be found to have its beginning there.

It is at the meeting-place of land and sea, in the shallow waters around the coast, that life most abounds, and here "the sea's abundant progeny . . . far passeth those on land." From this zone, amazing in its fertility, the rest of the world has been populated; streams of living forms have proceeded from it, and possibly still proceed from it, in all directions, out into the open ocean, giving rise to the floating world, known as the "planctone," down into its deep abysses, scantily occupying the desert " benthos," up the mouths of rivers into their remotest tributaries, across the beach into marshes and on to dry ground. The movement is almost wholly outwards, and only a few of the departing emigrants, once naturalised on land, return to the ancestral home: seals and whales will occur to us as notable instances of these exceptions.

It is with little less than astonishment that we turn from the rich and varied multitude of living forms in the 


\section{BRI'TISH FRESHWA'TER FAUNA 167}

sea to the comparatively scanty fauna of our rivers and akes.

The freshwater fauna of our own islands, though fairly representative, could almost be written on a sheet of notepaper. The following list, though very incomplete, is sufficient for our purposes :-

VERTEBRATA.-Mammals: Otter, Water-vole. BiRds: Ducks and other web-footed fowl. AmpHiBIA: Newts and tadpoles of frogs and toads. Fish : Bony fish with spiny fins:-Perch, Miller's Thumb, Blenny, Gudgeon. With soft fins :-Berbot, Carp, Bream, Roach, Dace, Tench, Chub, Minnow, Salmon, Shad, Eel. Cyclostomes : Lamprey.

INVERTEBRATA.-Insects : Beetles :-Dytiscus (Fig. 53), Gyrina, and others. Bugs: Water-boatman (Notonecta), Water-scorpion (Nepa), and others. Neuroptera, larvæ of dragon flies, caddis flies, and many others. Flies: larvæ of gnats and daddy-long-legs. SPIDERs, Water-mites and others. Tardigrades: Water bear. CrustaceA : Decapods, Crayfish. Isopods: Asellus (water-hog-louse). Amphipods: Freshwater shrimp (Gammarus), \&c. Phyllopods: Estheria, Branchipus. Cladocera: Water-fleas (Daphnia). Ostracods : Cypris. Copepods: Cyclops. Siphonostoma: Fish-lice. Worms. -Leeches: Clepsine, Nephelis, Piscicola, Branchiobdella. Chatopods: Tubifex, Stylaria, Nais. Nematodes, Cestodes, Trematodes, Nemertines. MoLuoscs; Lamellibranchs (Bivalves): Unio, Anodonta, Cyclas, Pisidium, Dreissena. Gasteropods (Univalves): Neritina, Paludina (Fig. 55), Bithynia, Valvata (Fig. 69), Limnæa (Fig. 56), Physa, Planorbis, Ancylus (Fig. 75). Rotifers : a vast number (Fig. 61). PolyzoA : Cristatella, Pectinatella, Lophopus, Alcyonella, Plumatella (Fig. 48), Fredicella, Paludicella, Urnatella, Victorella. Turbellaria: Planaria, Poly- 
cœlis, Mesostoma, Prorhynchus. Ceerenterata: Hydra (Fig. 49) and Cordylophora. Sponges: Spongilla, Ephydatia.

PROTOZOA : INFUSORIA, RHIZOPODA.

On first glance at this list we notice that among the

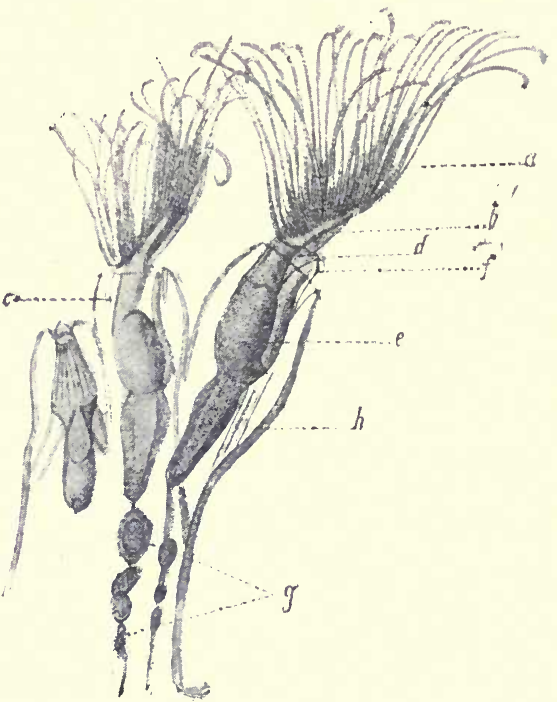

Fig. 48.--A Polyzoan, Plumatella fungosa, Pallas. Two individuals with extended tentacles. $a$. Tentacles. $b$. Tentacle carrier. c. Tentacle sheath. $a$. Gullet. e. Stomach. $f$. Intestines. g. Funiculus. $h$. Muscle. Magnified 20 diameters. After Vosseler, from Lampert, "Das Leben der Binnengewässer."

Invertebrata whole groups of marine forms are missing; the Echinodermata, of which that common object on the seashore, the reluctant starfish, is an example, are wholly unrepresented: so are the Brachiopoda, best known to us in this country by their fossil forms, such as Terebratula and Rhynchonella, so abundant in our stratified rocks: 
there are no Actinozoa (sea anemones and corals) and no Ascidia, or sea-squirts, otherwise abundant enough on our sea-coast, though perhaps unfamiliar to many of us. Other groups almost infinite in the number and variety of their marine forms are barely represented by a few freshwater species; Gromia, and maybe one or two others, stands for the great legion of Foraminifera. Of the

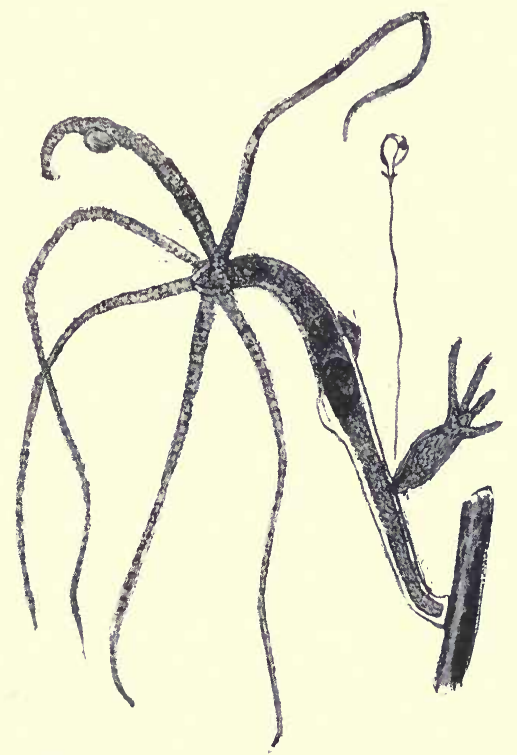

Fic. 49.-Hydra vulgaris, Pallas. Magnified 6 diameters. After Vosseler, from Lampert, "Das Leben der Binnengewässer."

sponges, the great majority are absent, there are no calcareous sponges, no Hexactinellids, no Tetractinellids, no horny sponges; in the seas around our own shores there are probably about 150 different species of this group, in our rivers and lakes not more than half a dozen. The same deficiency is manifested by the Hydrozoa; apart from missing families, there is the same contrast in 
number of species, over 150 marine, and less than half a dozen fresh water. So it is with the Polyzoa; some families are unrepresented, of marine species there are nearly 250 , of fresh water about a score. The same story is told by the Mollusca; the cuttlefish are conspicuous absentees, of the bivalves most of the families are missing, the total number of species of molluscs inhabiting our rivers, lakes, and ponds cannot exceed thirty, while in the British seas there are between five and six hundred. Apart from the minute Cladocera, which are more abundant in fresh water than salt, the Crustacea exhibit the same contrast. The rule is general, with only one or two exceptions, the Cladocera just mentioned, and the tiny Rotifers, which are predominantly fresh water; of 400 species or more, only seventy are found in the sea.

The difference which we observe in the case of our own islands is repeated to a greater or less degree all over the world, and, what is perhaps still more extraordinary, a great number, perhaps the majority, of our freshwater genera are the same, or nearly the same, as those which inhabit the rivers and lakes of the greater part of the world. The sameness of the freshwater fauna, almost wherever it is found, increases its contrast with that of the sea, and renders all the more difficult the problem which we must now attempt to solve.

The problem is evidently manifold. In the first place, we have to explain how it is that marine animals are so largely excluded from our rivers; in what manner those forms now found in fresh water have obtained their footing, by what means they have attained so wide a distribution, and what cause has prevented them, while exposed to such differences of climate and other conditions, from displaying the same originality as their marine relatives in developing new types of structure. It may not be possible to find answers to all these questions; we 
will begin with the first, and seek to discover the cause by which marine animals are excluded from the freshwater world.

No doubt the very first explanation which will suggest itself to every one will rest on the difference in character of fresh and sea water. The quantity of dissolved material in sea water is certainly considerable, it consists chiefly of sodium chloride or common salt: river water, on the contrary, is almost pure: the precise difference will be seen by inspection of the following table:-

\begin{tabular}{|c|c|c|c|c|c|}
\hline \multirow[b]{2}{*}{ Calcium carbonate ... } & \multirow[b]{2}{*}{$\ldots$} & \multicolumn{2}{|c|}{$\begin{array}{c}\text { Analysis } \\
\text { of Sea Water, } \\
\text { North Atlantic. }\end{array}$} & \multicolumn{2}{|c|}{$\begin{array}{c}\text { Analysis of } \\
\text { River Water, } \\
\text { Thames at Thames } \\
\text { Ditton. }\end{array}$} \\
\hline & & $\ldots$ & 0.004 & $\ldots$ & $0 \cdot 0168$ \\
\hline Magnesium carbonate & $\ldots$ & $\ldots$ & - & $\ldots$ & 0.0018 \\
\hline Calcium sulphate $\quad \ldots$ & $\ldots$ & $\ldots$ & $0 \cdot 140$ & $\ldots$ & $0 \cdot 0044$ \\
\hline Magnesium sulphate... & $\ldots$ & $\ldots$ & $0 \cdot 221$ & ... & - \\
\hline Potassium sulphate ... & $\ldots$ & $\ldots$ & - & $\ldots$ & $0 \cdot 0002$ \\
\hline Sodium chloride $\quad \ldots$ & $\ldots$ & $\ldots$ & $2 \cdot 773$ & $\ldots$ & 0.0016 \\
\hline Potassium chloride ... & $\ldots$ & $\ldots$ & 0.069 & $\ldots$ & $0 \cdot 0009$ \\
\hline Magnesium chloride... & $\ldots$ & $\ldots$ & $0 \cdot 344$ & $\ldots$ & - \\
\hline $\begin{array}{llll}\text { Silica } & \ldots & \ldots & \ldots\end{array}$ & $\ldots$ & $\ldots$ & 0.0015 & $\ldots$ & 0.0009 \\
\hline \multirow[t]{2}{*}{ Organic matter, \&c. ... } & $\cdots$ & ... & - & ... & $0 \cdot 0035$ \\
\hline & & Total & $3.552 \%$ & & $0.0304 \%$ \\
\hline
\end{tabular}

Thus sea water contains more than one hundred times as much dissolved material as river water, and as a direct consequence of this marine animals in general quickly succumb when transferred to fresh water, while freshwater animals when placed in sea water even more rapidly perish. The rule, however, is not without fairly numerous exceptions; the salmon and its tribe, which are able to pass direct from the sea to rivers, and from rivers to the sea, will at once suggest themselves. Indeed, the susceptibility of different kinds of animals to the change of medium would appear to vary within wide limits. In 
sea floods on the Norfolk Broads the first fish to suffer are the tench, pike, bream, and roach: perch bear a strong admixture of salt water, eels still more, while the stickleback will continue to live on in pure sea water.

In studying the effects of the change of medium, time must be recognised as an important element. If a body of sea water be slowly freshened, so that the fish living in it have time to grow accustomed to the change, many will be found to survive which would otherwise perish. The Romans took advantage of this fact, and so were able to breed marine fish in freshwater ponds, a practice lately revived in Guernsey and Yorkshire.*

The same is true of the Invertebrata, few survive a sudden transference from salt to fresh water, but many can be brought to endure a gradual change. This was first shown by the careful experiments of Beudant, made on fifteen different species of marine invertebrates, viz., the common limpet, whelk, oyster, mussel, the common cockle, Purpura lapillus, Turbo neritoides, Arca barbata, Venus maculata, Fissurella uncibosa, Haliotis tuberculata, Tellina incarnata, Chama lazarus, Pecten varius, and the acorn shell (Balanus striatus), none of which are capable of resisting a sudden change of medium. They were placed in a tank of sea water, which was very slowly replaced by fresh; the experiment was commenced on January 1st, and by June 1st one half of the sea water had been replaced, by September 1st the change was complete; a fortnight later the number of surviving individuals of each species was counted, the limpets, mussels, Turbo purpura and Arca, had lost none of their numbers; the cockles, oysters, Balanus and Venus, very few; but of Fissurella, Haliotis, Tellina, Pecten, Chama, and the whelks, not a single example was left alive. The positive result of this experiment is to show that many marine invertebrates * Day, "Fishes of Great Britain and Ireland," p. 84. 
are capable of living in fresh water,* and conseguently it cannot be merely the difference in composition of the media alone which is responsible for their absence from our lakes and rivers. Whether the experiment equally demonstrates a difference in susceptibility of different species to change of medium, might be doubted, because it is just possible that some other unfavourable conditions were necessarily associated with this; but, on the other hand, there is independent evidence to suggest that this is the case. The Baltic, for instance, on account of its landlocked position, is half lake, half sea, fresher on the eastern side, salter on the western; and it is just those species which proved most indifferent to the composition of the water in Beudant's experiment (Balamus, mussel, and cockle) which are found to live on the east side, while Tellina, which showed less power of accommodation, is confined to the western side.

Thus it appears that the absence of salt from our rivers, while, no doubt, a hindrance to the migration of marine animals, is by no means absolutely prohibitive.

A second check, probably of equal importance, is to be found in the greater severity of a fresh water climate, as opposed to that of the sea; and this must be especially operative in temperate regions: nearer the tropics it may be less effective, though droughts afford unfavourable conditions which must not be overlooked. Von Martens, who was the first to call attention to thisfactor, remarks : "The great richness of the sea is explained not only by its greater extent, butalso by its more uniform temperature. The fresh waters stand in the same relation to it as a continental to an insular climate: their alternation of temperature is the principal hindrance to their becoming populous; and this attains its maximum by freezing in

* See Semper, "Animal Life," International Science Series, and Vernon, "Variation of Plants and Animals," in the same series, p. 271. 
the colder zones. With the increase of temperature the populousness of the fresh waters increases, but is still limited in the sub-tropical zone by partial desiccation. In the tropical zone the conditions of temperature of the

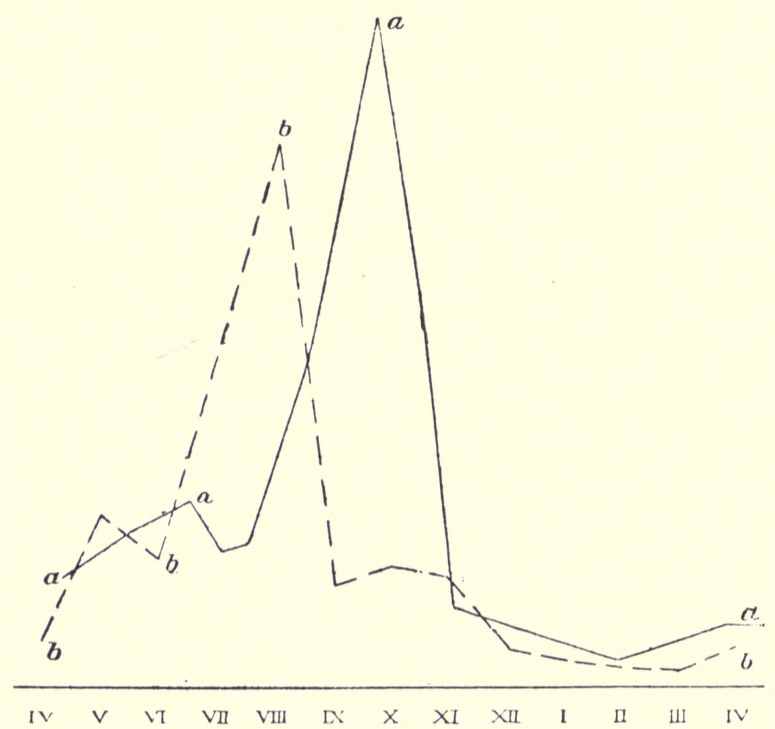

FIG. 50.-Diagram to show the increase and diminution of the Freshwater Planctone in the course of the year. The months are indicated by Roman numerals. Curve $a a$, given by Apstein for the Dobersdorf lake. In April, at the beginning of the curve, a column of water 1 square metre in section and 20 metres high contained 530 cubic centimetres of planctone; in October, near the culmination of the curve, 3,136 cubic centimetres. Curve $b \quad b$, constructed from data given by Zacharias for the Ploen lake. In April, 43 cubic centimetres, and in August, 509 cubic centimetres of planctone were observed in 40 cubic metres of water.

fresh waters approach most nearly to those of the sea, and with them their populousness." *

The effect of a temperate climate is well illustrated

* "On the Occurrence of Marine Animal Forms in Fresh Water," by E. von Martens, Ann. and Mag. Nat. Hist., 1858, vol. i. p. 50. 
by the observations made of late years on the variation from month to month in the volume of the living forms, animals and plants, which constitute the floating or swimming world (planctone) of lakes and rivers. An estimated quantity of water is allowed to pass through a muslin net with meshes fine enough to arrest the living creatures, the volume of the capture is then measured. The diagram on p. 174 illustrates by means of curves the change in volume of the planctone with the season of the year as observed in the case of the Ploen* and the Dobersdorf lakes in Holstein.t The rapid increase of living forms with rise of temperature and the sudden diminution with its fall are sufficiently striking.

The favourable influence of a less extreme climate is shown as we proceed southwards by the appearance of new elements in the freshwater fauna. The Melaniidæ, a group of univalve molluscs, which, during the warmer climate of the Mesozoic period, were inhabitants of our own rivers, but have long since deserted them, are represented by

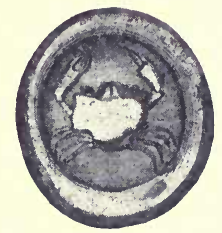

FIg. 51.-A Freshwater Crab, Thelphusa fluviatilis, represented on a Sicilian coin. After Vosseler, from Lampert. numerous species; crabs belonging to the family Thelphusidæ (sometimes represented on ancient Greek coins) (Fig. 51) occur in the rivers of Southern Europe, and are common in Africa; and various other Crustacea which we are accustomed to regard as purely marine have acquired a freshwater habitat in the tropics. The same is true of certain bivalve molluses; thus Arca scaphula lives in the Jumna, near Hamipur, in the interior of India; a species of piddock, Pholas rivicola, Sow., is found on floating timber in the River Pantai,

* See "Zacharias, Biol. Central-blatt," vol. xvi. p. 803, 1896.

† See "Apstein," ibid., vol. xii. p. 485, 1892. 
twelve miles above its mouth; a razor shell (Novaculina gangeticus) occurs in the Ganges; a Tellina (Galatea) in rivers in Africa; and a Mactra (Gnathodon) in fresh water about the Gulf of Mexico.

These instances might be added to, but without greatly diminishing the contrast between the marine and freshwater faunas. They show that climate has its effect, but on the whole this is perhaps not so great as we might have expected.

The composition of the water and the character of the climate, these are both barriers to the invasion of our rivers, but they are far from insurmountable. If these were all, we might expect to find numerous marine animals, under the pressure of existence, enterprisingly working their way along the shores of the numerous streams which open along the coast, and every river characterised by a modified marine fauna derived from the neighbourhood of its mouth.

So far from this being generally the case, freshwater forms of life are, as a rule, well distinguished from the marine, and many of them maintain their distinctive characters over the greater part of the world, and far back into geologic time.

Some other impediment, or more than one, must exist; and one-possibly one of the most important-is to be found in the movement of the river water, constantly directed towards the sea, always advancing, as it were, against a possible invasion. The effect is probably indirect. The prevailing method by which marine animals obtain a distribution over extensive areas is by means of free-swimming larvæ. The sedentary oyster, although unable when adult to leave the oyster bed, passes its early life in a round of dizzy movement (Fig. 54*).

* This figure represents the larval form of Dreissena, but will serve to illustrate the general appearance of a larval oyster. 
During this period of free larval existence it is at the mercy of winds and currents; these and its own movements carry it far and wide from the place of its birth, and thus it becomes distributed over large areas. What is true of the oyster is true also of thousands of other kinds of organisms, and the peopling of the sea by slowmoving or stationary animals has been accomplished chiefly, if not wholly, in this manner. But obviously no new forms can have been introduced into existing river systems through the agency of free swimming larvæ, for these fragile and feeble forms can by no means make headway against the steady flow of a river; indeed, as a matter of observation, larvæ are not known to swim against currents, but rather along with them. And thus the method which has been most potent in disseminating organisms through the sea has been wholly inoperative in transferring them to a freshwater habitat.

Further than this, if some slow-moving animal should manage in the adult state to work its way from the mouth of a river for a short distance up-stream, it could seldom succeed in permanently establishing itself so long as it passed through a free larval stage, for its larvæ would be carried out to sea, where they would perish or resume the ancestral habit.

Swift-moving animals such as fish are, of course, more advantageously situated, since they can rapidly travel a long way against a rapid stream, and may easily find some sheltered recess or quiet bend wherein their young may be brought to maturity.

Thus to difference in climate and in composition we now add a third obstacle, quite as efficient as either of the others, perhaps more so; and these, which must frequently act together, sufficiently bar the way against any general immigration from the sea. But, again, success engenders success, and the exclusion of some 
forms will entail the exclusion of others dependent upon them, which might not otherwise be disqualified.

The first stage in our inquiry is now completed, and we may next turn to the consideration of the means by which the marine ancestors of our freshwater fauna acquired their existing habitat.

There are at least three conceivable ways in which this may have been accomplished. Marine animals may (1) wander directly into rivers from the sea; slow-moving animals may go far with sufficient time; stationary aninals may be carried, like Birnham wood ; (2) they may acquire a terrestrial or marsh-loving habitat, and subsequently exchange this for a fluviatile or freshwater one; (3) the area they inhabit may be bodily transformed by some movement of the earth's crust into a more or less closed basin; during the conversion of this into a lake Nature will perform Beudant's experiment on a larger scale, and under much more favourable conditions than he could command.

If, now, we inquire by which of these ways freshwater faunas have originated, the answer will be, by all of them. The mammals and birds, insects and spiders, referred to in our list (p. 167) are modified land animalsthey have entered by the second route; the fish, or some of them at least, as well as some of the Crustacea, have come in by the first way, as direct immigrants; while many of the remainder have probably been captured by the closure of land-locked seas. Before examining this subject in detail let us turn our attention for a moment to the question of " establishment." To secure its place in running water the freshwater animal must lose its habit of propagation by free swimning larvæ, more especially if it be a slow-moving or fixed species; and this, as a rule, we shall find it has done; most freshwater animals of this kind, as well as others which are actively 


\section{MEANS OF DISPERSAL}

locomotive, have ceased to pass through a free larval stage. But mere fixity of tenure is not enough, i.e., it will not explain, for instance, the distribution of the same freshwater animals all over the British Isles, or in the case of many freshwater genera pretty well over the whole world. Free-swimming larvæ provide a means of distribution, and if this be lost some other must be found to take its place. Let us see how Nature has solved this problem. We may turn first to the remarkable case of our freshwater mussels, Unio and Anodon. The ova of these animals develop up to a certain stage within the

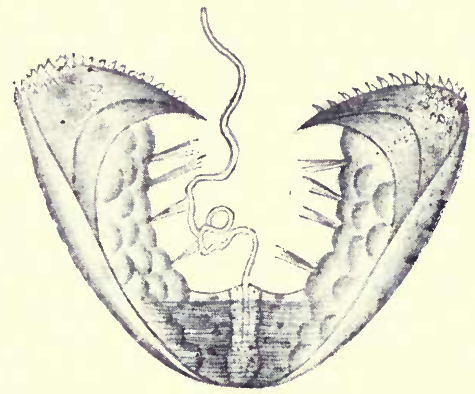

FIG. 52.-Larval form (glochidium) of the

Freshwater Pond Mussel. (x about 120.)

gill-pouches of their parent; they then somewhat resemble the spat of a sea mussel, in so far as they are provided with a small shell consisting of two valves; but they differ greatly in other respects, more especially by the production of the free edge of the valves into sharp, recurved hooks, and the possession of a long adhesive filament, technically known as the byssal filament (Fig. 52). They remain in the gill-pouch till some passing fish comes near, when they are discharged into the water, and attach themselves first by the byssal filament and then by the sharp teeth of the shell to its fins or tail. An 


\section{0}

\section{FRESHWA'TER FAUNA}

outgrowth from the wound they inflict closes over and encysts them, and they are carried about by their host and nourished at his expense till they attain the state of fully-formed young mussels. Then escaping from the cyst they drop to the bottom of the stream, and relinquish themselves to a sedentary life. In this way they become dispersed through the river they inhabit, and may even be transferred from one river system to another. As to the history of this cunning device we are entirely in the dark, but something might possibly be learned by observation of the fry of marine mussels. Pectens are known to make swift progression in the adult state by a series of leaps a yard or two in length, produced by a flapping of their valves, while Lima flies with the lightness of a butterfly. If young spawn are given to the same kind of locomotion, we might imagine that this was the first step towards acquiring the trick of the larval pond mussel. The next advance would be to hold on to objects of any kind, both animated and not. Grown-up bivalves have not infrequently been found tightly nipped on to the feet of newts and other animals (Fig. 55). From this to the selection of a fish might follow as a consequence of the advantage of obtaining nourishment, the advantage of dispersal following as an unforeseen result. All this, however, is a mere exercise of fancy, the poorest sort of substitute for knowledge; and besides, it would appear that larval freshwater musseis by the flapping of their valves do not fly, but simply produce an extension of the byssus.

It may be of interest to observe in passing that the mussel does not exact service from the fish in all cases without paying for it in kind. Thus in Central Europe a fish called the bitterling deposits its eggs by means of a long ovipositor in the mantle cavity of Unio or Anodon, where they undergo their development, and 


\section{MEANS OF DISPERSAL}

feed, when they become young fish, on the eggs of the mussel.

None of the other bivalves of our rivers or lakes offer an illustration so "sensational" as that of Anodon and Unio ; but in two of them, Cyclas and Pisidium, the free larval stage is suppressed, and development is intraparental. They have been seen holding on to the foot of various highly locomotive animals, such as the strong flying water beetle, Dytiscus (Fig. 53), as well as newts and frogs, thus recalling one stage in our fanciful

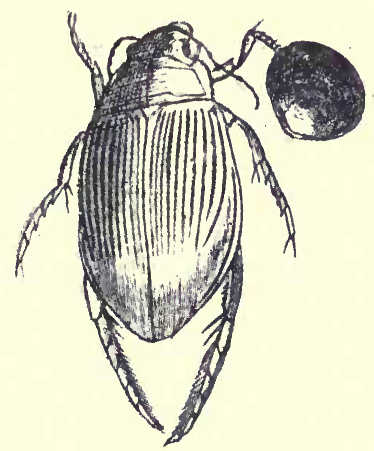

FIG. 53.-A Water Beetle, Dytiscus, a strong nocturnal flyer, with a bivalve, Cyclas cornea, holding on to one of its legs. After Kew,

"Dispersal of Shells."

account of the evolution of the mussel larva. It is obvious that by this means Cyclas and Pisidium might easily be carried from one river system to another.

Dreissena, which in outward appearance closely resembles the common sea mussel, offers the first serious exception to our rule, since it passes through a free larval stage of development, and the larvæ contribute freely to the floating population of lakes and rivers in various parts of Europe. The genus is, however, by no means so richly represented at the present day as it was during a 
great part of the Tertiary period, when it flourished in numerous extensive lakes and inland seas; and the species which is found in our islands, Dreissena polymorpha (Fig. 54), is said to be a recent immigrant, having made its appearance in the Thames and other rivers since the year 1824.* But its introduction is due to human agency; the mussel is provided with a byssus by which it attaches itself to floating objects, ships among others, and has thus been carried not only up the
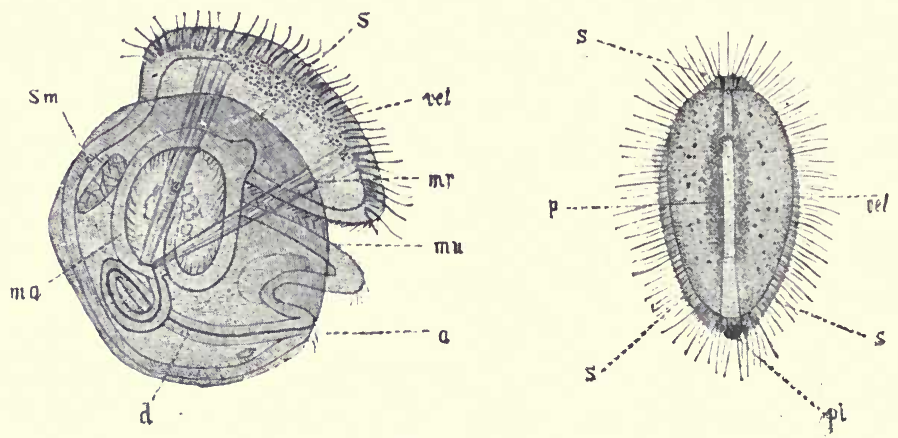

Fra. 54.-The Free-swimming Larva of Dreissena polymorpha, Pallas. Figure on the left, lateral view; on the right, as seen from below. $m u$. Mouth. ma. Stomach. d. Intestine. a. Anus. $s$. Sense organ. sm. Shell muscle. vel. Velum, bearing locomotive cilia. Magnified considerably.

Thames, but the Rhine, the Danube, and other rivers. Once introduced, its floating larvæ ensure its distribution over all that part of the river which lies below the highest point reached by the adult.

The freshwater univalves are Limnæa (the pond snail) (Fig. 56), Ancylus (the freshwater limpet) (Fig. 75), Planorbis and Valvata (Fig. 69), which belong to the Euthyneura, and Paludina (Fig. 55), Bithynia, and

* On this point see Scharff, "History of the European Fauna," p. 27. 
Neritina, which belong to the Streptoneura. None of them pass through a free swimming stage, as the majority of their marine relations do. The Euthyneura usually deposit their eggs in a jelly, which is attached to some foreign object, and the young emerge in a fullyformed state. Of the Streptoneura, Bithynia attaches its eggs to foreign objects, but Paludina is viviparous, and the young leave the mantle chamber of the parent as fully-formed adults. Since the univalves enjoy the power of creeping about, there is less necessity for devices to secure dispersal of the young, though the

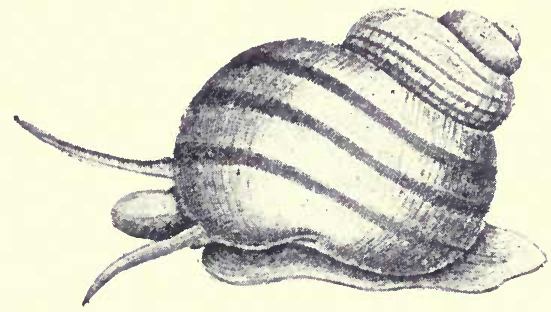

FIG. 55.-Paludina vivipara, Linn., a Freshwater Snail, which carries its eggs within its shell. Natural size. From Bronn's "Thierreichs."

attachment of the eggs may lead to this, for they are deposited on any surface that lies handy-stones, the leaves of plants, or the shells of other snails; and in ancient times, when crocodiles and tortoises were common inhabitants of our rivers, the hard surface of their scutes or armour would have suited the purpose admirably. Even the adult snail may get a lift on the back of one of these reptiles. A species of Limnæa has been seen riding on the backs of turtles which were kept in a pond near Belfast; and it would be strange if crocodiles and alligators, which lie like logs in the waters they infest, but travel swiftly enough in their annual migra- 
tions, were not sometimes made use of in the same way. Our freshwater genera had attained a wide distribution as early as the close of the Mesozoic æra, or even earlier; and hence, so far as this was brought about by the intervention of animal agency, it is to the extinct and not the existing forms of life that we must turn for an explanation. Amongst these, reptiles were so preponderant during the period when distribution was in progress that it seems not unnatural to attribute to them some share in the process. Whirlwinds sometimes act as a means of

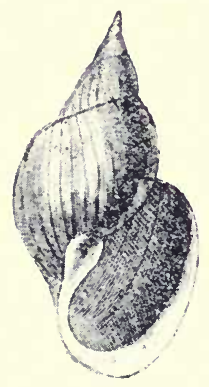

Fig. 56.-Limnca stagnalis, Linn., a Freshwater Snail. Natural size. From Bronn's "Thierreichs." transport, whirling bodies of water, full of living creatures, into the air, and showering them down in some distant place. Thus on February 9, 1859, a shower of minnows and sticklebacks fell in the valley of Aberdare; frogs have been rained down in the same way, and so has the freshwater mussel. *

Let us now descend to a lower stage of the animal kingdom, and consider first the freshwater sponges. Those of our islands, like the great majority of the family, are distinguished, whether they give rise to free larvæ or not, by a peculiar mode of propagation. Towards the end of autumn a number of the living cells, of which the sponge is composed, wander to certain points within it and accumulate in little heaps, as a preliminary to going into winter quarters (Fig. 57). Other cells then travel towards these heaps and invest them with a horny coat (Fig. 57, A); then still others come, each bringing with it a siliceous spicule which it has secreted within itself (Fig. 57, B) ; these spicules

* For a full account of these events see H. W. Kew, "The Dispersal of Shells," International Science Series, 1893. 

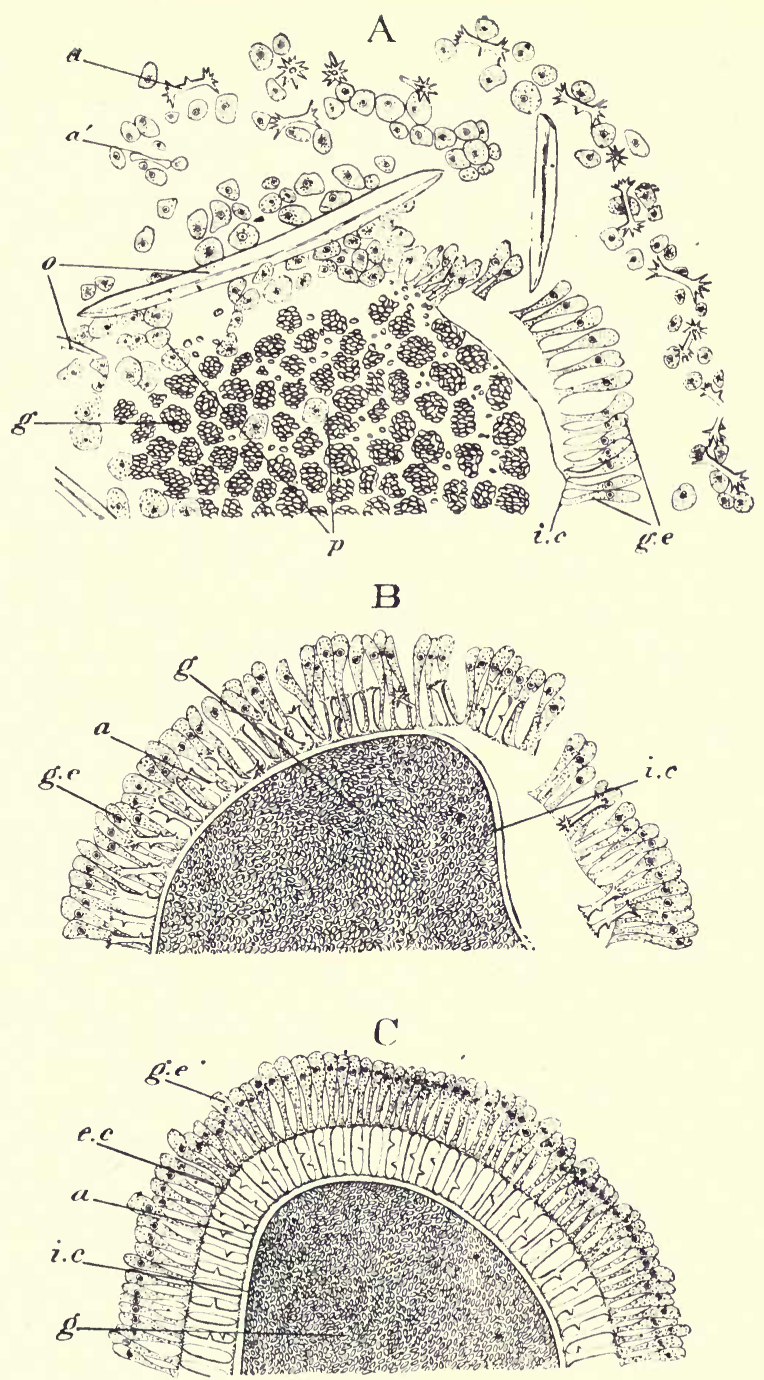

FIG. 57.-Three Stages in the Development of the Gemmule of a Freshwater Sponge, Elhidatia fluviatilis, Johnston. After Zykoff. (Only one-half the gemmule is shown in each case.)

A. g. Gemmule cells, destined to give rise to the young sponge. $p$. Amœboid cells. g.e. Glandular cells, which secrete the inner horny (chitinous) layer, i.c. a. Amphidisc spicules, shown at an earlier stage of development by $a^{\prime}$. o. Needle-shaped spicules which form the skeleton of the adult sponge.

B. Second stage. The inner coating of chitin (i.c.) is completed, and the amphidisc spicules $(a)$ placed in position.

C. Final Stage. The glandular cells (g.e.) have now retreated to the exterior, leaving the completed layer of amphidisc spicules behind. Magnified considerably. 
are regularly laid on to form a second coat around the first (Fig. 57, C). The finished product is a little round ball, containing living sponge cells in a state of hibernation, with a protecting double envelope, which is continuous save for one small hole. The rest of the sponge now disappears by death and decay, leaving only its bare skeleton and a multitude of the little seed-like balls or gemmules behind. Each gemmule is capable of giving rise to a young sponge, a fact that may be easily proved by any one who cares to make the experiment; the gemmules are not hard to find, and when obtained they should be dried and kept dry till spring: then if placed in
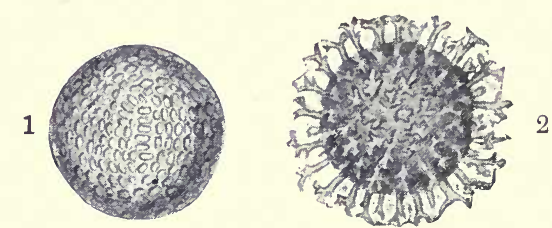

Frg. 58.-1. Egg of Hydra viridis enclosed in a horny shell. 2. Egg of Hydra grisea, with the horny envelope produced into spines. Both magnified. From Bronn's "Thierreichs."

fresh water a young sponge will soon make its appearance, creeping out of the small hole left for its exit.

A simple but important distinction is to be observed among the gemmules. Thus some are firmly attached to the skeleton of the dead sponge; these are the inheritors of the estate, and the young sponges to which they give rise clothe the skeleton of their parent with new flesh; but a host of others are not so attached, and these are free to float away with the stream, with a good chance of being washed ashore along its banks. They may then be dried by the wind and carried away by it for long distances, perhaps to other river systems. A vast number, no doubt, 


\section{DISPERSAL BY S'TATOBLASTS 187}

perish by the way, but this lavishness of material to ensure dispersal is nothing strange to the economy of Nature.

The formation of gemmules is not peculiar to our British freshwater sponges, but characterises the group all over the world. So far, only three or four exceptions are known to the rule, and these are met with in species which are somewhat recent immigrants into fresh water. In the tropics, where æstivation generally takes the place of hibernation, the gemmules are formed on the approach of the dry season.

The freshwater Hydra is the only member of the Hydrozoa which is at all generally distributed throughout
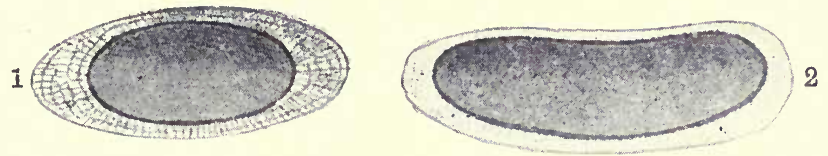

E'IG. 59.-Statoblasts of a Polyzoan (Plumatella fruticosa, Allm.). On the left the free form with its surrounding float; on the right the sessile form. Mignified 65 diameters. After Vosseler, from Lampert, "Das Leben der Binnengewässer."

our freshwater area, and this, in marked contrast to its marine relatives, does not pass through a free swimming stage; the egg is surrounded by a horny case (Fig. 58), and the young Hydra hatches out in the adult form.

The same avoidance of a free larval stage is manifested by the freshwater Polyzoa, the "statoblasts," which serve as seeds, reminding us in many respects of the gemmules of freshwater sponges: like these, some are secured to the parental skeleton, and others are sent floating on the stream to take what fortune they may find (Fig. 59). In two species (Cristatella mucedo and Pectinatella magnifica) the floating statoblasts are provided not only 
with the usual ring-shaped air-float, but with little spines terminating in recurved claw-like hooks (Fig. 60).

Two or three species exist which are unprovided with statoblasts: in one of these development appears to be intraparental.

The Rotifers, a vast number of which are of worldwide distribution, multiply by two different kinds of eggs; one of them, protected by a hard, thick covering, no doubt serves as a means of dispersal. An excellent summary of our knowledge on this matter is given by Dr. C. T. Hudson, ${ }^{*}$ from whom I quote the following: "How could these minute creatures, which are inhabi-

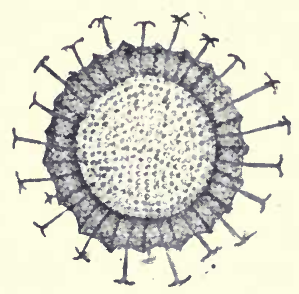

Fig. 60.-Gemmule or Statoblast of a Polyzoan (Cristatella. mucedo, Cuvier). ( $\times 40$ about.) tants of lakes, ponds, and ditches, contrive to spread themselves so widely over the earth? Take, for instance, the case of Asplanchna ebbesbornii, which, till quite lately, had but one known habitat, viz., a small duck-pond in a vicarage garden in Wiltshire. The very same animal has been found by Mr. Whitelegge in the botanical gardens at Sydney, New South Wales. No doubt in time it will be found elsewhere also: but how or when did it pass from the one spot to the other?

"Again, there is the strange Floscule, F. Millsii, . . . which has been found almost simultaneously by Mr. Whitelegge at Sydney, and Dr. Kellicott at Ontario. The possibility of its journeying between two such points seems quite as hopeless as that of Asplanchna ebbesbornii passing from New South Wales to Wiltshire.

"And such cases are numerous. How did Hydatina senta and Brachionus pala get to New Zealand? or Notops brachionus and Rotifer vulgaris to the top of Adam's * Nature, 1889, vol. xxxix. p. 437. 
Peak and the Pampas of La Plata? . . . You have, no doubt, long anticipated the solution of the puzzle, and see clearly enough that living creatures to whom a yard of sea water is as impassable a barrier as a thousand miles of ocean, could only have reached or left Australia, New Zealand, Jamaica, or Ceylon in the egg: not the soft delicately-shelled and quickly-hatching summer egg, but the ephippial egg, which is protected by a much harder and thicker covering, constructed to bear without injury a long absence from the water, and hatches, so far as is known, some months after it has been laid.

“... The case of the free swimming Rotifera is simple enough. They are, most of them, to be found at some time or another in small, shallow pools. . . . Such pools frequently dry up, leaving the ephippial eggs. . . . Then comes boisterous weather, and the dusty surface ... is swept by the wind, which raises the dust high in the air, ephippial eggs and all. For these latter are minute things : few exceeding one-three-hundredth of an inch in length, and many even half that size. Once raised in the air, I see no reason why they should not be driven by aerial currents unharmed half round the globe.

"To this aerial carriage of the eggs is due the fact that when any Rotifer is found in one spot, it is frequently found at the same time in closely-neighbouring ponds and ditches, even in such an unlikely hole as the print of a cow's foot filled with rain, but not at all in more promising places at some distance off.

"The eggs of the tube-makers (Fig. 61), however, and of such Rotifers as live only in the clear water of lakes and deep ponds, present a greater difficulty, for their eggs either lie within their tubes or are attached to growing weeds, or fall down to a bottom which lies covered all the year round with several feet of water. The wind and sun cannot be the only means of dispersion. Aquatic birds 
and dogs are probably assisting agents. The birds as they swim among the water-plants must frequently set free the eggs from the tubes of the Rhizota, as well as those which adhere to Confervæ, Potamogatons, and water-lilies, and so get them attached to their feathers.

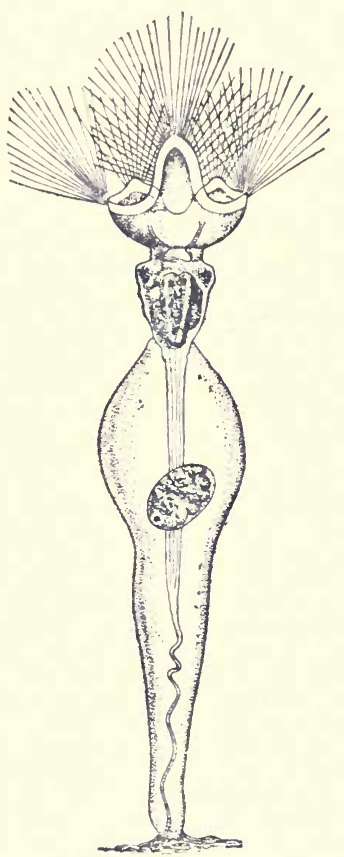

FIG. 61.-A Tube-making Rotifer (Floscularia longicaudata, Hudson). After Magnified about 100 diameters. Hudson and Gosse.

Then away they fly, carrying the eggs to some far-off lake, or shaking them into the air with the flapping of their wings.

"In confirmation of this idea, I may mention that the wellknown naturalist, Mr. John Hood, of Dundee, informs me that the Scotch lakes most prolific in new and rare species are those which are annually visited by wild fowl from the North."

I have given this quotation at some length, since it admirably states and meets the difficulties presented by the problem of dispersal, and its explanations are not restricted to the case of the Rotifers, but will be found to apply to the other classes of organisms which multiply by means of winter eggs.

No doubt many of the minute Crustacea are disseminated by the wind as well as by birds; some of them resemble the Rotifers in the production of two kinds of eggs.

The water-fleas, Daphnia, and its family afford an excellent illustration of this; development proceeds within the egg, and the young are hatched out fully 
formed. In summer, when algal growth is excessive, the Daphnids gluttonise on a mass of pasturage far beyond their requirements ; the excess of nourishment, powerless to increase the size of the individual beyond its fixed limits, is converted into summer eggs, which develop parthenogenetically within a brood chamber inside the shell. The number of individuals is thus enormously increased, but the supply of food persistently remains in excess of the demand and multiplication continues unchecked.* Now the feast is made ready for the fish ; perch, bleak, ruff, sticklebacks devour greedily the Daphnids and hosts of other minute crustaceans. Then,
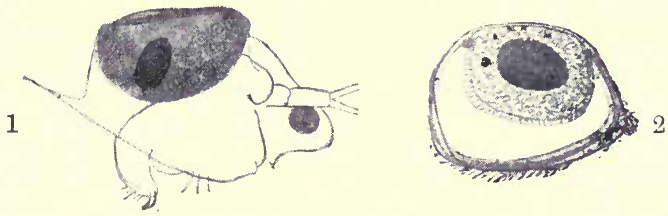

FIG. 62.-The Winter Egg, or Ephippium, of the Water Fleas. 1. Alona quadrangularis. $(\times 25) 2$. Scapholebris mucronata. $(\times 20$.$) From Lampert,$ "Das Leben der Binnengewässer."

as summer passes, the algal growth quickly falls off, and the Daphnids form their winter eggs, which are fertilised, well provided with yolk, and enclosed in a protective covering, the "ephippium" (Fig. 62), death follows and the Daphnids disappear, leaving the ephippial eggs at the bottom of the water, where they lie till spring comes round, when they give rise to fully-formed young Daphnids. At least one exception is, however, afforded to the last statement; the large and beautiful Daphnid, Leptodora hyalina, which enjoys a pelagic existence in

* Thus the formation of summer eggs both in Rotifers and Cladocera would seem to be an adaptation to the rapid appearance of a large supply of food. The annual cycle of excessive multiplication followed by a high death-rate may help to account for the exceptional preponderance of freshwater genera in these groups (sce p. 170). 
lakes, produces a winter egg, which floats freely on the water and gives birth to a larval form known as a nauplius (Fig. 66 shows the nauplius of a prawn).

Cyclops and the Copepods generally carry their eggs about with them, the young hatch out as a nauplius; the eggs of some of the Phyllopods, such as Apus, endure desiccation without injury, and are all the better for it;

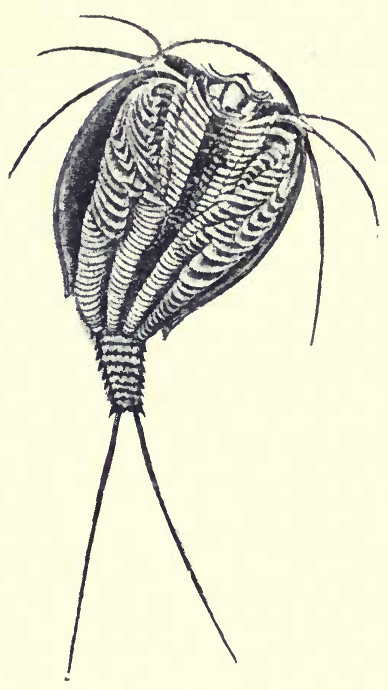

FIG. 63.-Apus cancriformis, a Freshwater Crustacean, whose eggs require to be dried in order to hatch. ( $\times$ 2.) From Lampert, "Das Leben der Binnengewässer." indeed, unless previously dried they do not develop. The eggs of the Ostracods, Cypris, and its allies will also bear desiccation. The dispersal of these forms may, therefore, be readily brought about.

The Amphipods (sand-hoppers) carry their eggs about, tucked under the abdomen, and the young are born in the mature form with their full number of segments and limbs. The same is true of the Isopods.

Palæmon (Fig. 64) is a prawn which lives in fresh water, though not in this country; it differs from its marine relatives (Fig. 65) which are set free in the zoëa stage (Fig. 66), by hatching out at a later stage of development, in a form more advanced than the mysis (Fig. 67).

The case of Palæomonetes, a sub-genus of Palæmon, is precisely similar, as has been shown by Professor Weldon. Palcomonetes vulgaris lives in the North Atlantic, sometimes ascending brackish water estuaries or even entering fresh water. After hatching out from the egg it moults 
five times before reaching the mysis stage. Examples which had acquired a brackish water habitat at Saltram Park, near Plymouth, were found to possess larger eggs than their marine relations, and the newly-hatched young

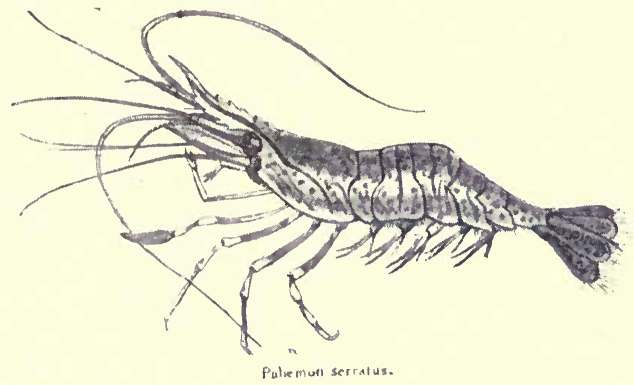

Fig. 64.-The Freshwater Prawn, Palamon serratus, which hatches out at the stage shown in Fig. 69. Half natural size.

moulted only three to four times before attaining the mysis stage.* But in the south of Europe this species has acquired a purely freshwater habitat, and is known under the name $P$. varians. This produces larger eggs than the brackish water forms examined by Professor Weldon, and hatches out at a stage much later than the mysis. ${ }^{\dagger}$ In North America the same species has also

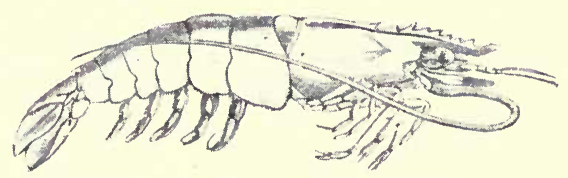

Fig. 65.-Peneus, a Marine Prawn. Onequarter natural size. After Fritz Müller.

become adapted to a freshwater life. Although practically the same species, it is distinguished as P. potiuna;

* Weldon, Journ. Marine Biol. Assoc., vol. i., n.s., 1889, p. 459.

† Paul Meyer, Mitth. Staz. Neaple, 1880, p. 197. 


\section{FRESHWA'TER FAUNA}

this produces larger eggs than the marine forms, and also enters upon life in a more advanced stage of development than the mysis.*

The freshwater crayfish bears its eggs with it, attached to the swimmerets of the abdomen, like the lobster. The young, however, unlike those of the lobster, are provided
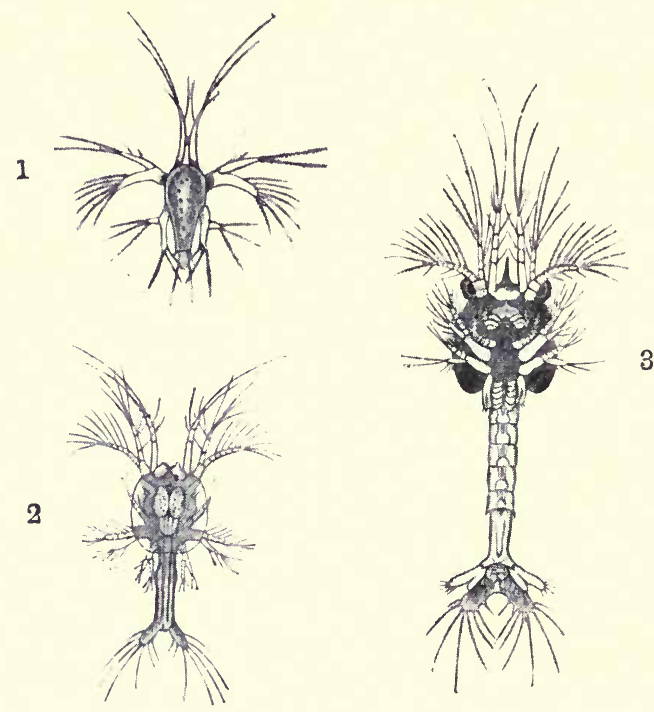

FIG. 66.-The Development of the Marine Prawn Peneus. 1. The first stage, or nauplius. 2. The second stage, or zoëa. 3. The zoëa somewhat farther advanced. Magnified 20 diameters. After Fritz Müller.

with sharply-hooked claws, by which they can hold on to the parent after they have entered upon a free existence.

As a result of this somewhat lengthy review it clearly appears that the majority of freshwater animals are provided with one device or another, sometimes surprisingly ingenious, for securing their place in a medium which is

* Faxon, Bull. Mus. Comp. Zool. Harvard, 1.979, p. 303 
always threatening to carry them to sea; and further, for ensuring their dispersion over extensive freshwater areas.

We may now return to an inquiry which we suspended when we set out to search for this result. We had enumerated three conceivable ways by which marine animals might enter the freshwater world; we abstained from adding a fourth, for that marine animals may be carried by birds or other organisms or winds, and plumped down into rivers and lakes, there to assume a freshwater existence, does not appear probable to us, however much it may to others. Our first step will be, then, to inquire into the evidence afforded by geology as to the conversion of marine areas into lakes. The first recognised existence

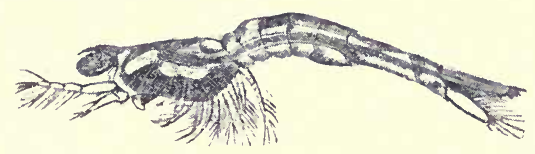

FIG. 67.-Further Development of Peneus. The mysis stage. Magnified 20 diameters. After Fritz Müller.

of lakes occurs in the Devonian period. The previouslyexisting Silurian sea became gradually differentiated into a northern region of lakes, which have left their sediments as the Old Red Sandstone, and a southern region which retained its marine character. The transformation took place under circumstances which afforded an opportunity for the contemporaneous development of a freshwater fauna. The lakes were possibly not all fresh, some may have been salt, but it is certainly significant that in the Old Red Sandstone of Ireland we know of one fossil, far from rare at Kiltorcan, which was pronounced by no less an authority than Edward Forbes to be a genuine ancestor of the existing pond mussel. This shell, now known as Palcanodonta Jukesii, is altogether different in 
character from the marine lamellibranchs of Devonian age ; and judging by its size, which rivals that of existing Anodonts, appears to have flourished under remarkably favourable circumstances. Somewhat recently, Amalitzky has described the occurrence of another group of freshwater shells, possibly related to Anodonta, from the Devonian beds of Russia; these are the Anthracosiidæ, which are also met with in these islands in beds of the Carboniferous system, and under such conditions as suggest their freshwater nature. In deposits of upper Permian age, Amalitzky has also discovered specimens of Palæanodonta, Oligodon, Palæomutela, and several genera of the family Anthracosiidæ; in association with Estheria, Cypris, and remains of plants and reptiles. The worldwide distribution of Unio and Anodon at the present day, and their extraordinary richness in subgenera and species, are in complete harmony with their appearance thus early in the stratified series.

The freshwater crustacean Estheria is also first met with in the Devonian rocks, Cypris in the Carboniferous.

No freshwater univalves have yet been recorded from Palæozoic rocks,* but land shells (Pupa and Conulites) closely allied to Helix, the common garden snail, have been found in the Carboniferous deposits of Nova Scotia (Fig. 68). But the pond snail (Limnæa), the freshwater limpet (Ancylus), and Planorbis are no very distant relatives of the Helix family, and might, therefore, fairly be looked for in rocks of the same age. We do not actually encounter any of them, however, till the Jurassic period, and Ancylus does not occur before the Miocene, though Acroloxus, a member of the family Ancylidæ, is found in the Laramie beds or uppermost Cretaceous of North America.

* Suess cites Planorbis from the coal measures of Upper Silesia. "Das Antlitz der Erde," vol. ii. p. 303. 
The next great lacustrine period began with the Permian and continued through the Trias. During this interval extensive lakes covered a large part of our northern continents: some were evidently salt, but

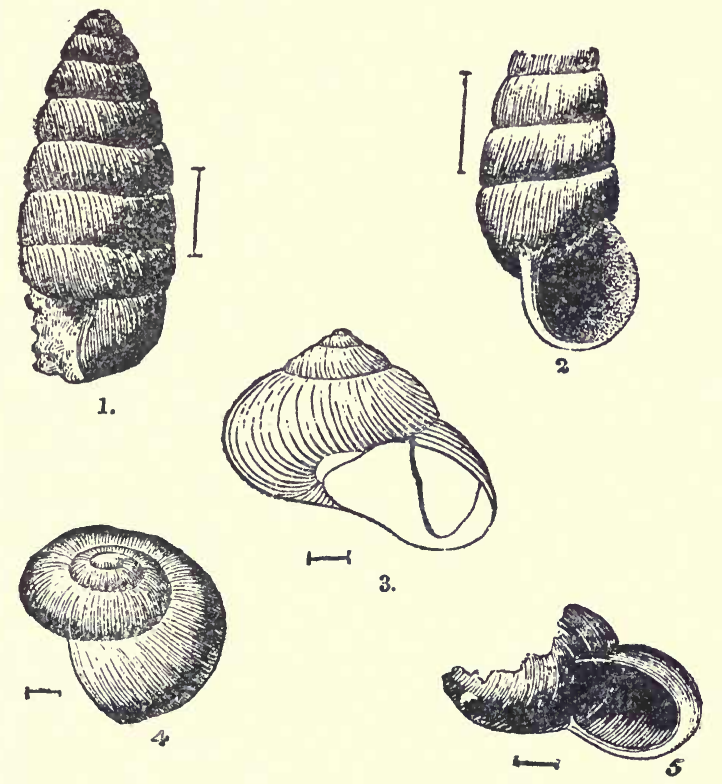

FIG. 68.-Air-breathing Shells from the Carboniferous System in North America. From White, "Nonmarine Fossil Mollusca."

1 and 2. Pupa vetusta, Dawson, after Dawson, from the coal measures of South Joggins, Nova Scotia.

3. Dawsonella Meeki, Bradley, after Whitfield, regarded by Dawson as allied to Helix, but according to Whitfield it approaches Helicina.

4 and 5. Zonites priscus, Dawson, found in association with Pupa retusta, and referred to the Arionidæ. After Dawson.

presumably not all. Unfortunately, except in Texas, where four species of Unio have been described from the Trias, these have not left behind sediments containing freshwater fossils. But in the immediately 
succeeding beds of the lower Lias we find Cyrena, Neritina, and, according to C. Moore, a species of Planorbis and two species of Valvata. Moore's identification of the last-named genus has been disputed, but I see no reason to doubt the accuracy of this cautious and sagacious observer. It is scarcely necessary, however, to argue the point, since recently Valvata has been described by M. Cossman * from the inferior Oolite of St. Gauthier, in the department of Indre, France. In the inferior Oolite we also find Cyrena, Corbula, Planorbis, Paludina, Hydrobia, Neritina, and Melania.

Thus even in these early Jurassic times a large number of our freshwater shells were already in existence, and this is precisely what their cosmopolitan distribution might have led us to expect. No doubt their origin antedates their first appearance, by how long an interval it is difficult to say, but in some cases a limit may be found by reference to the marine families with which they are most closely allied, and from which they have probably been derived. This is rendered possible by the fortunate fact that marine are much more abundant than freshwater shells, and far more frequently met with in a fossil state.

Melania, a member of a very large and heterogeneous family, was for a long time a common inhabitant of our rivers and lakes; but, with the increasing refrigeration of our climate, it left us for warmer regions, and is not now met with nearer than the south of Europe. The family Melaniidæ are freshwater representatives of the Cerithiidæ, which also affect the warmer zones, and are chiefly distinguished from the Melaniidæ by their marine habit. In connexion with this it may be observed that the majority of the Melaniidæ are viviparous; this is not the case with the Cerithiidæ.

* Bull. Soc. Geol. de France, 1899, Ser. III., vol. xxvii. p. 136. 


\section{JURASSIC FRESHWATER SHELLS 199}

The Cerithiidæ are certainly not older than the Trias; this, then, is also the earliest date we can assign to the Melaniidæ, which may certainly have originated in portions of the Trias sea, isolated from the open ocean and converted by the influx of rivers into lakes.

Neritina is in very much the same case as Melania, except that it is still an inhabitant of our area. It has affinities with Trochus and Turbo, the representatives of families which were already in existence in Cambrian times, but it is still more directly connected with the Neritidæ, marine forms, many of which are not averse to brackish or even fresh water; they are not known before the Trias, and this, then, is the limit to the past history of Neritina.

A similar argument may be applied to Hydrobia, a brackish water shell, first cousin to our existing Bythinia; its ancestral stem is the family of Littorinids, of which a familiar representative is the common periwinkle. They date from the Silurian, but

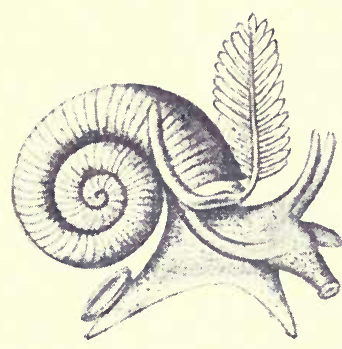

FIg. 69.-Valvata piscinalis, Müll. The gill plume, an archaic feature, is well displayed. Magnified. From Bronn's "Thierreichs."

Hydrobia is probably connected with the main stem through the intermediary family of the Rissoids, which make their first appearance at the beginning of the Jurassic period.

Paludina traces its descent from the ancient stem of the Trochids and Turbonids, which, as already mentioned, are found fossil in Cambrian sediments. It may possibly have originated in Devonian lakes, but its absence from Carboniferous and Permian rocks would suggest a later date.

Valvata (Fig. 69) is a little shell of considerable interest. 
Its nervous system almost precisely resembles that of Bithynia, and it has close affinities with the Rissoids; but it is distinguished by more than one strikingly archaic character, of which the possession of a bipectinate gill plume is the best known; it is also said to be hermaphrodite, but Bouvier considers that this needs confirmation. The Rissoids, as we have seen, are derived from the Littorinids, and were, no doubt, once connected by a series of intermediate forms. These may be spoken of as pro-Rissoids, and there would be nothing unreasonable in the supposition that Valvata is the transformed descendant of one of these pro-Rissoid links, and retains some of the archaic characters of its ancestors. The transiormation might well have been accomplished in some Trias lake.

The affinities of Cyrena and Corbula also indicate the Trias as the earliest date at which they are likely to have come into existence.

Thus the oldest known horizon on which Mesozoic freshwater fossils occur in a favourable state of preservation is the inferior Oolite, and a consideration of the zoological affinities of the various genera which this has yielded leads to the conclusion that their origin cannot be pushed further back than the Trias, though it may possibly be later; while the known occurrence of lakes during the Trias points to the existence of circumstances favourable to the evolution of freshwater forms of life.

Passing upwards in the stratified series we reach the deposits of the Purbeck and Weald, which at their base show a gradual passage from marine to freshwater conditions, but we cannot definitely claim them as lacustrine; this they may be, but according to the prevailing opinion they are to be regarded as deltaic sediments. They present us with most of our existing freshwater mollusca, and with many genera that no longer inhabit northern 
Europe. The following is a fairly complete list: Unionida : Unio ; Cyrenida: Cyrena, Corbula ; Valvatida : Valvata; Hydrobiida: Hydrobia, Amnicola (now living in North America), Bithynia; Neritida: Neritina; Melaniida: Pleurocera, Lioplax, Goniobasis, Leptoxis, Ptychostylus; Auriculida: Auricula, Carychium ; Limnaida: Limnæa, Planorbis; Mactride: Gnathodon. The last-named is commonly classed as a sub-genus of Mactra; it may have become specially modified in middle Jurassic times, for the genus is not known earlier than the Coral rag. Gnathodon still inhabits fresh water in the region of the Gulf of Mexico, and the Melanids, which occur in rich development, are closely related to North American forms. Beyond this the list calls for no special comment; many of the more important genera were, as we have seen, in existence at an earlier period.

Now we ascend a step higher in the series, and enter the uppermost part of the Cretaceous system. In North America this is represented by the Laramie beds, the sediments of a great lake or inland sea, which covered an area of 50,000 square miles. In the north the Laramie beds extend through Montana and Dakota into British Columbia; in the south they reach New Mexico; towards the west they may be traced as far as the south-west of Utah; they disappear east of the Rocky mountains, but probably underlie a part of the Tertiary beds of the great central plain. Their thickness is at least 5,000 feet, and they pass gradually down into the marine Cretaceous sediments below them. An inland sea of such magnitude would be long before it became completely freshened by the influx of rivers, and the passage from salt water to brackish or freshwater conditions would be accomplished in the most gradual manner. We are thus presented with all the circumstances favourable to the success of a grand experiment in the transformation of species. If, 
now, we turn to the fossils of the Laramie beds, we shall be disappointed when we find that a great number of them are forms such as were already in existence at a much eariier date, the fundamental elements of our existing universal freshwater fauna; ex. gr., Unio, Anodonta, Cyrena, Sphærium, Pisidium, Limnæa, Planorbis, Physa, Neritina, and Valvata, as well as Melanids, which present the same characters as at present distinguish the Melanids of North America.

This, however, need not occasion any surprise, for the forms just enumerated had long previously acquired the freshwater habit, and sufficient time had elapsed to ensure their dispersal over widely-extended areas. As an indication of this it may be pointed out that some of these forms are known to occur in approximately contemporaneous deposits of India, where we find, associated with the great lava flows of the Deccan, sediments containing Unio, Physa, Paludina, Valvata, Limnæa, and Pisidium. That already existing species should take advantage of the opportunity to colonise a new freshwater area is, indeed, only what we might expect.

But there are other shells present in the Laramie beds, some of which may well be regarded as relics of a marine fauna; such are several species of oyster, mussel (Volsella), and Anomia. Others which we might at first be apt to regard in the same light appear on further investigation to have originated elsewhere; such, for instance, are the two important shells known as Pyrgulifera and Goniobasis macilenta (Fig. 70). These are of such extreme interest in another connection, to be considered later, that they demand some little attention. Pyrgulifera humerosa, to give it its full name (Fig. 78), has been identified by Tausch with certain freshwater shells found fossil in beds of about the same age as those of Laramie, but 
occurring at Ajka, in Bakony, Hungary; and when similar and contemporaneous freshwater shells are found in localities so remote from one another as Western North America and the heart of Europe, the chances are immensely in favour of their having originated at some earlier date than the beds in which they are found. Pyrgulifera can scarcely, therefore, be regarded as indigenous to the Laramie beds. Goniobasis arctica

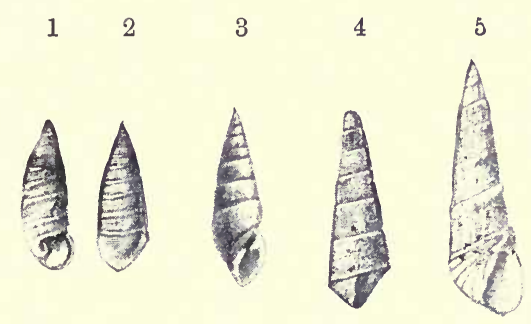

FIG. 70.-Goniobasis, Fascinella, and Syrnolopsis.

1 and 2. Fascinella, found fossil in the Cosina beds of Southern Europe. After Stache.

2. Syrnolopsis ancyana, Bourg., from Lake Tanganyika. After Bourguignat.

4. Goniobasis macilenta, White, and 5, Goniobasis chrysalis, Meek, are both found fossil in the Bear River beds, Laramie, North America. Twice natural size.

and G. macilenta, again, appear to closely resemble a little shell named by Stache, Fascinella, of which there are two species, F. eocenica and F. lacustris, found fossil in the Cosina beds of the Karst, in Carinthia, Istria, and Dalmatia. These beds, which contain abundance of Chara, a freshwater plant, are associated with coalbearing deposits at their base, and they lie between the upper Cretaceous and the lowest Alveolina beds of the Nummulitic limestone, so that, while they may be 
somewhat younger than the Laramie, they cannot be of a very different age. The Cosina beds contain a number of handsome freshwater shells, of which it may suffice to mention Melanopsis and Stomatopsis (Fig. 71); in the Ajka beds a Unio-like shell-Spatha-is of interest, since this now lives in the Nile, and its presence has suggested a connection of these beds with Africa. We shall recur to these facts later, and especially to

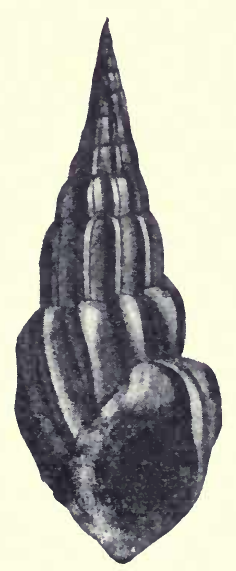

Frg. 71.-Stomatopsis, a Freshwater Shell, from the Cosina beds of Istria. After Stache, from Neumayr, "Erdgeschichte."

Pyrgulifera and Fascinella, but now we will resume our exploration of the stratified series. Disregarding many important deposits, we will pass at once to the great development of lakes which characterised the European area in the middle of the Tertiary period. In the Miocene, a great inland sea, the Sarmatian sea covered a large part of Europe and Asia; commencing west of the present termination of the Alps, it extended past Vienna, covered the south of Russia, the northern part of the site of the Black sea, proceeded still further east, embraced the Caspian and the sea of Aral, and may possibly have been continued further into Asia. Its waters were salt, and its fauna remarkably poor in species, though such as are present are often represented by an immense number of individuals. At the close of the Miocene the Sarmatian sea was converted into a number of brackish and freshwater lakes, which persisted throughout the lower Pliocene or Pontic period, some of them even later; indeed, some of the existing lakes of Europe, notably the Caspian, may be regarded as their direct descenlants. 
As in the case of the Laramie period, a large number of the freshwater inhabitants of these lakes were descendants of freshwater genera, which had been in existence for a long time previously, but some of them were fresh acquisitions from the sea. Cardium, the cockle, was one of these, and gave rise to some new genera under the
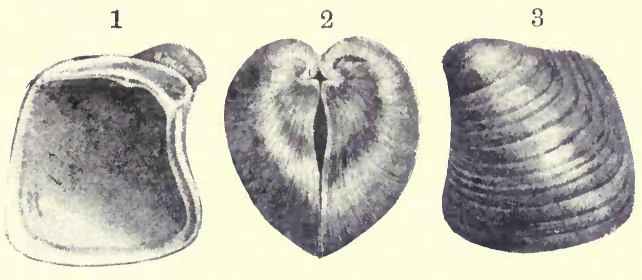

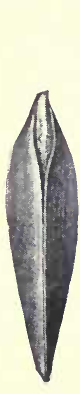

5

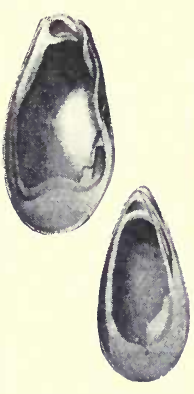

8

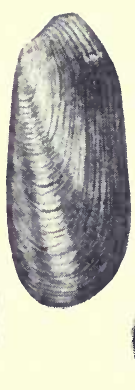

6

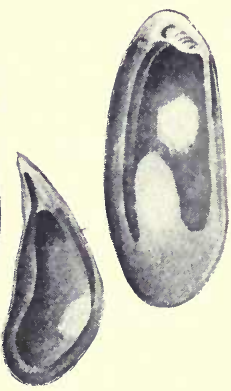

7

FIG. 72.-Congeria, from the Pontic beds. All the figures in this series are reduced a little more than one-half. 1,2,3. Congeria subglobosa. 4. Dreissenomya aperta. 5, 6, 7. D. Schrockingeri. 8. Congeria Czizeki. 9. C. spatulata. After Neumayr, "Erdgeschichte."

changed conditions to which it was exposed; Adacna is an example. Lithoglyphus, a transformed periwinkle, was another capture. Both this and the cockles still survive in the waters of the Caspian, and Lithoglyphus also inhabits the Danube. The shells which attained the most remarkable development in the Pontic lakes are the 
Dreissenas and Melanopsids (Figs. 72, 73). Both are poorly represented in rocks of an earlier period, Melanopsis in the middle Cretaceous, Dreissena in the Oligocene ( $D$. unguiculus of the Headon Hill beds), but now they burst out into a sudden and exuberant efflorescence; some of their forms, worthy to rank beside the robuster kinds of sea-shells, are shown in Fig. 73. A second, but less luxuriant, expansion took place in the middle Pliocene, and to-day these forms are richly represented in the

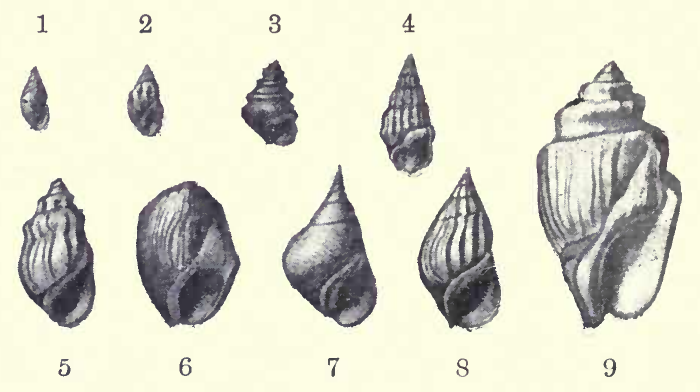

Frg. 73.-Melanopsidæ from the Miocene and Pliocene beds. The figures in this series are about twothirds natural size. 1. Melanopsis pygmaa. 2. $M$. Bouei. 3. M. atolica. 4. Melanoptychia Bittneri. 5. Melanopsis Heldreichi. 6. M. Vindobonensis. 7. M. Gorceixi. 8. M. Proteus. 9. M. Martiniana. After Neumayr, "Erdgeschichte."

Ohio basin of North America and some of the rivers of China.

The freshwater beds which succeed the Pontic deposits are the Levantine, corresponding approximately with the marine middle Pliocene in age. They are distinguished by their rich variety of freshwater shells, and especially by numerous forms of Paludina. Neumayr in a remarkable study of the latter has been able to trace the evolution of a series of species which, commencing with a form very similar to that of our own rivers, that is, with smooth 
rounded whorls, becomes continually more conical, keeled, and ridged, till at last it passes into the extremely modified shell shown in the figure (Fig. 74).

One point of interest presented by the freshwater shells of the Levantine stage is their resemblance to those of the west of America, on the one hand, and the south of China on the other. Indeed, in the case of the existing lake of Talifu, in the province of Junnan, South China, this resemblance is so great that Neumayr * speaks of the lake as the last survivor of the Levantine series.

In the Baltic we are presented with a sea in which marine species are now undergoing a transformation into brackish water forms. During the glacial period its basin was filled with the ice of confluent glaciers, and as this began to melt away its place was taken by fresh water. A great lake resulted, peopled by fresh-
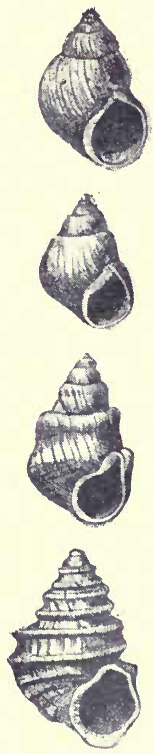

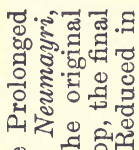
क्ष
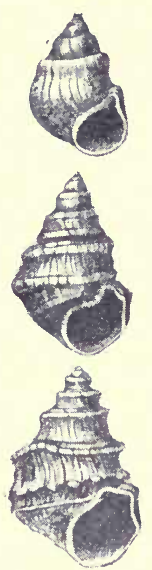
s.. कis

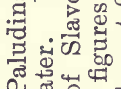
का

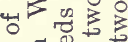

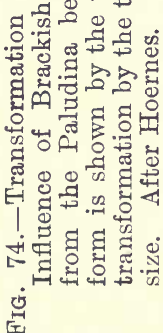
water forms, of which the little freshwater limpet, Ancylus (Fig. 75), was one of the most abundant; hence the lake has been named the Ancylus lake. Subsequently a subsidence of the Scandinavian mass placed the Ancylus lake in communication with the North sea, which, as it entered, brought with it a marine fauna. The saltness of the Baltic is far from uniform, the water on the east side being much * Neumayr, "Erdgeschichte," vol. ii. p. 536. 
fresher than that on the west; opportunity is thus afforded to the marine inhabitants to adapt themselves to brackish or even freshwater conditions ; many of them have succeeded in doing so, more have failed; the former have paid for their success by a diminution in bodily bulk. Moebius and Heincke remark that the characteristics of the brackish as opposed to the saltwater fauna are fewer species, represented by individuals of comparatively small size, which are present, however, in immense numbers.

These, it will be recalled, are the distinctive features of the Sarmatian fauna.

We have now completed our review of the successive transformation of marine into lacustrine areas, and have found the freshwater fauna increasing in complexity with

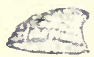

FIG. 75.-The Freshwater Limpet, Ancylus fluviatilis, Müll.

the flow of time. The passage from Silurian to Devonian would seem to have brought into existence Unio and its allies, that from Permian to Trias may have supplied the greater part of the Mollusca, which are now almost universally distributed. With each successive later transformation these enforce their claims to the new freshwater domain, but some few additional marine forms contrive to adapt themselves to the changed conditions and contribute a slight accession to the freshwater fauna.

There still remain a few lakes which have been regarded as relic scas, and foremost among these is lake Tanganyika, concerning which a large volume by $\mathrm{Mr}$. J. E. S. Moore was published in 1903, under the title of "The Tanganyika Problem." This lake contains, in addition to the common and widespread freshwater genera, which are common to it and the other great lakes 
of central Africa, a peculiar fauna of its own, which is even more marine-looking than the Melanopsids of the Pontic beds. A little jelly-fish, Limnocnida tanganyicaa, also occurs, the second known instance of a jelly-fish inhabiting fresh water, the first (Fig. 76) having been discovered in the tanks containing Victoria regia at Regent's Park; its original home is supposed to have been Brazil. There are also crabs, belonging to the freshwater family of Thelphusidæ, some sponges, and a polyzoon, Arachnoidea ray lankesteri.

The molluscs are of great interest, particularly as throw-
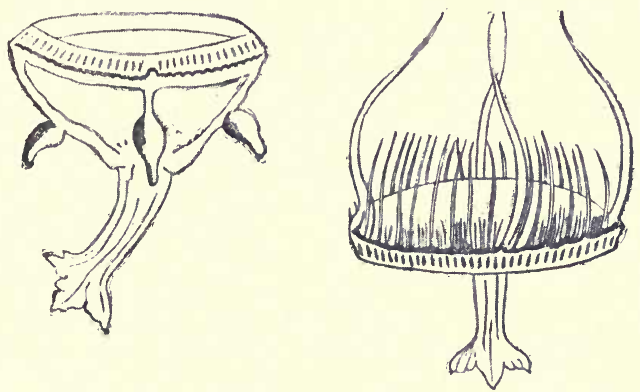

Frg. 76.-The Freshwater Jelly-fish, Limnocodium victoria. The figure on the right shows the jelly-fish as seen floating. After Lankester.

ing additional light on the anatomy of the Melaniidæ and Melanopsidæ. According to the evidence furnished by the dissection of the nervous system by Mr. J. E. S. Moore, five of them are members of the Melaniidæ; these are Tiphobia (Fig. 77), Bathanalia, Paramelania (Fig. 78), Tanganyicia, and Bythoceras, which have a very marine appearance. Another, Nassopsis, agrees in the structure of its nervous system with Melanopsis, but is described as possessing a labial commissure, a somewhat archaic character. These, then, enlarge our knowledge of an already recognised freshwater group, but there are 
others which cannot be so summarily dealt with: these are Chytra and Limnotrochus, which find their nearest affinities with marine forms, especially Capulus and Aporrhais; and Spekia, which is said to be nearly allied to an existing marine shell, Lamellaria perspicua. The existing Lamellaria is a genus of recent date, first known in the Pliocene, but it belongs to an ancient family, the Velutinidæ, which contains some forms not at all unlike Spekia in outward appearance. Syrnolopsis, the last of the peculiar Mollusca of Tanyganyika, is known only by its shell, its anatomy not yet being worked out. In

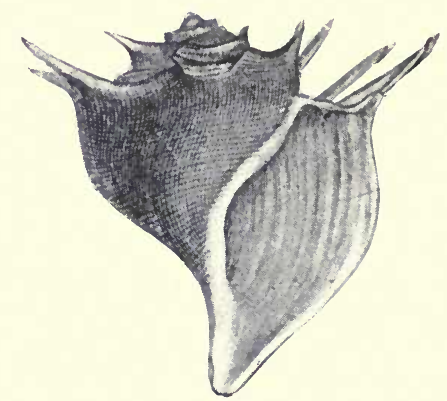

FIG. 77.-Tiphobia Horei, from lake Tanganyika. After Crosse, from Bronn's "Thierreichs."

addition to Mollusca with close affinities to marine genera, there is also present the little jelly-fish, Limnocnida tanganyicca, which, however, is not restricted to Tanganyika, but occurs also in the Victoria Nyanza. This, we might suppose, must surely have been captured by the isolation of a marine area : it certainly seems very unlikely that creatures so sensitive to changes in the composition of the environment would voluntarily make their way from the sea to a river; still, instances are known in which they have gone far in this direction. Dr. J. von Kennel has described lagoons bordering the 
coast of Trinidad, how produced he does not say, which communicate at times with the sea, and then receive a number of marine inhabitants. When subsequently the water of these lagoons becomes fresh, several of these animals, adapting themselves to the changed conditions, continue to live on, and amongst these is a jelly-fish, of which Dr. von Kennel tells us nothing further, except that it is not a Limnocodium. The transformation of a marine jelly-fish into a freshwater one has thus been brought about in a very simple manner, without invoking the tremendous machinery of earth movements. This, however, is only the first step to account for the presence of a jelly-fish in the interior of a continent; it must next be shown that the creature is capable of making its way up the course of a river, and on this point we have little evidence. A great jelly-fish, Crambessa Tagi, is described by Haeckel as ascending the Tagus till it reaches quite fresh water, and other instances of a similar kind are on record. In considering the possibilities of the case we should neglect none, however unlikely it may appear at first sight, and there is one which we must not overlook. Although Limnocnida is not known to pass through the hydroid stage now, yet it may once have done so ; Limnocodium still does, as we know from the descriptions of Dr. A. G. Bourne.* If, while in the hydroid stage, it grew attached to the outer skeleton of some actively locomotive animal, such, for instance, as one of the reptiles which abounded in Mesozoic times, and even at a later date, then, on the further supposition that its host sometimes made excursions from the sea into fresh water, we should have a means by which the hydroid might be introduced. The natural objection to this hypothesis will be found in the danger attending a rapid transference from a salt to a freshwater medium, and * Proc. Roy. Soc.. vol. xxxviii., 1884, p. 9. 
this would be fatal were it not for the fact that at least one genus of the Hydrozoa, Cordylophora, seems to be able to survive somewhat rapid changes in the saltness of the surrounding water, and is introduced into our rivers by vessels sailing up from the sea.

Mr. Moore very definitely maintains that the whole of the peculiar forms of Tanganyika are to be regarded as a relic fauna found dwelling in a relic lake; i.e., that lake Tanganyika was at one time an arm of the sea, and that its peculiar fauna were originally marine inhabitants of that sea. On the supposed similarity of some of the Mollusca to Jurassic fossils, he assigns a date to the sea, and regards it as having been in continuous existence from an early part of the Jurassic period. Mr. Huddleston, our leading authority on Jurassic shells, is unable to find any very close resemblance between the peculiar Tanganyika shells and the Jurassic fossils which have been compared with them; * on the other hand, some of these shells already existed as freshwater forms at the close of the upper Cretaceous period. Thus Paramelania has been identified by White and Tausch with Pyrgulifera (Fig. 78), which, we have seen, is found in approximately contemporaneous beds in North America and Europe; the same is true of Syrnolopsis, already identified with Fascinella; further, the association of Spatha with these forms in Europe naturally suggests a connection with Africa. It is quite within the bounds of possibility, therefore, that the Tanganyika fauna, or at least a part of it, is a survival of the once widely-distributed freshwater fauna of the uppermost Cretaceous deposits. The introduction of this fauna into lake Tanganyika may have been a comparatively late event. If much stress is to be laid on the resemblance of Spekia to Lamellaria, then even the Pliocene is suggested, and the presence of the * W. H. Huddleston, Geol. Mag. Dec., VI., vol. i. p. 338, 1904. 

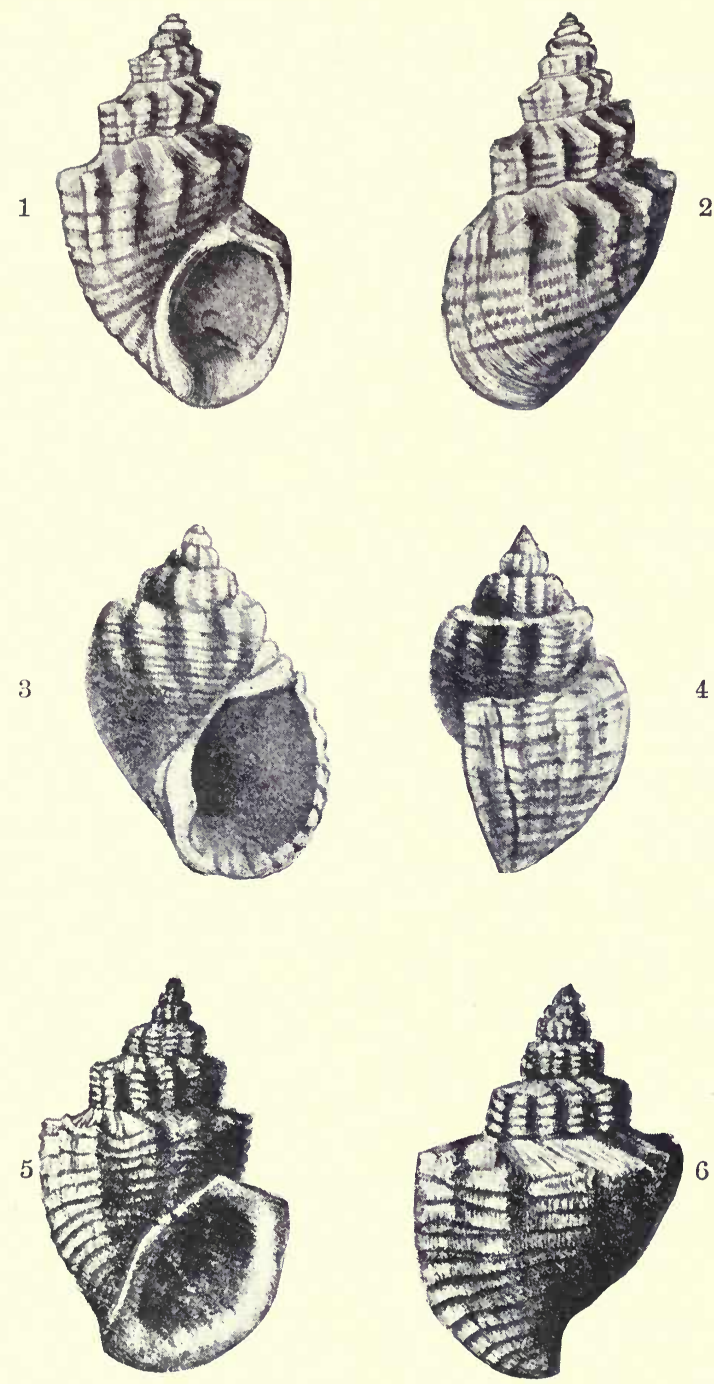

Fig. 78.-Pyrgulifera and Paramelania.

1 and 2. Pyrgulifera humerosa, Meek, found fossil in the Bear River Beds, Laramie, North America. After C. A. White. 3 and 4. Lavigeria coronata, Bourg., or Paramelania Damoni, E. Smith, from Lake Tanganyika. After Bourguignat. 5 and 6. Paramelanı Damoni, E. Smith. After J. E. S. Moore. 


\section{FRESHWATER FAUNA}

large Paludina-Neothauma-points to this period. This shell recalls the Paludinas, described by Neumayr, from the Pontic beds, especially in the singular modifications which it presents. According to Mr. Moore, its different forms characterise particular bays, as though they were the result of special local conditions; while Neumayr's forms succeed one another in different beds; there is, however, a possibility that Paludina will at any time respond to a similar change of conditions by passing
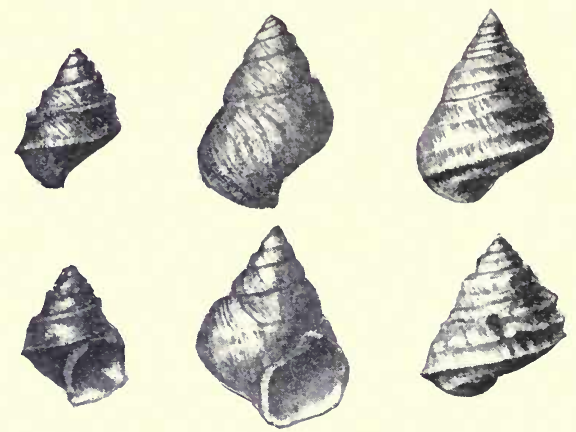

FIG. 79.-Paludinas from the Laramie beds and lake Tanganyika. The four figures on the left, Neothauma Tanganyicense, from Lake Tanganyika. After J. E. S. Moore. $\left(\times \frac{2}{5}.\right)$ The two on the right, Tulotoma Thompsoni, White, from the Laramie beds of North America. After C. A. White. $\left(\times \frac{2}{3}\right.$. $)$

through a similar series of forms. This seems very likely, and finds confirmation in the fact that a Paludina of the Laramie beds presents similar varieties, i.e., conical and keeled, to those of the Pontic beds and the Tanganyika bays.

The region in which the fauna took its origin is unknown, it can scarcely have been Tanganyika. Mr. Huddleston has summed up the geological evidence on that point and given an adverse judgment, but it may 


\section{LAKE BAIKAL}

possibly have been situated not far off. Thus, during Jurassic and Cretaceous times a gulf of the sea extended over the east of Africa; its deposits succeed one another as a series extending through the lower Oolites to the upper Cretaceous, and for twenty-five miles inland from the coast we meet with Eocene beds containing nummulites ; but no intercalations of freshwater beds are known among these sediments, so that the gulf seems to have been in free communication with the sea throughout its existence. It is of course conceivable that the most western part of the gulf might have become cut off from the rest by a rising ridge of land, and then converted into an inland sea; but if this had persisted long enough to give birth to a freshwater fauna, it ought to have left some traces of its existence in the form of sedimentary deposits, but none are to be found. It may be answered that such sediments were formed, but have since been destroyed, or that they are still in existence, but have not yet been discovered; these apologies may indeed be admitted, but they do not supply the place of evidence.

At present the problems presented by lake Tanganyika are unsolved; they are of great interest, and their solution will possibly be found to involve important consequences; all the more necessary, therefore, that it should be based on sufficient evidence: this, we may hope, will be furnished with the progress of exploration.

A somewhat similar difficulty is presented by lake Baikal; this, in common with the Caspian, the sea of Aral, and many other sheets of water in Europe, contains relics of the Pontic fauna, but it does not follow that lake Baikal itself is a relic sea; like Tanganyika, it seems to be of comparatively recent origin. In this case also we must be content to wait for the clue which future discoveries may provide.

It remains now to refer to the possibility that some 
freshwater organisms, besides swift-moving forms, like fish, may have entered a river system directly from the sea. In our islands we might be apt to underestimate the chances in favour of this method; our rivers where they approach the sea are burdened with sediment, our tides run high, and in estuaries where tide and river meet, a vast quantity of mud is constantly suspended in the water. As a consequence, the tides, though they bring with them flotsam and jetsam from the sea, do not succeed in introducing any additions to our freshwater fauna. It is quite possible to conceive of far more favourable conditions than these, and such appear to exist in a number of cases. Dr. von Kennel mentions marine mussels (Mytilus), a small species of Pholas, and a marine worm, Lumbriconereis, as living in the fresh water of the river Ortoire, Trinidad, eight miles above its mouth. Dr. Perceval Wright describes a freshwater Teredo, Nausitora Dunlopi, as occurring in the river Hurreegovga, a tributary of the Ganges; and we have already called attention to the great jelly-fish, which ascends the Tagus till it meets with fresh water. A sea snail, Natica helioides, which lives off the coast of America, has found its way into the rivers of Mexico. The list might be added to, but these examples will suffice to show that direct introduction of slow-moving marine forms does sometimes occur, and even if it happen very rarely, yet rare events scattered through the many millions of years of past time may sum up to a very respectable total. It thus becomes an extremely difficult matter to assign their true relative values to the two principal methods by which the freshwater world has been peopled from the sea.

Let us now cast a brief retrospective glance over our somewhat discursive argument. The first step taken by the marine organism in qualifying for a freshwater existence is to surmount the obstacle presented by the 
difference in composition of the two media. A considerable number of marine organisms appear to be endowed with the requisite adaptability, but not all: further information is required on this point, and a wide field of experiment here lies open.

The second step is to acquire some means of defence against extremes of climate, chiefly against cold in the temperate regions, against drought in the tropics. This is attained by the production of eggs or gemmules protected by resistent envelopes, or by the habit of hibernation or æstivation.

The third step is to obtain fixity of tenure and means of dispersal. This has been anticipated already by the formation of the protected eggs and gemmules, though some trifling modifications have been added to fit these for both purposes.

There are some freshwater animals, like Dreissena, which have not taken the third step; their hold on the freshwater is consequently precarious.

An organism may take the first step while residing near the mouth of a river, and may then enter the river basin either by its own unaided exertions or as a passenger carried by a fish, reptile, bird, or, in these days, by boat. On the other hand, a whole world of marine organisms, for no fault of their own, may become imprisoned in a closed sea by movements of the earth's crust, and if this should become filled with fresh water by the influx of rivers, they are under compulsion to take the first step or perish. Probably but few survive.

A study of the earth's crust reveals to us the repeated formation of lakes by the process just imagined, and following the existence of these lakes, or even contemporary with them, a number of freshwater animals make their appearance.

And finally, a study of existing rivers discovers to us 
here and there marine animals, which have wandered into them directly from the sea.

Thus the origin of our freshwater faunas is complex, having been accomplished, sometimes in one way, sometimes in another.

It would appear that the particular forms which succeed in completely adapting themselves to a freshwater life are relatively stable organisms. Like the marine Lingula * - which has persisted from the Cambrian times down to the present day-they are capable of much endurance; they have withstood change of medium, they can suffer extremes of climate, often they survive prolonged desiccation; and with this hardiness of nature there is possibly associated a rigidity of structure, an absence of plasticity, which has led to their retention of ancestral characters through a long period of time. Such modifications as they have undergone are chiefly in adaptation to the inorganic environment: in the sea, adaptation to the living environment plays a relatively much greater part.

* Morse, speaking of Lingula and the group of Brachiopods to which it belongs, says: "The tenacity of life manifested by this group is almost beyond belief. The Testicardine Brachiopods do not possess this tenacity, and we may correlate with this fact the infinite diversity of form shown by them since they first made their appearance in geological time." 


\section{VIII}

\section{THE INFLUENCE OF OXFORD ON THE HISTORY OF GEOLOGY}

NE of the most immediate effects produced by contemplation of the world around us is that of pleasure in its abounding beauty. Whether we wander through the smiling country which surrounds this University, or climb the snowy peaks of the Alps, or visit the sunlit islands of the Tropics, wherever we turn, the feeling expressed by a German poet will spontaneously arise, "Oh! Wunderschön ist Gottes Erde, Und Schön auf ihr ein Mensch zu sein "- "Beautiful is God's Earth, and good it is to be a Man thereon."

This æsthetic delight, while it may sometimes suffice for the poet, is succeeded generally by a desire for closer acquaintance; a certain Divine curiosity implanted in the breast of man leads him to search into the inner mysteries of Nature, and to explore the causes of the wonderful phenomena which surround him. He begins to examine and compare, to analyse the complex into its elements, and to build up again the elements into a new and intellectual cosmos. Thus he gains a new pleasure from contemplation of the world, and labouring in the pleasant work of investigation experiences the joy of discovery. 


\section{0 'THE HIS'TORY OF GEOLOGY}

The pleasures of sport are generally supposed to be those to which the soul of the Englishman is most deeply responsive. Thus the famous Darwin, writing of his youth, remarks: "The autumns were devoted to shooting . . . my zeal was so great that I used to place my shooting-boots open by the bedside when I went to bed, so as not to lose half a minute in putting them on in the morning. . . . How I did enjoy shooting!" But a little later and he writes: "During the first two years my old passion for shooting survived in nearly full force, and I shot all the birds and animals for my collection myself; but gradually I gave up my gun more and more to my servant, and finally altogether, as shooting interfered with my work, more especially with making out the geological structure of a country. I discovered, though insensibly and unconsciously, that the pleasure of observing and reasoning was a much higher one than that of skill and sport."

This fragment of personal history seems to me even more impressive than the glowing words of Thierry, who, although himself an invalid, wrote, "Il y a au monde quelque chose qui vaut mieux que les jouissances matérielles, mieux que la fortune, mieux que la santé elle même, c'est le dévouement à la science!"

So much I have ventured to say in eulogy of all science. Of my own subject I would only add that it enjoys what is supposed to be a thoroughly English characteristic, it is fond of the open air; its best work can only be accomplished in the open air ; it is there that its greatest triumphs have been won, and must continue to be won.

Many great discoveries have been made by observers who did not consciously set out with a predetermination to discover something, but whose imagination was fired by some object or occurrence rather out of the ordinary 


\section{NATURE OF FOSSILS}

course of Nature. As Bacon has observed, "It is probable that Prometheus, when he first struck the flint, must rather have marvelled at the spark than expected it." With the advance of science we become less open to surprises, and the number of discoveries due to some happy chance constantly tends to diminish; such, on the other hand, are peculiarly characteristic of science in its infancy. It would appear that the strange phenomenon which first directed attention to the problems of geology was the occurrence of curious stones, such as are now termed fossils, that, having a likeness to the hard parts of animals and plants, are yet found, to the surprise of the observer, lying embedded in the substance of rocks which form the interior of a country often at a great dis. tance from the sea, and sometimes at a great elevation above it, as in the case of fossils in the Himálaya, which are obtained from that lofty mountain chain at a height of 16,000 feet.

No doubt the nature of fossils had awakened a lively interest in very early times. In Babylonia, that ancient mother of arts and sciences, many different kinds of fossils must have been familiar objects to the workmen who dug clay for bricks, or hewed stone out of the quarry; they were probably seen and pondered over by Chaldean philosophers, whose speculations concerning them were afterwards embodied in a mythical cosmogony.

In ancient Greece they were well known and understood; but in Christian Europe, up to the sixteenth century, the civilised world was occupied with problems more important than the study of fossils; and even when in the revival of learning Fracastoro, Leonardo da Vinci, and Pallisy the potter uttered true words concerning them, these were little heeded, and it was not till after the middle of the seventeenth century that fossils com- 


\section{THE HISTORY OF GEOLGGY}

menced to arouse that serious attention which with increasing earnestness has continued to be given to them ever since. It is in two little books, one entitled " Canis Carchariæ Dissectum Caput," and the other "De Solido intra Solidum Naturaliter Contento," published in 1669 , that the germ of modern geology is to be found. They were written by the

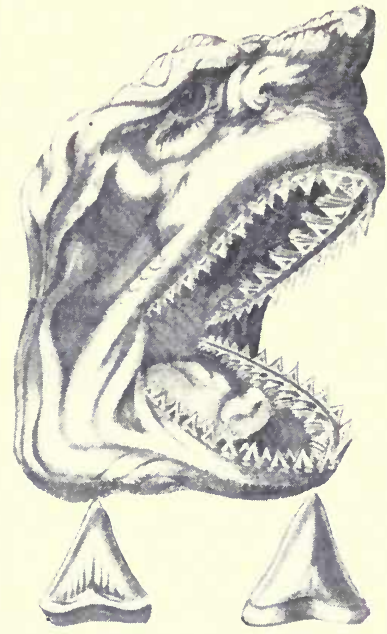

Fig. 80.-Steno's Figure of the Head of a Shark, showing its teeth, with two "glossopetræ " represented below for comparison. Taken from his work "Canis Carchariæ Dissectum Caput," 1669.

famous Steno, the true founder and father of our science. Steno was by birth a Dane, who occupied for a time the Chair of Anatomy at Padua. Dwelling thus not far from the shores of the Adriatic, he was able to make studies in marine zoology, and of these the most important was his dissection of a shark's head. Steno paid particular attention to its jaws and teeth, which are well worthy of study, as being probably the sharpest cutting instruments naturally produced. But these put him in mind of certain "glossopetræ" which are dug out of the ground in Malta, and on making a careful comparison of the fossil with the recent teeth he convinced himself of their precise similarity (Fig. 80). But according to Steno's logic, nothing but a shark could malie shark's teeth, and he consequently concluded that the ancient glossopetræ had once belonged to the mouth of a shark, and that the mouth opened into a shark's body behind it. You cannot assert, he remarks, that Nature 
will make the hand of a man without the man himself, and the argument is just as true of sharks' teeth. Lest the great numbers in which the glossopetræ occur should be thought a difficulty - they were carried away from Malta in bushels - he points out that every shark's jaw contains sixty teeth in good working order, and these as they wear out are continually replaced by fresh ones; further, he adds, sharks swim about in schools, so that a great many teeth will generally be found bristling about in the same place at the same time. Since sharks are very voracious creatures, the multitude of glossopetræ implies the existence not only of sharks, but of a whole world of other animals, including those which live on cockles and other shell-fish. That we next find Steno giving serious attention to the study of cockle-shells is only, therefore, what we might expect. He patiently traced the manner of their growth, and ascertained, with a degree of accuracy remarkable for those times, the minute details of their structure. From the living cockle he turned to the fossil shells, and by a careful comparison showed how they agree, feature by feature, both in form and more particularly in structure, with their modern representatives. This structure, Steno insists, is the direct result of the manner in which the shell is produced by the animal, and he concludes that the fossil, like the recent cockle-shell, once contained a living cockle inside it.

Having thus, by close observation and strict logic, breathed life afresh into these fossil remains, Steno proceeded to provide them with an environment: they were bathed, he says, with an ambient fluid, which was none other than sea-water; hence it follows that the lands in which such fossils occur were once submerged beneath the sea. This conclusion, he pointed out, is in complete harmony with the nature of the material of which the 


\section{4 'THE HIS'TORY OF GEOLOGY}

land consists, and in which the fossils lie embedded, for it resembles in the most striking manner the ooze of the sea-floor. In support of his argument Steno called attention to many interesting points of detail, such as the discovery of a fossil pearl-oyster, with a pearl still sticking to it: of fossil oysters perforated by galleries such as are produced by boring worms; and of another fossil shell, covered with barnacles, which were adherent to its worn surface, a fact from which he drew several ingenious conclusions.

Returning to the sediments in which fossils lie buried, Steno pointed out that they are distributed in beds or strata, which are frequently horizontal; and he concluded that the edges of each bed corresponded originally to the margin of some sea, and its lower surface to the sea-floor. In a series of beds all except the lowest were originally contained between two planes parallel to the horizon. In these statements there is contained implicitly the modern doctrine of super-position-i.e., that the order in which beds succeed one another vertically in space is the order in which they have been deposited, or the order of their succession in time. This is explicitly stated by Steno in another paragraph, "at what time there was formed any Bed, the matter incumbent on it was all fluid, and by consequence, when the lowest Bed was laid, none of the upper Beds was extant."

Steno, however, pursued his inquiry far beyond this stage. He proceeded to point out that some strata occupy an inclined or even vertical position, and he rightly inferred that these must have been tilted out of the horizontal by some natural disturbance subsequent to their formation.

The crowning triumph of Steno's achievement lay in the application which he made of these conclusions to the explanation of the structure of Tuscany. 
The structure of Tuscany as Steno conceived it is shown in the diagram on p. 226 (Fig. 81), copied from his work, "De Solido intra Solidum Naturaliter Contento." The mountains are for the most part composed of horizontal beds, C, F, but dislocated and sloping towards the low ground, on their flanks. On these fundamental rocks others of a later date, C, A, B, rest discordantly, and thus it appears that Steno was familiar with the important phenomenon now termed an unconformity. Now, since the strata were originally deposited as continuous horizontal layers, it follows that the rocks $\mathrm{C}, \mathrm{A}, \mathrm{B}$ at one time extended in an unbroken sheet between the flanks of the surrounding mountains, as shown in Fig. 2. Further, since the bed B, A, C could not have been selfsupporting, but must have rested on older sediments, the gap below it must have been filled up with a succession of horizontal deposits as shown in Fig. 3. This state of things, again, was not original; there was a time when these sediments did not exist, and the Tuscan district appeared as in Fig. 4. Once more, the argument which applied to the latest rocks holds equally for the older ones G, F, so that we must restore these, first as represented in Fig. 5, and next as in Fig. 6. Beyond the last stage, when Tuscany lay inchoate, a mass of sediments beneath a primæval sea, we can only take one step farther back into the abyss of time, and this brings us to a period antecedent to the deposition of any sediment whatever, and to a state of Tuscany which Steno does not venture to represent by a diagram.

Steno did not regard the explanation, just set forth, as restricted in its application to Tuscany ; but distinctly affirmed, from his knowledge of other countries, that similar reasoning would hold for every part of the world where stratified rocks occur.

The first to logically demonstrate the true nature of 16 


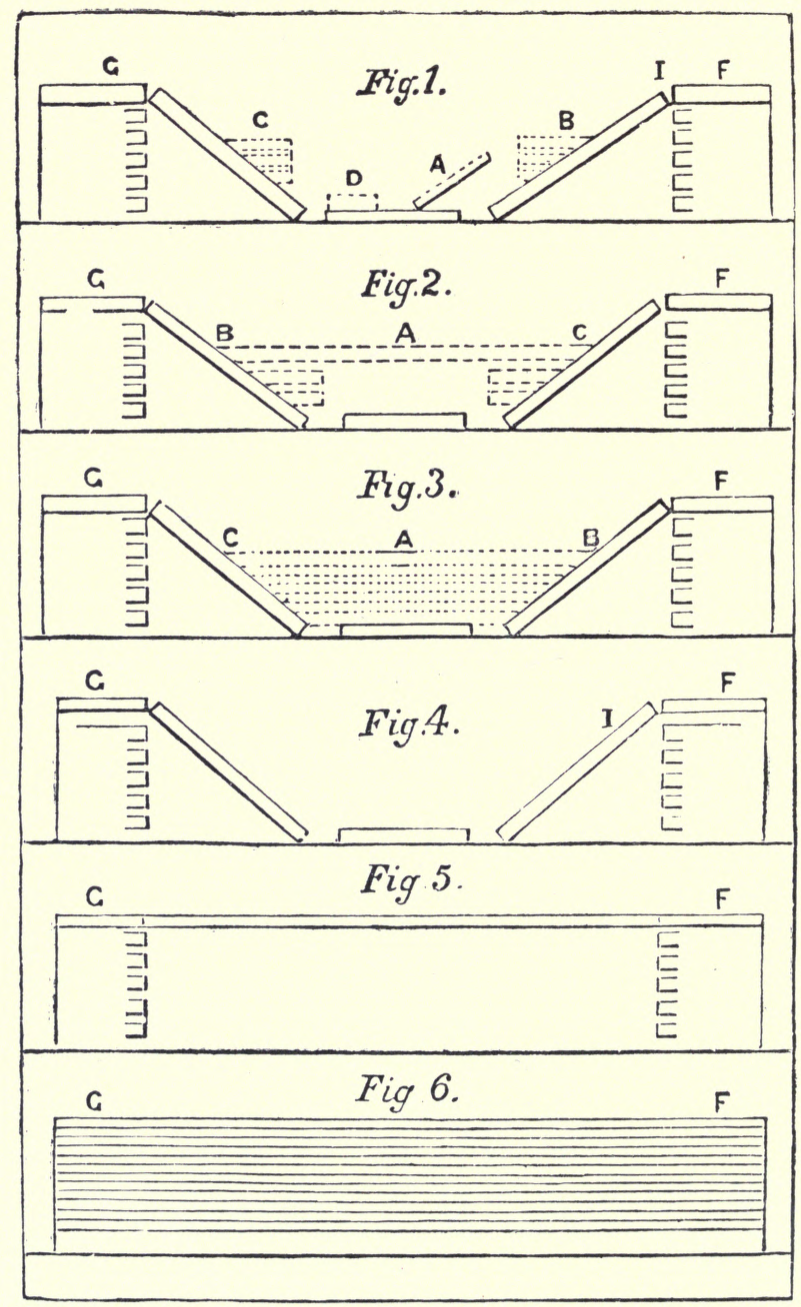

FIG. 81.-Successive stages in the History of Tuscany, as represented by Steno. 


\section{PLO'T}

fossils; the first to recognise the orderly sequence of deposits ; the first to perceive their occasional interruption by those discordances, which we now term unconformities; the first to employ geological structure to arrive at geological history and to inform us of the revolutions through which our globe has passed; said we not truly that this man was the father and founder of our science?

In attempting to carry his explanations farther and to push them deeper, Steno was less happy: his brave imagination, successful so far, was now to suffer from the restraints imposed upon it by a belief in the brevity of the world's existence. The stage which immediately preceded that represented by Steno's sixth diagram stood before his mind as the beginning of created times, and all the subsequent events of the earth's history had to be compressed into a poor 6,000 years! Without a more generous allowance of time no genius, however gifted, could hope to trace the slowly pacing processes of Nature; and the fame of Steno would undoubtedly have burned brighter had he desisted from the attempt and refrained from an endeavour to reconcile the irreconcilable.

Contemporary with Steno was the celebrated Dr. Plot of this University, the first keeper of the Ashmolean Museum, whose great work on "The Natural History of Oxfordshire" appeared in 1677, eight years after the publication of Steno's “De Solido," \&c. This was 220 years ago, in the middle of the reign of Charles II., about fifty years after the Fellows of Wadham College and their friends met together to bring into existence the Royal Society, for which the good king did so much by judiciously letting it alone; modern chemistry had but just sprung into being under the influence of Robert Boyle, and Newton's " Principia " had not yet enlightened the world. 


\section{8 'THE HIS'TORY OF GEOLOGY'}

"The History of Oxfordshire" is a very interesting work, full of queer old-world infornation, quaint digressions, and pleasant meanderings, winding gently on each side of the main current of discourse. It contains a map of Oxfordshire curiously bordered round with the arms of the resident nobility and gentry, and each of its excellent plates of illustrations bears a dedication in the corner to some noble patron, with the emblazonment of his arms.

Dr. Plot was evidently acquainted with the views of Steno, but he did not share them; on the contrary, he met them with a strenuous opposition, in which he displayed great resources of learning and dialectic skill. A whole chapter of the History is devoted to the description of the Fossils, or, as they are there termed, the "Formed Stones" of the county. It is illustrated by engravings which, for truthfulness, leave little to be desired, so that, even at this distance of time, there is little difficulty in recognising and identifying the different genera or even species that they represent.

The stones to which Dr. Plot first directs attention are those that stand in some connexion with the heavenly bodies, such as the Sun-stone, of which, however, there are none in Oxfordshire; the Moon-stone, or Selenites; the Asteriæ, or Star-stones, which are evidently the joints of the stem of a fossil, now called Extracrinus briareus; the Astroites, bodies of irregular form, but adorned with constellations of stars; these are clearly corals, such as are now named Isastrea and Thamnastrea; and finally such stones as are supposed, "by the vulgar at least," to be generated in the Clouds and discharged thence in the times of Thunder and violent Showers"; such are Belemnites, and Brontiæ and Ombriæ; in the two latter we now recognise several kinds of Sea-urchins. The author then passes to "The Stones that concern the Watery Kingdom" ; some of these are spars or minerals ; 


\section{PLO'T}

others are true fossils such as a "Strombites," which is compared to the living "Concha Tridacna," so called, the author quaintly observes, "because they made three Mouthfuls apiece," and he ingenuously adds that were "the Strombites not a Stone I must pronounce it the Same," i.e., as the living Tridacna. A "Conchites" of the kind we now term "Rhynchonella" is introduced to us, and in a digression we are informed that specimens of this "made red-hot and put into drink are accounted a present Remedy for a Stitch."

There is also a Pecten, which the author compares with the Pecten asper of Aldrovandus, and an Oyster (evidently Ostrea dilatata), of which it is remarked, "I could easily have assented that these ... might once indeed have been Shell-fish, but that (just as with the Escallops) we only find the protuberant parts of the Shells [convex valves] and never any of the flat ones." We then come to a fossil, now known as Cidaris, which is spoken of as " a curiously embroidered Stone, much resembling the petrified Riccio Marino, or Sea-Urchin of Imperatus," also known to old authors as Mamelles de Saint Paul and as Ova Anguina, "because from the Basis there issue as it were five Tails of Serpents, waved and attenuated towards the Upper part of the Stones." These "Old Authors" regarded it as "engendered from the Salivation and Slime of Snakes, and cast into the Air by the Force of their Sibilations: where if taken, has Effects as wonderful as its Generation, and therefore of great Esteem amongst the French Druids." "But," concludes our excellent author, "I care not to spend my time in Romance and therefore proceed," and so passes to the Cornua Ammonis, or Ophiomorphites, our Ammonites. Some of these are found "about Adderbury, about two Miles from Banbury, but . . . that the Town has not its Name from these Stones (as Mr. Ray thinks) I dare 


\section{THE HIS'TORY OF GEOLOGY}

confidently avouch, Adderbury being only the vulgar Name: for in the Court-Rolls of New College . . . it is written Eabberbury, perhaps from St. Ebba, the tutelar Saint of the Church."

The "Formed Stones" having been sufficiently described, Dr. Plot proceeds to a discussion of "The great Question now so much controverted in the World: Whether the Stones we now find in the form of Shell-fish be Lapides sui generis, naturally produced by some extraordinary plastic virtue, latent in the Earth or Quarries where they are found? Or whether they rather owe their Form and Figuration to the Shells of the Fishes they represent, brought to the places where they are now found by a Deluge, Earthquake or some other such means, and then being filled with Mud, Clay, and petrifying Juices, have in tract of time been turned into Stones, as we now find them, still retaining the same Shape in the whole, with the same Lineations, Sutures, Eminences, Cavities, Orifices, Points that they had whilst they were Shells?" "In the handling thereof" the author modestly disclaims any intention of arriving at a "peremptory Decision," and invites merely to "a friendly Debate." Let no one be beguiled, however, by these fair words, which are but the bow of a champion on entering the arena. It is true the debate proceeds smoothly enough, but it is also conducted according to all the rules of fence and with the art of a master. Steno's weakest point was the deluge, which he had to bring over Tuscany in his final explanation of geologic changes. Plot, with unerring instinct, makes straight for this. He considers first the difficult question of the means by which these fossils, if they were originally parts of living animals, could have been transported from the sea to the interior of the country: deluges had been suggested, but with deluges, whether Noachian, Ogygian, 


\section{ARGUMEN'T FROM ANALOGY 231}

Deucalonian, or purely local or national floods, Plot will have no dealings, alleging very sufficient reasons for regarding all deluges as unfitted, by their very nature, for the effects required; while as to earthquakes, he remarks, that to suppose "the Mountains (where such Stones as most resemble them [shell-fish] are now found) were heretofore low places and since raised by Earthquakes : [is] a thing by no means to be believed of our Northern Parts, where the Earthquakes we have at any time are so inconsiderable that they scarce sometimes are perceived, much less affrighten us; unless we shall groundlessly grant, that in the infancy of the World, the Earth suffered more concussions, and consequently more mutations in its Superficies, than it has done ever since the Records of Time":- an argument that cannot but appeal to every orthodox Uniformitarian.

Having thus shown an antecedent improbability against the view that fossils are the remains of organisms, he proceeds to attack the enemy in his stronghold. It is affirmed, Dr. Plot remarks, that "these Formed Stones are many of them in all repects, like the living Shell-fish: thus says Boccone, the Herrison's Spatagi of Stone, the Cornua Ammonis or Nautili Lapides have the very Marks, Characters, Eminences, Cavities and all other parts alike, with the true living Nautili, and Herrison's Spatagi, .. which proves, says he, the Body changed to have been the very same thing with that which is living. But I must tell him, it does but very weakly, all Arguments drawn a similitudine, being the most inefficacious of all others, such rather illustrating than proving, rather perswading than compelling an Adversary's Assent. For how many hundred things are there in the World, that have some Resemblance of one Another, which no Body will offer to think were ever the same, and particularly among some other Formed Stones hereafter to be men- 


\section{THE HISTORY OF GEOLOGY}

tioned. Such are the Stones Otites, or Auriculares, several sorts of Cardites, which though they as exactly resemble those parts of Men, from whence they have their Names as any Conchites or Echinites do those Shellfish: yet no Man that I ever heard of, so much as dreamed that these were ever the real parts of Men, in process of time thus turned into Stone. As well might we say that our Kettering Stone in Northamptonshire, here in England, was once nothing else but the spawn of Lobsters: than which that I know of, there is nothing more like." If I might express an opinion, I should say that, as it stands, this is a very excellent argument; but it would have been open to an opponent to reply that it is vitiated by one serious mis-statement: the simulacra of human organs which are referred to as Otites and Cardites do not as exactly resemble those organs as the Conchites and Echinites do those shell-fish; in the latter case the resemblances are far more numerous and precise, and are, if anything, more marked in the internal structure than the external form; so that, even when agreement in form fails, similarity in structure, which is all-important, remains. This cannot be said of the Otites and Cardites.

The argument is then pushed a step farther by pointing out that the resemblance between organism and formed stones is frequently not so close as is asserted: thus the Cornua Ammonis had been likened to the shells of Nautilus from which they certainly differ in important particulars; but in addition to these minor points of difference Dr. Plot triumphantly cites instances in which they had been observed with " heads." " "Vidimus enim lapidem hinc delatum serpentis in spiram revoluti effigie, cujus caput in circumferentia prominuit, extrema cauda centrum occupante,' are the very words of Mr. Cambden." Although this instance is an unfortunate one, since the 
"heads" were no doubt the work of some practical joker or fraudulent fossil-finder, yet the argument will not be greatly affected, since it is admitted that the fossil forms often differ markedly from their living representatives. The explanation of these differences had been arrived at long before by Palissy, and is suggested by a writer, bearing the illustrious name of Lister, who says truly that these fossils must be either "terrigenous, or, if otherwise, the animals they so exactly represent have become extinct." Referring to this, Dr. Plot remarks: "If it be said, that possibly these Species may be now lost, I shall leave it to the Reader to judge, whether it be likely that Providence, which took so much care to secure the works of the Creation in Noah's Flood, should either then, or since, have been so unmindful of some Shell-fish (and of no other Animals) as to suffer any one Species to be lost."

Since this was written we have learnt to accept the doctrine of the extinction of species; it has become a commonplace amongst the educated, and has passed into the language of our poets-

"So careful of the type she seems! But no!

'From scarped cliff and quarried stone,' She cries, 'a thousand types are gone!

I care for nothing; all shall go." "

After his exposition of the weak points in Steno's argument Dr. Plot proceeds to consider the alternative view, that the formed stones are the result of some "plastic force"; and as later writers have made merry over this expression, it will be merest justice to explain what Dr. Plot meant by it. Whatever the plastic force of Theophrastus may have been, that of Dr. Plot was certainly what we now recognise as crystallisation. His words 


\section{4 'THE HIS'TORY OF GEOLOGY}

are: "There is no other Principle that we yet know of naturally shooting into Figures, each peculiar to their own kind, but Salts, thus Nitre always shoots into Pyramids, salt Marine into Cubes, Alum into Octo" and Sal Ammoniac into Hexahedrums, and other mixt Salts into as mixt Figures.

"Of these spontaneous inclinations of Salts each peculiar to its $K$ ind, we have further evidence in the Chymical Anatomy of Animals, particularly in the Volatile Salt of Harts-horn, which in the Beginning of its Ascent is always seen branched in the Head of the Cucurbit, like the Natural Horn. And we are told by the very ingenious and learned Sidleyian Professor here in Oxon, That the Salt of Vipers ascends in like manner, and shoots into Shapes somewhat like those of Animals, placed orderly in the Glass. Thus in Congelations, which are all wrought by adventitious Salts, we frequently find curious Ramifications, as on Glasswindows in Winter, and the figured Flakes of Snow, of which Mr. Hook observed above an Huadred several sorts, yet all of them branched as we paint Stars, with six principal Radii of equal Length, Shape and Make, issuing from a Center, where they all joined in Angles of 60 Degrees.

"What Salt it should be that gives this Figure, though it would be hard to determine, yet certainly it must not be a much different one from that which gives Form to our Astroites and Asteria, whereof, though the latter have but five Points, and therefore making Angles where they are joined at the Center of 72 Degrees : yet the Astroites both in mezzo Rilievo and Intagli have many more.

"Perhaps there may be something of an Antimonial Salt that may determine Bodies to this Starry Figure, as no Question it does in the Regulus, and the Caput 
mortuum of the Cinnabar of Antimony. To such a Salt may also be referred our Brontice or Ombria, and all the Echinites, some whereof are plainly, all in some measure stellated at the Top.

"The Belemnites, which are all striated from a Center, yet in the whole affect a Pyramidal Form, seem to have somewhat also of an Antimonial, but a more prevalent Quantity of a Nitrous Salt.

"The Conchites, Pectinites and Ostracites, whether transversely striated, or from the Commissures to the Rim, seem to owe their origin to Urinous Salts, which start likewise from a Center (as suppose from the Hinges of these Stones), but generally are most extended to one side, as may be seen in the branched Figure formed on the Surface of Urine by freezing, as in Mr. Hook's Micrography, whose Strice not obtaining much above the Quadrant of a Circle, whatever other Differences they may be, in this respect at least is agreeable to our Stones.

“To which add the Ophiomorphit's or Cornua Ammonis, most probably formed either by the Salts shooting different ways, which by thwarting one another make a Helical Figure, just as two opposite Winds or Waters make a Turbo, or else by some simple, yet unknown Salt, that affects such a Figure: perhaps the Stems and Branchings bended in a most excellent and regular Order, like the ribs of some of our Ophiomorphit's, observed by Mr. Hook in Regulus Martis Stellaris, might not a little conduce to the clearing of this Matter."

The difficulties which beset this explanation are duly considered and disposed of; the last of them is so quaintly treated that I cannot forego the pleasure of quoting it. "That it seems quite contrary to the infinite Prudence of Nature, which is observable in all 


\section{6 'THE HISTORY OF GEOLOGY}

its Works and Productions, to design every thing to a determinate end, and for the attaining of that End, makes use of such ways as are (as far as the Knowledge of Man has yet been able to reach) altogether consonant and agreeable to Man's Reason, and of no way or means that doth contradict, or is contrary to Human Ratiocination: Whence it has been a general Observation and Maxim, that Nature doth nothing in vain. It seems, I say, contrary to that great Wisdom of Nature, that these prettily shaped Bodies should have all those curious Figures and Contrivances (which many of them are adorned and contrived with) generated or wrought by a plastick Virtue, for no other higher End than only to exhibit a Form. To which I answer, that Nature herein acts neither contrary to her own Prudence, human Ratiocination or in vain, it being the Wisdom and Goodness of the Supreme Nature (by the Schoolmen called Naturans) that governs and directs the Natura naturata here below, to beautify the World with these Varieties, which I take to be the End of such Productions as of most Flowers, such as Tulips, Anemonies, etc., of which we know as little Use as of Formed Stones. Nay, perhaps there may proportionately Number for Number be as many of them of Medicinal or other Use, such as Selenites, Belemnites, Conchites, Lapis Judiacus, etc., as there are of Plants: so that unless we may say also (which I guess no Body will) that these are produced contrary to the great Wisdom of Nature, we must not of Stones."

There were, however, certain fossils, known to Dr. Plot, the organic nature of which he was ready to admit, for they possessed not only the outward form of bones, but exhibited, though turned to stone, a characteristic bony structure. One of these was a thigh bone, of what nature it would from the descrip- 


\section{ELEPHAN'TS OR GIAN'TS?}

tion be difficult to say; it was found in the parish of Cornwell and is thus considered by the author: "It remains," he says, "that it must have belonged to some greater Animal than either an $O x$ or Horse: and if so (say almost all other Authors in like Case) in all probability it must have been the Bone of some Elephant, brought hither during the Government of the Romans in Britain: but this Opinion too lies under so great Difficulties, that it can hardly be admitted; which are briefly these:None of the Roman Authors, who elsewhere are large enough in describing the Elephant's Behaviour in Fight, and how terrible they were to some of the Trans-Alpine Nations, mention any such Matter in any of their Expeditions into Britain. . . . One there was 'tis true sent hither as a Present by St. Lewis IX., King of France to King Henry III. Anno 1255, which, says Matthew Paris, was the first seen this side of the Alps, and perhaps there may have been two or three brought for Show hither since: but whether it be likely any of these should have been buried at Cornwell let the Reader judge."

A point is made of the fact that tusks had not been found associated with the supposed elephant's bones, a piece of negative evidence the worthlessness of which is shown by the subsequent discovery of such tusks.

Instances are then given of the exhumation of similar bones from churchyards. "Since the great Conflagration of London, Anno 1666, upon the pulling down of St. Mary Wool-Church, and making the site of it into a Marketplace there was found a Thigh-bone (supposed to be of a Woman) which was to be seen at the King's Head Tavern at Greenwich in Kent, much bigger and longer than ours of Stone could in proportion be, had it been entire." Two other similar bones were dug up in the parish churchyard of Merton Valence. “Now," ex- 


\section{8 'THE HISTORY OF GEOLOGY}

claims our author in triumph, "how Elephants should come to be buried in Churches, is a Question not easily answered, except we will run to so groundless a shift, as to say, that possibly the Elephants might be there buried before Christianity flourished in Britain and that these Churches were afterwards casually built over them."

It is possible that the thigh-bone in which Dr. Plot was so much interested was not that of an elephant, for he says: "But what is instar omnium in this difficult point, there happily came to Oxford while I was writing of this, a living Elephant to be shown publickly at the Act, An. 1676, with whose Bones and Teeth* I compared ours: and found those of the Elephant not only a different Shape, but also incomparably bigger than ours, though the Beast were very young and not half grown."

The conclusion follows that the thigh-bone is human and belonged to a giant: many marvellous accounts of giants are then cited, some clearly fabulous, and not carrying conviction to the author himself, who proceeds as follows: "But to come closer to the Business, and more determinate Statures, the same Pliny tells us of two others living in the time of Augustus, nicknamed Pusio and Secundilla, whose Bodies were preserved for a Wonder in the Sallustian Gardens, that were ten Foot high; and that in his time, there was one Gabbara, brought out of Arabia in the days of Prince Claudius the Emperor, exactly of the height of Goliath, viz., nine Foot nine Inches high, which being a Size very proportionable to our Bone found at Cornwell, I am rather inclined to believe, that Claudius brought this Gabbara into Britain with him, who might possibly dye and lay his Bones here, than that ever they belonged to any Elephant: except we shall rather say that here also Corinaeus, Cousin to * The teeth were evidently those of a ruminant. 


\section{REVIEW OF PLO'T'S POSI'TION 239}

Brute, might kill one of Gogmagog's Race, and that from him the Place doth take its Name, as well as the County of Cornwall."

In reflecting on these views of Dr. Plot, no one will fail to recognise his perfect good faith; he does not appear to have been greatly influenced by theological prepossessions, and is honestly anxious to arrive at the truth.

What, then, it may be asked, was it that led him, and many great naturalists with him, to conclusions so opposed to those of Steno, so opposed as we now know to the truth itself?

There were evidently several reasons. In the first place, Plot clearly perceived that the admission of the organic nature of fossils brought with it a whole train of perplexing consequences. To avoid these, he preferred an appeal to crystallisation, as raising ultimately fewer difficulties. Other branches of science were not at that time sufficiently advanced to show the baselessness of this explanation; the subject was a difficult one, many additional observations were needed, and the mind of Plot was eminently critical. When we survey the vast superstructure that modern science has raised on the foundation prepared by Steno, i.e., on the organic nature of fossils, and the superposition of stratified rocks, none but an impatient mind will feel other than grateful to Plot for having subjected these fundamental principles to the severest examination, for having spared no argument which could possibly be brought against them. Next to suggestive generalisation, science stands in need of honest criticism. Geology required a prophet, and she found him in Steno, but she also required a critic, and in Plot she met with one of the most penetrating intellect and uncompromising spirit.

We have, perhaps, lingered too long in the delightful 


\section{THE HISTORY OF GEOLOGY}

mediæval world of Plot, and have left but scant space for the laborious Llwyd, who succeeded him as keeper of the Ashmolean Museum, or "Cimeliarcha," as it seems to have been called at that time. Out of the 1766 specimens, which formed the geological collection under Liwyd's care, two are still to be seen in the University Museum; one is an Orthoceras, the other a sea-lily; the latter is of particular interest; it was described and figured by Llwyd in his "Iconographia," * and afterwards in a letter to Dr. Lister. $†$ It was again described and figured by Miller as a type of his species, Actinocrinus polydactylus. $\ddagger$ To have survived after other vicissitudes two centuries of human custody, and to have been chosen to represent its species after its claims to a place in the organic world had been hotly contested, is in itself something, but the chief claim this fossil makes upon our attention is a reference to it by Llwyd in a letter to Dr. Lister, when he says $\S:$ “. . . the rest are Modioli or Vertebre of Sea-stars: for I have long since been fully satisfied that all sorts of Entrochi and Asterice must be referred thither; not that I conclude either these or any other Marine terrestrial Bodies were ever really either Parts or Exuvia of Animals, but that they bear the same relation to the Sea-stars that Glossopetra do to the teeth of Sharks : the Fossil Shells to the Marine ones, \&c."

We might be tempted to regard the concluding words of this quotation as a clever evasion, worthy to be ranked with the apology of Copernicus, but this would be to do a serious injury to Llwyd; he was perfectly honest, as we shall find if we turn to his monumental work entitled " Lithophylacii Britannici Ichnographia." This contains

* P. 104, pl. xxii. fig. 4.

† Phil. Trans., 1698, vol. xx. p. 279, fig. 14.

+ "Nat. Hist. Crinoidea," pl. i. fig. 2.

Loc. cit., p. 279. 
a description of fossil remains classed according to their resemblance with existing living forms. The classification shows remarkable insight, and at first glance we might suspect the arguments of Steno were now producing their natural effect, but we need not read very far to be undeceived; the arguments of Steno are quoted, indeed, but only to be refuted. Only two views seem possible to Llwyd: fossils are either the reliquiæ of the universal deluge, or they are due to a formative force acting within the earth's crust upon the seeds of organisms brought by rain from the sea. It is the latter view that he adopts, and this has in it a certain ingenuity, since the characters which fossils and organisms possess in common are attributed to a common origin, i.e., the seeds, while such differences as distinguish them are due to a difference of environment during their germination; and so, as G. Agricola remarks: "Quanto Terra est crassior quàm aqua; tantò imperfectiores gignit formas et quae animalibus careant."

Both sides of this momentous controversy had now been fairly presented to the world, and it was left for the faithful labours of the next century to arrive at a decision. The principles of Steno eventually prevailed, and Geology entered upon a new phase of her existence; she commenced to free herself from the trammels of time!

Hutton, in his great work, "The Theory of the Earth," published in 1788, attacked the subject on that side where Steno had most conspicuously failed. His method was the same as Steno's; just as Steno had explained fossil remains by comparison with living animals, so Hutton explained the past history of the earth by comparison with the present. If this county of Oxfordshire was, together with all England, at one time submerged fathoms deep beneath the sea, it was owing to a slow 


\section{THE HISTORY OF GEOLOGY}

movement of subsidence such as Hutton considered was affecting islands and continents at the present day. Would we account for the marine sediments of which our land consists, we have but to turn our eyes to the rivers constantly bearing their burden of mud into the sea, where it is spread abrowd in strata precisely similar to those of the remote past. As strata are formed now, so have they always been formed; as lands rise and fall now, and seas pass imperceptibly into continents, and continents into seas, so they have always done in the past. But how slowly all these changes proceed! A human lifetime is not long enough to witness any appreciable effect. In this period the thickness of stratified material laid down by a river in the sea would not amount to more than a few inches, and the rocks of the earth's crust are many thousands of feet in thickness. Well might the stoutest-hearted be appalled before the vast æons of time which Hutton conjured up before the imagination! Not so Hutton; having broken the narrow bonds of time previously imposed upon our science, he revelled in excess of freedom, and declared that the duration of our planet was practically infinite!

How was this new teaching received in Oxford?

The title of a work by Dr. Kidd, who was Professor of Chemistry in 1803, will inform us. It runs as follows: "A Geological Essay on the Imperfect Evidence in Support of a Theory of the Earth, 1815" ; and the book itself concludes with the assertion that " ancient strata cannot be explained by existing causes : that the Science of Geology is so completely in its infancy as to render hopeless any attempt at a successful generalisation." In this opinion I believe Dr. Kidd to have been in sound agreement with the teaching of the leading geologists of the day; his work is by no means aggressive, and might rather be regarded as a text-book than a polemic ; as a text-book it 
was well " up to date," and we are impressed on reading it with the great advance which had been made since the time of Plot.

Here must be mentioned the name of William Smith, a native of Oxfordshire, though not a member of this University. His various works were published between the years 1790 and 1815, and to him we owe a discovery that excited no controversy, but which nevertheless was the greatest made in our subject since the time of Steno. It was, that different strata contain different kinds of fossils, which are peculiar to them, and thus serve as marks by which the strata can be identified; so that with the aid of fossils it has become possible to trace the same group of strata across the length of the British Isles, nay, even throughout the whole of Europe and into distant parts of the world. This discovery made historical geology for the first time possible as an exact science.

The successor to Dr. Kidd was a geologist of the very highest rank, one eminently great amongst a crowd of great contemporaries. I allude to the famous Dr. Buckland.

The period of Buckland has been styled, and justly styled, the "Golden Age of Geology." Sedgwick was his contemporary in Cambridge, Phillips, afterwards to succeed him, was his contemporary in Dublin, Murchison learnt his first lesson in the field from him, Lyell was his pupil, Agassiz a ccadjutor, and Conybeare his nearest friend.

When Buckland was appointed Reader in Geology, the foundations of the science were already laid, but great problems remained for solution. The question of the deluge and how far its effects could be recognised in the structure of the earth's crust was still one of these.

Buckland appeared at first as a champion of the deluge: 


\section{THE HISTORY OF GEOLOGY}

thus in his inaugural lecture delivered before this University in 1819 he expressed himself in the following words: "The grand fact of an universal deluge at no very remote period is proved on grounds so decisive and incontrovertible, that had we never heard of such an event from Scripture or any other Authority, Geology of itself must have called in the assistance of some such catastrophe to explain the phenomena of diluvial action."

Subsequently pursuing his researches into this question he seems to have ransacked the whole world for evidence and found everywhere confirmatory proofs. The ancient gravels of Wytham were, he considered, swept from Warwickshire and counties still farther north, in the rush of the great flood; stones from Norway were carried to the east coast of England, and the mass of pebbles and other débris, which were driven along with it, scoured the face of the country, and thus produced the polishing and striation so frequently visible on the surface of the harder rocks of our islands; the bones of mammoths and other mighty monsters of prediluvial times, that lie buried in caves and elsewhere, were eloquent in their testimony to the destruction which it wrought on the living world. That the loftiest mountains were submerged by it was proved by the discovery of the bones of horses and deer at an altitude of 16,000 feet above the sea on the slopes of the Himálaya. They are brought down by the avalanches of those mountains, and are said by the natives to have fallen from the clouds and to be the bones of genii. The "Reliquiæ Diluvianæ," in which these views appear, was published in 1823, and by its skill, learning, and eloquence at once attracted universal admiration.

But Buckland, though he appears in this work as an advocate, was by no means merely an advocate, his was a mind too highly endowed to rest satisfied with any but the most convincing proof, and as time elapsed, and he 
extended his researches, the evidence, which he so industriously accumulated, so far from strengthening his position, began to gradually undermine it, and already in 1837, when he published his great work on "Geology and Mineralogy Considered with Reference to Natural Theology," we find him wavering. While still asserting the occurrence of a diluvial catastrophe, he was prepared to abandon the view, which would connect this with the Noachian deluge. "It has been justly argued," he writes, "that as the rise and fall of the waters of the Mosaic deluge are described to have been gradual and of short duration, they would have produced comparatively little change on the surface of the country they overflowed. . . . This important point, however, cannot be considered as completely settled till more detailed investigations of the newest members of the Pliocene and of the diluvial and alluvial formations shall have taken place."

Scarcely a year had elapsed after this opinion had been expressed when investigations were commenced which were to cast a flood of light on the question from an unexpected quarter. Agassiz in 1838 was already engaged in those observations on the glaciers of Switzerland, and had commenced that series of brilliant discoveries which eventually culminated in a clear and reasonable explanation of the so-called diluvial phenomena. Buckland's study of these phenomena in Europe and the British Isles had rendered him the first authority of the time on this subject, though the cause of these phenomena, as we now know, was really not diluvial as he then imagined, but glacial. Buckland therefore was perfectly familiar with all the signs now recognised as characteristic of ice-action, no man more so; consequently when Agassiz took him over the glaciers of Switzerland, and showed him these agents actually at work, smoothing, polishing, and striating the surface over which they 


\section{THE HIS'TORY OF GEOLOGY}

flowed, the evidence was presented to a mind already prepared to appreciate it, and a few days' personal investigation sufficed to convince Buckland of the truth of Agassiz' opinions. This was not a case of a mere tyro, introduced to the subject for the first time, but of a skilled and trained observer, familiar by experience with results, the cause of which he had for long been 7rying vainly to discover. Here, however, it may be better to allow Dr. Buckland to tell the story in his own words. Among his MSS. I have found a rough draft of a letter, evidently written to Agassiz, in which he says: "In October, 1838, I for the first time attended to the effects of Glaciers, which you pointed out to me in the phenomena of polished and striated and furrowed Surfaces in the S.E. slope of the Jura, near Neuchatel, the origin of which, as well as the Transport of the Boulders of Granite, \&c., from the Alps to the Jura, you referred to the Agency of ancient Glaciers. Not then satisfied with your Explanation, I proceeded to devote some days to the examination of actual Glaciers, and the result was my conversion from a sturdy Opponent to the adoption of your Theory as far as relates to Switzerland by the strict accordance which I found between many residuary Phenomena of existing Glaciers in the high Alps, and similar residuary Phenomena that are equally apparent on the S.E. slope of the Jura, fronting the Alps" [I mentioned to you] "that Sir J. Hall had in 1812 described similar polished surfaces, grooves, and furrows in the vicinity of Edinburgh, and that other observers had occasionally noticed them on the surfaces of hard Rocks, which have been protected from the weather in many parts of Scotland and England. I also proposed to conduct you to some of the most remarkable of these spots on your visit to England in 1840, which you have just accomplished." 


\section{AGASSIZ AND BUCKLAND}

How justly Buckland estimated the importance of this great discovery is shown by notes in his handwriting, that were probably used to assist him in one of those remarkable speeches the echoes of which still reverberate in our time. In one he says: "For some time to come the Glacial Theory must occupy a prominent place in Geological Investigation. The Subject appears to me the most important that has been put forth since the propounding of the Huttonian Theory: and the surface of the whole Globe must be examined afresh with the View of ascertaining how far the Effect of Glaciers and Ice-bergs and of Floods produced by melting ice and snow can be found and identified with the actual effects of Ice and Snow in our present Polar and Alpine Regions." This prediction has been verified; even now, fifty years after these words were uttered, observers are still engaged in the investigation of glacial phenomena; the subject still occupies as prominent a place as it did then, and promises to do so for an indefinite time yet to come. In another note Buckland comments on "The vast field of new Enquiry which the introduction of the Glacial period between our Epoch and the Newest Tertiary opens to the Geological Enquiry. The fact of the Greater Part of Europe and North America having for many years been sealed up under a cover of frozen Snow converted to the state of Glaciers is certain. . . . Thus the flood that caused the Diluvium which in my 'Bridgewater Treatise' I have put back to the latest of the many Geological Deluges, was probably due to the melting of the Ice. The details of this Ice flood will fill a Volume and will constitute Vol. II. of my 'Reliquiæ Diluvianæ and Glaciales,' which for fifteen years has been retarded for lack of the grand key which Agassiz has supplied in his "Ettudes des Glaciers."

Thus Buckland courageously recanted his earlier opinions 


\section{8 'THE HIS'TORY OF' GEOLOGY}

on the deluge; and of the Noachian deluge as a geologic agent from this time forth we hear no more. This was one of the greatest benefits that Buckland conferred on geology; commencing as the most powerful champion that had ever appeared on the side of the Noachian deluge, he step by step and by slow degrees was led to reconsider his position, till finally he abandoned it altogether, and left geology freed from a mistaken doctrine to pursue her peaceful path, disturbed by no difficulties, beyond those naturally inherent in the subject. For this alone we owe him a debt of deep gratitude; but our obligations do not cease here. He introduced to the eyes of an astonished world a strange procession of extinct forms of life, with whom he seemed on most familiar terms; parodizing a line from Juvenal he exclaimed, "Quicquid agunt ' Sauri,' votum timor ira voluptas gaudia discursus nostri est farrago Libelli," and then proceeded to describe "the details of their political and domestic economy."

In his "Bridgewater Treatise" we may still read with interest and profit his vivid account of the Icthyosaurs, Plesiosaurs, Megalosaurus, and Pterodactyles, and other monsters of the mighty past. This work was written sixty years ago, and yet such was the sagacity of the author in selecting only those facts which were well ascertained and sure, that it may be put into the hands of the youngest and most innocent of geologists, without fear of infecting his mind with forgotten error.

Nor must we here overlook his success in informing and convincing the world of science of the fact that in times immediately antecedent to the glacial period, our country and Europe generally was the home of a vast number of animals no longer found in it, some of them altogether extinct, such as the mammoth, rhinoceros, hippopotamus, cave hvæna, bears and tigers, and the arctic glutton. 
Of Buckland's pupils, the greatest was Lyell, whose fame, indeed, overshadows his master's. Hutton had propounded the theory of the efficacy of modern causes, Playfair had illustrated it, and Lyell spent his life in defending and elaborating it. In consequence of his success in this work, it is far more often associated with Lyell's name, who was its foster-parent, than with Hutton's, who was its true originator.

We have already alluded to this doctrine. It is that the only method by which an explanation of the past can be obtained is by a careful study of the processes of the present, or, as it is often epigrammatically expressed, "Geology finds in the processes of the present a key to unlock the past." It must be confessed at the outset that it is difficult to see where else she would find it; not in the future, of which we know nothing, and scarcely in the past itself, whose problems are to be explained. Epigrams are frequently only a neat way of obscuring a truth; in this case the fact would appear to be that most of the older observers, when they encountered interruptions in the succession of strata, were accustomed to explain them by interruptions in the orderly progress of nature, by sudden and violent changes, which were spoken of as catastrophes. Hutton and Lyell were able to offer explanations of these without the invocation of catastrophes. They certainly introduced the scientific method into cases which had previously been treated by a too free use of the imagination, and thus their doctrine, the doctrine of uniformity, has dominated geologic thought for the past sixty years, and will probably continue to do so for many years to come. The teachings of Hutton and Lyell have, however, another side; they assume not only that existing causes have acted in the past as in the present, but at the same uniform rate: this was the natural result of 


\section{0 'THE HIS'TORY OF GEOLOGY}

a reaction, which followed when geology was loosened from her ancient bondage to time, and under the influence of which geologists came to regard the periods at their disposal as practically infinite. The mathematician often employs in his calculations the device of assuming some very large quantity to be infinite, and in this way obtains approximate results sufficiently close for working purposes. This is precisely what Hutton and Lyell did in their explanations. But when a limit becomes assignable to this quantity, the mathematician will abandon the fiction of infinitude and introduce the ascertained or estimated value into his equations with a view to arriving at greater exactitude. Of late years it has been asserted by a very high authority-Lord Kelvin-that a limit can be assigned to geological time; once more geology is put under bondage, not, however, as in her youth, tethered to a mere 6,000 years, but free to roam through the ample magnitude of $30,000,000$ ! It is at present impossible to say how near the truth Lord Kelvin's estimate may be; it is founded on data which may be inexact, and on assumptions which may be illegitimate, but that it is approximately correct the preponderance of evidence seems to show.

That the strict uniformitarian view is as false in philosophy as it is unfounded on fact is an opinion which was shared by the late Professor Prestwich, and which is held by many of the geologists of to-day, as it was by the great masters of old. It is tantamount to asserting that the progress of events on the earth can be represented by a curve which is a straight line. We should think strangely of the physicist who, from the behaviour of a fluid through the range of ordinary atmospheric temperature, should proceed to deduce from it a rate of expansion up to the temperature of the sun in one direction and down to absolute zero in the other; 
and yet this would scarcely show greater wisdom than the procedure of the geologist who, from a knowledge of the earth's history during the past few thousand years, should endeavour to deduce from it the rate of events during $30,000,000$ of years in the past!

Dr. Buckland was succeeded by Professor Phillips, a man of most varied genius, a classical scholar, an expert mathematician, an omnivorous reader, facile both with pencil and pen, interested in all science and a master in his own. He taught in this University for more than twenty years, and during that period he enriched our science by numerous contributions of the highest value. A smooth and easy progress marked the course of geology, and knowledge steadily enlarged its bounàs. The great Cetiosaurus, one of the greatest of the oldworld monsters, larger even than the great Iguanodon which is now represented in our museum, we owe to him. Towards the end of his career, geology, like all other science, was confronted by the reappearance of an old and discredited doctrine, but now presented afresh with new and startling vigour; it was the doctrine of evolution as expounded in the famous " Origin of Species by Natural Selection." Once more an Oxford professor was called upon to pronounce judgment on one of those momentous questions which arise from time to time to disturb the steady current of established thought.

Darwin's present of a copy of his book was accompanied by the following letter:-

"Mr Dear Phillips,--I have directed Murray to send you a copy of my book on the 'Origin of Species,' which as yet is only an abstract. I fear that you will be inclined to fulminate awful anathemas against it. I assure you that it is the result of far more labour than is apparent in its present highly condensed state. If you have time to 


\section{2 'THE HISTORY OF GEOLOGY}

read it, let me beg you to read it all straight through, as otherwise it will be unintelligible. Try not to condemn it utterly till you have finished it and reflected on the recapitulation. Not that I am so foolish as to expect to convert any one who has long viewed the subject from an opposite point of view. I remember too well how many long years my own conversion took. The utmost which I hope is that you may see that more can be said on the side of mutability of specific forms than is at first sight apparent. If, indeed, your own observations have made you at all sceptical on the subject, then my book may produce some effect. . . .

"Yours very sincerely,

"Charles Darwin."

Phillips had for a long time previously given careful attention to the "Succession of Life on the Earth," and had chosen this subject for the Read lecture, which he delivered before the University of Cambridge, shortly before the appearance of the "Origin of Species."

His pronouncement on Darwin's work was adverse. "Dead against," as Darwin wrote. His opinion as expressed in a letter to Darwin, of which he did not preserve a copy, called forth the following reply :-

"Ilkhey Wells House,

“ Otley, YoRkshire, 26th November, 1859.

“Mr dear Phillips,-Thank you for your note. Permit me to say one word about my book. Though many facts in palæontology may appear, or be really, opposed to my notions, and though my explanations may be quite fallacious, I earnestly beg you to consider whether a theory wholly false would explain, as it seems to me to explain, several classes of facts-as affinity of inhabitants of islands to nearest continent; the nature of the inhabi- 
tants of oceanic islands; the affinities and classification of organic beings and their arrangement in groups; the strange fact of a member of one group being adapted to the habits of another group; the facts of morphology or homology; embryology and rudimentary organs. If you think the theory of Natural Selection does not to a large extent explain these classes of facts, I have not a word to say. Pray forgive me saying a word in favour of my own offspring to one whom I consider an important judge.

"Yours very sincerely, "C. Darwin."

That Phillips betrayed no bigoted opposition to the doctrine of evolution is shown by several attempts which he himself subsequently made to construct a phylogeny of different groups of animals from a knowledge of their fossil remains; but while he succeeded in tracing several interesting lines of descent annong species, he confessed himself unable to bring the more widely-separated groups or genera into an ancestral connexion. Since these early attempts of Phillips, we have learned not only to affiliate species and genera, but even families and orders, and the frequent discovery of missing links offers the most striking testimony to the truth of the theory of evolution.

That Phillips was thoroughly justified in his position towards evolution is suggested by the fact that even Huxley, the most philosophic advocate of the theory, fully admitted that at the time of publication of the "Origin," palæontology lent to its doctrine no support.

An argument which evidently had great weight with Phillips, in his rejection of the theory of natural selection, was the excessive duration that it postulated for geological time. This still remains an argument of weight, so that some biologists impressed with the vast periods which the Darwinian theory demands for its 


\section{THE HISTORY OF GEOLOGY}

operations, are prepared to measure geologic time by Darwinian requirements. On this subject Huxley expressed himself with his usual wisdom, perceiving plainly enough that biologists are in possession of no data as to the rate at which species may become modified-were we to judge the past from the present we might have to admit that they do nct become modified at all-he referred biologists to the geologist, telling them in pithy words that they must take their time from the geological clock.

Phillips' position towards the Darwinian theory seems to me to have been altogether a wise one; since his time the doctrine of evolution has obtained universal acceptance, but Darwin's theory is still a battle-ground for contending opinions.

And though we are compelled to call evolution to our aid when we attempt to explain the facts of palæontology, yet it is well we should bear in mind that evolution does not advance us far. It is a great generalisation, as was the maxim that "Nature abhors a vacuum," but, like this maxim, it stands itself in need of an explanation.

Suppose by some ingenious cinematograph we could recall in a continuous picture the succession of vanished forms of life, and watch the transmutation of animals as they passed from formless protoplasm to man; the spectacle would be interesting, but would the fact it displayed be one whit less a miracle than that we witness every time we plant the seed in the ground and watch the green shoot spring forth, to produce in due time the secret buds which unfold in leaf and flower?

Or even suppose we take the one step farther, and admit the Darwinian explanation, with its three factors of selection, variation, and inheritance, are we much nearer to the ultimate truth? A certain Paley once considered a certain watch; the watch has grown so old-fashioned since evo- 
lution attained its vogue that it is now rarely seen in polite society, but it did great service in its time. Permit me on this occasion to draw attention to another analogy, - to the curious similarity that exists between the progress of human invention and the evolution of organic species. From the great kingdom of locomotive machines a lowly stirp arose known as the "hobby horse"; it lingered on unregarded for a while, and then was superseded by a new species technically called the " bone-shaker." This gained a place in the world, multiplied rapidly, and became represented by a great number of individuals; as it multiplied it gave rise, by a process called "variation," to a number of related forms, such as the "ordinary bicycle," the "extraordinary," and the "kangaroo"; many of these species of machine exhibited a decided advance in organisation upon their ancestor; a process of selection then set in, the fittest types survived, the unfit became extinct; the good qualities, which had secured this success in life, were handed down by a process of inheritance; variation of these successful types produced others still more successful, and selection, always operative, continually weeded out the less fit, till one sole survivor now remains ; the summit of evolution is reached in the genus "bicycle," species "safety," variety "pneumatic"! Just such a kind of succession may be traced in the series of animal remains preserved in stratified deposits. A few simple forms appear, drag on a lowly existence for a while, and then unexpectedly blossom out into an infinitude of varieties; with lapse of time these become thinned out, but organisation all the time advancing, there results at last some happilyendowed form, which supplants the inferior competitors, and becomes lord and master of creation.

In the case of the machine we think we know the causes of variation and inheritance, we attribute them to the action of the human mind. In the case of the organic 


\section{THE HIS'TORY OF GEOLOGY}

world, we assert that we know not to what these processes are due; and yet, somehow, to my thinking there stands behind them, connected in some incomprehensible manner, but still connected, the working of a mind which is Divine.

Professor Phillips was succeeded by Professor Prestwich, the Nestor of English geologists, who maintained the principle of evolution in geology, as opposed to uniformitarianism; and to him followed Professor Green, whose loss is still fresh and still deplored.

The influence of Oxford on geology has been far greater than in this imperfect sketch can be made to appear; she has never shut her eyes to a new theory, but, whether by criticism or advocacy, has endeavoured to 'stablish the truth that it might prevail; her direct contributions to knowledge have been very many and very great; if we mentioned no other work but one; "The Principles of Geology," by the immortal Lyell, would alone suffice to vindicate her fame. 


\section{IX}

\section{THE KEY TO TERRESTRIAL HISTORY}

ПHE history of the earth, so far as it is known to us L since the ocean first came into existence, has been obtained from a study of sedimentary strata, which are arranged in a definite series. The series differs in completeness in different parts of the earth, but its various terms always succeed each other in the same order. This order of superposition in space corresponds to the order of deposition in time, or the place of any stratum in the stratified series represents its geological age.

This principle, the foundation of our inquiry into terrestrial history, we owe to Steno (v. p. 224).

But it is only very limited portions of the series which are exposed to observation at any single locality; sections, revealing the edges of the strata and their superposition, are provided for us by sea-cliffs, riverbanks, or artificial excavations, but these rarely enable us to follow the succession for any great distance. The beds themselves are frequently interrupted, partly as a consequence of the conditions under which they were originally formed, partly as the result of changes which they have subsequently undergone; faults of greater or less magnitude traverse them, bringing different beds into the same horizontal line; undulations affect them, which 


\section{KEY 'TO 'TERRESTRIAL HISTORY}

sometimes pass into folds, by which the beds are bent double upon themselves, so that their order appears to be inverted. Rivers, arms of the sea, the sea itself, interrupt their path, and marsh and meadow-land blot out large intervals from view.

Thus the surface of the earth presents us with only fragmentary glimpses into the great succession of strata which record terrestrial history. In some regions, as in the Himálaya, or the Great Cañon of Colorado, chapter after chapter is continuously displayed as in a mighty scroll before the eye; but even in these most favoured spots there are great deficiencies, and in our own island, where the succession was first painfully spelled out, letter by letter, as we might say, sections are even less complete and their interpretation correspondingly more difficult.

Our very first step, if we are to discover an order of succession among the strata, must be to find some means by which any particular stratum may be identified, a mark by which it or its equivalent may be recognised, even in widely separated localities, not only within these islands, but beyond their confines, over all Europe, even, indeed, over the whole world.

The recognition of such a character we owe to William Smith, the second of the great pioneers in the study of terrestrial history, as Steno was the first.

The centenary of this fundamental discovery has been suffered to pass without notice, without comment even; but at this period, when we are engaged in recounting the successes of our science during the last hundred years, it is most fitting that we should recall some memory of the discoverer, and trace to its fruition the growth of his idea.

The history of William Smith's life may be briefly told.

He was born on the 23rd of March, 1769, at Churchill, in Oxfordshire. His father was a small farmer belonging 
to that hardy yeoman class, now, unfortunately, almost extinct, which has contributed so much in the past to the greatness of our land. Of school-teaching he had but little, but his mind was busy at a very early age over the fossils he picked up from his father's fields. At the age of eighteen he had the good fortune to be apprenticed to a land surveyor and engineer, and thus acquired a training as well adapted to the requirements of the field geologist as the period could provide. His work took him into the country, and afforded him excellent opportunities for observation. These he used to such good purpose that by the time he had reached the age of twenty-two he had already constructed a system of geology for himself. He had discerned something of the order which prevails among the secondary rocks of our country, and had even discovered their discordant superposition upon the underlying carboniferous system.

The rage for constructing canals which prevailed in England between the years 1791 and 1794 happened rather fortunately for geology. The cutting of these long trenches through the country afforded numerous glimpses of its structure; but though canals had often enough been cut before, no William Smith had been there to see them. Now the happy conjunction was made, and his appointment to assist in the construction of the Somerset coal canal was fertile in important results. The year 1794 brought him further opportunities. He was invited to accompany as engineer two members of a Government Commission which had been appointed to investigate the English canals. He did so, and travelled with them over nine hundred miles of country, from Oxford through York to Newcastle, and back again through Wales and Shropshire to Bath. At the end of the journey Smith felt himself in possession of the clue which was to lead him through all the in- 


\section{KEY 'TO 'TERRES'TRIAL HISTORY}

tricacies of stratiform arrangement--he had found the key to terrestrial history. The rest of his life was devoted to making use of it. By its means he proceeded to make clear the structure of our land, and conceived the idea of representing the results in a geological map. Alone and single-handed he determined to accomplish in outlin that which the organised efforts of H.M. Geological Survey, extended over half a century, have not yet completed in detail; and he succeeded in his task.

The knowledge of geological structure which William Smith acquired proved incidentally of great value to him in his profession, and gave him unique advantages over his contemporaries. His services were consequently in great request, and he might easily have become fairly prosperous; but he spent what he earned, and the time in which he might have been earning more, in travelling about the country, mapping out the relations of the strata, drawing geological sections, and collecting fossils. So while Fortune smiled upon him and offered gifts, Smith remained true to his idea; and Fortune, who is feigned to be a woman, did not forgive him. He died a poor man-as we count wealth--but well content, for the dream that he had dreamt in his youth had become, by his labour and self-devotion, the reality of his later years. In 1839 , the year of his death, it was already an established truth, and furnished inspiration to a great band of followers, of whom it may now suffice to mention Sedgwick, Buckland, and Murchison, the heroes of the so-called "golden age" of geology.

Let us now proceed to give some further account of the great discovery which, as we have indicated, was a means of identification. At first such a means was sought in the nature of the sediment of which a stratum or group of strata consists; this had already been made 


\section{LI'THOLOGICAL CHARAC'TERS 261}

use of by Werner, and was employed by Smith himself. Thus by its colour, texture, and composition he tracked the red marl, which we now assign to the Trias, across a great part of the length and breadth of England; so by its alternating layers of thin, hard limestone and blue clay he followed the Lias. Indeed, by this means alone he gained a considerable insight into the structure of the eastern half of England. The red marl he represented as lying unconformably upon the older coal-measures; it forms the fertile plains of central England, and disappears to the east beneath the thin limestones and clays of the Lias (Fig. 82); these also slope gently to the east, and similarly disappear beneath the Oolites, which again

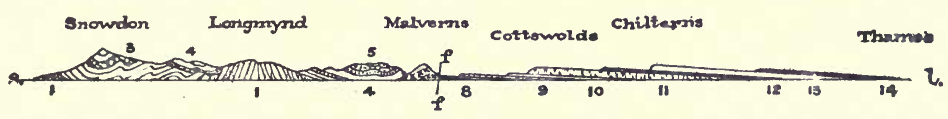

FIG. 82.-Section across England and Wales. 1. Pre-Cambrian Rocks. 3. Ordovician. 4. Silurian. 5. Old Red Sandstone. 8. and 9. The "Red marl" or Trias. 10. Lias. 11. Oolites. 12 and 13. "Greensand and Chalk" Cretaceous. 14. Eocene. f f. A fault. s.l. Sea-level.

slope eastwards and disappear below the greensand and chalk.

Here we may briefly refer, in passing, to a discovery which lies outside our immediate problem. The strata which we have just enumerated are of differing degrees of hardness, and Smith connected this difference with the contour of the land, pointing out that the softer beds form low plains; the harder, ranges of hills which face with a comparatively steep scarp towards the west; while on the east they very gently slope away, to disappear beneath succeeding strata. This difference in relief is a consequence of the unequal resistance of the beds to the wearing action of rain and rivers. Even the subtleties of form, which we call the modelling of the hills, did not 


\section{KEY TO TERRESTRIAL HISTORY}

escape this acute observer; so that when for the first time he viewed the wolds of Yorkshire from the top of York Minster, he gleefully remarked he could "see at once they were chalk from the form of their contours." Thus, while steadfastly pursuing the main object of his search, he discovered by the way one of the most interesting branches of popular geology - the connexion between structure and scenery.

The simplicity in structure which he attributed to the east of England would not appear to the eye of a casual observer; it is often masked by the irregular manner in which the strata crop out at the surface of the ground. But Smith was a born geometer, and recognised very early the effects which the contour of the surface must produce on the outcrop of gently-sloping beds.

The nature of the sediments may thus prove of great value as a means of identification; Smith's own work shows this clearly. Yet it is a means open to much suspicion, only to be employed with the greatest prudence; for observation shows that the same sheet of sediment may change its character when traced over a considerable area; while, again, two or more strata of different ages, or belonging to different horizons of the series, may consist of the same kind of sediment, so as in this respect to be indistinguishable from each other. If this be true of such a limited area as the British Isles, as it undoubtedly is, how far less trustworthy must the sedimentary character become when applied to the identification of strata in different parts of the world. So greatly have geologists been impressed by this consideration that they have sometimes shown signs of undervaluing the evidence to be drawn from the nature of sediments, and have been led to underestimate its constancy in geographical distribution-it is difficult to avoid Scylla without running into 


\section{IDEN'TIFICA'TION BY FOSSILS 263}

Charybdis. But no one would pretend that sediments alone could be trusted as a means of identification of strata; the remarkably slow progress made in the study of terrestrial history so long as this was the sole criterion is an indication of its inefficiency.

It was William Smith's merit to make known for the first time another character, and of a more trustworthy kind, by which the strata could be traced under their varying disguises from one region to another.

Without knowledge of zoology, even of such zoology as was current at the time, this acute observer, with unrivalled sagacity, arrived at the conclusion that the fossils contained in the strata were not only the remains of once living organisms,---that Steno had already shown, that they were not only the remains of extinct forms of life,- - that Pallisy the potter had divined, but that they are peculiar to the several groups of strata in which they occur, and, indeed, peculiar to the time in which these beds were formed. He was thus the first to behold with an inward eye the ancient populations of the earth which he summoned from the far-vanished past. Now we have learnt to see with his eyes they throng upon us in myriad forms, no two the same, each distinguished by some trick or fashion from his fellows, a wonderful phantasmagoria of varied shapes. In quaint and wonderful ways Life has fashioned her garment, the threads are all one and the same, and they run through to the beginning of time, but they are woven in forms and colours that change with each flash of her shuttle; the same form is never repeated, and the new is always more wonderful than the old. Thus has Life worked to music of changing time. Sometimes she has drooped droningly over the loom, sometimes urged it eagerly to violent measure, sometimes, too, followed a motif that lay dormant, as half forgotten, for awhile, and was then resumed to an exultant conclusion in the ap- 


\section{KEY 'TO 'TERRES'TRIAL HIS'TORY}

pearance of some marvellous complex, wonderful beyond finding out.

Thus incidentally did the great pioneer open to us new visions, while his own mind was concentrated on another aim. It was the application of his discovery to the identification of strata, and the unravelling of the complicated suructure of the earth's crust thereby rendered possible, that dominated his soul as by an intellectual possession.

He had found the key to terrestrial history, and he knew that he had found it; a reluctant writer, untrained to express his thoughts, chiefly occupying himself in trying his key on the various wards, determined to see how far it would master them all, yet every now and again giving utterance to some remark, that shows how fully he recognised the nature of his task, and how great he expected to be the results which would follow from its accomplishment. Here are a few instances:- "Fossils have long been studied as great curiosities, collected with great pains, treasured with great care, and shown to be admired ... (without) the least regard to that wonderful order and regularity with which Nature has disposed of these singular productions and assigned to each class its peculiar stratum" (January 5, 1796). Again, "I wished to travel, for I foresaw that the truth and possibility of my system must be tested far and wide before it could be generally known and appreciated" (1794). Or, once more, "As the result of my observations on this tour . . . it plainly appeared that [my method] was to become a system of experimental philosophy, which would embrace the whole surface of the globe."

The way in which William Smith set about the vindication of his principle was characteristic of the man, not by any means to write treatises upon it, but to show what it could do; and his construction by its aid of 


\section{SYS'TEMS AND PERIODS}

the first geological map of these islands, which crowned his labours, was the most conclusive testimony to its powers.

A geologist crossing to America and visiting the Falls of Niagara may pick up fragments of limestone which will at once strike him as remarkably similar to certain rocks he is familiar with at home; his thoughts will naturally revert to Dudley or Wenlock, classic localities for Silurian limestone, and he will have little hesitation in asserting that the Niagara limestone has a very Silurian aspect. But when he looks more closely into it and discovers the fossils it contains, the Dudley " butterfly," or the Dudley "locust," or the familiar Chain-coral, then any doubt he may have entertained will disappear, and he will exclaim, "This is not merely like, this is Silurian limestone." Yet in taking this step from a mere conclusion of similarity to that of identity, he has perhaps been governed more by common sense than logic, and may then easily fall into the assumption that since the limestone at Niagara and at Dudley are the same thing, they must not only have been formed under similar physical conditions, but during the same period of time. This is, indeed, precisely what as a rule geologists did: having identified strata by their fossils, and thus arrived at a Silurian and Devonian and other systems, they next began to speak of a Silurian and Devonian period, meaning a period of the earth's history when Silurian or Devonian rocks were in course of deposition.

Geologists had been so intent in putting fossils to their newly-discovered use as a means of identification, that they had scarcely paused to consider closely what principles of logic might be involved. This, of course, gave opportunity to the critic, and several candid friends of our science, who had been watching its progress, now became aware of the need for caution. Herbert Spencer, 


\section{KEY 'TO 'TERRES'TRIAL HISTORY}

for one, had little mercy on the rough-and-ready methods of geologists, and seriously lectured them on what he regarded as their illogical procedure. Huxley was no less emphatic, and adopting an argument first employed by Edward Forbes, boldly asserted that the presence of similar fossils in strata of distant parts of the world-such, say, as thase of the Silurian of North America on the one hand and of England on the other-so far from proving an identity in age, points rather in a contrary direction, and suggests a difference in age. For these fossils are not merely signs by which a rock may be identified, they are the remains of organisms, and, as such, must have come into existence at some definite place and at some definite time: each species must have arisen-as Edward Forbes phrased it-at some centre of creation. The descendants of the original species issuing forth from this centre, peopled the surrounding seas, and wandered, generation after generation, further and further away from their original home, till, after a long lapse of time, they found a grave in distant parts of the world. Thus, if we assume some Silurian species to have had their origin in the neighbourhood of Dudley, a long period might have elapsed before their descendants reached in their migrations the shores of North America, and consequently the presence of these species in sediments on opposite sides of the Atlantic would be a proof, not of the identity, but of the difference in age of the se deposits. Huxley proceeded further, and put the cause more strongly still, asserting that "for anything geology and palæontology are able to say to the contrary, a Devonian fauna and flora in the British Isles may have been contemporaneous with Silurian life in North America, and with a Carboniferous fauna and flora in Africa." "Not proven and not provable" is the verdict he records against all the grand hypotheses of the palæontologist respecting the general. succession of life on the globe. 
Huxley, indeed, wished to expunge the word " contemporaneous" from the vocabulary of the geologist, and proposed to substitute for it a new term, "homotaxis," which could be used without involving unwarranted assumptions. To say that the Silurian beds of North America are homotaxial with those of Europe is simply a statement of fact, since their position in the succession of stratified rocks is the same in both countries; they overlie similar systems below, and are succeeded by similar systems above, but to speak of them as contemporaneous involves assumptions and begs the question.

One cannot help wondering how the Fellows of the Geological Society received these arguments, which were provided for them on the encouraging occasion of the President's annual address. One can imagine the effect if the President of a Historical Society, after congratulating his hearers on the interests and importance of their studies, had proceeded to point out certain theoretical difficulties which affected their procedure, say, in the treatment of dates. We may suppose him to argue that, considering the imperfect means of communication which existed in these Islands before the establishment of the penny post and the introduction of telegrams, there was at least a possibility that the commencement and termination of the reigns of our English kings were not simultaneous over the whole extent of their dominion, and that it was conceivable, nay, on the whole rather likely, that while a Stuart was seated on the throne in London, a Tudor might have been reigning in Cornwall, and a Plantagenet in the Scilly Isles. If, further, he had been able to support so disturbing a suggestion by good reasons, it is to be feared the Fellows of the Society might have been tempted to abandon the study of history for some more promising pursuit. It does not appear, however, that this argument as applied to geology excited 


\section{KEY TO 'TERRESTRIAL HISTORY}

the consternation that might naturally have been expected. Geologists did not offer much in the way of confutation, but went on with their work and continued the identification of strata by fossil remains : the chief effect, indeed, appeared to be that logical persons who were not averse to neologisms now began to say "homotaxial" when formerly they would have used the word "contemporaneous."

Nevertheless the polemic of Huxley struck at the very root of the historical study of stratified rocks, and the most important advance which this branch of our science has made during the past twenty years is to be found in its successful attempt to turn aside the blow. Before considering the recent additions to our knowledge, let us diverge for a moment to discuss one or two arguments which might have been offered in defence, even without more information than we possessed at the time this address was delivered.

Admitting unreservedly that contemporaneity cannot be directly inferred from homotaxis, yet it may be possible to connect them by some third term. Confining our attention in the main to the parallel systems of Europe and North America, no one will deny that the deposits now forming on each side of the Atlantic are both homotaxial and contemporaneous, nor probably would even the most captious critic think it worth while to dispute the contemporaneousness of the homotaxial gravels and alluvia belonging to the so-called "recent" period of the two continents. But immediately below these we find in both hemispheres a series of beds known as Pleistocene : these are undoubtedly homotaxial, are they also contemporaneous? In both areas there is conclusive evidence to prove that they were formed under glacial conditions of climate: similar homotaxial deposits in Australia, Tasmania, New Zealand, and South America prove the 


\section{ARGUMEN'T FROM CLIMA'IE 269}

existence of a similar climate in the southern hemisphere, and there are not wanting indications to show that a fall of temperature has at no distant date affected tropical Africa under the equator. Is it likely that this cold climate wandered about the earth, paying flying visits to one country after another in turn? Are not the chances many times greater that it was universal and affected simultaneously the whole globe? An affirmative answer to the latter question may be fortified by independent evidence, and carries with it the precise contemporaneity of the Pleistocene glacial deposits. It would not, however, be given altogether unanimously, for an opinion has been expressed that the climatal conditions of the glacial

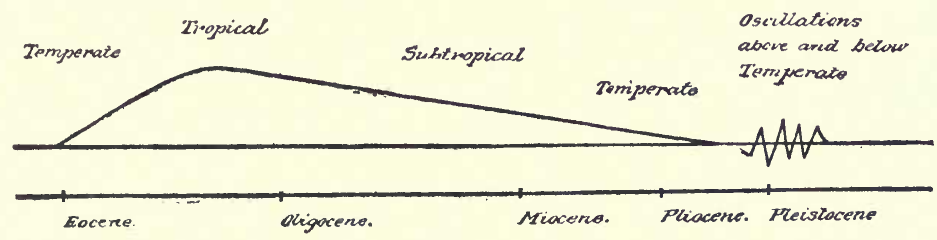

Temporatuze curve for Britiste Isles dureng the Tertuary Aera. Fig. 83.

period passed rhythmically to and fro between Europe and America, and even oscillated across the equator between the northern and southern hemispheres. But even on this view the contemporaneity of the Pleistocene series as a whole is not necessarily denied; all that is denied is the contemporaneity of individual beds, which, as it has not yet been asserted, and forms no part of existing geological doctrine, is for our argument of no consequence.

A similar argument may be applied to the evidence afforded by the Tertiary systems which lie below the Pleistocene. In proportion as we descend lower in this series, we encounter both in America and Europe signs of a progressive amelioration of climate (Fig. 83); glacial con- 


\section{KEY 'TO TERRES'TRIAL HISTORY}

ditions retreat polewards, temperate conditions tread upon their heels, till a sub-tropical or even tropical climate prevails in temperate latitudes, while the ice in the Arctic regions grows thinner and finally dissolves away. If, as would seem most probable, this gradual rise of temperature was due to some general cause, then again we are led to the conclusion that in cases where independent testimony is forthcoming, homotaxis and contemporaneity prove to be interchangeabie terms.

The underlying Mesozois deposits might also be called as witnesses for the defence, but we can afford to pass them over and proceed at once to the examination of the Carboniferous system. This is pre-eminently the system of coal-fields, which are widely distributed over the temperate regions of both the northern and southern hemispheres, and extend far within the limits of the Arctic zone. The coal of these deposits is the product of ancient forests, which, as botanists assure us, flourished in a moist, equable, and fairly warm climate; and this, as we may infer from the distribution of the coal, prevailed over the temperate and Arctic regions of the globe. But when we pass upwards from these beds into those of the overlying Permian system we encounter signs of extensive glacial action. In Australia, South Africa, and India deposits are met with as truly glacial as those of the much later Pleistocene. These Permian beds are, indeed, related to the Carboniferous much in the same way as the Pleistocene to the Tertiary; and thus, unless climate is a purely local phenomenon, we are once more presented with evidence to suggest that homotaxy and contemporaneity are equivalent terms.

Leaving these arguments for what they are worth, and they can only be regarded as establishing a prima facie probability, we may turn next to another point of view, suggested by the American geologist, Professor Heilprin. 


\section{ABSENCE OF INVERSION 271}

Let us, he says, suppose with Professor Huxley, that a Silurian, Devonian, and Carboniferous fauna were simultaneously in existence in three different geographical regions. They may be represented by the letters S.D.C. arranged in any order as in the diagram (Fig. 84). If, now, these three faunas, preserved in the fossil state, are to succeed one another vertically in the same order in the sediments deposited in the three regions, then it is necessary that their migrations from area to area should take place in one direction only, as indicated by the arrows, so that D shall come to be found over $\mathrm{S}$ and $\mathrm{C}$ over $\mathrm{D}$. If migrations should occur in contrary directions, as $\mathrm{S}$ towards $\mathrm{D}$ or $\mathrm{D}$ towards $\mathrm{C}$, then beds containing

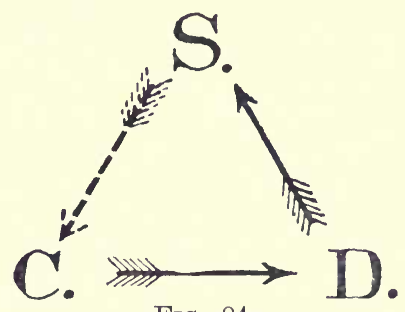

Fig. 84.

remains of Silurian organisms would be found overlying others containing Devonian fossils, and similarly Devonian beds would be found above Carboniferous; i.e., there would be no homotaxis, or the universally observed order of succession would be inverted: and since not a single case of such inversion has been shown to exist, Heilprin concludes that the simultaneous existence of three such different faunas as the Silurian, Devonian, and Carboniferous is, to say the least, very unlikely.

The argument is specious, and may contain some germ of truth, but it is not conclusive; for causes may exist which do actually determine that movement of migration in one direction which at first sight seems to be so im- 


\section{KEY 'TO 'TERRES'IRIAL HISTORY}

probable. If we turn our attention to the closing days of the Palæozoic period, we find that two very different floras were then in existence: one occurring in the northern hemisphere, characterised by Lepidodendra and Sigillaria, the other in the southern hemisphere containing much more highly organised plants, such as Conifers, and characterised by abundant ferns, particularly Glossopteris and Gangamopteris. Thus Australia, which is now behind the times as regards its indigenous inhabitants, peopled by an old-fashioned flora and fauna, was then as far ahead, compared with our northern lands: it led the way, and had already given birth to a Mesozoic flora. The state of affairs imagined by Huxley would seem at this time to have been partly realised since a Mesozoic flora in the southern was flourishing contemporaneously with a Palæozoic flora in the northern hemisphere. It might be supposed that all the conditions requisite for an inversion in the order of succession of our fossil floras were now fulfilled. Like two opposing armies, the two hosts of plants stood facing each other all round the world, with the equator for their frontier. If anywhere the northern forms should succeed in effecting a crossing, and obtaining a foothold in the south, the fact would be recorded by an inversion of the succession; Palæozoic plants would be found in deposits lying upon others containing Mesozoic species (Fig. 85).

Such an inversion has never been brought to light, and thus the absence of inversion does not prove the impossibility of the simultaneous coexistence of two different floras.

Improbable as we have supposed it to be, migration was, so far as we know, everywhere in one direction, in the direction, that is, of a yielding foe. The newer flora of the south maintained a steady advance northwards, the older flora of the north everywhere gave way before it, 
and the triumphant progress of the Mesozoic forests did not cease till they had dominated the world.

Here, then, we may expect to find the clue to the unfailing regularity with which systems of organisms succeed each other all over the world : inversion does not occur because the newer forms of life, in virtue of their higher organisation, are more efficient than the old.

Although the instance we have just considered is the

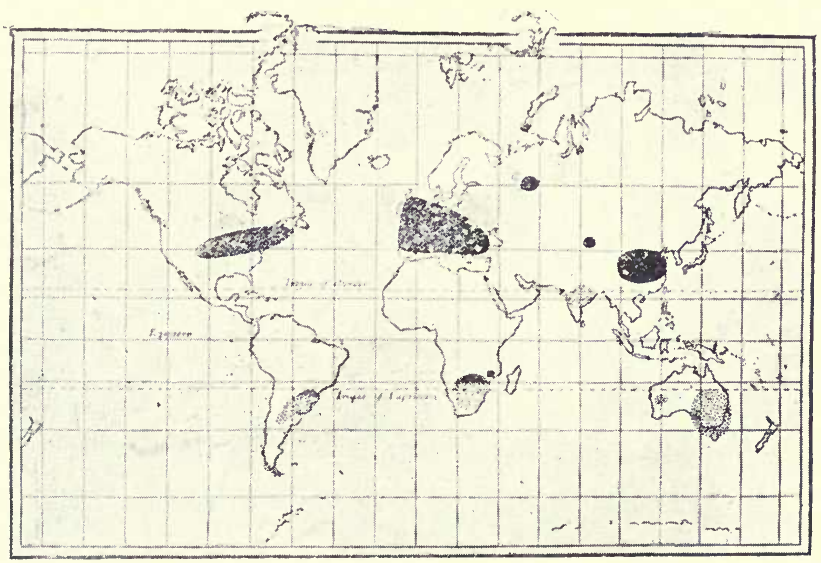

Fig. 85.-The Northern and Southern Floras at the close of the Carboniferous Epoch. The northern flora is indicated by black patches, the southern by dots. After Seward.

most striking to be found, it is certainly not so extreme as that conjectured by Huxley, and on the whole, so far from diminishing our faith in William Smith's method, is rather likely to strengthen it, since it plainly appears that when two different floras do happen to coexist, this method is not incompetent to discover the fact.

We may now resume our account of the progress of discovery, as geologists continued to identify strata by fossil remains. In William Smith's time and that of his 


\section{KEY 'TO 'TERRESTRIAL HIS'TORY}

immediate successors, it was only large groups of strata that were thus identified, but with the courage born of success the method began to be applied in greater detail, and much smaller subdivisions were made amenable to the test. It was the gifted Oppel, too early lost to Science, who, so long ago as 1856, first led the way. Confining his studies to the Jurassic system, he subdivided it into a number of smaller groups of beds known as zones, each of which he found to be distinguished by a group of fossils peculiar to itself. Taking Ammonites as his most trustworthy guides, he associated with each zone the name of some species of Ammonite, which occurs in it, but not in the beds above or below, and thus succeeded in establishing in the Jurassic system alone no fewer than thirty-three of such zones.

Oppel occupied himself in tracing his zones all over Europe, and was at length able to prove that everywhere within this continent they succeed each other in the same order.

This was in itself a sufficiently noteworthy fact, but further revelations were in store, for Waagen, working on the Geological Survey of India, was able in 1875 to prove that even in the remote region of Cutch similar zones distinguished by similar Ammonites are present, and succeed each other in the same order as in Europe. Thus a considerable number of Oppel's zones were found to continue in unchanged sequence some four thousand miles to the east of our area; but, again, still later investigations by Steinmann, Tornquist, and Burckhardt have brought to light a similar succession between lat. $32^{\circ}$ and $39^{\circ} \mathrm{S}$. in the Argentine and Chilian Andes of South America, seven or eight thousand miles to the south and west, and thus many of the thin zones of the Jurassic system have been traced in undeviating order over nearly half the circumference of the globe. 
Similar facts have been afforded by the study of the Cretaceous strata; and even the complicated lower Palæozoic sediments, yielding to the genius of Lapworth, have been reduced to a regular succession of zones, which, so far as our knowledge extends, follow one another in the same order wherever they are visible in the northern hemisphere.

The fossils which Lapworth made use of as a means of identification are the Graptolites, small and frequently obscure forms, which depend on minute observation for their specific distinction, and not likely at first sight to recommend themselves as the most promising of guides: but by their means it has been found possible to unravel the amazing intricacy of the southern Uplands of Scotland, a district which, on account of its complications, had resisted all previous efforts to reduce it to order. Messrs. Marr and Nicholson have extended Lapworth's classification to the lake district of Cumberland and Westmoreland: it has been shown to obtain in Wales, France, Spain, Bohemia, Thuringia, Scandinavia, and North America. In the southern hemisphere, beds have been observed containing the same Graptolites as occur in the Ordovician system of the northern hemisphere, but in this case the succession is by no means so clear. In New Zealand it has not yet been studied. In Australia,* Mr. T. S. Hall thinks he has discovered a divergence from Lapworth's succession, but the facts are somewhat doubtful. Some of the genera extend through longer intervals than in our hemisphere, but this, as Waagen has pointed out, is by no means inconsistent with zonal identity, which depends on identity of species, and these, as Mr. Hall admits, may not have been rightly determined in the case of the Australian specimens (loc. cit., p. 177). We must there-

* T. S. Hall, "Presidential Address to Section C. Australasian Assoc. for the Adv, of Science," 1900, p. 176. 


\section{KEY 'TO 'TERRES'TRIAL HIS'TORY}

fore suspend our judgment while awaiting further discoveries.*

The immediate motive which prompted geologists in their efforts to carry the identification of strata down to such extreme limits was their desire to determine the structure of the earth's crust, and to read its history in greater detail; and so far as their efforts have met with success, so far does the fundamental assumption upon which they have proceeded meet with its justification.

As a direct consequence of a stricter study of the distribution of fossils, the whole aspect of this discussion has undergone a change: the general correspondence of sedimentary systems to periods of time can no longer be in doubt; our difficulties would seem to be restricted to the consideration of zones. $\uparrow$ This will almost appear selfevident if we picture to ourselves the case as it would arise if we accept for a moment the startling assertion of Huxley, and admit the simultaneous coexistence of three sedimentary systems. Let us select for one of these the Jurassic system, then it is not a single fauna common to the whole, but the thirty-three distinct faunas of its several zones, with which we have to deal. If now we add the next system below, the Trias, this means so many more faunas; and again more when we take into account the next system above, the Cretaceous. Having then chequered the earth with these multifarious faunas, we have next to conceive of some method by which they may be made to succeed each other in all parts of the world in an unvarying order, and this seems to my mind

* In a work which has appeared as these sheets are passing through the press, Mr. Rudolf Ruedemann has shown that the succession in Australia is in strict conformity to that which prevails elsewhere ("Graptolites of New York," N.Y. State Museum, Memoir 7).

+ For an interesting discussion of this subject, see J. E. Marr, "The Principles of Stratigraphical Geology," 1898, p. 50, and Proc. Camb. Phil. Soc., 1898, vol. vi. p. 74. 


\section{SYS'TEM EQUIVALEN'T 'TO PERIOD 277}

to surpass the bounds of possibility. It may be urged, perhaps, that the conditions here indicated are not precisely those Huxley had in mind, but it will, I think, be found that, however we modify the statement, the existence of a universal homotaxis will be found fatal to the views the example was intended to illustrate. The mere mechanical transport of dead shells would almost certainly carry some species from one region to another; validity would thus be given to Heilprin's argument, and inversions in the succession would almost certainly be effected. Not the possible coexistence of three systems, but of three zones, is the direful possibility that geologists have now to face. Let us admit this possibility, and even then we shall not be so badly off. A Jurassic zone is only one-thirty-third of the whole system, and our conclusions will not be sadly in error if the period designated Jurassic in one country should possibly differ in exact contemporaneity from that so called in another by a fraction of this amount. Not that this fraction is to be lightly disregarded; if, accepting the old analogy, we compare the duration of a geological system to a single day, then an error of onethirty-third would be equivalent to one of twenty-two minutes, too fast or too slow, in the geological clock, and a deviation from the truth to this amount would scarcely be tolerated even in a clepshydra. Is there, then, any prospect of arriving at closer approximation? Without venturing on a positive affirmative, we may point out reasons for thinking that there may.

Thus in the Cretaceous rocks of India, which have afforded to investigation the same zones as those which have been distinguished in Europe, certain groups of Ammonites are met with in such abundance as to suggest that they originated in or about that province. India. is regarded as the metropolis of these forms; they are 


\section{KEY TO TERRESTRIAL HISTORY}

represented in the accompanying diagram by the letter $p$

EUROPE.

$a_{1} \ldots a_{10}, p_{2}, p_{3}$
INDIA.

$p_{1} \ldots p_{10}, a_{1}, a_{4}$

to indicate their association with the Pacific Ocean. In the corresponding rocks of Europe certain other groups of Ammonites are found which appear to be equally characteristic of an Atlantic province; they are indicated by the letter $a$ in the diagram. But, and this is the point of real significance, in the same zone as represented in the two remote localities, we find an admixture of these two groups of Ammonites: in Europe, though Atlantic types preponderate, yet a few Pacific forms occur; in India there is a similar collocation, but with more Pacific and fewer Atlantic species.

This may be most readily explained by supposing that contemporaneous migration in opposite directions was proceeding while each zone was in process of formation, Pacific Ammonites travelling to Europe, while Atlantic Ammonites were on their way to India. What, then, becomes of the argument that the presence of similar species in remote regions indicates a difference of age equivalent to just so much time as was required for these species to migrate from one area to the other? Since the Atlantic species $a_{1}, a_{4}$, spent time in accomplishing the journey from Europe to India, the beds in which they occur in India must, on this showing, be older than those in Europe by this interval ; but again, since the Pacific species $p_{2}, p_{3}$, require time to travel from India to Europe, the beds in Europe must be older than those in India, and thus each must be older than the other, which is impossible.

The apparent absurdity arises, however, to some 
extent from the method by which it is presented. To state it more exactly, we may represent the time taken by the Atlantic species to reach India by $x$, and that taken by the Pacific species to reach Europe by $y$, then $x-y=d$, the true difference in age of the homotaxial deposits of the two regions, probably in any case a small quantity, while if $x=y, d$ vanishes and the deposits are precisely contemporaneous.

In apposition to this conclusion we may place the following question: "Were the British Cretaceous rocks deposited at the same time as those of India, or are they a million years younger or a million years older?" This was the question put to geologists by Huxley in his famous address, and was followed by the statement that they were in no way able to answer it.

Of the many-sided results which have followed from a study of the distribution of fossils, one in particular seems to call for consideration. The notion that underlies the use of zonal fossils is that they were short-lived species, which speedily attained a very wide distribution over the globe; but this idea is in flagrant contradiction to a supposed biological law, for it is an accepted maxim among biologists that a species widely distributed in space is also widely distributed in time. It would perhaps argue excessive hardihood to suggest that this generalisation may rest on too slender a basis, but without now entering into this question, we may endeavour to find some other explanation of the undoubted fact that species which have evidently enjoyed only a very brief existence have yet become very generally distributed over the floor of the oceans. It may at once be pointed out that it is not every sort of fossil that can be made use of for the identification of zones; the two groups of organisms that have hitherto best served the purpose are Ammonites and Graptolites. 


\section{KEY 'TO 'TERRES'TRIAL HISTORY}

Thus the correlation of the Jurassic beds of Cutch with those of Europe depends entirely on the Ammonites, it could never have been established by a study of the Corals or Brachipods, for instance. The Ammonites possessed peculiar chambered shells, constructed on the same principle as those of the modern Nautilus or Spirula.

The Nautilus lives at considerable depths in the sea, and is rarely seen at the surface, yet its shells are found widely scattered over the shores of the Pacific Ocean. The numerous specimens to be found in museums or adorning old-fashioned collections of "curiosities" have almost all been picked up off the beach. The explanation of this lies in the fact that after the death and decay of the animal, the shell, owing to its water-tight compartments being filled with air, rises to the surface of the sea, and is then blown by winds or drifted by currents till it strands on some shelving shore.

The little Spirula is, perhaps, even a more striking illustration of this method of distribution; it is very rare in the flesh, not more than half a dozen specimens have ever been seen alive, and it is confined during life to tropical seas, yet its shell is one of the common objects of the seashore. It is found floating in mid-ocean, and is washed up on almost all shores of the world, finding its way even to the northern coast of Scotland.

From these facts Professor Walther has been led to suggest that the wide distribution of single species of fossil Ammonites may be accounted for in a similar manner; they may have lived remote from the spots where they are now found fossil, and have been dispersed far and near as dead shells by wind drift and ocean currents. If so the difficulties of the biologist would be met, but it is doubtful how far the explanation can be regarded as general: Ammonites, like modern cuttle-fish, appear 


\section{DISPERSAL OF GRAP'TOLITES 281}

to have been active creatures, and may have made their passage from place to place by their own muscular exertions. That many of them certainly lived in the locality in which they are now found is proved by the occurrence of vast numbers of uninjured shells of the same species, and in all stages of growth, crowded together within very limited areas.

Whatever explanation we adopt, there can be no possible doubt that the transformation of Ammonites from species to species took place with an altogether exceptional degree of rapidity, and it is to this unusual plasticity, as well as to some exceptionally rapid means of distribution, that they owe their value for geological purposes.

In the case of the Graptolites, Professor Lapworth has proposed to account for their wide distribution by means similar to those conceived by Professor Walther for the Ammonites. They usually occur in blackish sediments supposed to owe their colour to the carbonaceous matter of decayed seaweeds, and it is suggested that these were floating forms like those of the modern Sargasso Sea. If, as Professor Lapworth supposes, the Graptolites grew attached to these seaweeds, their wide distribution might be brought about by winds and currents. Some species are supposed, on very good evidence, to have shared with some of their existing relatives among the Hydrozoa the possession of a pneumatophore, or swimming bladder, like that of the "Portuguese man-of-war" ; beneath this the gonothecæ, or reproductive individuals of the organism, appear to have been situated. Such forms might float for long long distances (Figs. 86 and 87).

No doubt the explanations of Professors Walther and Lapworth offer a partial solution of the difficulty, but the evidence, particularly in the case of Ammonites, is so 


\section{KEY TO TERRESTRIAL HISTORY}

strongly in favour of these organisms having lived near or upon the spot where they are now found fossil, that some wider-reaching theory seems to be demanded; and some geologists have not hesitated to cut the knot by imagining some distribution of the land and sea, specially designed to favour migration in desired directions.

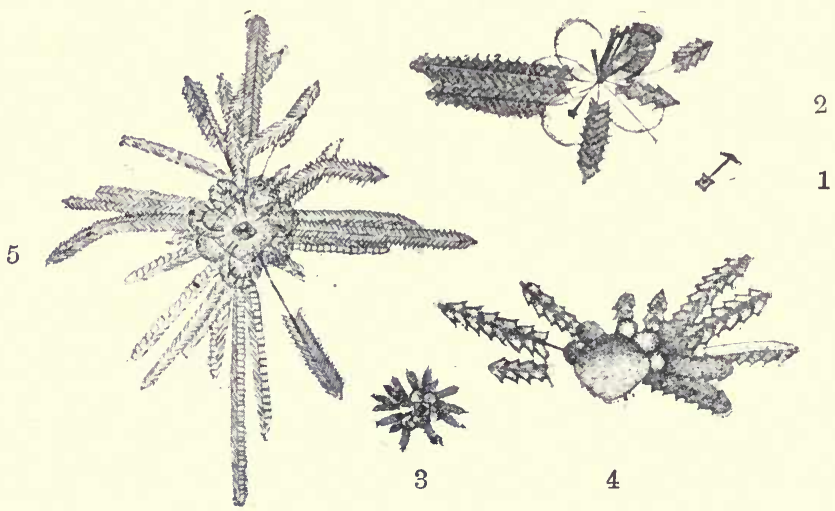

FrG. 86.-A Graptolite (Diplograptus foliaceus, MacCoy) in various

1. The youngest form. $(\times 3$.)

2. A young adult, showing very young individuals within the reproductive vesicles (gonothecæ) and fully formed branches of different age. $(\times 3$. $)$

3. A colony in which all the branches belong to a single generation. $\left(\times \frac{3}{4}.\right)$

4. Similar, but showing the swimming bladder, pneumatophore (the rounded body in the middle), surrounded by gonothecæ. $\left(\times \frac{9}{2} \cdot\right)$

5. A fully grown colony, with the pneumatophore in the centre, surrounded below by gonothecæ, and supporting several whorls of branches of different age. $\left(\times \frac{3}{4}.\right)$ After Ruedemann.

Indeed, there exists a considerable body of independent evidence to show that these imaginary distributional areas did, at least in part, actually exist. No one now doubts the wide extension of the Mediterranean in Jurassic times, when it spread through the heart of Europe and Asia. Along the shores of this ancient Tethys, as Professor Suess names it, the Ammonites of the Jurassic 
zones could freely wander. But having got them, say, from India to Europe, how shall we account for their onward journey across the Atlantic into the Cordillera of the Argentine and Chili? An ocean shore has so far served their needs, what more simple, then, than to imagine this continued across the Atlantic into South America? It may seem a bold undertaking to connect

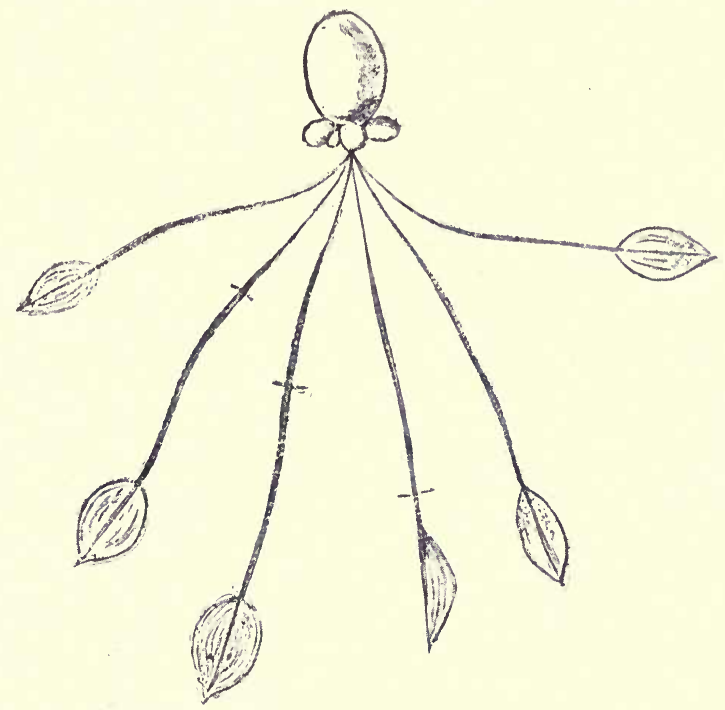

FIG. 87.-A Graptolite (Pristiograptus pala, Mob.) as conceived by Frech. The swimming bladder is seen at the top, surrounded below by gonothecæ, and supporting several long colonial stems. After Frech, "Lethea Geognostica."

Africa and Brazil by a continental mass of land in order to explain a simple fact in animal distribution; but the independent investigations of Suess and a great number of other thinkers have afforded much evidence in support of the supposed extension of the Mediterranean into the Carribean sea at a period when neither North nor South Atlantic, at least in their present conformation, were in existence. 


\section{KEY 'TO 'TERRESTRIAL HISTORY}

The little that we know about the habits of the Ammonites, and indeed it is not much, points decidedly to a mode of life not unlike that of the existing Nautilus, which certainly could not cross deep oceans; nor is it likely that the drifting of abandoned shells could explain a community of species between Cutch and England, and England and Chili.

The more we consider the matter the more do we seem driven to admit that a continuous distribution of such forms as Ammonites must be dependent on a more or less continuous shore-line.

The Graptolites are in a different case: there is clear evidence that some of them were provided with a pneumatophore, and that, consequently, they were floating organisms. Some may, as Professor Lapworth suggests, have been attached to floating seaweed, and some may even have been propagated through the intermediation of jelly-fish, as happens with many modern Hydrozoa.

Thus, then, either by the influence of a particularly favourable distribution of land and sea, or by a special mode of life, we are enabled to understand the peculiarly wide distribution which is characteristic of the fossils used in correlating geological horizons. Is it possible to proceed further, and throw some light on the rapidity with which these forms seem to have succeeded in occupying the globe?

There is abundant evidence to show that many of the activities of the earth were enhanced in past time. Even its rotation on its axis is a changing quantity. About 56 millions of years or so ago, as Professor George Darwin informs us, the length of the day was only some ten hours instead of twenty-four, and I suppose that 26 millions of years back, which brings us within the limits of the sedimentary record, it would be about twenty hours, so that a point on the equator would then have 


\section{ANCIEN'T CLIMA'TES}

described 1,200 miles in an hour instead of 1,000 as at present.

This increased rapidity of rotation would have affected the distribution and velocity of the winds, consequently of sea drift and ocean currents, and therefore of the floating organisms they bear along.

Still greater would appear to have been the modifications which have affected the past climates of the globe, though these, unlike the spin of the earth, were not always in one direction, but seem to have followed a mighty rhythm. Three times at least the temperature of our planet would seem to have fallen so low that glacial conditions intervened within the temperate zone: once at the beginning of the Cambrian; again, and more evidently, during the Permian period: and yet once again, in times comparatively near our own, when the Great Ice Age held the temperate regions in its grasp, and even touched the high mountains of central Africa. It is indeed doubtful whether we can speak of this interval as wholly past. Three times at least has the temperature varied in the opposite direction, rising so high as to bring the existing climate of the tropics into the temperate zones; as in the Palæozoic æras, when coral reefs and coal forests could flourish within the Arctic circle, as again during the Mesozoic periods, and one more finally in the Cainozoic æra, when we can trace the rise of temperature as it follows a curve, making a steep ascent to its culmination in the Eocene, and then slowly and gradually descending till it terminates in a series of oscillations during the last glacial epoch (Fig. 83).

Such changes surely cannot have been without their effect on the evolution of living forms, and may also have indirectly influenced their distribution. Genial climates would remove many barriers to dispersal, and they would be accompanied by a more active atmospheric 


\section{KEY 'TO 'TERRES'TRIAL HIS'TORY}

circulation and more rapid oceanic currents ; floating forms would be swept along by more swiftly-moving vehicles of transport, and would spread along the seachore and pass from island to island with a velocity which might perhaps be twice as great as at present.

Those organisms which pass through a free swimming larval state of existence would be affected as well as those which float by means of a pneumatophore or in other ways. The developmental history of the organisms probably differed in the past in a manner favouring a wider distribution than they now enjoy, for it is a universal tendency among such forms to shorten in the course of successive generations the period of a free larval existence; possibly in order that all the advantages of the adult state may be acquired as early as possible. If this be so, and there can be little doubt of it, then as we proceed backwards in time, we shall find that sessile organisms will pass a longer and longer time in their probationary locomotive stage; 20 millions of years ago, perhaps as many weeks as now days might have been expended in a state of free larval existence. It might even occur to some one to suggest that, in this case, the Graptolites might have been dispersed over the whole world merely as a consequence of a protracted existence in the larval state. This, however, is not likely; the equatorial current of the Atlantic, by no means a slow stream as ocean currents go, has a speed of from eight to eleven miles a day; supposing this increased to twenty miles, as the result of changed conditions, then it would require just a hundred days proceeding at this speed to cross the Atlantic in a straight line in its narrowest part, that is, between Sierra Leone and Brazil; so that, unless we invent a sufficient number of islands as stepping-stones on the way, even comparatively long-lived larvæ would not be likely to make the passage across deep oceans as these 
now exist. Herein we find a justification for those hypothetical shore-lines which so many geologists now seem driven to assume.

We must not, in our zeal for extending our knowledge of zones and their distribution, be misled into the unreal assumption that the faunas of these zones were worldwide in their extension; that is by no means the case. Regional provinces, distinguished by species peculiar to them, would seem to have existed as far back as the geological record extends. Possibly the number of cosmopolitan species was, on the whole, greater in the early stages of the earth's history than it is now, but such a phenomenon as a universal fauna or flora has not yet been brought to light. This, however, is all pure gain, for if the zonal fossils enable us to link the several provinces together, the regional species, on the other hand, provide us with a means of discriminating between them; while the one points out the lie of an ocean shore, the other indicates the position of some dividing barrier.

We have seen what causes may have contributed to bring about a rapid and widespread distribution of species, but we must not omit to repeat that these by themselves would not provide us with species useful for zonal purposes; for this, organisms must exist characterised by the special facility they display for specific transmutation. Such, in opposition to those sluggish forms Lingula and Nautilus, were the Graptolites and Ammonites, which are almost startling in the rapidity of their change. Speaking in the language of metaphor, we might remark, especially with regard to the Ammonites, that they impress us as alert and intelligent beings, seeking by rapid Protean changes to escape an impending fate, postponing their doom successfully throughout the whole of Mesozoic time, and then succumbing to the inevitable, 


\section{KEY TO 'TERRESTRIAL HISTORY}

possibly during some world-wide revolution, possibly at last vanquished by some superior living foe. They go down into the abyss, and not one survives to enjoy the new world of the Cainozoic æra.

Looking back on the history of the study of strata, we find at the beginning of the last century the stimulus of William Smith's discovery producing its first effects, and this branch of our science entered upon its golden age. The middle of the century was a period of difficulty and doubt; first principles were subjected to an anxious and almost desponding scrutiny. At the close we enter the dawn of renewed hope, and the prospect of a universal history of the earth begins to open before us. Already as a preliminary a new branch of our science-the geography of past features of our planet-is in process of creation; the first contribution we owe to Neumayr, who has given us a chart of land and sea as he conceived it to exist in

Jurassic times: this has been followed by many others, constructed by Koken, De Lapparent, and Frech, to represent the geography of almost all the other periods. Possibly these charts are as far removed from the truth as were the mappa mundi of the sixteenth century; it is the task of the future to improve them, already taken in hand by explorers as ardent as were the famous navigators who sailed on unknown seas in the time of Elizabeth. While the geologist, as cartographer, is thus restoring the outlines of vanished continents and oceans, as palæontologist he is acquainting us with the nature of their inhabitants; some regions he leaves desolate, desert lands and dead seas, others he clothes with meadows and forests, and peoples with strange and grotesque animal forms, which are becoming as familiar as the giants and dragons of faery tale.

Thus we are entering into the treasure-house of past events; as we wander through its chambers the petrified 


\section{KEY TO 'TERRES'TRIAL HIS'TORY 289}

forms live for us again; some day we hope to awaken the sleeping Princess, and to learn from her the whole truth. Whatever fate attend our quest, let us not forget that we should never have set out upon it, but for the identification of strata by fossil remains, the key to terrestrial history, delivered to us by William Smith. 


\section{$\mathrm{X}$ \\ GEOLOGIES AND DELUGES}

$T^{N}$ the days when geology was young, now some two 1 hundred years ago, it found a careful foster-mother in theology, who watched over its early growth with anxious solicitude, and stored its receptive mind with the most beautiful stories, which the young science never tired of transforming into curious fancies of its own, which it usually styled "theories of the earth."

Of these, one of the most famous in its day and generation was that of Thomas Burnett, published in 1684, in a work of great learning and eloquence. Samuel Pepys, of diary fame, is said to have found great delight in it, and it is still possible to turn to it with interest when jaded with the more romantic fiction of our own day.

It was the fashion to commence these theories with chaos, and chaos (Fig. 83), according to Thomas Burnett, was a disorderly mixture of particles of earth, air, and water, floating in space; it was without form, yet not without a centre, a centre, indeed, of gravity, towards which the scattered particles began to fall, but the grosser, on account of " their more lumpish nature," fell more quickly than the rest, and reaching the centre first accumulated about it in a 290 
growing heap-a heap, as we might now express it, of fallen meteorites; the lighter particles, which form fluids, followed the heavier in their descent, and collected around the solid kernel to form a deep ocean. This was at first a kind of emulsion, like milk, formed of oily and watery particles commingled, and just as in the case of milk, there separated, on standing, a thick creamy upper layer, which floated on the "skim-milk" below (Fig. 89).

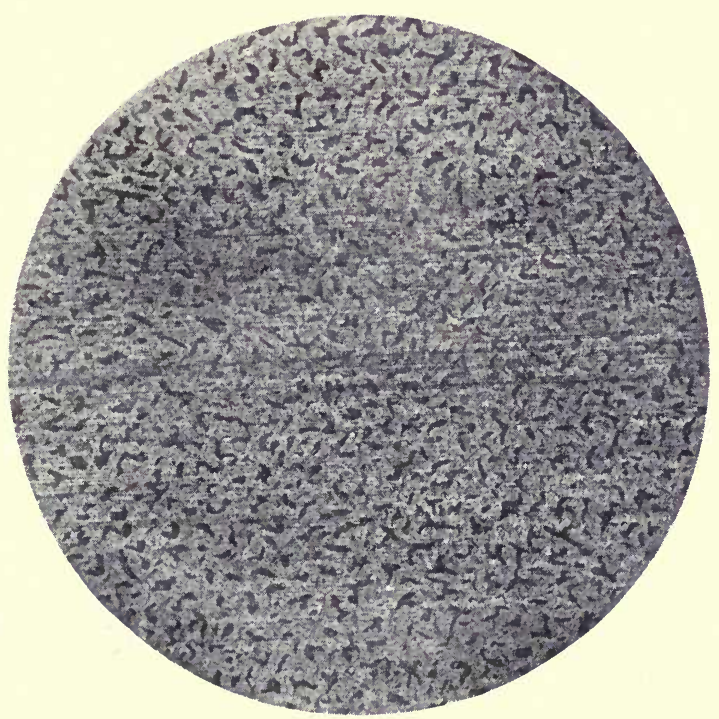

FIG. 88.-Chaos, according to Thomas Burnett.

That this really happened, the good Burnett bravely remarks, "we cannot doubt." The finest dust of chaos was the last to fall, and it did not descend till the cream had risen; with which it mingled to form, under the heat of the sun, the earth's first crust, an excellent but fragile pastry, consisting of fine earth mixed with a benign juice, which formed a fertile nidus for the origin of living things. Outside nothing now was left, but 


\section{GEOLOGIES AND DELUGES}

the lightest and most active particles of all, and these "flying ever on the wing, play in the open spaces" about the earth, and constitute the atmosphere of air.

Such was the earth (Fig. 90) when first it formed the

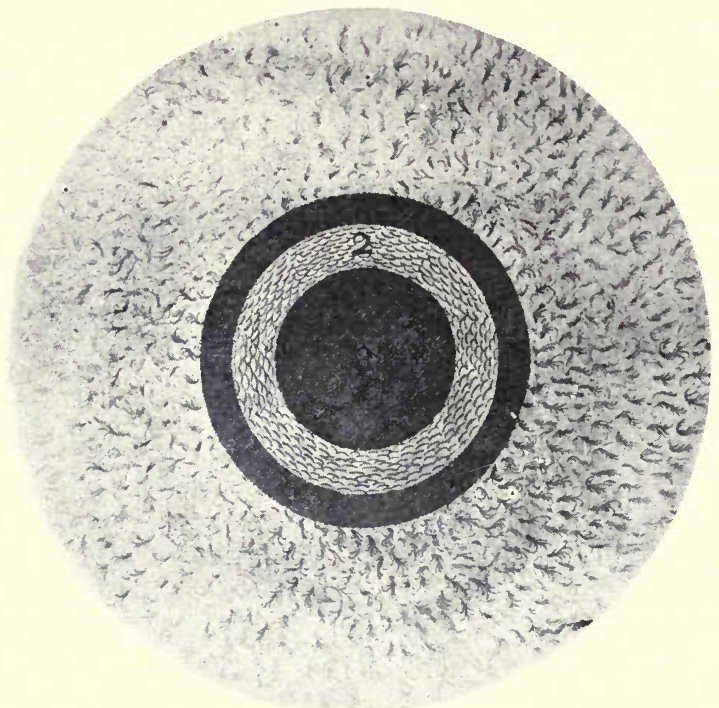

Fig. 89.-The Fall of the Finest Particles, as represented in the fourth figure of Burnett's "Theory of the Earth," on page 57, where he says: "The lesser and lighter particles would sink too, but more slowly, ... so that in their descent they would meet with that oily liquor upon the face of the Deep... which would entangle and stop them from passing any further; so as mixing there with that unctious substance they composed a certain slime, or fat, soft, and light Earth, spread out upon the face of the Waters: as 'tis represented in the fourth figure."

abode of unfallen man-perfect in form and beauty, for it was a true sphere, smooth as an egg; undisfigured by mountains, and unwasted by the sea. It was, unfortunately, but too like an egg, since its fragile shell rested on the treacherous waters of the interior abyss, "the 


\section{BURNE'I'I'S DELUGE}

waters under the earth," and the sun over-roasting, finally cracked and burst it; the broken fragments of the ruined world fell downwards into the abyss, and the subterranean waters rushed out in a mighty flood to remain as our present seas and oceans, from which the broken crust protrudes as continents and islands.

As might naturally be anticipated, the bursting out

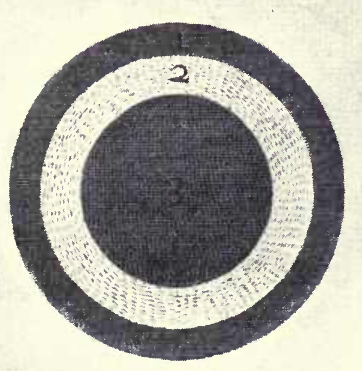

Fig. 90.- "Such was the Earth when first formed." 1. The Crust of the Earth. 2. The Waters under the Earth. 3. The interior parts of the Earth.

of the abyss corresponds to the Noachian deluge, which we thus perceive to have been profounder in its origin and wider-reaching in its effects than we might previously have supposed. This, for distinction, we may call Burnett's deluge (Fig. 91) ; of his geology we may say that it is cosmological, since it endeavours to trace the history of the earth backwards to its origin in chaos; that it 


\section{GEOLOGIES AND DELUGES}

is catastrophic, because it attempts to account for all the great features of the earth by a single event which occurred suddenly and with violence; and that it is theologic, since it owes its inspiration to Holy Writ.

As geology grew older it went to school: what was the name of the school is not quite certain; some have called it " Science falsely so called," others, more briefly,

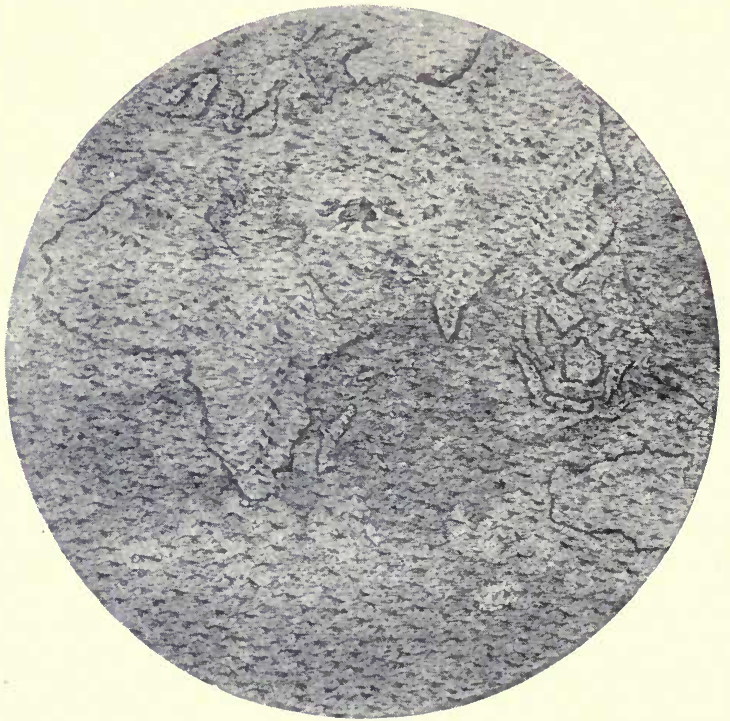

Fig. 91.-The Deluge, according to Burnett.

"Inductive Science." However this may be, the immediate effect on the manners of young geology was very distressing. It grew contradictory, and was frank in the expression of obnoxious opinions. One of its most irritating remarks was that the world was not made in a week, and it would appear that at this time the relations of child and foster-parent became not a little strained. Still geology proved an apt scholar, and 


\section{BREAKS IN THE SUCCESSION 295}

its progress was rapid. One of the most important lessons it learnt was that if we want to know how the world was made, the first essential is to study the earth itself, to investigate with patient drudgery every detail it presents, and particularly the structures that can be seen in river-banks, sea-cliffs, quarries, pits, and mines. Thus it discovered that the solid land beneath our feet is to a large extent composed of layers of sediment which were once deposited more or less quietly at the bottom of ancient seas, and certain curious bodies known as fossils, it concluded to be the remains of plants and animals, sea-shells, and the like, which were once the living denizens of these seas.

It discovered that these deposits lie so regularly one upon another, that it compared them to a pile of books, or to a slanting row of books lying cover to cover; and that in some cases at least the simile was not strained, will appear if we trace the structure of England from Oxford westwards towards Bristol. We then find that the thick bed of clay upon which Oxford stands lies evenly on a series of gently-sloping beds known as the lower Oolites; these in like manner repose on those thin seams of limestone and clay called the Lias, and these in their turn upon the red beds of the Trias. It might, perhaps, have been expected that this uniform arrangement would continue through the whole thickness of the stratified rocks, but it was discovered, and the importance of the discovery was recognised so early as 1670 by Bishop Steno, a man of great genius, that the regularity of the succession is liable to interruption at intervals. Thus as we approach Bristol we encounter those beds of limestone which are associated with our coal-bearing strata, and which are consequently called "Carboniferous"; but these are by no means related to the beds we have just passed over in the same manner 


\section{GEOLOGIES AND DELUGES}

as they are to one another-we do not find the highest bed of the Carboniferous series offering its upper surface as a gently-sloping platform on which the Trias may rest; on the contrary, the Carboniferous bees are seen to lie in great rolling folds, with the tops of the rising folds absent, as it were sliced off, and it is on the edges, not on the surface, of these beds that the red Trias layers are seen to be spread out.

This sudden change in disposition may well be called a break in the succession of the rocks, and, as if to emphasise and compel attention to it, we find it accompanied by a complete change in the character of the fossils, those occurring in the Carboniferous rocks being of entirely different kinds to those which are found in the overlying beds.

Evidently the Carboniferous beds could not have been laid down in the sea in the steeply-folded form they now present; at first they must have been spread out in nearly horizontal layers (Fig. 92 (1)), and the folded form (Fig. 92 (2) ) must have been subsequently impressed upon them, no doubt by the action of some stupendously powerful force. Subsequent, also, must have been the removal of the upper parts of the folds and the general planing-down which they appear to have undergone (Fig. 92 (3)).

To the young geology all this might seem perfectly clear, but in its impulsive explanations it assumed that Nature must have frequently acted in a great and terrible hurry: thus the folding of the rocks was supposed to have been produced suddenly and violently by a single mighty convulsion, which simultaneously changed sea-floors into mountain-chains, split open the land in wide-gaping chasms-our present river valleys-and with the same blow destroyed every living inhabitant in the world.

But the discordance between two sets of rocks is met 


\section{IMAGINARY CATAS'TROPHES 297}

with not once only, but several times, in the stratified rocks of the earth's crust, and for every discordance there must have occurred a corresponding catastrophe.

These catastrophes were as wonderful as Burnett's, and there were more of them, so that at this stage of its

1

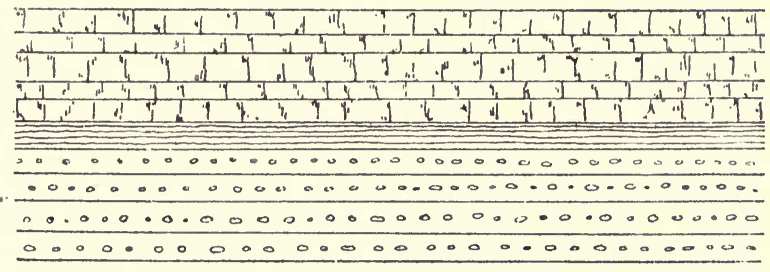

2

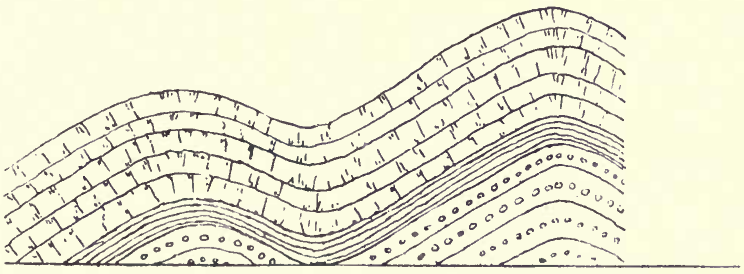

3

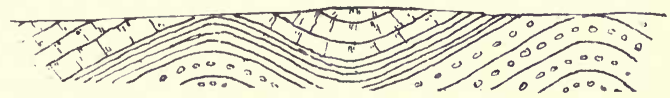

Frg. 92.-Formation of the Mendip Hills.

1. Old red sandstone at the base, succeeded by shales and carboniferous limestone horizontally deposited.

2. The same after folding had taken place.

3. The same after denudation had worn away the summits of the folds and so given rise to the existing relief.

existence geology was appropriately designed "catastrophic." It had completely severed the apron-strings, and ceased to be theologic, but it still, to its credit, remained cosmologic. It traced the earth from chaos up to a stage when islands and continents rose out of a primeval 


\section{GEOLOGIES AND DEI,UGES}

ocean, the waters of which were boiling; saw it peopled with strange and various forms of life, and watched it run its course, rejoicing in the sun, "chearfull, fresh, and full of joyaunce glad," then pictured it overtaken with disasters, shaken with earthquakes, overwhelmed by floods, and agonising in the labours of a new birth. Calm followed after storm, and life rejoiced afresh in a remade world to be again destroyed. Thus, through alternations of peace and strife, the earth moved on its changeful way, to the crowning creation of man, who was himself a living witness of the last great catastrophe of all, the Noachian deluge. Its waters covered the whole earth, to the tops of the highest mountains under heaven, and on their retreat they left behind, as a standing witness to their extension, great sheets of sediment, supposed to be spread out over the entire surface of the globe, and appropriately named the "diluvium." The diluvium may be seen in most parts of the British Isles, except in the south of England; it consists of clays and sands, containing vast numbers of curiously scratched stones.

As the powers of geology matured it became increasingly able to dispense with catastrophes. The very diluvium itself was shown to be local in its distribution, and glacial in its origin ; masses of moving ice, like that which buries the greater part of Greenland out of sight, covered a large part of the temperate regions, and this it was that produced the curious scratched stones and the deposits containing them, which are consequently no longer called "diluvial," but "glacial." More important yet, land could be shown to be still actually rising from the sea, and mountains growing into the air, but so slowly that the fact was not established without much dispute, which is hardly yet over. Valleys could be shown to result, not from any bodily fracturing of the land, but from the 


\section{DISCORDANCES EXPLAINED 299}

slow-wearing action of the rivers which flow through them, and the waves of the sea were shown to be capable of cutting down cliffs and of reducing the land to a plain.

From these facts the discordance in the succession of stratified rocks found an easy solution. Recurring to the instance of the Carboniferous rocks and their relations to the Trias, we no longer need suppose that the stupendous force which folded the Carboniferous rocks and raised them into the air, acted suddenly or even very rapidly; judging from the rate at which mountains rise now, their upheaval may have proceeded slowly; a few feet in a century would suffice. If we allow but one foot in a century, it would only require two millions of years to produce a mountain range 20,000 feet in height. The movement might naturally be expected to be accompanied by earthquakes, possibly on a much grander scale than those of the present. During its slow elevation, the mountain range would be exposed to wind and weather, rain and rivers would carve it out into ridges and valleys, and frost would splinter its peaks into spires and pinnacles. Subsequently it would sink beneath the sea, and the waves of the sea, as they battered down its cliffs, would remove the last remnants which had escaped the rain and rivers, and roll over an unbroken plain. On this plain, as it continued slowly to subside beneath the sea, the immense deposits of the Trias, Lias, lower Oolites, and Oxford clay would be piled up.

If the rise of the sea-floor into the Bristol Alps took place slowly, and involved a great lapse of time, so equally did the sinking of the land to form the sea-floor afresh, and in this long interval time was afforded for great changes in the organic world; and thus we reach an explanation of the great and striking differences which distinguish the fossils of the Carboniferous rocks from those of later date. 


\section{GEOLOGIES AND DELUGES}

There is no insuperable difficulty in this explanation; its great merit lies in its accordance with the course of Nature as we observe it at the present day; and henceforward it became the motto of geology that the processes of the present furnish the key to the interpretation of the past. The changes in which the life of the earth is manifest are not only slow and gradual now, but they have ever been the same. The earthquakes, which in ancient times shook the land, were supposed to have been no more violent than those of which we have lately read in the daily newspapers; the ancient volcanos not more terrible in their outbursts than Krakatoa; floods not more appalling than those which still from time to time sweep away tens or even hundreds of thousands of human beings from the Ganges Plain, and the earth, instead of falling into convulsions every now and then, was imagined to proceed on the even tenour of her way, without haste and without rest, preserving a uniformity in her progress which impresses us with its solemn grandeur, but sometimes seems a trifle monotonous. From its belief that an unbroken uniformity in the operations of Nature extends from the present into the most remote past, geology now came to be called " uniformitarian." It was no longer theologic, no longer catastrophic, and, I am sorry to add, no longer cosmologic. It persistently refused to inquire into the early history of our planet, and restricting its study to the accessible parts of the earth's crust, it abdicated its regal position as the science of the earth, and became as it were a mere petty chieftain, dealing only with rocks and the fossils they contain; the fossils, by the way, not rightly belonging to its province at all. Apart from this, however, and in its self-limited career, geology pursued a luminous advance, and as it did so the Noachian deluge began to sink into an oblivion which it might be thought 
to have scarcely merited. For if the biblical account is to be taken literally, it furnishes us with a catastrophe of the first order, and since this is said to have occurred comparatively recently, or at least in historic time, the uniformitarian, by his own principles, would have been compelled to infer, as the catastrophist had done, that such deluges form a part of the orderly scheme of the world. The universality of the deluge had, however, for various reasons, been denied, not only by geologists, but by writers of other schools of thought, and towards the middle of the century, belief in it amongst the learned was gradually expiring; such a number and variety of convincing arguments as converged against it could, indeed, but lead to that result; and that the deluge, so far from being universal, was a local, and very local phenomenon, became an article of belief, so settled amongst all good geologists-and I think I may add theologians - that it may be said to have finally fallen into the deep slumber of a decided opinion, from which I for one have no desire to arouse it.

Thus the deluge, so far from shaking the uniformitarian position, was rather itself submerged by uniformitarian views, and growing geology was in danger of taking the uniformitarian formula for an infallible dogma. It was saved from this by physics, a clever brother of its own, which had now discovered the famous principle of the "conservation of energy," and another equally famous, "the dissipation of energy." From these it was deducible that the duration of the earth as a living planet must be strictly limited in time. It must have had a beginning, and at the beginning was furnished with a store of energy, which it has ever since been spending. In this spending of energy its life consists, and when the store is at length exhausted 


\section{GEOLOGIES AND DELUGES}

its life will cease, and it will become numbered amongst the dead planets.

A good deal of this uniformitarian geology might perhaps itself have guessed, had it extended its views beyond rocks and fossils to the stars and other shining bodies which people the vast realms of space. The present, then, strange to say, will still afford a key to the past. We have but to turn to the sun, our nearest luminary, though still more than ninety millions of miles away from us, and in that great orb we find much to suggest the state of our planet some ninety millions of years ago or more. It is scarcely necessary to remind you of the fact that the sun is a body so hot that the most refractory substances known to us on the earth exist in it in a state of gas or vapour; tongues of glowing gas shoot from it like flames; the clouds which emit its brilliant light are probably clouds of carbon or silicon, which have momentarily condensed from a gaseous state; and rain, if rain ever occurs, must be a rain of molten metals such as iron, which will be dissipated in gas before it has fallen very far.

If we proceed to the more remote nebulæ, largely composed of glowing masses of gas, we find a suggestion of a stage more embryonic still, when the earth had as yet no separate existence, but formed, with its sister planets and the sun, a single shining cloud.

On the other hand, if we turn our gaze on our nearest relative-offspring possibly-that dead planet, the moon, we may read in its pallid disc the sad reminder, "Such as I am, you, too, some day will be."

But this was not all that was contained in the admonition of physics; it showed not only that the earth is mortal, but that its span of life, as measured in years, or millions of years, is brief compared to the almost unlimited periods which geology had been in the habit 
of postulating. If catastrophic geology had at times pushed Nature to almost indecent extremes of haste, uniformitarian geology, on the other hand, had erred in the opposite direction, and pictured Nature when she was "young and wantoned in her prime," as moving with the tame sedateness of advanced middle age. It became necessary, therefore, as Dr. Haughton expresses it, " to hurry up the phenomena."

With its uniformitarianism thus moderated, geology has again become cosmologic, and neglecting no study that can throw light on any question connected with our planet, has regained its position as the science of the earth: it is henceforth known as evolutional geology.

The change has not taken place without occasional relapses into catastrophism. Some indications of this can, I fancy, be perceived in the writings of that eminently great geologist, Suess, who, amongst other suggestions savouring of heresy, has lately recalled attention to the "deluge," and endeavoured to show that, though certainly local, and indeed confined to the Mesopotamian valley, it was on a grander scale than we had been accustomed to suppose, or, in plain language, a genuine historic catastrophe.

A clue to the locality of the deluge is furnished by Genesis itself, which informs us that Abraham, the founder of the Hebrew race, left his ancestral city, "Ur of the Chaldees" (Fig. 93), at a time long subsequent to the flood; it is, therefore, rather in the land of the Chaldees than in Palestine that we should be led to seek the scene of this momentous tragedy.

This land is no other than the famous and once beautiful valley of Mesopotamia, through which the great Euphrates and arrow-swift Tigris flow to empty themselves into the Persian gulf Almost lost sight of for awhile, interest in it was reawakened some seventy years 


\section{GEOI.OGIES AND DELUGES}

ago by the investigations commenced by Mr. Rich, and followed up with such wonderful results by Botta, Place, Layard, George Smith, and others. Their discoveries have revealed to us in unexpected fulness the details of a complex and advanced civilisation almost, if not quite, as ancient as the Egyptian, and far more profoundly interesting, for the ancient nations of Mesopotamia are

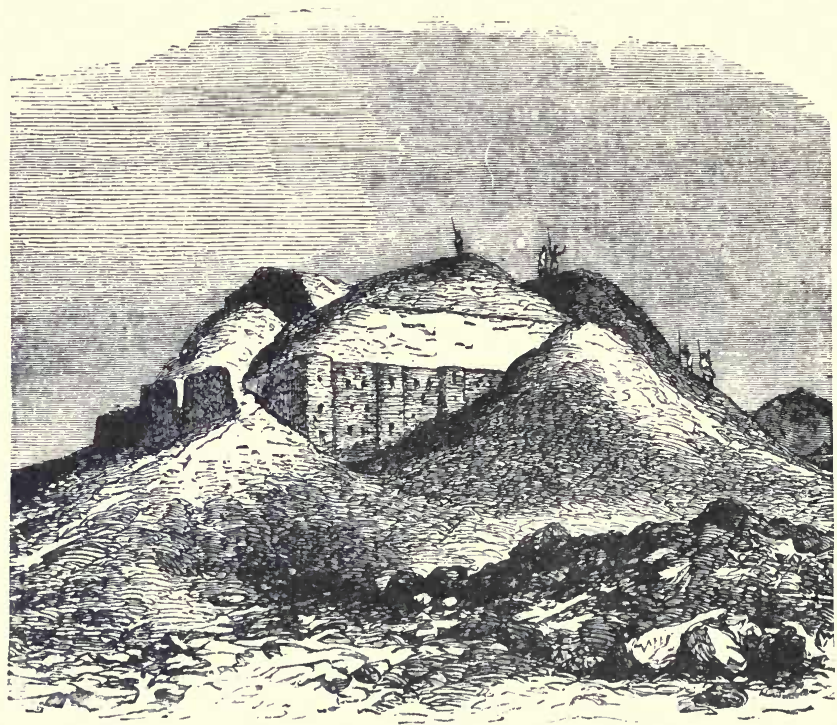

Fig. 93.-Mound of Mugheir (Ancient Ur). From "Chaldea," Story of the Nations.

the intellectual forefathers of the modern world. The learning of the Chaldees was the heritage of the Jews and Greeks, from these the torch was handed on to the Romans, and Jew and Greek and Roman inspired, and still inspire, for good and evil, the civilisation of the present century. There is much more of the Chaldean in every one of us than we are given to imagine. 
The people whom we find in possession at the dawn of history were Semites, the parent stock from which the Jews subsequently branched off; and one has but to glance at their faces and forms, as portrayed in their statues and pictures, to recognise the strong family likeness, while the emphasis with which muscular development is expressed in parts of the human figure suggests that the remarkable assertion, "The pride of a young man is in his legs," was a Semitic opinion long before the time of Solomon.

Just as Egypt is the gift of the Nile, so is Mesopotamia equally the gift of the Tigris and Euphrates, for it is built up of the mud brought down from the mountains by these two streams into the Persian gulf, which is thus in process of obliteration. So long as the two great rivers were not regulated, they produced terrible floods in the wet season; and one of the earliest works of the Chaldeans was to control their flow by great dams, and by diverting a part of their water into canals. These canals covered the country like a network, and served not merely to ease the rivers, but also to irrigate the land, which, thus richly supplied by water, became, under the hot sun, so fat and fruitful, that corn is said to have borne three hundredfold. Groves of palms, orchards, with grapes and many other luscious fruits, were cultivated, while the pastures supported abundant flocks and herds. It was a true garden of Eden, and differed chiefly from the biblical paradise, which Delitsch thinks was actually situated within this garden, in the fact that even here man had still to earn his bread in the sweat of his brow. This the Turks, who now possess the country, have no inclination to do, and consequently it is rapidly returning to its primitive desolation. Were England as enterprising as she was in the time of Elizabeth, we should rent this land from the Porte, run a railway 


\section{GEOLOGIES AND DELUGES}

through it, and thus shorten our route to India by a thousand miles, farm it, and thus provide ourselves with one of the richest granaries in the world.

In a land so favoured, it is nothing wonderful that the inhabitants teemed in millions, villages were everywhere dotted about, and in their midst great and flourishing cities arose-Ur, the City of the Moon-good; Erech, the City of Books; Nippur, and, most famous of all, proud Babylon, "the Gate of God," which stood on the left bank of the Euphrates, some 280 miles above its present mouth (Fig. 94).

In early times, probably about 2300 B.c., the Jews left this beautiful land for some unknown reason, and after various vicissitudes settled in Palestine. Another branch of the Chaldean stock migrated in later times to the northern part of the Tigris valley, where they built many mighty cities, and founded the warlike kingdom of Assyria. Of their cities it is sufficient to mention Assur, which gave its name to the kingdom, and Nineveh, which afterwards became the capital.

The Mesopotamian plain, owing to the way in which it has been produced, is an almost dead flat, and offers no natural elevations for building; the Chaldees, therefore, to raise the foundations of their palaces, temples, and houses above the reach of floods and fever, and for better defence against their enemies, constructed, with incredible labour, great mounds, by piling together quantities of sun-dried bricks and rubbish, and building round this a thick wall of burnt bricks, well cemented together. Some of these mounds, as that of Kojundjik at Nineveh, are as much as 60 feet in height, and it has been computed that this mound alone would have required the labour of 20,000 men for six years in its construction. But there was never any difficulty in obtaining all the labour that was wanted. Prisoners of war were compelled 


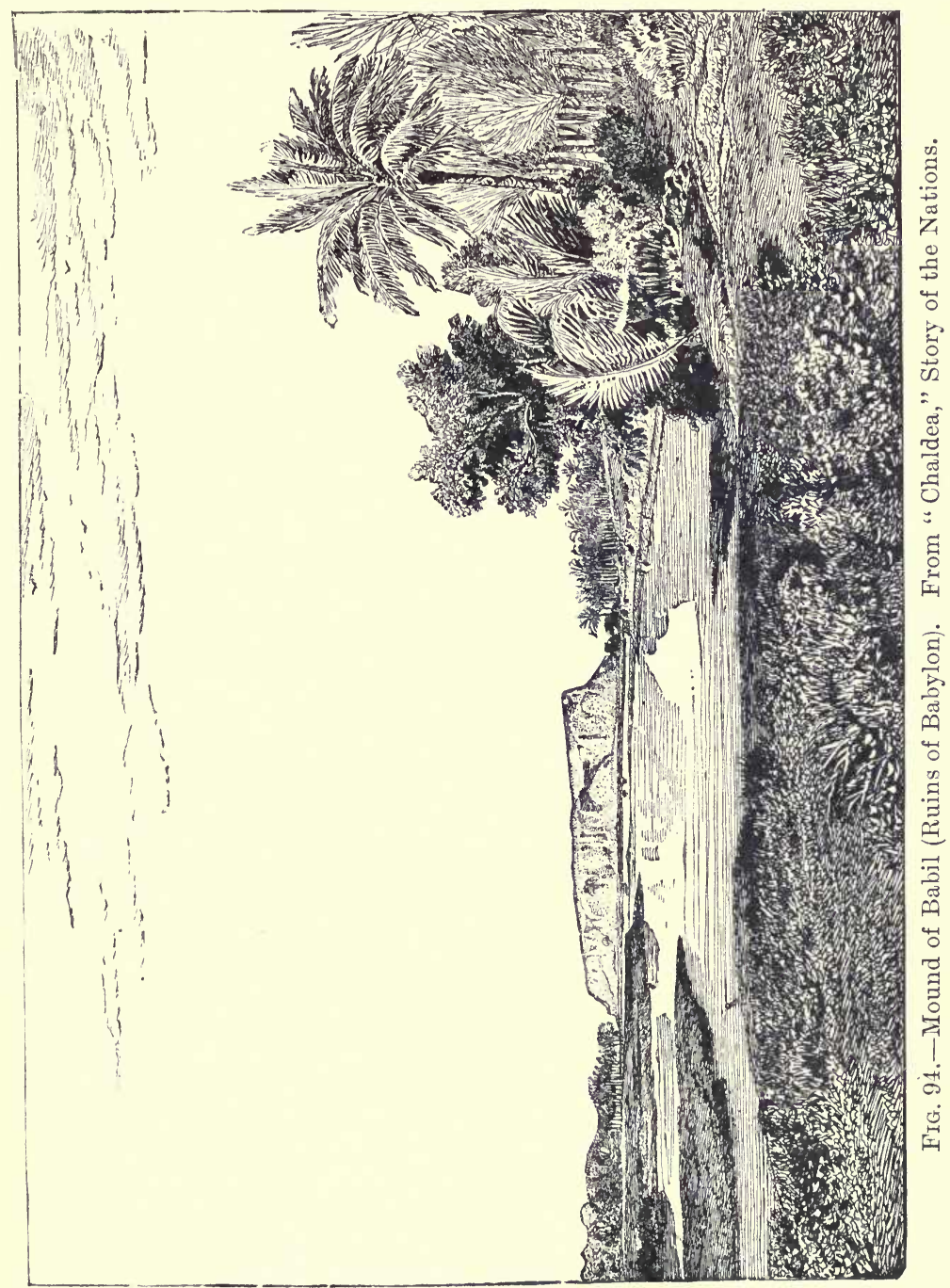




\section{8}

\section{GEOLOGIES AND DELUGES}

to work under the stick, and the building of mounds was one of the wholesome occupations to which the Jews were set during their captivity in Assyria (Fig. 95).

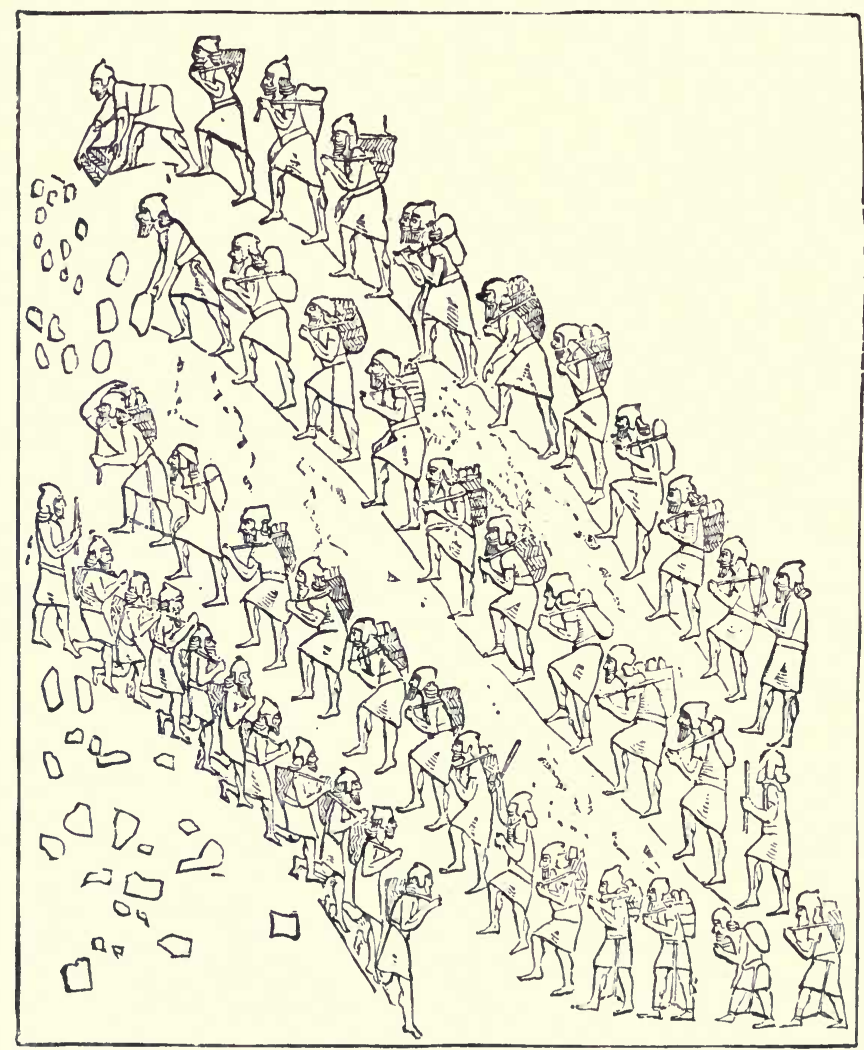

FIG. 95.-Captives Building a Platform-mound. From "Assyria," Story of the Nations.

On the mound of Kojundjik stood two great palaces, one of them that of King Assurbanipal. It was evidently not merely a royal residence, for one of its chambers at least was devoted to public purposes ; this was the king's 
library, to which the citizens, who were taught in their early years to read and write, had free access. Whether any of the books were written on papyrus is uncertain; all that have survived the conflagration, in which the palace was destroyed, are on tablets of kiln-made brick. Of such tablets many thousands have been recovered, not only from Nineveh, but from other towns, and many of them are now preserved in the British Museum. Thus within the last fifty years modern Europe has obtained a glimpse, and more than a glimpse, into the literature of a civilisation that perished just as the Roman was coming into existence; for, as Sir Walter Raleigh puts it, "In Alexander's time learning and greatness had not travelled so far west as Rome, Alexander esteeming of Italy but as a barbarous country, and of Rome as but a village. But it was Babylon that stood in his eyes, and the fame of the East pierced his ears."

The recovered literature covers a vast field of human interest, in science, as in astronomy and mathematics, particularly in astronomy, for the Chaldeans were famous star-watchers, and had already named the stars and constellations, associating them with the deeds and mighty works of their heroes and demigods, so that the star-lit sky became a pictured dome, and the zodiac a frieze to the Assyrian, reminding him of history or fable, like the sculptures and paintings which adorned the king's palaces; in religion and poetry, and in commerce, many of the tablets recording business contracts, and revealing a system of mortgage and banking, money being frequently lent at from 13 to 20 per cent., which was moderate; for the advantages of cent. per cent. were already known and appreciated by these simple Semitic folk.

It was amongst the tablets from King Assurbanipal's library at Nineveh that George Smith, now over twenty years ago, made a famous discovery. He found a frag- 


\section{GEOLOGIES AND DELUGES}

ment of a tablet, bearing words, which he deciphered as follows: "On the mount Nizir the ship stood still. Then I took a dove, and let her fly. The dove flew hither and thither, but finding no resting-place, returned to the ship." Every Englishman who knows his Bible would have guessed, as George Smith immediately did, that he had before him a piece out of a Chaldean account of the deluge. He searched for more fragments, and found them. He went out to Assyria, visited the king's palace, and found still more tablets and pieces of tablets, some of them just those he required to fill up missing gaps in the story. Since its first translation by its discoverer, it has been again translated and retranslated by some of the acutest scholars in Europe, so that we now possess a fairly complete knowledge of it; a few missing words, or even lines, and occasiona! obscurities occur, but these are of no great importance. In Oxford, which has the privilege to number the distinguished Assyriologist, Professor Sayce, among its residents, there will be no necessity to present the story more than briefly. It runs as follows: Sitnapistim, the Chaldean Noah, is warned by Ea, the god of wisdom and the sea, that the gods of Surippak, a city on the Euphrates, even then extremely old, had decided in council to destroy mankind by a flood. Sitnapistim is told to build a ship in which to save himself, his family, household, and belongings. Anticipating the curiosity of his neighbours, since he had never before built a boat, he asks what answer he is to make when questioned as to his unusua? proceedings. Ea, who as the god of wisdom is naturally a master of evasion, provides him with a subterfuge, and Sitnapistim sets about building his boat. He forms it of timber and reeds, and makes it water-tight by filling up the crevices with pitch, which he poured over it both within and without. It is of great interest, as showing 
the local colouring of the legend and the survival of an ancient custom, to observe that this practice of paying the native boats of the Euphrates with pitch has persisted in Mesopotamia down to the present day, natural pitch being used, which occurs at various localities in the valley, but particularly near the town of Hit. Sitnapistim's method of procedure, both in building and paying his boat, may still be witnessed at Hit as a matter of almost every-day occurrence.

Sitnapistim having provisioned the vessel, and brought into it all his goods and chattels, received an intimation of the immediate approach of the catastrophe; he went on board with his family and friends, closed the roof, and prudently entrusted the helm to the sailor-Buzar-sadirabi. Heavy rain fell during an anxious night, and as soon as daybreak appeared-

"There arose from the foundation of heaven, a dark cloud,

The storm-god Ramân thundered in its midst and

Nebo and Merodach went in front.

As leaders they passed over mountain and plain

Ninib went therein, and the storm behind him followed.

The Anunnali raised high their torches,

With their radiant brightness the land glittered,

The turmoil of Ramân reached to heaven,

All that was light was turned to darkness.

In the earth men perished. . . .

Brother beheld not his brother, men knew not one another. In the heaven

The gods were terrified by the deluge, and

Hastened to ascend to the heaven of Anu.

The gods were like a dog-sat down cowering on the ring wall of heaven.

Ishtar cried like one filled with anger.

Cried the mistress of the gods-the sweet-voiced-

' The former generation is turned to clay. . . .

What I have borne, where is it?

Like fish spawn it fills the sea.'", 


\section{GEOLOGIES AND DELUGES}

For six days the flood lasted, and ceased on the seventh, and then Sitnapistim is made to say-

"I looked on the sea and called aloud, But the whole of mankind was turned to clay.

I opened the air-hole, and the light fell on my face:

I bowed low, sat down, and wept,

Over my face flowed my tears."

Sitnapistim then beheld the land, mount Nizir, on which the ship grounded. It remained swinging there for seven days; on the seventh day Sitnapistim sent out a dove, which returned, then a swallow, which flew to and fro, but also returned, and finally a raven: "The raven went, saw the going down of the waters, came croaking nearer, but did not come back." Sitnapistim then left the ship with his people, built an altar on the summit of the mountain, and offered sacrifice. The poem then runs-

"The gods smelt the savour, the gods smelt the sweet savour, The gods gathered like flies over the sacrificer.

The mistress of the gods, Ishtar, lifted up the (bow ?) which Anu had made according to her wish."

A discussion then takes place among the gods, who all through are very human, and in its course Ea suggests to Bel, who seems to have been the prime mover in all the mischief, that he should for the future destroy mankind in a less undiscriminating manner-by wild beasts, pestilence, and famine. The scene ends happily with the apotheosis of Sitnapistim and his wife.

The surprising resemblance of the story to the biblical narrative, extending into identity of words, as in the case of the "gods smelt the sweet savour," points to direct derivation or borrowing, and there can be very little 


\section{NIZIR MOUN'TAINS}

doubt in deciding on which side the borrowing lay. The biblical narrative is indeed a Jahvistic or monotheistic edition of the Chaldean. To this conclusion the most distinguished Assyrian scholars have been led. I need only mention here Professor Sayce, whose opinion is expressed on page 119 of his work on "The Higher Criticism and the Monuments," published by the Society for Promoting Christian Knowledge, during the current year (1894).

The Chaldean story certainly reduces the flood to much smaller dimensions, and so far brings it nearer the range of probability; the rain lasted only seven days, and the waters have subsided sufficiently at the end of a fortnight for Sitnapistim to land. They do not cover all the high mountains, and the stranding of the ship on mount Nizir when the flood was at its climax gives us a maximum height, which it cannot have exceeded; for if this mountain had been deeply submerged it could not have arrested the passage of the ship. The height of the Nizir mountains is about 1,000 feet above the sea-level, which still leaves room for a very respectable flood.

The scepticism which prevailed in the middle of this century with regard to legend seems to have given place to an almost equally great credulity. The older argument seemed to be that the presence of some obviously unveracious statements in a legend condemned the rest, want of faith in some was want of faith in all; while the more modern view would appear to be that since so many discredited legends have been found to enshrine some important truth, all are to be assumed trustworthy till they are proved otherwise.

It may be in this spirit that Suess * has elaborately discussed the Chaldean legend as though it presented

* E. Suess, "The Face of the Earth." Oxford, 1904. Cap. i. p. 17 . 


\section{GEOLOGIES AND DELUGES}

us with a trustworthy account of the Mesopotamian deluge.

Reasoning from the facts as it records them, Suess lays great stress on the course taken by the ship from Surippak, supposed to have been situated near the mouth of the Euphrates, to the land of Nizir, a distance of about 240 miles up stream. Had the flood been produced solely by heavy rainfall, and a consequent overflowing of the swollen rivers, the ship, instead of being carried inland, would have been drifted out to sea, i.e., southwards into the Persian gulf. Suess therefore suggests that a great wave was produced in the Persian gulf, partly by a cyclone and partly by an earthquake. This wave of twofold origin then rolled in upon the low-lying land of Mesopotamia, and drove its floods of water up the valley till they washed the foot of the Nizir hills.

Of all catastrophes none are more terrible, none more disastrous than those thus produced. When the shock of an earthquake occurs beneath the sea, and affects the adjacent land, a trembling of the ground is first felt, then the sea retires and leaves the beach bare, only to return in a long mighty wave which breaks with violence on the shore. Thus on October 28, 1746, Callao, in Peru, after being shaken by an earthquake, was overwhelmed by a sea-wave and utterly destroyed; of its 5,000 inhabitants only 200 survived the flood. Still more destructive was the famous earthquake of Lisbon, November 1, 1755, when the inhabitants, without a warning, were destroyed in the falling city, and in six minutes 60,000 persons perished. The sea in this case, as in others, retired first, and then rose 50 feet or more above its usual level, swamping the boats in the harbour; at Cadiz the wave is said to have reached a height of 60 feet, and it was felt over the greater part of the North Atlantic Ocean, arriving even on our own shores, as at Kinsale, in Ireland, 
where it rushed into the harbour and poured into the market-place.

That a great sea-wave so produced might have thus arisen in the Persian gulf is quite within the bounds of possibility, particularly as a zone of the earth's crust, very liable to earthquakes, stretches across the mouth of the Gulf near the Ormus mountains.

But if we are to follow the legend, we must follow it faithfully, and as a result of the most recent investigations, it turns out that all the passages which were supposed to refer to an earthquake have been mistranslated. The earthquake is thus put out of court, and we are left with what help we can get from the hurricane, a kind of disturbance which often vies with the earthquake in the destructive nature of the sea-waves to which it gives rise.

The Andaman islands of the East Indies are a centre which give birth to some of the most terrific hurricanes in the world. Travelling more or less westwards and northwards, these whirlwinds sweep over the waters of the bay of Bengal, and raise the sea into waves mountains high, which every now and again rush over the low-lying lands of the Ganges delta, overwhelming the unfortunate inhabitants by myriads. Thus on the night of October 14, 1737, one of these waves, estimated at 40 feet in height, suddenly overtook the dwellers by the Ganges and destroyed them to the number of 100,000 , or, as some say, 300,000 souls.

These storms do not, as a rule, travel towards the Persian gulf, and the North Arabian sea is singularly free from them; but Suess, tracing the course of the storm of October 24, 1842, suggests that for once, in the case of the deluge, an East Indian storm may have lost its way and blundered, as it were, into the Persian gulf. The track of this storm of 1842 was as follows: At five 


\section{GEOLOGIES AND DELUGES}

o'clock on October 24th it reached Pondicherry; it then slightly altered its direction and veered more to the southwest, and on the 25th, at midday, it crossed the western Ghats, and then divided into two parts; the south centre need not concern us. The northern centre travelled north-eastwards towards the Persian gulf, and was felt from the gulf of Aden to cape Guardafui, wrecking in this tract a number of vessels.

The greatest estimated height of storm-waves is from 40 to 45 feet, and, as Suess points out, it must have needed a much greater wave than this to drown out all Mesopotamia up to the Nizir hills. How much greater, is a question we are fortunately able to answer positively, thanks to the accurate measurements made by the engineer Czernick during a survey for a projected railway. The Tigris rises very slowly from its mouth inland, but at Bagdad it is already 154 feet above the sea-level, and at Mansurijah, the lowest point where its tributary Diala Tschai emerges from the Hamrin mountains, the height is given as 285 feet; but the land of Nizir lies even still more to the north than this, and the Lower Zab, which cuts through it, cannot have a less elevation than 600 or 700 feet. No storm-wave of which we have any record, no recorded earthquake wave, nor any combination of the two, approaches even remotely the height that would be required to carry the sea even to Bagdad; while as for the Nizir mountains, the Valiant Pherson, who " nearly spoilt the flood," might have drank up all the sea-water which came there without any assistance from Glenlivat. If we admit that the Tigris valley was ever submerged up to this point and restored to its original condition in the course of fourteen days, we are confronted with a catastrophe not only stupendous in degree, but of a nature beyond our present powers of explanation. 


\section{S'TORY OF 'THE CHALDEAN MY'TH 317}

But are we compelled to admit anything of the sort? And would it not be well before doing so to inquire a little more closely into the credentials and character of the Chaldean story? We have seen that the tablets on which it occurs were found in King Assurbanipal's library, and it is fairly certain that they were copied from others much older preserved in the ancient city of Erech,

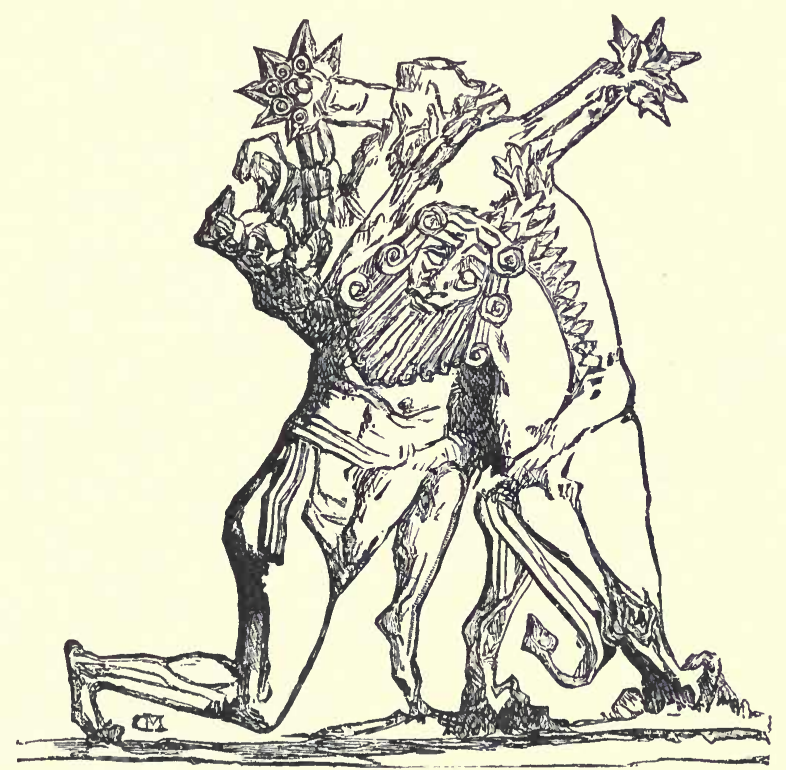

Fig. 96.-Gizdubar and the Lion. British Museum. From "Chaldea," Story of the Nations.

the city of books. It is, indeed, probable that the tablets in Erech may date from the time of King Khammarubi, or from about 2350 B.c. The tablets present themselves, therefore, with good recommendations, and we proceed to the character of the story itself. It does not occur alone, but as one chapter out of twelve in a long poem of about three thousand lines, concerning the adventures of 


\section{GEOLOGIES AND DELUGES}

a mythical hero named Izdubar or Gizdubar, perhaps the same as Nimrod, that "mighty hunter before the Lord" of biblical story, and plainly the prototype of the Greek Heracles.

The first tablet, containing the first chapter, is incomplete. So far as can be made out, it sets forth the misfortunes of the city of Erech, probably under the oppression of its Elamite enemies, who were so terrible in battle that poor Ishtar, its protecting goddess, " could not lift up her head against the foe."

The second and third introduce Gizdubar (Fig. 97),

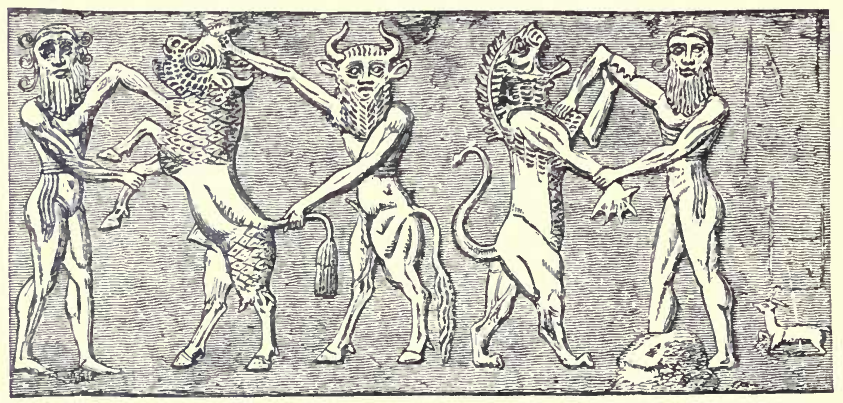

FIG. 97. - Gizdubar and Eabani fight the Bull of Ishtar; Gizdubar fights Eabani's Lion (Babylonian Cylinder). From "Chaldea," Story of the Nations. After Smith.

already famous as a hunter, as the hero, who was looked for to deliver the city. His rivals induce Ururu, the mother of the gods, to fashion a strange being, Eabani, half man and half bull, to fight with Gizdubar. This monster comes to Erech, bringing with him a powerful lion, desert-bred, to fight Gizdubar; but the hero succeeds in slaying the lion, and so wins the friendship and esteem of Eabani (Fig. 97).

In the fourth and fifth tablets the friends encounter and overcome the terrible tyrant Humbaba, whose voice was as "the roaring of the storm, his mouth wickedness, 
and his breath poison." The sixth tablet, which is well preserved, tells how the hero was beloved of Ishtar. "Be my husband," she says, " and I will be thy wife. I will make thee to ride in a chariot of gold and precious stones, with golden wheels and diamond horns. When thou enterest our house under the pleasant fragrance of the cedar, men shall kiss thy feet. Kings, princes, and lords shall bow down before thee, and bring tribute." Gizdubar, however, is not to be seduced; he repels the advances of the goddess, who then presents herself as a naturally angry woman before her father Anu, and persuades him to frame a divine bull which is to destroy Gizdubar.

$\mathrm{He}$ and Eabani together slay this bull, however, and the goddess, now terribly incensed, pronounces a terrible curse upon Gizdubar. The seventh tablet is, unfortunately, missing. The eighth, ninth, and tenth narrate how Gizdubar, suffering under the divine anger, loses his friend Eabani, and is smitten with a grievous illness.

He journeys to the river's mouth to consult his divine ancestor Sitnapistim. On his way he crosses a desert where "scorpion men" guard the dark path to the "waters of the dead," which separate him from his quest (Fig. 98).

On the shore of this sea he finds a park of the gods, with wonderful trees bearing precious stones for fruit. After waiting here a long time a ferryman takes him over to the fields of the blessed, where he meets Sitnapistim. He tells his sorrowful tale, and the heart of Sitnapistim is filled with pity; but, alas! neither gods nor men can give him help. In the eleventh tablet Gizdubar inquires 


\section{GEOLOGIES AND DELUGES}

of Sitnapistim how he became immortal, and receives in answer the story of the deluge. After its recital Sitnapistim heals Gizdubar of his disease, and gives him the plant of life, its name being “Altho'-a-grey-beard-theman-becomes-young-again." Unfortunately, an evil demon robs him of this on the way home. In the twelfth and last tablet Gizdubar returns to Erech, and utters a lament over his lost friend Eabani, whose ghost subsequently appears and recounts the doings of the dead in Hades.

Thus the deluge story is a myth within a myth, containing statements plainly unveracious; and how we are to distinguish in this mass of fiction the true from the false passes the wit of man to conceive. If we say of the deluge-part of it that it is a gross exaggeration, the judgment will sound mild, but this is all that is requisite to reduce the catastrophe to commonplace proportions.

Whether Gizdubar ever existed in the flesh or not has been doubted; it is certainly remarkable that each of the chapters of the poem corresponds to one of the signs of the zodiac, and they are arranged in the same order as the signs of the zodiac. A fanciful correspondence is thus drawn between the succession of events in the life of Gizdubar and the yearly course of the sun through the heavens, and it has consequently been maintained that Gizdubar is no other than the sun himself personified. The stages in the life of man find, however, so ready an analogy in the course of the sun, that this conclusion is by no means forced upon us, and we may turn to another identification of more significance in our inquiry. It is that of the Greek story of Heracles with the legend of Gizdubar. Heracles himself is no other than a Greek Gizdubar, the Chaldean Eabani corresponds to the centaur Cheiron, the tyrant Humbaba to the tyrant Geryon, the divine bull to the bull of Crete, the park of the gods to 


\section{NO DELUGE MYTH IN EGYP'T 321}

the garden of the Hesperides, the lion slain by Gizdubar to the lion of Nemea which Hercules slew; and finally, just as Gizdubar is ferried across the waters of the dead, so Hercules is taken by Helios in the golden boat of the sun across the ocean.

As the Greeks have borrowed so much of the legend it would be surprising if they had not taken the rest, including the story of the deluge, and accordingly we find the Greeks provided with a legend of the flood, or with more than one, as they appear to have had more than one Heracles; but that which most closely accords with the Chaldean is the flood of Deukalion.

On the other hand, the Egyptians, who had sun-stories of their own, did not borrow the legend of Gizdubar, and are silent as to a deluge; a fact of extreme importance when we consider that the Egyptian civilisation was contemporaneous with the Chaldean, if not indeed older. The Nile is gentler in its overflowing than the Tigris, so that Egypt did not suffer under the scourge of unexpected floods.

If, finally, we turn to China, also possessed of very ancient historic records, and liable to the destructive deluges of the Yellow River, which have earned for it the designation "The Scourge of China," we discover a deluge story of great importance, to which Suess has already called attention. In the third Schû of the Canon of Yao, a monarch who reigned, it is supposed, somewhere about 2357 B.C., and therefore contemporaneous with Khammurabi, we read: The Tì said, "Prince of the Four Mountains, destructive in their overflowings are the waters of the flood. In their wide extension they enclose the mountains and cover the great heights, threatening the heaven with their floods, so that the lower people is unruly and murmur. Where is a capable man whom I can employ this evil to overcome?" Khwan was engaged, 


\section{GEOLOGIES AND DELUGES}

but for nine years he laboured in vain; a fresh engineer, named Yû, was therefore called in; within eight years he completed great works; he thinned the woods, regulated the streams, dammed them, and opened their mouths, provided the people with food, and acted as a great benefactor to the State.

It is refreshing thus to pass from the ornate deceptions of legend to the sober truth of history; and if the facts on which the Gizdubar legend of the deluge is founded could be expressed in the same simple language, we should probably find it narrating similar events, or events as little likely to excite surprise as those of the straightforward Chinese Schû.

History, then, fails to furnish evidence of any phenomenon which can be called catastrophic in the geologic sense of the word, and geology has no need to return to the catastrophism of its youth; in becoming evolutional it does not cease to remain essentially uniformitarian.

And the careful foster-mother? She too, as it appears to me, has widened her studies, and must, I should think, recognise with pride the stalwart growth of her early friend. May they be drawn nearer together, and feel the warm glow which is produced by the sympathy of a common love for truth. 


\section{Index}

Absexce of fossils from pre-Cambrian rocks, 28

Africa, the middle of the land hemisphere, 50

Agassiz, Prof. A., 13; area of sedimentation in Gulf of Mexico, 37; tertiary limestone, 125; talus growth in coral reefs, 126

Agassiz, Prof. L., on glaciers, 245

Age of the earth, Kelvin, 1, 9, 16, 18, 20, 64; G. Darwin, 7, 16 ; J. Joly, $9,16,21$; estimated from thickness of stratified series, 24 ; and radium, 63 ; in relation to biology, 25-28; and flints, 157

Agricola, G., 241

Ainsworth, theory of coral atolls, 95

Ajka beds, 203

Allan, Dr., rate of growth of corals, 40

Amalitzky, Devonian and Permian freshwater shells, 196

Ananchytes, 158

Ancient sediments, unaltered state of, 29

Ancylus lake, 207

Andes, Jurassic zones, 274

Apstein, Dobersdorf lake, 174

Apus, 192

Aral, sea of, 215

Area scaphula, 175
Atlantic, a secondary ocean, 50

Atmosphere, primæval, 5; condensation of, 9

Babylon, 306

Baikal, lake, 215

Baltic, 173, 207

Banded flints, 152

Barus, C., 12 ; coefficient of expansion of diabase, 60

Bathanalia, 209

Bathymetrical limit of coral growth, 129

Beaumont, Élie de, dodecahedral form of earth, 55

Bertrand, M., tetrahedral form of earth, 55

Beudant, experiment by, 172

Bicycle, evolution of, 255

Birgus, the robber crab, 106

Blytt, Prof., estimate of length of Tertiary æra, 36

Bonney, Rev. Prof. T. G., Archæn rocks, 24 ; coral reefs, 38, 99, 121

Bore hole in Funafuti, abandonment of, 116 ; successful boring, 118, 122

Bourne, A. G., Limnocodium, 211

Bouvier, 200

Boys, Prof., comets and radium, 64

Brackish-water fauna, 208

British freshwater fauna, 167 
Buckland, paramoudra, 136 ; flint, 165, and Oxford, 243

Burckhardt, Jurassic zones, 274

Burnett, Thomas, 290

Bythoceras, 209

CALapya, burrows of, 102

Calumet and Hecla mine, U.S., 20

Cambrian sediments, changes in thickness, 41

Carboniferous air-breathing shells, 197

Caspian, 215

Cassini, form of the earth, 45

Catastrophic geology, 297

Chaldean deluge, 31

Chalk, rate of formation, 16 ; porosity of, 151

Chamisso, nature of atolls, 90

Chapman, F., Foraminifera, Funafuti, 126

Chytra, 210

Clarke, Col., form of the earth, 46

Climates and homotaxy, 268; ancient, 285

Coccoliths, 137, 139

Congeria, 20j

Consolidation of the earth, 8

Contraction of cooling globe, 33

Coral, limit of growth, 91, 129

Cordylophora, 212

Cosina beds̀, 203

Cossman, Jurassic freshwater shells, 198

Crambessa Tagi, 211

Cretaceous of India, 278

Cristatella mucedo, 188

Cryptone, fauna of atoll beach, 112

Cullis, Dr. C. G., Funafuti, 123

Cutch, Jurassic zones, 274

Cyclas, 181

Cyclonic waves, 315

Danwin, C., 1 ; coral islands, 91-94 ; letter to A. Agassiz, 99 ; love of sport, 220; letter to Professor Phillips, 251
Darwin, George, 7, 39 ; stresses produced by weight of continents, 48 ; radium, 63

David, Prof. Edgeworth, successful boring, 118, 122 ; talus growth, 128 ; limit of coral growth, 129

Davison, C., 33 level of no strain, 59

Day, fishes of Great Britain, 172

Deposition, rate of, 37; and subsidence of sea floor, 39

Devonian lakes, 195

Diatoms, 161

Diplograptus foliaceus, 282

Dodecahedron, pentagonal, É. de Beaumont, 56

Dreissena, 181, 206

Dytiscus, 181

EARTH, constitution of interior, 7; consolidation of, 8 ; rigidity of, 16

Egypt, 25; does not possess a deluge myth, 321

Ellice islands, 99

Energy of the earth in the past, 284

England, section across, 261

Ephippium of water-fleas, 191

Ephydatia fluviatilis, 185

Erech, 306

Expansion of rocks near critical fusionpoint, 11, of basalt and diabase, 60

Euplectella, 143

Everett, Prof., geothermic gradient, 61 Evolution of animal forms, time required for, 28

Fascinella, 203

Faxon, Palæomonetes, 194

Field, Capt. Mostyn, I.N., Funafuti, 117

Finckh, A. E., Funafuti, 122 ; limit of coral growth, 129

Fisher, Rev. O., condition of no strain, 59

Fitzgerald, George F., 12

Flints, 131-165; mode of occurrence, 135 ; forms of, 141; and sponges, 
142 ; silicified chalk, 150 ; date of formation, 153; weathering, 155; and geological time, 157; mineral characters, 163 ; bibliography, 165

Forbes, E., Palæanodonta, 195; centres of creation, 266

Foraminifera, silicified, 150

Fossils, absence of from pre-Cambrian rocks, 28

Fracastoro, 221

Frech, 283-288

Freshwater faunas, 166-218; British, 167 ; poverty of, 169 ; influence of medium, 171; of climate, 173 ; of river movement, 177 ; means of dispersal, 179; fossil freshwater shells, 195-208; lake Tanganyika, 208 ; summary, 216-218

Funafuti, 86-132 ; recent elevation, 107 ; ocean beach, 112 ; submarine slopes of, 117; successful boring, 119; composition of core, 123; Tertiary limestones, 125; talus growth, 126 ; limit of coral growth, 129 ; dolomitisation, 130 ; lagoon deposits, 130 ; the Tyrol, 131

Garmard (and Quoy), limit of coral growth, 91

Ganges, deluge of the delta, 315

Geikie, Sir A., 16; rate of deposition of sediment, 37 ; growth of peat, 40 ; volcanos, 83

Gemmules of sponges, 185

Geologies and deluges, 290-322. Bur. nett's deluge, 293; discordances and deluges, 296; diluvium, 298; Mesopotamia, 303 ; George Smith's discovery, 309; Chaldean deluge, 311 ; Egypt and China, 321

Geology, its aim and scope, 4

Geothermic gradient, 17-20, 61-63

Geyser in Iceland, 23

Gilbert, G. K., tilting of North America, 39

Gizdubar, 317
Glacial periods, 270

Glochidium, 179

Gnathodon, 176

Goniobasis macilenta, 202, 203

Gordon, Mrs. (Miss Ogilvie), on Tyrol, 131

Grapsus, a shore crab, 112

Graptolites, 275, 281

Green, Lowthian, tetrahedral form of earth, 55

Gyroporella, 131

HALDANE, geothermic gradient, 62

Halimeda, 131

Hall, Sir J., 246

Hall, T. S., graptolite zones, 275

Halligan, G. H., limit of coral growth, 129 ; boring in lagoon, 130

Hawaii, 22

Heat, loss of, by earth, 62

Heilprin, A., 270

Heincke, brackish water fauna, 208

Hinde, Dr., Funafuti, 124 ; tertiary limestone, 125

Hise, van, Professor, 29

Homotaxis, 267

Huddlestone, Tanganyika, 212, 214

Hudson, C. T., Rotifers, 188

Hutton, 1, 2, 241

Huxley, on chalk, 158; on evolution, 254 ; homotaxy, 266

Hydra, eggs of, 186

Indian Ocean, secondary origin of, 50

Interior of earth, 7

Inversion, absence of, 271

Izdubar, 318

JEANs, J. H., form of the earth, 47 deformation of the earth, 49

Jelly-fish, freshwater, 209, 210, 211

Joly, J., age of earth, $9,16,21$; ex pansion of basalt, 60 ; radium, 63

Judd, Prof. J. W., Funafuti, 123 ; tertiary limestone, 126 ; talus growth, 127 
Kelvin, Lord, age of the earth, 9, 16, $18,20,64$

Kennel, J. von, 210, 216

Kew, dispersal of shells, 184

Kidd, Dr., 242

King, Clarence, 18

Klement, on flint, 163, 165

Koken, 288

LAGoon deposits, Funafuti, 131

Land of coral island, mode of formation, 113

Lane, A. C., 30

Langenbeck, coral reefs, 96

Lapparent de, churt of Cambrian Europe, 41, 288

Lapworth, graptolite zones, 275 ; dispersal of graptolites, 281

Laramie lake, 201

Lavis, Johnston, Dr., 73

Levantine be Is, $_{2} 206$

Level of no strain, 33

Lévy, Michel, tetrahedral form of earth, 5.5; on flint, 164

Liebenow, G., 63

Limnocnida, 210

Limnotrochus, 21

Limpet, freshwater (Ancylus), 208

Lingula, 26, 218

Lipari islands, 65-83

Lisbon, earthquake, 314

Lithoglyphus, 205

Llwyd, 240

Lohmann, coccoliths, 138

Lyell, 2 ; on chalk, 158, 245, 24.)

McGee, Gulf of Mexico, 37

Mangrove swamp, Funafuti, 107

Marr, J. E., graptolite zones, 275 ; homotaxis, 276

Martens, von, climate, 173

Maxwell, Walter, 22

Meachem, geothermic gradient, 62

Megascleres, 146

Melaniidæ, 198

Melanopsidæ, 206
Meridional continental ring, 51

Mesopotamia, 303

Meteorites, 7, 8

Meyer, P., Palæomonetes, 193

Microscleres, 146

Milne, Prof., rigidity of the earth, 17

Mineral characters of flint, 163

Mississippi delta, 38

Moebius, brackish water fauna, 208

Mojsisoviks, von, on Tyrol, 131

Moon, origin of, 7 ; primitive volcanic action, 8

Moore, C., Lias freshwater shells, 198

Moore, J. E. S., Tanganyika, 208

Moseley, Prof., coral sand, 103

Mountain chains, formation of, 31-36

Miiller, Fritz, Peneus, 194

Munier-Chalmers, on flint, 164

Murray, Sir J., 23 ; coral atolls, 85

Narlian, Vulcano, 68

Nassopsis, 209

Nauplius, 194

Nautılus, 280

Neumayr, permanence of oceans, 97 ; Paludina, 207; chart of Jurassic seas, 288

Newton, Sir Isaac, form of the earth, 45,46

Niagara limestone, 265

Nicholson, H. A., graptolite zones, 275

Nizir mountains, 313

Norway, stones from, found on the east coast of England, 244

Novaculina gangeticus, 175

Obstacles to migration from the sea, $171,173,177$

Ocean of molten rock, 6

Ocean, salt in, 21, 171

Ocean basins, permanence of, 97

Ogilvie, Miss (Mrs. Gordon), on Tyrol, 131

Opal, 143, replaced by carbonate of lime, 145 
Oppel, Jurassic zones, 274

Ordovician sediments, changes in thickness, 43

Oxford and Geology, 219-256 ; Steno, 222 ; Plot, 228; Llwyd, 241 ; Kidd, 242 ; William Smith, 243 ; Buckland, 244; Agassiz, 246; Lyell, 249; Phillips, 251; Darwin, 251; Prestwich, 256; Green, 256

Pacific, the primitive ocean, 50

Palæmon, 192

Palæmonetes, 192

Paley, 254

Pallisey, 221, 263

Paludina, 183; transformation of, 207; in lake Tanganyika, 214

Pangbourne, 147

Paramelania, 209

Paramoudra, 136

Pear-shaped earth, 47, 54

Penck, 17

Peneus, 193

Penokee series, 29

Phillips, Prof. J., 251

Pholas rivicola, 175

Pisidium, 181

Plastic force, 235

Plot, 227

Polynesians, 114

Pontic lakes, 204

l'ressure, effects on fusion-point, 11

Prestwich, Sir J., 18, 250

Pristiograptus pala, 283

Przibram mines, 20

Purbeck and Weald, 200

Pyrgulifera, 202

Quoy and Gamard, limit of coral growth, 91

Radiun, relation to geothermic gradient, 63

Ramisden, surface tension, 152

lieef-rock of Funafuti, chemical composition, 123
Renard, on flint, 165

Reptiles as agents of dispersal, 183, 211

Richthofen, Baron von, coral reefs of Tyrol, 131

Rigidity of earth, 16

River water, composition of, 22; analysis of, 171

Rotifers, dispersal of, 188

Ruedemann, R., Graptolite zones, 276 ; structure of graptolites, 282

Rupert Jones, on flint, 165

St. Margaret's Bay, Dover, 154

Sand, coral, 103

Sarmatian sea, 204

Schubert, form of the earth, 46

Scleroplegma, 145

Scorpion men, 319

Sea water, analysis of, 171

Sediment, rate of deposition, 37

Sedimentation, area of maximum, 34

Seismic waves, 314

Semper, animal life, 173

Seward, A. C., 273

Silica, in sea water, 155 ; source of, 155 ; amount of, in sponges, 156 ; concentration of, 157

Silurian, changes in thickness, 43

Skeats, Dr. E. W. ; Funafuti, 123; dolomitisation, 130 ; Tyrol, 132

Smith, George, deluge tablets, 309

Smith, William, 2 ; and Oxford, 243 ; life of, 258 ; fossils as a means of identification, 263

Solvent power of superheated water, 23

Spatha, 204

Species, persistent, 26, 218

Spekia, 210

Spencer, Herbert, 265

Spirula, 280

Sponge spicules, casts in chalk, 146

Sponges, in flints, 141

Stability of freshwater animals, 218

Stable and labile organisms, 218, 287 
Statoblasts of Polyzoa, 187

Stauronema, 145

Steinnann, Jurassic zones, 274

Steno, 2, 222, 256

Storm-beach of Funafuti, 109

Strain, level of no, 33

Stromboli, state of, in 1889, 72

Stuart, Prof., coral reefs, 99

Sturdee, F. C. D., boring in lagoon, 130

Subsidence of sea floor and deposition of sediment, 39

Succession of animal forms, 27

Suess, 39, 50 ; Paludina, 196 ; Tethys, 282 ; deluge, 313

Supan, A., 39

Sweet, G., 122

Swift, Laputa, 45

Syrnolopsis, 203, 210

TABasheer, 143

Talifu, lake, 207

Talus growth of coral reef, 126, 128

Tanganyicia, 209

Tanganyika, lake, 208

Tausch, Pyrgulifera, 203

Temperature, increase beneath the British Isles, 19

Tertiary limestones and Funafuti, 125

Tethys, the, 282

Tetrahedral form of earth, 5 J

Thelphusidæ, 175

Theories of coral atolls, Darwin's and Murray's compared, 98

Thierry, 220

Thomas, T. H., 70

'Tornquist, Jurassic zones, 374

Trias lakes, 197

Typhobia, 209

Tyrol, coral reefs, 131

Uniforsity, doctrine of, 1, 2, 249, 300

Ur, 304
Valtata, 199

Venus's Flower-basket, 143, 145

Vernon, variation, 173

Victoria Nyanza, 210

Vinci, Leonardo da, 221

Volcanic dykes as registers of eruptions, 85

Volcanic eruption, cause of explosion, 82-85

Volcanos, 17

Vulcano, history of, 68 ; eruption in 1888,63 ; eruptions in 1889,75

WAAGEN, Jurassic zones, 274

Wallerand on flint, 164

Walther, J., ammonites, 280

Water, superheated effect on silicates 23

Water-fleas and Rotifers, more abundant in freshwater than salt, 170; reason of this, 191

Weldon, Prof., crabs in Plymouth Harbour, 26 ; Palæomonetes, 192

Wharton, Admiral Sir J., coral reefs, 99

Whirlwinds, as a means of dispersal, 184

White, Pyrgulifera, 212 ; Syrnolopsis, 212

Wiechert, 7

Wilson, W. E., 64

Woodward, S. P., on flint, 165

YeLlow River, deluges of, 321

ZaCharias, Ploen lake, 174

Zirkel on flint, 165

Zoea, 194

Zonal fossils, peculiarities of, $\mathbf{2 7 9}$

Zykoff, on gemmules of Ephidatia, 185 


\section{Siberia:}

\section{A Record of Travel, Climbing, and Exploration.}

\section{By SAMUEL TURNER, F.R.G.S.}

WITH A PREFACE BY BARON HEYKING.

With more than 100 Illustrations, and with 2 Maps.

Demv 8vo, cloth, 21/- net.

THE materials for this book were gathered during a journey in

I Siberia in 1903. Helped by over roo merchants (Siberian, Russian, Danish and English) the writer was able to collect much information, and observe the present social and industrial condition of the country. The trade and country life of the mixed races of Siberia is described, and valuable infcrmation is given about their chief industry (dairy produce), which goes far to dissipate the common idea that Siberia is snow-bound, and to show that it is now one of the leading agricultural countries in the world.

The author describes his unaccompanied climbs in the mountains which he discovered in the Kutunski Belki range in the Altai, about 800 miles off the Great Siberian Railway line from a point about 2,500 miles beyond Moscow. He made a winter journey of 1,600 miles on sledge, drosky, and horseback, 250 miles of this journey being through country which has never been penetrated by any other European even in summer. He also describes 40 miles of what was probably the most difficult winter exploration that has ever been undertaken, proving that even the rigour of a Siberian winter cannot keep a true mountaineer from scaling unknown peaks.

The volume is elaborately illustrated from photographs by the author.

"To the trader and to the explorer, and to many who are neither, but who love to read books of travel and to venture in imagination into wild places of the earth, this book is heartily to be commended. It is lively, entertaining, instructive. It throws fresh light on the Empire of the Czars. Above all, it is a record of British pluck."-Scotsman.

\section{LONDON : T. FISHER UNWIN.}




\section{In Search of El Dorado:}

\section{A Wanderer's Experiences.}

\section{By ALEXANDER MACDONALD, F.R.G.S.}

With 32 Illustrations. Large crown 8vo, 5/-net

R EADERS with a taste for adventure will find this book a mineralogical expeditions the author has roughed it in many remote quarters of the globe, and a large share of strange and thrilling experiences has fallen to his lot. At the same time he possesses a literary skill with which few travellers are gifted.

The episodes in his career which the book relates fall under three heads. In Part I., "The Frozen North," he gives some vivid sketches of rough and tumble life in the Klondyke region; Part II., "Under the Southern Cross," describes his adventures while prospecting for gold in Western Australia; Part III., "Promiscuous Wanderings," tells of his experiences in the Queensland Back Blocks, in the Opal Fields of New South Wales, in British New Guinea, in the Gum Land of IVangeri, New Zealand, and with the Pearlers of Western Australia.

"It was with a secret joy that we sat up till the small hours of the morning to finish Mr. Alexander Macdonald's new buok, 'In Search of El Dorado: A Wanderer's Experiences.' The author's wanderings have led him all over the world, digging for gold, silver, opals, and gum. The wonderful characters are vividly drawn, and his two companions, Mac and Stewart, are men one would like to shake hands with. . . . We can conscientiously say that we have had as much pleasure from this book as from the half dozen best novels of the year."-Bystander.

LONDON: T. FISHER UNWIN. 


\section{From Carpathian to Pindus:}

\section{Pictures of Roumanian Country Life.}

\section{By TEREZA STRATILESCO.}

With 2 Maps and many Illustrations. Demy 8vo, cloth, 15/-net.

"Singularly vivid and interesting."-Truth.

"It is primarily a description, and a very pleasant one, of the Carpathian forests and valleys, and of the kindly, genial, picturesque peasantry that inhabit them."-Manchester Guardian.

“Miss Stratilesco's fascinating work."-Scotsman.

"A comprehensive book written by one who knows the country and people intimately."-Daily Graphic.

"The book is very full and useful, amounting to a complete study from all points of the Roumarrian peasant-nation. It is well illustrated from photographs, and will at once take rank among the works of reference necessary to the student of European affairs." Outlook.

"A book as full of merit as it is of observation. From it we learn much of a subject that is not only of great interest in itself, but also one of which comparatively little is known."-Graphic.

LONDON : T. FISHER UNWIN. 
- Medium 8vo, Cloth, 21/- net.

\section{THE SAVAGE CLUB}

A Medley of History, Anecdote and Reminiscence

\section{BY \\ AARON WATSON}

\section{With an Original Chapter by Mark Twain.}

With a Photogravure Frontispiece, Four Coloured Plates, and about Sixty other Illustrations.

"We read of so many cordial, clever and clubbable fellows that we lay Mr. Watson's book down with a sense of having spent a few hours in jollier company than may easily be found in any circle nowadays."-Daily News.

"The Savage Club has been happy in so admirable an historian as Mr. Watson. . . . Publisher, author, and Savage Club should rest equally content with what has been done. It is a book to buy and a book to treasure."-Tribune.

"Mr. Aaron Watson is to be congratulated on a book which people who have not been inside the Savage Club will appreciate, and which every member of that charmed circle will assuredly prize."-Standard.

LONDON : T. FISHER UNWIN. 


\title{
English Wayfaring Life in the Middle Ages (XIVth Century)
}

\author{
BY J. J. JUSSERAND. \\ Translated by Lucy A. Toulmin Smith.
}

\section{OPINIONS OF THE PRESS.}

"The book is a translation and an amplification of one of those enchanting volumes which only Frenchmen have the gift of writing, . . . a pleasure to handle, a joy to read, and bearing with it, when one gets to the end of it, a conviction that one has become a much more learned man than one was a week ago, for that somehow one has absorbed a great deal that the outer world knows little about. Pray do not order this volume at the library. Buy it if you are wise, and keep it as a joy for ever."-Dr. Augustus Jessopp in the Ninctcenth Century.

"A mine of information regarding the roads, the travelling, and the travellers of the fourteenth century.... The book is crammed with curious information of all kinds."-Spectator.

"The best and most picturesque account of English outdoor life in the period of Chaucer that our literature possesses."-Gentleman's Magazine.

"An extremely fascinating book."-Times.

"All readers of history are laid under obligation by M. J. J. Jusserand's thoroughgoing inquiry into 'English Wayfaring Life in the Middle Ages.' . . . M. Jusserand is the very opposite of a dry-as-dust antiquarian. The records from which he has compiled his material are both dry and dusty, but by their help he fills the old roads of England with living people, and most vividly reproduces the fourteenth century. . . M. Jusserand's volume is one of permanent value, and will be read with avidity by any who have the slightest fraction of the historical spirit."-British Weekly.

"We are much obliged to the learned and genial French author for this accurate and picturesque survey of some interesting features in the cominon life of England during the fourteenth century. His book should be read along with the immortal Prologue, at least, to the Tales of the delightful Canterbury Pilgrimage. 'English Wayfaring Life' is a scientific treatise on its subject, and is one of the pleasantest gatherings of antiquarian knowledge."-Illustrated London News. 
Illustrated. Large crown 8vo, cloth, 7s. $6 d$.

\section{The English Novel in the Time of Shakespeare}

BY J. J. JUSSERAND.

Translated by Elizabeth LeE.

\section{OPINIONS OF THE PRESS.}

"All lovers of Elizabethan literature will welcome M. Jusserand's new book. . . No Englishman who has written on the period has shown him self more completely in touch with his subject, or more fully and widely read in the authors with whom he deals. Want of accuracy or of literary insight is never apparent, and it is very rarely that even the smallest feature is missed because of a 'foreigner's standpoint.' . . . M. Jusserand's book and its exquisite engravings form a most valuable contribution to the study of English literature."-Stındard.

"The handling has all the traditional (and sometimes rather imaginary) Gallic lightness, combined with an accuracy and precision of fact and reference which is traditionally (there is some, though less, of the courtesy of imagination here also) German. And in particular M. Jusserand is very happy in his historical citations serving as parallels to the novel. In short, it is an excellent book in all ways for the student." -Manchester Guardian.

"A contribution of permanent value to the history of Elizabethan literature. The points of interest about this book are so numerous that it would be impossible to deal with them in detail here. But those who read for amusement only may be as safely recommended to procure it as the smaller class who seek to extend their knowledge of the Elizabethan epoch."-Athenceum.

"We hasten to invite the attention of the reader to one of the brightest, most scholarly, and most interesting volumes of literary history which it has been our good fortune to meet with for many a long day."-Spcaker.

"M. Jusserand's book is scientific in the best sense of the word; it shows that he has thoroughly explored the literary province he sets forth to describe, and that he possesses in a high degree the faculty of critical co-ordination. Yet so lucid is his style, so happy his power of seizing upon the salient and characteristic features of his subject, that he never becomes tedious or needlessly discursive. To the general reader, and even to many who would call themselves students of our literary renascence, his work will prove a valuable corrective of false preconceptions."-Pall Mall Gazette.

"A work of solid value. The book is full of suggestiveness, and shows by a variety of incidental remarks the author's mastery of the subject."Spectator. 
Crown 8vo, limp cloth, silk sewn, 3s. $6 d$.

\title{
The Coming of the Friars
}

\section{And other Mediæval Sketches}

\section{BY AUGUSTUS JESSOPP, D.D.}

\author{
Fourteenth Impression.
}

\section{OPINIONS OF THE PRESS.}

"The papers which show Dr. Jessopp at his best are, without doubt that on 'Village Life Six Hundred Years Ago' and the two on 'The Black Death in East Anglia.' These reveal that historic imagination, that power of making the past live again, of taking one beyond the record of the court roll to the man who signed the deed or the suitors who formed the court, and finding out how they lived and what they did, which Dr. Jessopp possesses, perhaps, in a unique degree. Nothing can be more telling than these essays, with their light touches of humour."-Athencum.

"The antiquarian information is conveyed in the most attractive form by a writer who has nothing of a dry-as-dust in his composition except the zeal and the patience of investigation, while the East Anglian colouring gives that individuality and precision to the descriptions which materially a-sist the imagination to realise with distinctness the required pictures. Another peculiar charm of Dr. Jessopp's writings is the freshness of his sympathies. ... Always lively, picturesque, and suggestive, he is in living touch with existing realities, and uses his historic gleanings to illustrate by contrast or by resemblance some present condition of modern society."-Guardian.

"In the present volume Dr. Jessopp has developed a power almost equal to that of the author of 'John Inglesant,' of catching the tone of a generation that has passed away, and of depicting the condition of England in the Middle Ages, unhidden by a veneer of modern conventionalism. ... It would be difficult to find a more graphic picture of old English life, or one in which even the driest facts of history are presented in a more attractive garb."-Morning Post.

"It is delightful to have them thus collected, for few writers have Dr. Jessopp's gift of painting to the life. His 'Village Life Six Hundred Years Ago' is as graphic and as truthful as one of Richard Jefferies's sketches of to-day. His papers on 'The Black Death' and on 'The Building of a University' are full of teaching; and no one has ever discussed with more intelligent appreciation that mediæval Salvation Army of which Franciscans and Dominicans were the two main corps." - Graplic.

"The glimpses into the social life of the past afforded by these essays will impress all who reflect for a moment upon the marvellous growth of England."-Daily Chronicle. 


\title{
A Literary History of the English People
}

\author{
BY J. J. JUSSERAND.
}

VOLUME I

From the Origins to the Renaissance

\section{OPINIONS OF THE PRESS.}

"The execution of tho task so far as it has proceeded at present is masterly. M. Jusserand's erudition is vast, but it does not overwhelm his sense of proportion nor distort his fine critical sense. . . . M. Jusserand has many advantages over Taine. His learning and his industry are certainly not less conspicuous, his critical method is less rigid and mechanical, his English sympathies are stronger and based on a much more familiar knowledge of English habits and English modes of thought; at the same time, like Taine, he is independent of purely English prejudices, and his literary judgments are those of a citizen of the great republic of letters which knows nothing of national or political boundaries. Altogether, the work is full of a rare attraction."-Times.

"I envy this man his style, his subtlety, his lightness of touch, his thoroughness.... At last we have-or rather shall have when the vork is complete-a real History of literature."-Dr. AUGUSTUs JEssopP in the Illustrated London News.

“M. Jusserdnd's qualifications for the task which he has undertaken are of a high order. . . . We cordially commend both to English and French readers this brilliant and thoughtful book, and shall look forward with high expectation to the appearance of its successor."-Athenceum.

"We may say, without contradiction, that the marvellous story of our literature in its vital connection with the origin and growth of the English people has never been treated with a greater union of conscientious research, minute scholarship, pleasantness of humour, picturesqueness of style, and sympathetic intimacy."-Daily Chronicle.

"The success which has been attained by M. Jusserand, one of the most accomplished of modern French students of this country, in his latest enterprise is exceedingly remarkable. He brings to the task which he has undertaken not merely a deep erudition, but an extraordinary insight into and sympathy with our national modes of thought and expression."-Daily Telegraph.

"We have no work at once so trustworthy and so captivating. . . M. Jusserand knows, in a judicial way, what is and what is not evidence and authority ; he is fresh, animated, eager, yet he never speculates without a warrant. It is his method that is practically an innovation. . . . As we follow his skilful guidance, we see almost in action the making of England, of English character, and of English literature."-Speaker. 

RETURN TO the circulation desk of any

University of California Library

or to the

NORTHERN REGIONAL LIBRARY FACILITY

Bldg. 400, Richmond Field Station

University of California

Richmond, CA 94804-4698

ALL BOOKS MAY BE RECALLED AFTER 7 DAYS

2-month loans may be renewed by calling

(415) 642-6233

1-year loans may be recharged by bringing books to NRLF

Renewals and recharges may be made 4 days prior to due date

DUE AS STAMPED BELOW

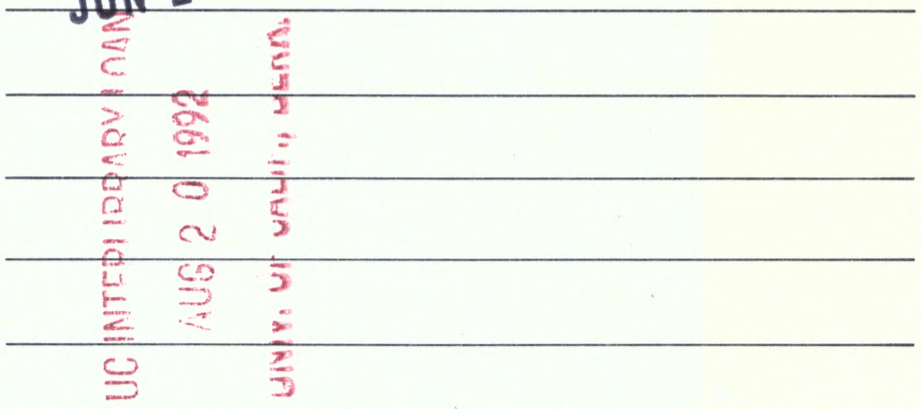


615

Storage 


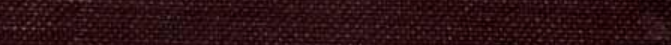

